\title{
Recent developments in enantioselective zinc-catalyzed transformations
}

\author{
Hélène Pellissier \\ Aix-Marseille Univ, Centrale Marseille, CNRS, Marseille, France
}

\begin{abstract}
This review collects the recent advances in the field of enantioselective zinc-catalyzed transformations, covering the literature since the beginning of 2015, illustrating the power of chiral green zinc catalysts to promote all types of reactions. A range of highly enantioselective reactions have been developed in the last six years, including cycloadditions, alkynylation/allylation reactions of carbonyl compounds and derivatives, additions of diorganozincs to carbonyl compounds and derivatives, Mannich reactions, (nitro)aldol reactions, other 1,2-nucleophilic additions to carbonyl compounds and derivatives, Michael additions, Friedel-Crafts reactions, reductions, $\alpha$-functionalizations of carbonyl compounds, ringopening reactions, epoxidations, halolactonizations, domino/tandem reactions and miscellaneous reactions.
\end{abstract}

\section{Contents}

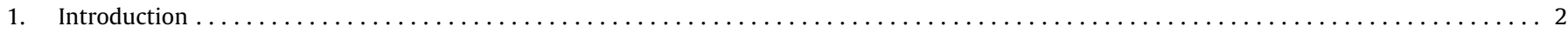

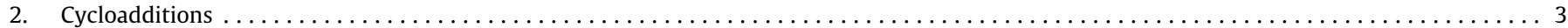

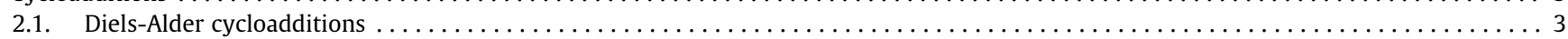

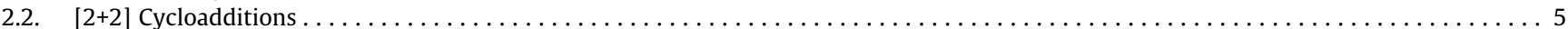

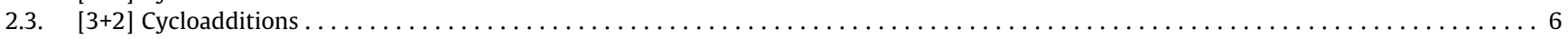

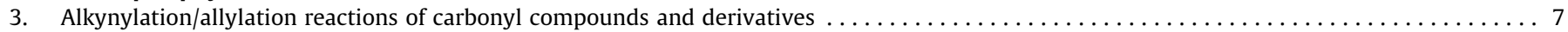

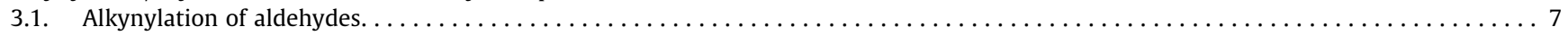

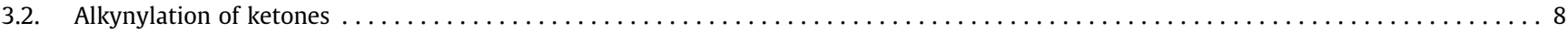

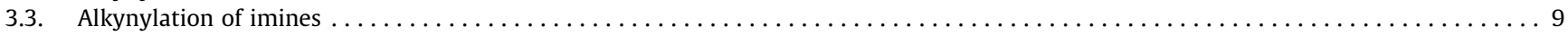

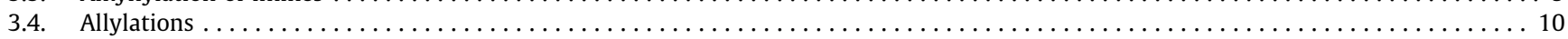

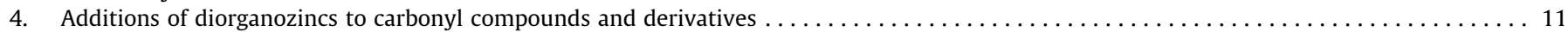

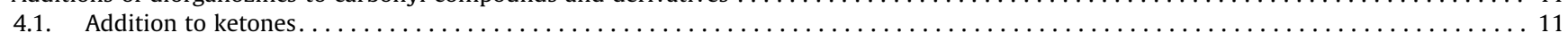

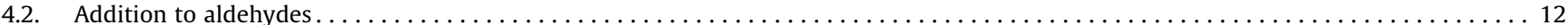

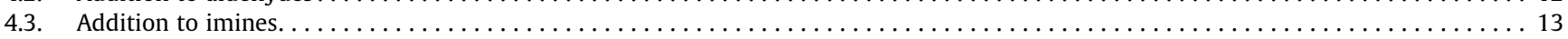

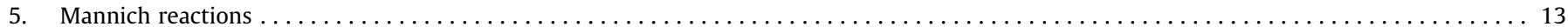

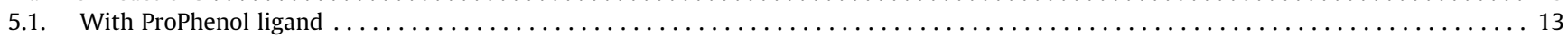

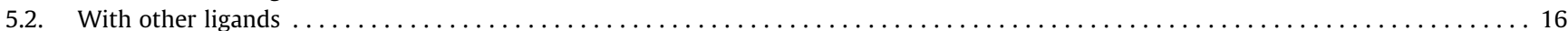

Abbreviations: Ad, adamantly; Ar, aryl; BDPP, 2,4-bis(diphenylphosphino)pentane; BINAP, 2,2-bis(diphenylphosphanyl)-1,1-binaphthyl; BINIM, binapthyldiimine; BINOL, 1,1'-bi-2-naphthol; BIPHEP, 2,2'-bis(diphenylphosphino)-1,1'-biphenyl; Bn, benzyl; Boc, tert-butoxycarbonyl; Bz, benzoyl; Cbz, benzyloxycarbonyl; CMHP, cumene hydroperoxide; cod, cyclooctadiene; Cy, cyclohexyl; DCE, dichloroethane; de, diastereomeric excess; Dec, decyl; DIFLUORPHOS, 5,5'-bis(diphenylphosphino)-2,2,2',2'-tetra fluoro-4,4'-bi-1,3-benzodioxole; DIMPEG, polyethyleneglycol dimethyl ether; DIPEA, diisopropylethylamine; dppe, 1,2-bis(diphenylphosphine)ethane; ee, enantiomeric excess; Hept, heptyl; Hex, hexyl; L, ligand; Mes, mesityl; MOM, methoxymethyl; MS, molecular sieves; Naph, naphthyl; NBS, $N$-bromosuccinimide; NIS, $N$-iodosuccinimide; Oct, octyl; PCPC, polycyclopentene carbonate; Pent, pentyl; PG, protecting group; Phanephos, 4,12-Bis(diphenylphosphino)-[2,2]-paracyclophane; Phth, phthalimidyl; Pin, pinacolato; Piv, pivalate; PMB, para-methoxybenzyl; PMHS, polymethylhydrosilane; PMP, pentamethylpiperidine; Pybox, pyridine bisoxazoline; r.t., room temperature; Salen, 1,2-bis(salicylidenamino)ethane; Segphos, 4,4'-Bi-1,3-benzodioxole-5,5'-diylbis(diphenylphosphane); TBAF, tetra- $n$-butylammonium fluoride; TBDPS, tertbutyldiphenylsilyl; TBHP, tert-butyl hydroperoxide; TBS, tert-butyldimethylsilyl; TEA, triethylamine; Tf, trifluoromethane sulfonyl; TFA, trifluoroacetic acid; THF, tetrahydrofuran; TIPS, triisopropylsilyl; TMS, trimethylsilyl; Tol, tolyl; Ts, 4-toluenesulfonyl (tosyl); VAPOL, 2,2'-diphenyl-[3,3'-biphenanthrene]-4,4'-diol. 


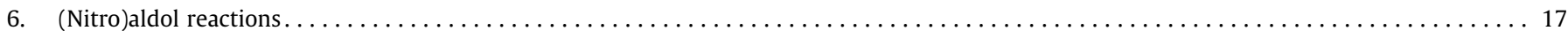

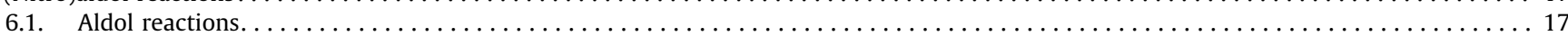

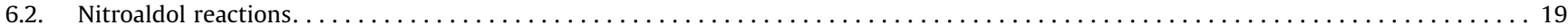

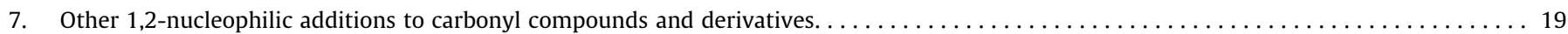

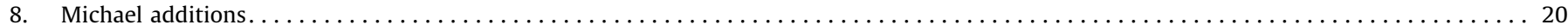

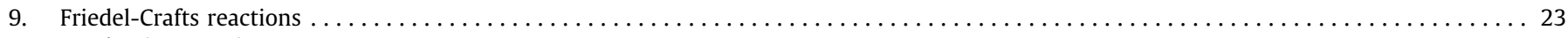

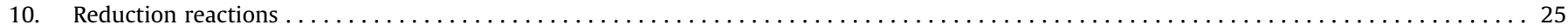

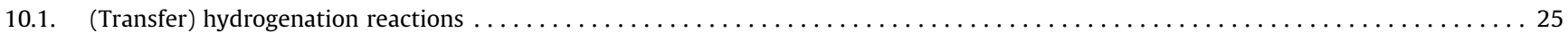

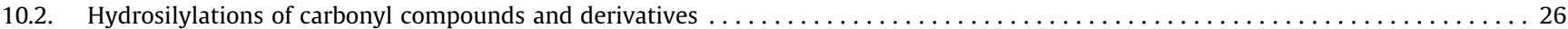

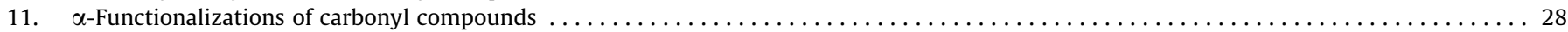

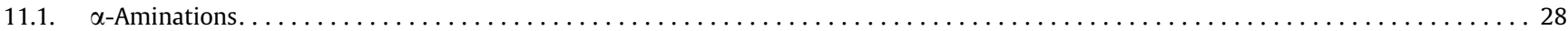

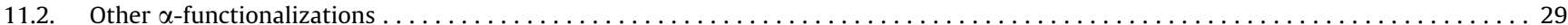

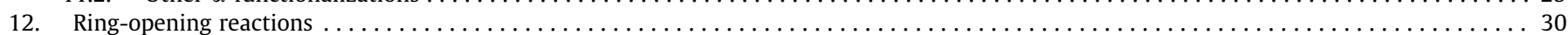

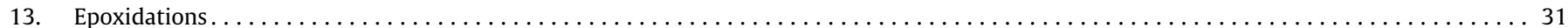

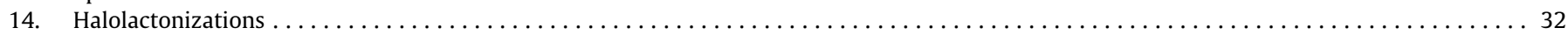

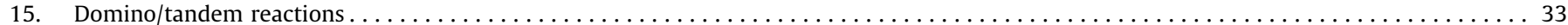

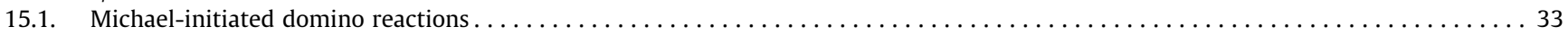

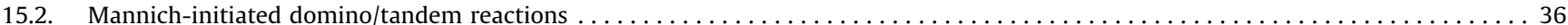

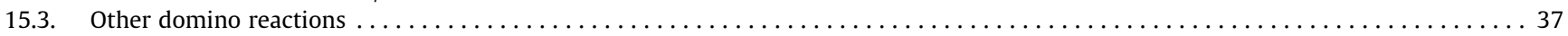

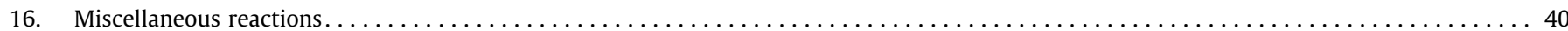

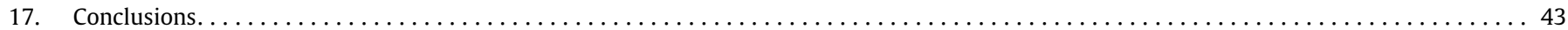

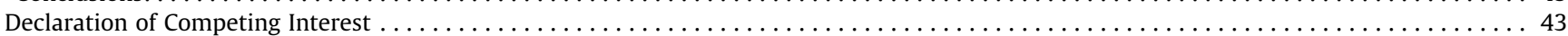

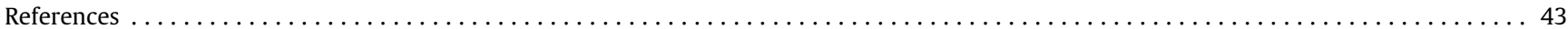

\section{Introduction}

Zinc is the 24th most abundant element in the Earth's crust [1], the first discovery of which goes back to 1746 . As a material, zinc is used for the corrosion-resistant zinc plating of steel, and is also applied in batteries and alloys. Biologically, it is an essential element with exceptional biological importance. For example, zinc deficiency is responsible of many diseases, such as growth retardation, infection susceptibility, delayed sexual maturation, diarrhea, etc [2]. It is present as co-catalyst in many enzymes, which has inspired chemists to design artificial zinc chiral catalysts. Chemically, zinc has a completely filled electron configuration of [Ar] $3 \mathrm{~d} 104 \mathrm{~s} 2$ and acts as a strong reducing agent. It tends to form bonds with a greater degree of covalency and stable complexes with $\mathrm{N}$ and S-donor ligands. In synthetic organic chemistry, the main role of zinc salts is as Lewis acid catalysts. In comparison with most transition metals employed in catalysis [3], zinc complexes present the advantages to be inexpensive, abundant and less toxic, which have triggered the development of a wide range of more ecologic and economic zinc-catalyzed transformations. These green catalysts have been proven to be highly efficient to promote many

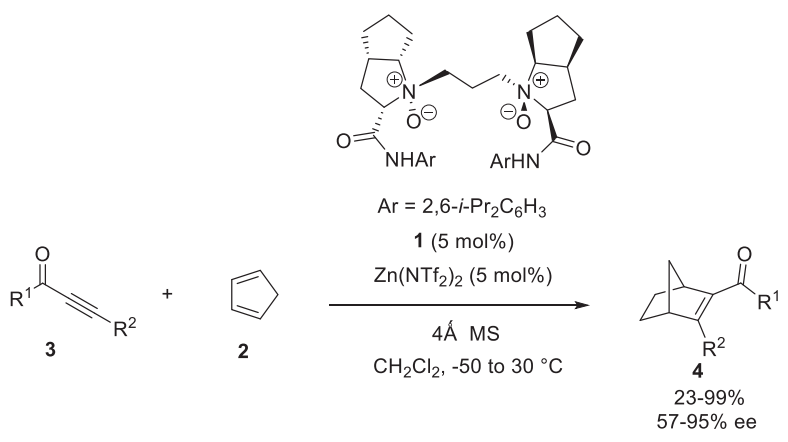

$\mathrm{R}^{1}=\mathrm{Ph}, m-\mathrm{BrC}_{6} \mathrm{H}_{4}, p-\mathrm{BrC}_{6} \mathrm{H}_{4}, m-\mathrm{FC}_{6} \mathrm{H}_{4}, p-\mathrm{FC}_{6} \mathrm{H}_{4}, p-\mathrm{F}_{3} \mathrm{CC}_{6} \mathrm{H}_{4}, p-\mathrm{ClC}_{6} \mathrm{H}_{4}$ $m$ - $\mathrm{F}_{3} \mathrm{CC}_{6} \mathrm{H}_{4}, p$-Tol, $m$-Tol, o-Tol, 3-PhO-4- $\mathrm{FC}_{6} \mathrm{H}_{3}, m-\mathrm{MeOC}_{6} \mathrm{H}_{4}, p-\mathrm{MeOC}_{6} \mathrm{H}_{4}$ 3,4- $\mathrm{Cl}_{2} \mathrm{C}_{6} \mathrm{H}_{3}, 2-\mathrm{Naph}, 2$-thienyl, 2-furyl, $n$-Pent $\mathrm{R}^{2}=\mathrm{H}, n$-Pent, Me, TMS, I

Scheme 1. Diels-Alder cycloaddition of cyclopentadiene with alkynones in the presence of a $N, N^{\prime}$-dioxide ligand [17]. types of organic transformations spanning from basic ones, including $\mathrm{C}-\mathrm{C}, \mathrm{C}-\mathrm{O}, \mathrm{C}-\mathrm{N}, \mathrm{C}-\mathrm{S}, \mathrm{C}-\mathrm{P}$, and $\mathrm{C}-\mathrm{H}$ bond forming reactions, to modern and complex one-pot methodologies, such as domino and tandem reactions. Indeed, the diversity of transformations in which zinc has been successfully applied is impressive and confirms its versatility as catalyst. This review updates the field of enantioselective zinc-catalyzed reactions published since the beginning of 2015 , since this area was most recently updated by

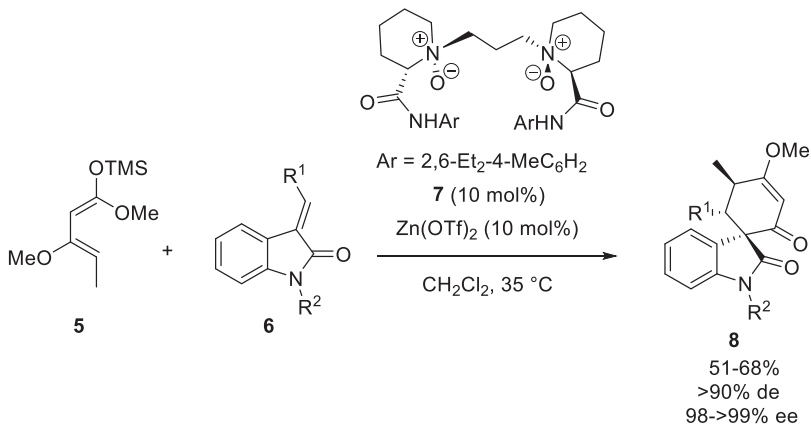

$\mathrm{R}^{1}=\mathrm{Ph}, m-\mathrm{ClC}_{6} \mathrm{H}_{4}, m-\mathrm{BrC}_{6} \mathrm{H}_{4}, m-\mathrm{Tol}, m-\mathrm{MeOC}_{6} \mathrm{H}_{4}, m-\mathrm{PhOC}_{6} \mathrm{H}_{4}, p-\mathrm{FC}_{6} \mathrm{H}_{4}, p-\mathrm{ClC}_{6} \mathrm{H}_{4}$ $p$ - $\mathrm{BrC}_{6} \mathrm{H}_{4}, p-\mathrm{F}_{3} \mathrm{CC}_{6} \mathrm{H}_{4}, p-\mathrm{O}_{2} \mathrm{NC}_{6} \mathrm{H}_{4}, p$-Tol, 1-Naph, 2-Naph, 2-furyl, $\mathrm{CO}_{2} \mathrm{Me}, \mathrm{CO}_{2} \mathrm{Et}$, $\mathrm{CO}_{2} i-\mathrm{Pr}, \mathrm{CO}_{2} t-\mathrm{Bu}, \mathrm{CO}_{2} \mathrm{Bn}$ $\mathrm{R}^{2}=\mathrm{Boc}, \mathrm{Ac}, \mathrm{Cbz}, \mathrm{Bn}$

proposed transition state (with $\mathrm{R}^{1}=\mathrm{Me}, \mathrm{R}^{2}=\mathrm{Boc}$ ):

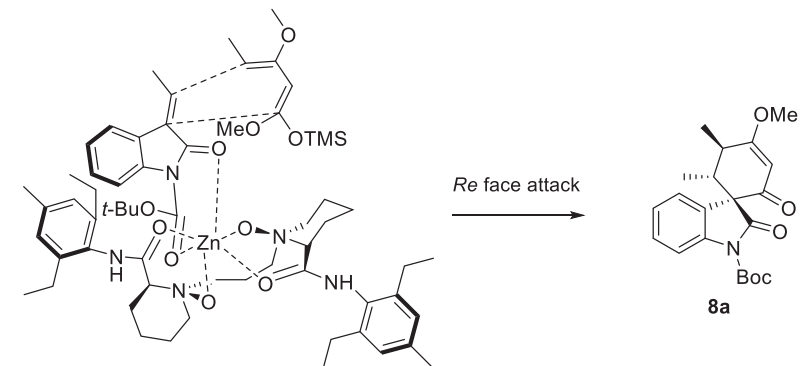

Scheme 2. Diels-Alder cycloaddition of Brassard-type diene with methyleneindolines in the presence of a $N, N^{\prime}$-dioxide ligand [18]. 


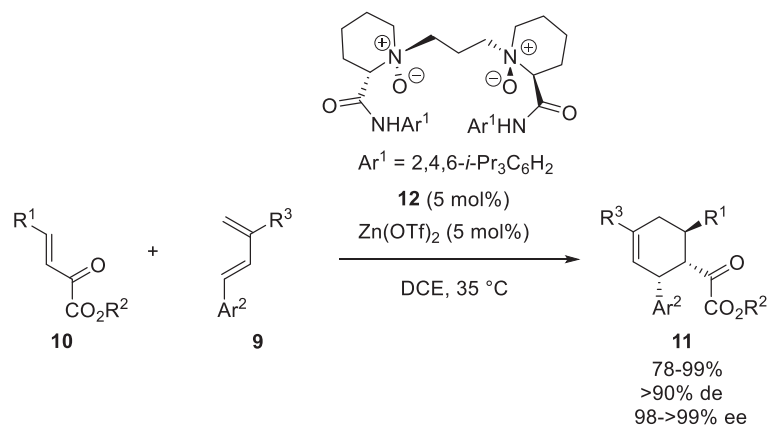

$\mathrm{R}^{1}=\mathrm{Ph}, m$ - Tol, o- $\mathrm{MeOC}_{6} \mathrm{H}_{4}, p-\mathrm{MeOC}_{6} \mathrm{H}_{4}, p-\mathrm{PhC}_{6} \mathrm{H}_{4}, o-\mathrm{FC}_{6} \mathrm{H}_{4}, p-\mathrm{FC}_{6} \mathrm{H}_{4}$, $m$ - $\mathrm{ClC}_{6} \mathrm{H}_{4}, 2,6-\mathrm{Cl}_{2} \mathrm{C}_{6} \mathrm{H}_{3}, p-\mathrm{BrC}_{6} \mathrm{H}_{4}, 2-\mathrm{Naph},(E)-\mathrm{PhCH}=\mathrm{CH}$, 3-thienyl, $\mathrm{Cy}$ $\mathrm{R}^{2}=\mathrm{Me}, \mathrm{Et}, \mathrm{Bn}$

$\mathrm{R}^{3}=\mathrm{Me}, \mathrm{Et}, \mathrm{Ph}$

$\mathrm{Ar}^{2}=\mathrm{Ph}, o-\mathrm{ClC}_{6} \mathrm{H}_{4}, m-\mathrm{FC}_{6} \mathrm{H}_{4}, p-\mathrm{FC}_{6} \mathrm{H}_{4}, m-\mathrm{MeOC}_{6} \mathrm{H}_{4}, p-\mathrm{MeOC}_{6} \mathrm{H}_{4}$

proposed transition state:

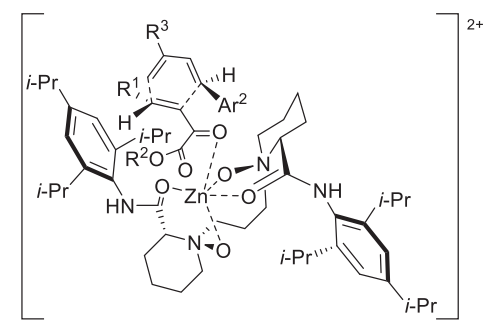

Scheme 3. Diels-Alder cycloaddition of $(E) 1$-phenyl dienes with $\beta, \gamma$-unsaturated $\alpha$ ketoesters in the presence of a $N, N^{\prime}$-dioxide ligand [19].

Mlynarski this year [4]. Previously, the general field of zinc catalysis (not especially asymmetric) was reviewed by Enthaler and $\mathrm{Wu}$ [5]. Moreover, it must be noted that in 2015, three reports focusing on special reactions catalyzed by zinc were published, such as enantioselective aldol reactions [6], asymmetric dialkylzincmediated alkynylation, arylation and alkenylation reactions of carbonyl compounds [7], and tandem reactions based on the use of organozinc reagents [8]. In 2017, a report on zinc-promoted Henry reactions was published, citing only five references dealing with asymmetric processes all dating back to 2015 [9]. The same year, the asymmetric alkylation of ketones with organozinc reagents was subject to a short review albeit containing none reference $\geq 2015$ [10]. In 2018, a review on zinc-catalyzed Michael reactions was published with few asymmetric works and none reference $\geq 2015$ [11]. Also in 2018, was reviewed the synthesis of $N$-hetero-

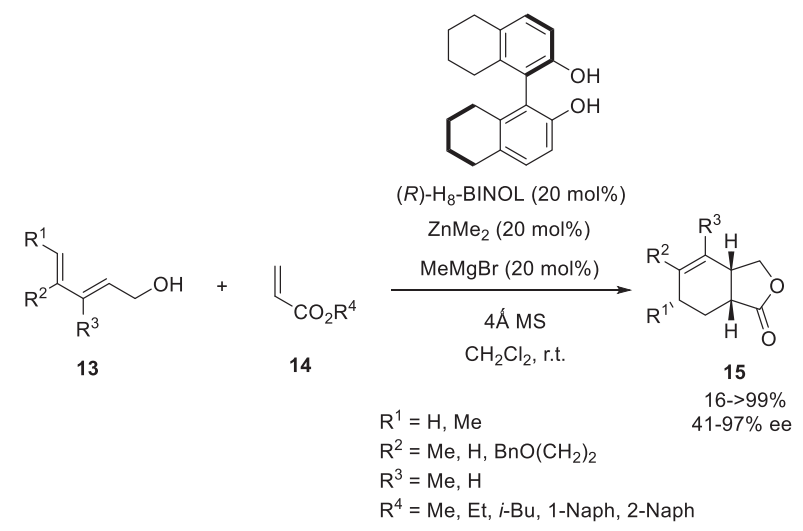

Scheme 4. Diels-Alder cycloaddition of 2,4-dienols with acrylates in the presence of $(R)-\mathrm{H}_{8}$-BINOL ligand followed by lactonization [20]. cyclic carbene-supported zinc complexes and use in racemic catalysis [12]. Later in 2019, a report on the synthesis of heterocycles via zinc catalysis was published with only one reference concerning asymmetric work and moreover dating back to 2015 [13]. In 2020, racemic zinc-catalyzed multicomponent reactions were collected in another review [14]. The present review is divided into fifteen parts, outlining successively enantioselective zinccatalyzed cycloadditions, alkynylation/allylation reactions of carbonyl compounds and derivatives, additions of diorganozincs to carbonyl compounds and derivatives, Mannich reactions, (nitro)aldol reactions, other 1,2-nucleophilic additions to carbonyl compounds and derivatives, Michael additions, Friedel-Crafts reactions, reduction reactions, $\alpha$-functionalizations of carbonyl compounds, ring-opening reactions, epoxidations, halolactonizations, domino/tandem reactions and miscellaneous reactions.

\section{Cycloadditions}

\subsection{Diels-Alder cycloadditions}

The first examples of enantioselective zinc-catalyzed (hetero)Diels-Alder cycloadditions were independently reported in 1997 by the groups of Takacs [15] and Jørgensen [16] who both employed chiral bisoxazoline ligands, allowing similar enantioselectivities of $78-79 \%$ ee to be achieved. Ever since, other types of ligands have been successfully investigated in these reactions [4]. For example, chiral $N, N^{\prime}$-dioxide ligand 1 was combined at $5 \mathrm{~mol}$ $\%$ of catalyst loading to $\mathrm{Zn}\left(\mathrm{NTf}_{2}\right)_{2}$ (5 mol\%) to promote the enantioselective Diels-Alder cycloaddition of cyclopentadiene 2 with a variety of alkynones $\mathbf{3}$ (Scheme 1) [17]. The corresponding chiral 2-acyl substituted norbornadiene derivatives $\mathbf{4}$ were generated in dichloromethane as solvent with low to quantitative yields (23-99\%) and moderate to high enantioselectivities (57-95\% ee). Actually, the enantioselectivities were found of $81-95 \%$ ee for all substrates excepted for a TMS-substituted alkyne $\left(R^{2}=T M S\right)$ which provided the lowest enantioselectivity ( $57 \%$ ee).

The same authors also developed asymmetric zinc-catalyzed Diels-Alder reaction of Brassard-type diene $\mathbf{5}$ with methyleneindolines 6 by using related $N, N^{\prime}$-dioxide chiral ligand 7 (Scheme 2) [18]. Indeed, the chiral zinc catalyst in situ generated from $10 \mathrm{~mol} \%$ of this ligand and the same quantity of $\mathrm{Zn}(\mathrm{OTf})_{2}$ in dichloromethane as solvent was found to promote this reaction at $35{ }^{\circ} \mathrm{C}$, resulting in the formation of the corresponding chiral functionalized spirooxindoles $\mathbf{8}$ exhibiting three contiguous stereocenters in moderate yields (51-68\%) albeit as almost single diastereo- (>90\% de) and enantiomers (98->99\% ee) regardless

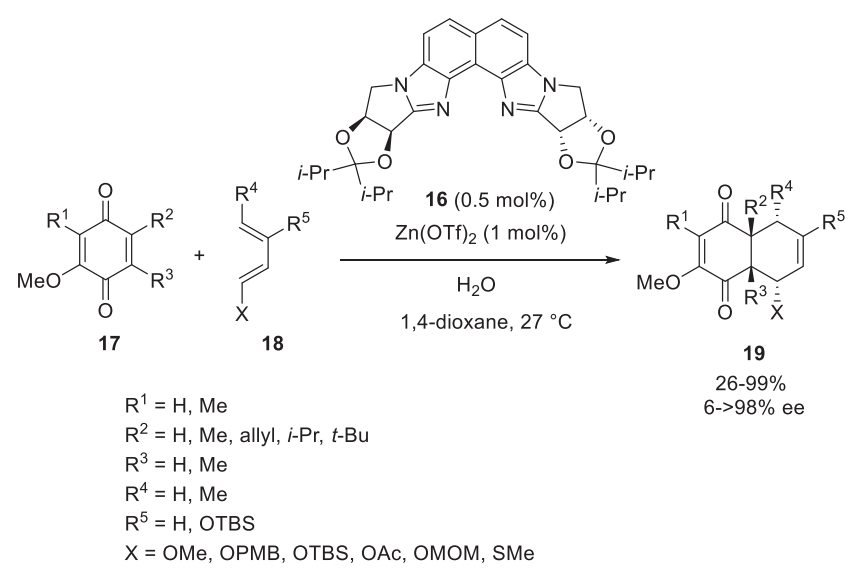

Scheme 5. Diels-Alder cycloaddition of o-alkoxy- and o-thiomethyl-p-benzoquinones with 1-alkoxy-1,3-butadienes in the presence of a bisamidine ligand [21]. 


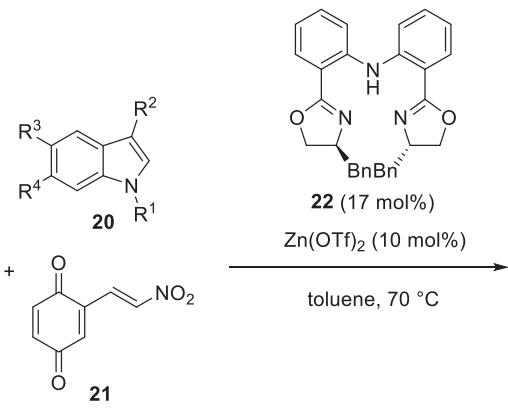

$\mathrm{R}^{1}=\mathrm{Me}$, allyl, $n-\mathrm{Pr}$, 2-propynyl, $\mathrm{Bn}, p-\mathrm{BrC}_{6} \mathrm{H}_{4} \mathrm{CH}_{2}$

$\mathrm{R}^{2}=\mathrm{Me}, \mathrm{MeO}\left(\mathrm{CH}_{2}\right)_{2}$

$\mathrm{R}^{3}=\mathrm{H}, \mathrm{F}, \mathrm{Cl}, \mathrm{Br}, \mathrm{MeO}, \mathrm{BnO}, m-\mathrm{Tol}, p-\mathrm{MeOC}_{6} \mathrm{H}_{4}, p-\mathrm{FC}_{6} \mathrm{H}_{4}, p-\mathrm{F}_{3} \mathrm{CC}_{6} \mathrm{H}_{4}, \mathrm{Me}$ $\mathrm{R}^{4}=\mathrm{H}, \mathrm{F}, \mathrm{Cl}, \mathrm{Br}, \mathrm{MeO}, \mathrm{BnO}, m-\mathrm{Tol}, p-\mathrm{MeOC}_{6} \mathrm{H}_{4}, p-\mathrm{FC}_{6} \mathrm{H}_{4}, p-\mathrm{F}_{3} \mathrm{CC}_{6} \mathrm{H}_{4}, \mathrm{Me}$

mechanism with $\mathrm{R}^{1}=\mathrm{R}^{2}=\mathrm{Me}, \mathrm{R}^{3}=\mathrm{R}^{4}=\mathrm{H}$

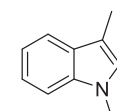

$\mathrm{Zn}(\mathrm{OTf})_{2} / 22$<smiles>O=C1C=CC(=O)C(C=C[N+](=O)[O-])C1</smiles>

21

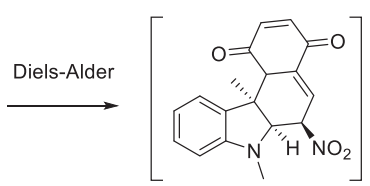

24

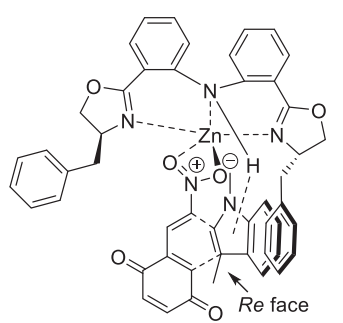

oxidation

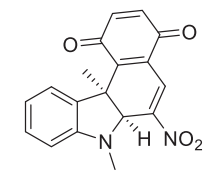

23
Scheme 6. Inverse-electron-demand Diels-Alder cycloaddition of indoles with 2(2-nitrovinyl)-1,4-benzoquinone in the presence of a bisoxazoline ligand followed by oxidation [22].
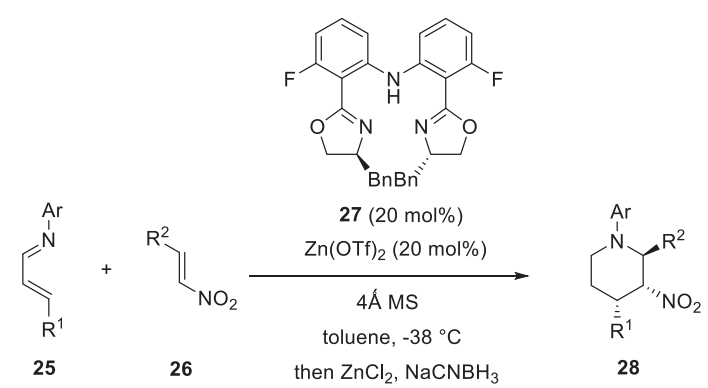

28

$31-87 \%$

$46-92 \%$ ee

$\mathrm{Ar}=p-\mathrm{PhOC}_{6} \mathrm{H}_{4}, p-\mathrm{MeOC}_{6} \mathrm{H}_{4}, \mathrm{Ph}$

$\mathrm{R}^{1}=\mathrm{Ph}, p-\mathrm{O}_{2} \mathrm{NC}_{6} \mathrm{H}_{4}, p-\mathrm{BrC}_{6} \mathrm{H}_{4}, p-\mathrm{MeOC}_{6} \mathrm{H}_{4}, 2$-furyl, $i-\mathrm{Pr},(E)-\mathrm{PhCH}=\mathrm{CH}$ $\mathrm{R}^{2}=\mathrm{Bu}, \mathrm{BnCH}_{2}, i-\mathrm{Bu}, i-\mathrm{Pr}$, TBSOCH

Scheme 7. Aza-Diels-Alder cycloaddition of 1-azadienes with nitroalkenes in the presence of a bisoxazoline ligand followed by reduction [24].

the nature of substituents beared by methyleneindolines. A possible transition state is depicted in Scheme 2 in which oxygen atoms of the amide and $\mathrm{N}$-oxide are coordinated with $\mathrm{Zn}(\mathrm{II})$ in a tetradentate manner to form a six-membered chelate ring. Meanwhile, the methyleneindolinone $\mathbf{6}$ coordinates to the $\mathrm{Zn}(\mathrm{II})$ in a bidentate fashion with its dicarbonyl groups. Then, Brassard-type diene $\mathbf{5}$ attacks $\mathbf{6}$ from its Re face, since the $S i$ face is shielded by the neighboring 2,6-diethyl-4-methylphenyl group of ligand 7.

Another chiral $N, N^{\prime}$-dioxide ligand was later employed by these authors to promote highly regio-, diastereo-, and enantioselective Diels-Alder cycloaddition of (E) 1-phenyl dienes 9 with $\beta, \gamma-$ unsaturated $\alpha$ ketoesters 10 [19]. Only one diastereomer $(>90 \%$ $\mathrm{de}$ ) of the corresponding cyclohexenes $\mathbf{1 1}$ containing three contiguous stereocenters was obtained in all reactions when catalyzed at $35{ }^{\circ} \mathrm{C}$ by a combination of $5 \mathrm{~mol} \%$ of ligand 12 and $5 \mathrm{~mol} \%$ of $\mathrm{Zn}$ $(\mathrm{OTf})_{2}$ in DCE as solvent (Scheme 3). Excellent results were achieved since the cycloadducts were obtained enantiopure (98->99\% ee) in high yields (78-99\%). A transition state was proposed by the authors with the four oxygens of the $N, N^{\prime}$-dioxide ligand and the two oxygens of the $\beta, \gamma$-unsaturated $\alpha$-ketoester substrate coordinated to zinc, thus forming an octahedral complex (Scheme 3). Since the Si face of the $\beta, \gamma$-unsaturated $\alpha$-ketoester was shielded by the neighboring amide group of the ligand, the (E) 1-phenyl diene attacked from the Re face of the $\beta, \gamma-$ unsaturated $\alpha$-ketoester to give the final cycloadduct.

Earlier in 2015, Ishihara et al. reported the first asymmetric Diels-Alder reaction of 2,4-dienols 13 with acrylates 14 performed in the presence of an in situ generated bimetallic chiral catalyst derived from $20 \mathrm{~mol} \%$ of $(R)-\mathrm{H}_{8}-\mathrm{BINOL}, \mathrm{ZnMe}_{2}$ and $\mathrm{MeMgBr}$ [20]. This catalyst system allowed at room temperature in dichloromethane as solvent the formation of a series of functionalized bicyclic chiral $\gamma$-lactones $\mathbf{1 5}$ as single diastereomers in low to quantitative yields $(16->99 \%)$ and moderate to excellent enantioselectivities (41-97\% ee), as shown in Scheme 4. Actually, the Diels-Alder cycloaddition was followed by a lactonization, providing $\gamma$-lactones. It must be noted that this work could also be situated in Section 15 dealing with domino/tandem reactions since it follows a domino Diels-Alder/lactonization mechanism.

In 2019, Kitamura et al. demonstrated that a chiral zinc catalyst in situ prepared from only $1 \mathrm{~mol} \%$ of $\mathrm{Zn}(\mathrm{OTf})_{2}$ and as low as $0.5 \mathrm{~mol}$ $\%$ of chiral bisamidine ligand $\mathbf{1 6}$ was able to promote an asymmet-

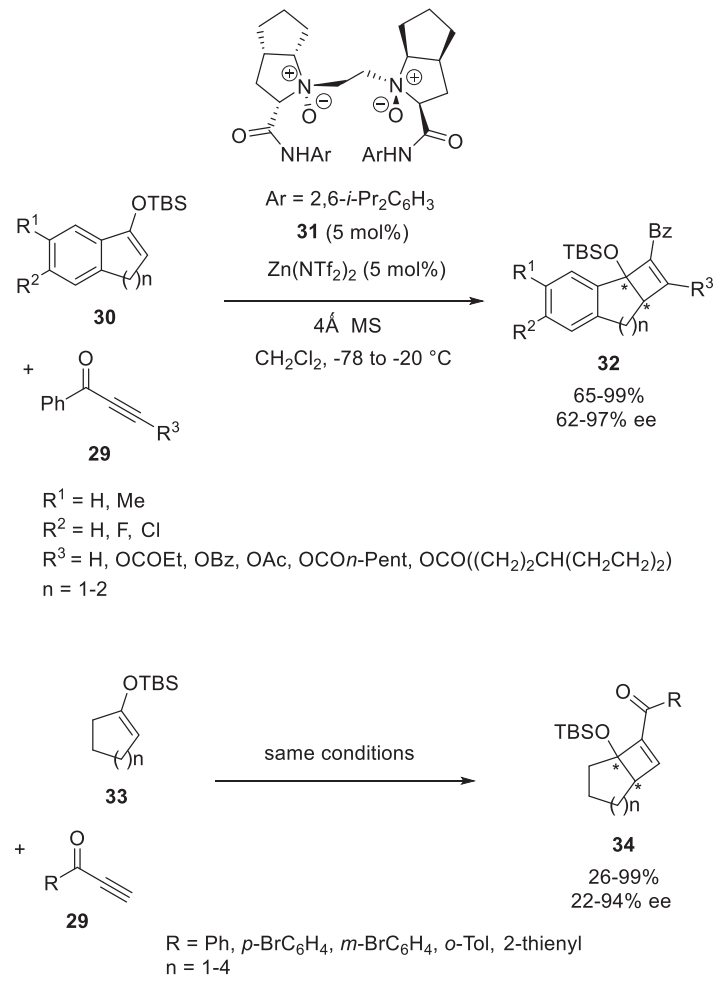

Scheme 8. $[2+2]$ Cycloadditions of alkynones with cyclic enol silyl ethers in the presence of a $N, N^{\prime}$-dioxide ligand [26]. 


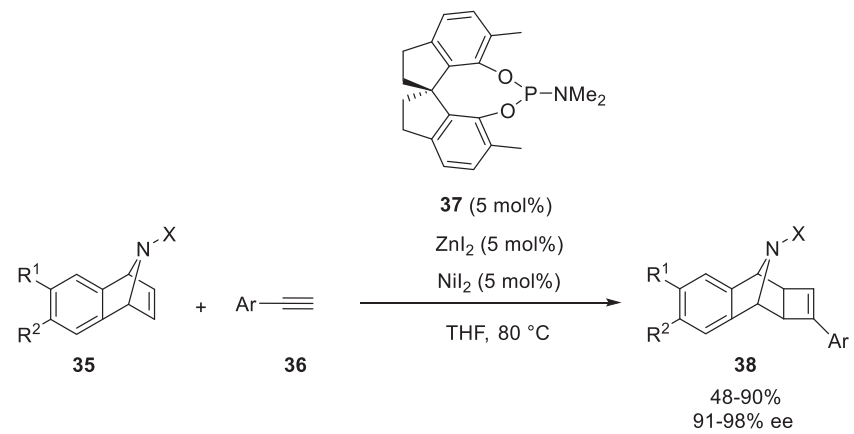

$\mathrm{Ar}=\mathrm{Ph}, p-\mathrm{Tol}, p-\mathrm{MeOC}_{6} \mathrm{H}_{4}, m-\mathrm{MeOC}_{6} \mathrm{H}_{4}, p-\mathrm{PhOC}_{6} \mathrm{H}_{4}, p-\left(\mathrm{HOCH}_{2}\right) \mathrm{C}_{6} \mathrm{H}_{4}$, $p-\mathrm{FC}_{6} \mathrm{H}_{4}, p-\mathrm{ClC}_{6} \mathrm{H}_{4}, m-\mathrm{ClC}_{6} \mathrm{H}_{4}, p-\mathrm{BrC}_{6} \mathrm{H}_{4}, p-\mathrm{F}_{3} \mathrm{CC}_{6} \mathrm{H}_{4}$

$\mathrm{R}^{1}=\mathrm{H}, \mathrm{Me}, \mathrm{OMe}$

$\mathrm{R}^{2}=\mathrm{H}, \mathrm{Me}, \mathrm{OMe}$

$\mathrm{X}=\mathrm{Boc}, \mathrm{Cbz}, \mathrm{CO}_{2} \mathrm{Me}$

Scheme 9. $[2+2]$ Cycloaddition of azabenzonorbornadienes with terminal alkynes in the presence of a phosphoramidite ligand [27].

ric Diels-Alder cycloaddition between 0 -alkoxy-p-benzoquinones $\mathbf{1 7}$ and 1-alkoxy-1,3-butadienes $\mathbf{1 8}$ to generate highly functionalized chiral cis-decalins 19 [21]. As illustrated in Scheme 5, these products were synthesized at $27^{\circ} \mathrm{C}$ in 1,4-dioxane as solvent with variable yields (26-99\%) and enantioselectivities (6->98\% ee) as single regio- and endo-diastereomers. The catalyst system was also compatible with a 1-thiomethyl-1,3-butadiene $(X=S M e)$ which gave the corresponding product in $93 \%$ yield and $84 \%$ ee. It was found that the reaction did not work in the absence of water as an additive.

In 2020, an enantioselective dearomatization inverse-electrondemand Diels-Alder cycloaddition of indoles 20 with 2-(2nitrovinyl)-1,4-benzoquinone $\mathbf{2 1}$ was disclosed by Zhang et al., using a combination of $17 \mathrm{~mol} \%$ of chiral bisoxazoline $\mathbf{2 2}$ with $10 \mathrm{~mol} \%$ of $\mathrm{Zn}(\mathrm{OTf})_{2}$ as catalyst system [22]. This reaction performed at $70{ }^{\circ} \mathrm{C}$ in toluene allowed the synthesis of chiral sixmembered [2,3]-fused indolines 23 to be achieved as single diastereomers in moderate to quantitative yields (34-99\%) and enantioselectivities (37-88\% ee), as illustrated in Scheme 6. Actually, the cycloaddition underwent through the Re face of the 2-(2-nitrovinyl)-1,4-benzoquinone activated by the chiral zinc catalyst also $\mathrm{N}$-chelated to the indole substrate through $\mathrm{NH}-\mathrm{p}$ interaction to give Diels-Alder cycloadduct 24. However, the latter was unstable and further underwent an oxidation to give final product 23. It must be noted that this work could also be situated in Section 15 highlighting domino/tandem reactions since it involves a Diels-Alder/oxidation domino reaction.

Despite the prevalence of piperidine moieties in drugs, the azaversion of the all-carbon [4+2] cycloaddition is still less developed [23]. To fill this goap, Rovis reported in 2015 a rare example of asymmetric synthesis of piperidines through zinc-catalyzed azaDiels-Alder cycloaddition of 1-azadienes $\mathbf{2 5}$ with nitroalkenes $\mathbf{2 6}$ (Scheme 7) [24]. A chiral catalyst in situ generated from $20 \mathrm{~mol} \%$ of $\mathrm{Zn}(\mathrm{OTf})_{2}$ and the same quantity of chiral bisoxazoline $\mathbf{2 7}$ was employed in toluene at $-38^{\circ} \mathrm{C}$, affording a range of chiral piperidines 28 in variable yields (31-87\%) and enantioselectivities (46$92 \%$ ee) as single regio- and diastereomers ( $>90 \%$ de). Actually, due to the instability of the tetrahydropyridine arisen from the cycloaddition, its enamine functionality was directly reduced by treatment with $\mathrm{ZnCl}_{2}$ and $\mathrm{NaBH}_{3} \mathrm{CN}$ in methanol to give more stable 3-nitropiperidine 28. The lowest enantioselectivity (46\% ee) was obtained in the reaction of an alkyl-substituted azadiene $\left(\mathrm{R}^{1}=i\right.$-Pr $)$. Furthermore, the reaction of a more conjugated azatriene $\left(\mathrm{R}^{1}=(\mathrm{E})-\mathrm{PhCH}=\mathrm{CH}\right)$ required $30 \mathrm{~mol} \%$ of catalyst to provide the corresponding product in $65 \%$ yield and $63 \%$ ee. For all the

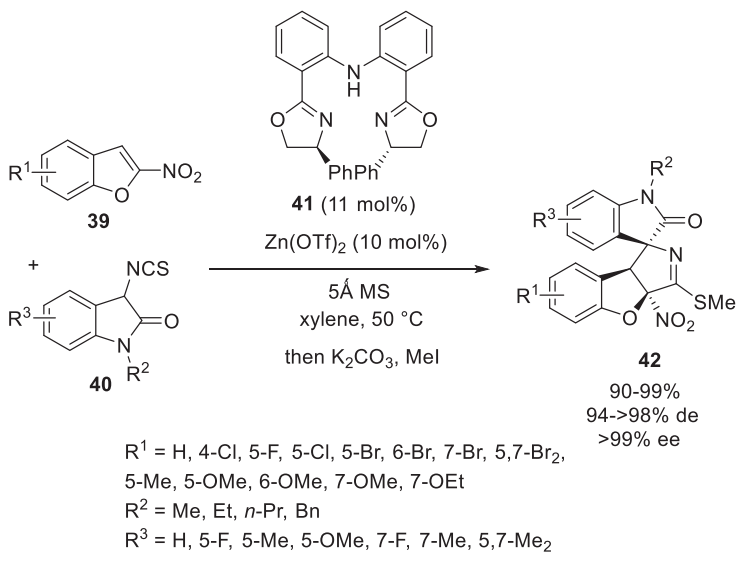

possible transition state with $\mathrm{R}^{1}=\mathrm{R}^{3}=\mathrm{H}$ :

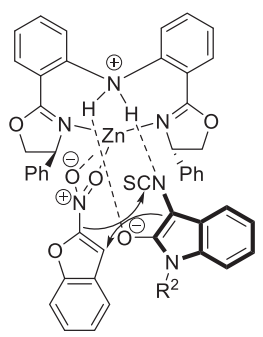

Scheme 10. $[3+2]$ Cycloaddition of 2 nitrobenzofurans with 3 isothiocyanato oxindoles in the presence of a bisoxazoline ligand [29].
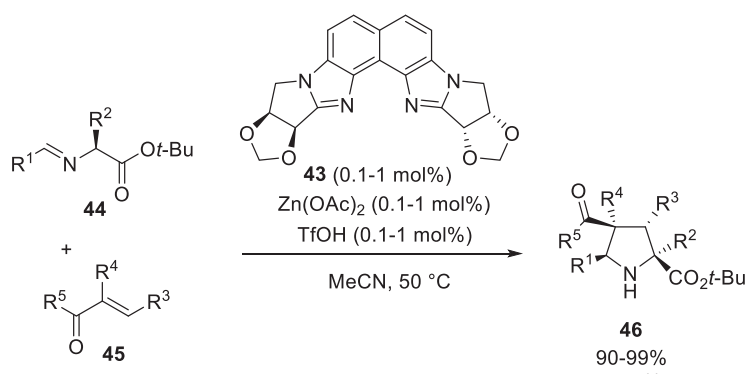

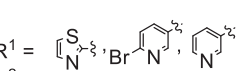

46

$90-99 \%$

$88->98 \%$ ee

$\mathrm{R}^{2}=\mathrm{H}, i-\mathrm{Bu}, i-\mathrm{Pr}, \mathrm{Ph}, t-\mathrm{BuOCH} \mathrm{H}_{2}, \mathrm{BocNH}\left(\mathrm{CH}_{2}\right)_{4}, \mathrm{MeS}\left(\mathrm{CH}_{2}\right)_{2}, \mathrm{MeO}_{2} \mathrm{C}\left(\mathrm{CH}_{2}\right)_{2}$

$\mathrm{R}^{3}=\mathrm{H}, \mathrm{Me}, \mathrm{CO}_{2} \mathrm{Et}$

$\mathrm{R}^{4}=\mathrm{H}, \mathrm{Me}$

$\mathrm{R}^{5}=\mathrm{OMe}, \mathrm{OPh}, \mathrm{NMe}_{2}, \mathrm{Me}, \mathrm{OEt}$

Scheme 11. $[3+2]$ Cycloaddition of chiral imino t-butyl esters with acrylates/ acrylamides in the presence of a bisamidine ligand [30].

other differently substituted substrates, enantioselectivities $\geq 69 \%$ ee were obtained. This work could also be considered as a tandem aza-Diels-Alder/reduction reaction and consequently situated in Section 15.

\section{2. [2+2] Cycloadditions}

Cyclobutene moieties are found in many natural products and bioactive compounds [25]. The most direct route to these products deals with the $[2+2]$ cycloaddition. However, only rare examples of asymmetric catalytic versions of this transformation have been reported so far. Among them, an enantioselective zinc-catalyzed [2+2] cycloaddition of alkynones $\mathbf{2 9}$ with cyclic enol silyl ethers 30/33 was developed in 2016 by Feng and Liu [26]. It involved a catalyst system composed of $5 \mathrm{~mol} \%$ of chiral $N, N^{\prime}$-dioxide ligand 
31 and the same quantity of $\mathrm{Zn}\left(\mathrm{NTf}_{2}\right)_{2}$ as precatalyst. Performed in dichloromethane as solvent, the cycloaddition yielded a range of chiral fused cyclobutenes $\mathbf{3 2 / 3 4}$ in low to excellent yields (2699\%) and enantioselectivities (22-97\% ee), as shown in Scheme 8. This method was compatible with a variety of terminal alkynes $29\left(R^{3}=H\right)$ as well as cyclic enol silyl ethers 30/33. Furthermore, internal alkynes $29\left(\mathrm{R}^{3} \neq \mathrm{H}\right)$ were tolerated, leading to the corresponding products 32 in good to quantitative yields (65-99\%) and good enantioselectivities (71-86\% ee). It must be noted that this work represented the first example of catalytic enantioselective [2+2] cycloaddition of internal alkynes with cyclic enol silyl ethers to give fully substituted cyclobutenes.

In 2018, the asymmetric [2 + 2] cycloaddition of azabenzonorbornadienes $\mathbf{3 5}$ with terminal alkynes $\mathbf{3 6}$ was investigated by Fan and $\mathrm{Xu}$ in the presence of a dual metal catalyst system based on nickel and zinc [27]. Indeed, promoting this reaction with $5 \mathrm{~mol} \%$ of $\mathrm{ZnI}_{2}, \mathrm{NiI}_{2}$ and chiral spiro phosphoramidite ligand 37 in THF at $80^{\circ} \mathrm{C}$ allowed the corresponding chiral cycloadducts 38 to be synthesized in good to high yields (48-90\%) and uniformly excellent enantioselectivities (91-98\% ee), as presented in Scheme 9. A variety of terminal alkynes and azabenzonorbornadienes exhibiting different substituents were tolerated. The exact roles of each metal in the process were not precised by the authors.

\section{3. [3+2] Cycloadditions}

In 2002, Jørgensen et al. described the first enantioselective zinc-catalyzed $[3+2]$ cycloaddition of azomethine ylides generated from glycine methyl esters with alkenes, leading in the presence of chiral bisoxazoline ligands to chiral pyrrolidines with up to $90 \%$ ee [28]. Later in 2018, Yuan and Xu reported the first enantioselective zinc-catalyzed dearomative $[3+2]$ cycloaddition of 2 nitrobenzofurans 39 with 3 isothiocyanato oxindoles 40 [29]. The process, performed at $50{ }^{\circ} \mathrm{C}$ in xylene as solvent, employed a chiral catalyst in situ generated from $10 \mathrm{~mol} \%$ of $\mathrm{Zn}(\mathrm{OTf})_{2}$ and $11 \mathrm{~mol} \%$ of chiral bisoxazoline 41, allowing a direct access to complex chiral spirooxindoles 42 containing a 2,3-dihydrobenzofuran motif and three contiguous stereocenters. These densely functionalized polycyclic cycloadducts were obtained in uniformly excellent yields (90-99\%) as almost single stereomers (94->98\% de and >99\% ee) in all cases of substrates studied. In a possible transition state depicted in Scheme 10, the zinc atom of the chiral complex coordinated the 2 nitrobenzofuran substrate through the nitro group. At the same time, the 3 isothiocyanato oxindole substrate chelated the $\mathrm{NH}$ group of the ligand, acting as a Lewis base. Thus, under the bifunctional activation of the chiral zinc complex, the C3position of the 2-nitrobenzofuran underwent nucleophilic attack at the Re face of the activated 3-isothiocyanato oxindole. A subse-

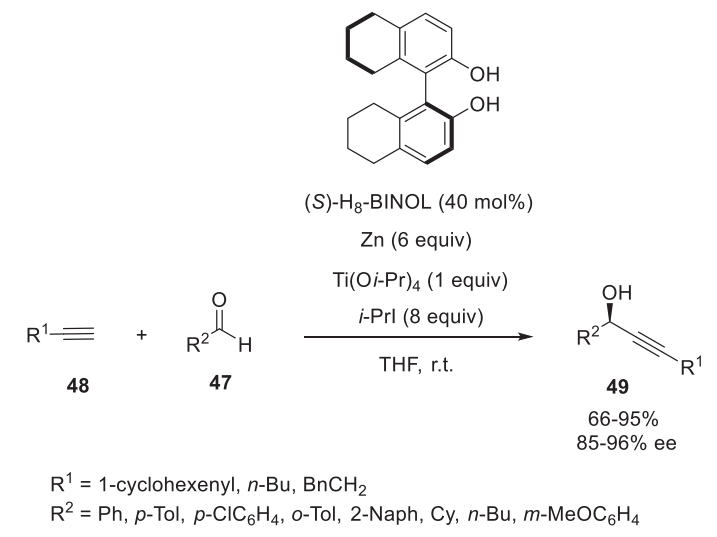

Scheme 12. Alkynylation of aldehydes in the presence of (S)-H $\mathrm{H}_{8}-\mathrm{BINOL}$ [35].

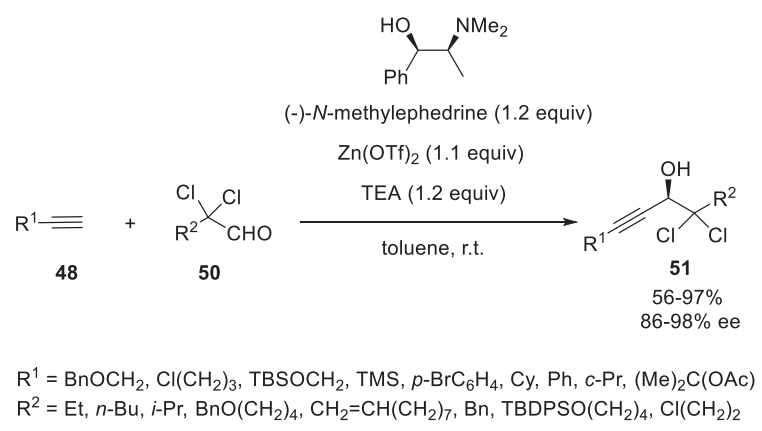

Scheme 13. Alkynylation of $\alpha, \alpha$-dichlorinated aldehydes in the presence of (-)-Nmethylephedrine [36].

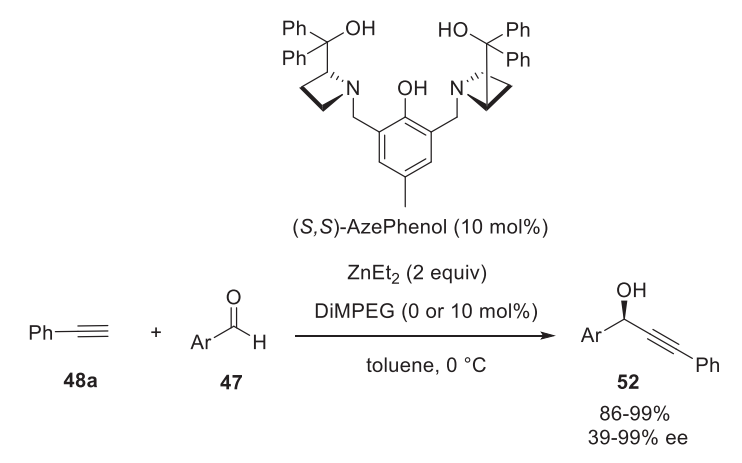

$\mathrm{Ar}=o-\mathrm{ClC}_{6} \mathrm{H}_{4}, m-\mathrm{ClC}_{6} \mathrm{H}_{4}, p-\mathrm{Tol}, p-\mathrm{ClC}_{6} \mathrm{H}_{4}, o-\mathrm{BrC}_{6} \mathrm{H}_{4}, m-\mathrm{BrC}_{6} \mathrm{H}_{4}, p-\mathrm{BrC}_{6} \mathrm{H}_{4}$, $m$-Tol, o- $\mathrm{MeOC}_{6} \mathrm{H}_{4}, m-\mathrm{MeOC}_{6} \mathrm{H}_{4}, p-\mathrm{MeOC}_{6} \mathrm{H}_{4}, 2$-furyl, 2,3-(MeO) ${ }_{2} \mathrm{C}_{6} \mathrm{H}_{3}$, 2,4-(MeO) $)_{2} \mathrm{C}_{6} \mathrm{H}_{3}, 2,6-(\mathrm{MeO})_{2} \mathrm{C}_{6} \mathrm{H}_{3}, 2,5-(\mathrm{MeO})_{2} \mathrm{C}_{6} \mathrm{H}_{3}, 2,3,4-(\mathrm{MeO})_{3} \mathrm{C}_{6} \mathrm{H}_{2}$, $2,4,6-(\mathrm{MeO})_{3} \mathrm{C}_{6} \mathrm{H}_{2}, 2,4,5-(\mathrm{MeO})_{3} \mathrm{C}_{6} \mathrm{H}_{2}$

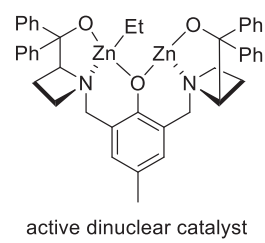

$\mathrm{EtZn}_{2}((S, S)-$ AzePhenol)

Scheme 14. Alkynylation of aromatic aldehydes in the presence of $(S, S)$-AzePhenol [38].

quent intramolecular annulation process from C2-position of the 2-nitrobenzofuran to the NCS group generated the final formal cycloadduct.

In 2020, Kitamura et al. employed a chiral cationic zinc acetate complex derived from as low as $0.1-1 \mathrm{~mol} \%$ of chiral bisamidine ligand $\mathbf{4 3}, \mathrm{Zn}(\mathrm{OAc})_{2}$ and $\mathrm{TfOH}$ to promote a 1,3-dipolar cycloaddition between chiral imino $t$-butyl esters $\mathbf{4 4}$ and acrylates $\mathbf{4 5}$ $\left(\mathrm{R}^{5}=\mathrm{OMe}, \mathrm{OEt}, \mathrm{OPh}\right)$ [30]. In the absence of an external base, the reaction led to the corresponding multi-substituted chiral prolines 46 with complete regio- and diastereoselectivities, combined with uniformly excellent yields (90-99\%) and enantioselectivities (88$98 \%$ ee), as illustrated in Scheme 11. The scope of the methodology could be extended to acrylamides $\left(R^{5}=N M e 2\right)$ and methylvinylketone $\left(R^{3}=R^{4}=H, R^{5}=M e\right)$ with comparable excellent results $(93 \%$ yield, $>98 \%$ ee).

It must be noted that recently, another type of cycloadditions was reported by Charette et al. [31]. It dealt with the synthesis of chiral fluorocyclopropanes via asymmetric cyclopropanation of the corresponding fluoro-substituted allylic alcohols using zinc carbenoids. Since this reaction employed a superstoichiometric amount of a chiral dioxaborolane ligand, it was decided not to detail this work. 


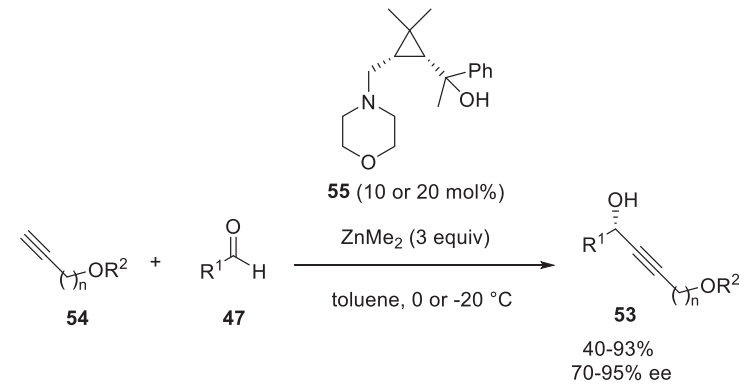

$\mathrm{R}^{1}=\mathrm{Ph}, o-\mathrm{Tol}, m-\mathrm{Tol}, p-\mathrm{Tol}, p-\mathrm{MeOC}_{6} \mathrm{H}_{4}, m-\mathrm{MeOC}_{6} \mathrm{H}_{4}, o-\mathrm{MeOC}_{6} \mathrm{H}_{4}, p-i-\mathrm{PrC}_{6} \mathrm{H}_{4}$ $o-\mathrm{BrC}_{6} \mathrm{H}_{4}, p-\mathrm{BrC}_{6} \mathrm{H}_{4}, p-\mathrm{ClC}_{6} \mathrm{H}_{4}, p-\mathrm{NCC}_{6} \mathrm{H}_{4}$, 2-Naph, 1-Naph, 2-furyl, $i-\mathrm{Pr}, c-\mathrm{Pr}, \mathrm{Cy}$ $t-\mathrm{Bu}, \mathrm{CH}_{2}=\mathrm{C}(\mathrm{Me}), \mathrm{CH}_{2}=\mathrm{C}(\mathrm{Et}),\left(\mathrm{CO}_{2} \mathrm{Et}\right) \mathrm{CH}=\mathrm{C}(\mathrm{Me}), \mathrm{PhCCH}=\mathrm{C}(\mathrm{Me}), \mathrm{MeCH}=\mathrm{C}(\mathrm{Ph})$, $\mathrm{EtCH}=\mathrm{C}(\mathrm{Ph}),(i-\mathrm{Pr}) \mathrm{CH}=\mathrm{C}(\mathrm{Ph})$

$\mathrm{R}^{2}=\mathrm{Ac}, \mathrm{Bz}, \mathrm{Piv}, i-\mathrm{PrCO}, c-\mathrm{PrCO}, \mathrm{Boc}, \mathrm{BnCO}, \mathrm{CyCO}$, TBDPS, $n$-BuCO, $t$-BuCO $n=1-4$

Scheme 15. Alkynylation of aldehydes in the presence of a cyclopropyl 1,4-amino alcohol ligand [39].

\section{Alkynylation/allylation reactions of carbonyl compounds and derivatives}

\subsection{Alkynylation of aldehydes}

The asymmetric addition of organometallic reagents to carbonyl compounds represents the most direct route to chiral alcohols [7,32]. In particular, chiral propargylic alcohols, which constitute key synthetic intermediates in the total synthesis of many natural products and drugs, can be easily prepared in situ from the reaction of acidic terminal alkynes with a zinc reagent, followed by condensation on carbonyl compounds [32c-e,33]. Since the first asymmetric addition of alkynylzinc reagents to aldehydes using chiral amino alcohol ligands derived from ephedrine reported by Niwa and Soai in 1990 [34], many chiral ligands, including 2amino alcohol-type ligands, oxazaborolidines, BINOL derivatives, $\beta$-sulfonamide alcohols, salens, ProPhenol derivatives, and Schiff base amino alcohols, among others have been designed to catalyze

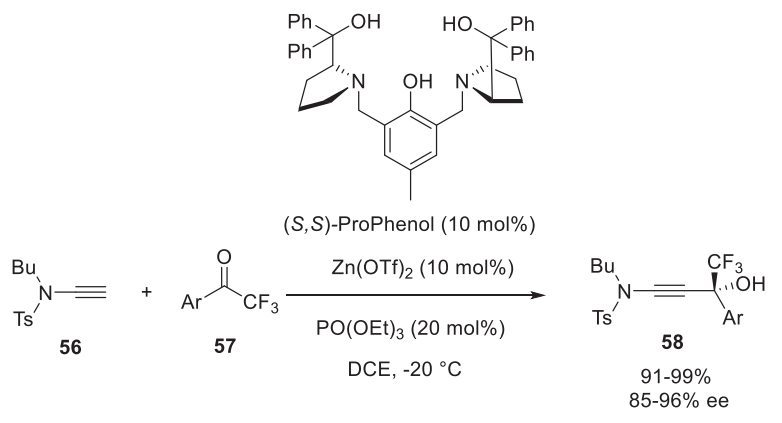

$\mathrm{Ar}=\mathrm{Ph}, o-\mathrm{Tol}, m-\mathrm{Tol}, p-\mathrm{Tol}, p-\left(t-\mathrm{Bu} \mathrm{C}_{6} \mathrm{H}_{4}, p-\mathrm{FC}_{6} \mathrm{H}_{4}, p-\mathrm{ClC}_{6} \mathrm{H}_{4}, p-\mathrm{BrC}_{6} \mathrm{H}_{4}\right.$, $p-\mathrm{F}_{3} \mathrm{CC}_{6} \mathrm{H}_{4}, p-\mathrm{NCC}_{6} \mathrm{H}_{4}, p-\mathrm{EtO}_{2} \mathrm{CC}_{6} \mathrm{H}_{4}, p-\mathrm{MeSC}_{6} \mathrm{H}_{4}, p-\mathrm{MeOC}_{6} \mathrm{H}_{4}$

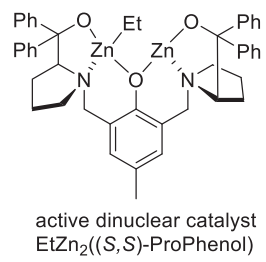

Scheme 16. Alkynylation of aromatic trifluoromethyl ketones in the presence of $(S$, S)-ProPhenol [41].

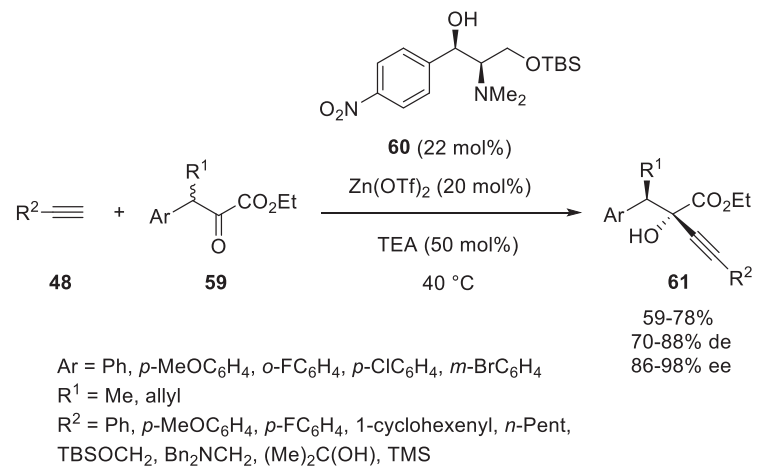

Scheme 17. Alkynylation of $\beta$-stereogenic $\alpha$-ketoesters in the presence of a $(-)-N-$ methylephedrine-derived ligand [43].

enantioselective alkynylations of carbonyl compounds. Among these catalytic systems, zinc complexes have attracted considerable attention owing to their superior catalytic efficiency. However, the asymmetric alkynylation of carbonyl compounds mediated by truly catalytic amounts of zinc still remains an underdeveloped field, with few chiral ligands disclosed to date. In 2015, (S)- $\mathrm{H}_{8}$-BINOL was employed by Pu et al. at $40 \mathrm{~mol} \%$ of catalyst loading in combination with $\mathrm{Zn}$ (6 equivalents), $\mathrm{Ti}(\mathrm{O} i \text {-Pr })_{4}$ (1 equivalent) and $i$-PrI (8 equivalents) [35]. This novel catalyst system presented the advantage to avoid the common use of pyrophoric $\mathrm{ZnEt}_{2}$. As presented in Scheme 12, it promoted the asymmetric alkynylation of aromatic as well as aliphatic aldehydes $\mathbf{4 7}$ with various terminal alkynes $\mathbf{4 8}$ to give the corresponding chiral propargylic alcohols $\mathbf{4 9}$ at room temperature in THF as solvent with both high yields (66-95\%) and enantioselectivities (85-96\% ee).

With the aim of synthesizing chlorinated natural products, such as chlorosulfolipids, Carreira et al. disclosed in 2017 an asymmetric zinc-mediated addition of terminal alkynes $\mathbf{4 8}$ to $\alpha, \alpha$-dichlorinated aldehydes $\mathbf{5 0}$ performed in the presence of a chiral 1,2-amino alcohol ligand, such as (-)-N-methylephedrine [36]. The reaction required 1.1 equivalent of $\mathrm{Zn}(\mathrm{OTf})_{2}$ and 1.2 equivalent of ligand. It led in toluene at room temperature to the corresponding chiral propargylic alcohols $\mathbf{5 1}$ in good to quantitative yields (56-97\%) and high enantioselectivities (86-98\% ee), as shown in Scheme 13. A wide range of aliphatic and aromatic alkynes as well as aliphatic $\alpha, \alpha$-dichlorinated aldehydes were compatible.

The same year, Wang et al. reported the use of $10 \mathrm{~mol} \%$ of their chiral semi-aza-crown ligand (S,S)-AzePhenol [37] combined with two equivalents of $\mathrm{ZnEt}_{2}$ to promote the asymmetric addition of phenylacetylene 48a to aromatic aldehydes 47 [38]. A dinuclear zinc active catalyst $\mathrm{EtZn}_{2}((S, S)$-AzePhenol) was in situ generated in the presence of polyethyleneglycol dimethyl ether (DiMPEG) as an additive (Scheme 14), providing a range of chiral propargylic alcohols 52 to be synthesized in uniformly high yields (86-99\%) and variable enantioselectivities (39-99\% ee). It was found that the enantioselectivity of the reaction was dramatically influenced by the position of substituents exhibited on the phenyl ring of the aldehyde. Indeed, the highest enantioselectivities were achieved in the alkynylation of ortho-substituted aryl aldehydes.

In 2020, Zong et al. developed the synthesis of a wide range of chiral hydroxyalkynol esters and ethers $\mathbf{5 3}$ through novel enantioselective alkynylation of aldehydes $\mathbf{4 7}$ with alkynyl esters and ethers 54, respectively [39]. This simple process was catalyzed at 0 or $-20^{\circ} \mathrm{C}$ by a combination of three equivalents of $\mathrm{ZnMe}_{2}$ with 10 or $20 \mathrm{~mol} \%$ of chiral cyclopropyl 1,4-amino alcohol ligand $\mathbf{5 5}$ in toluene. The products were obtained in good yields (40-93\%) and enantioselectivities (70-95\% ee), as illustrated in Scheme 15. 

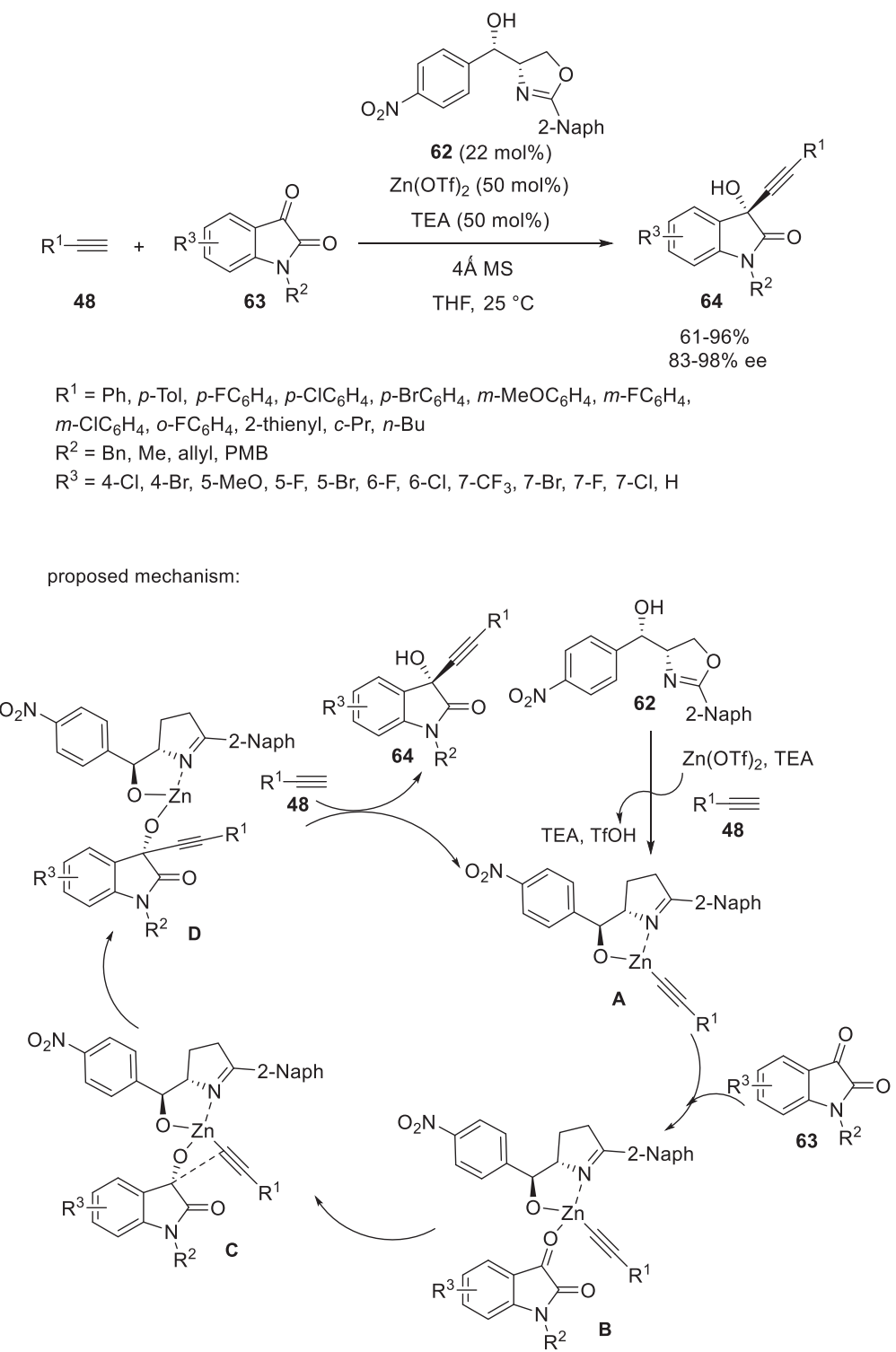

Scheme 18. Alkynylation of isatins in the presence of a hydroxyl oxazoline ligand [44].

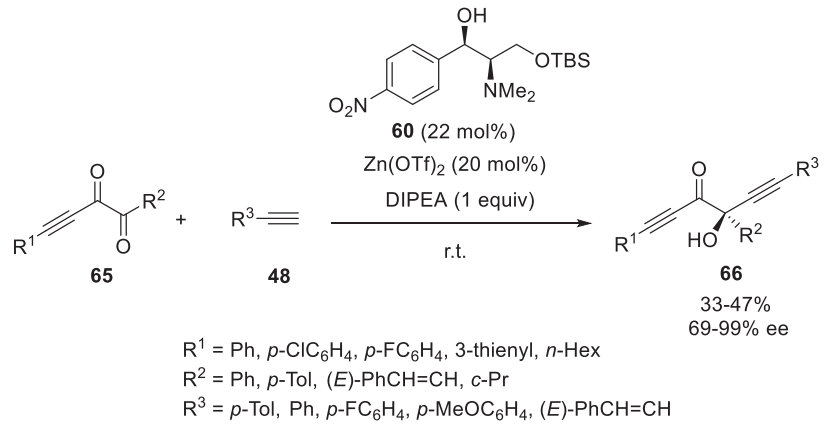

Scheme 19. Alkynylation of alkynyl 1,2-diketones in the presence of a (-)-Nmethylephedrine-derived ligand [45].

Aromatic aldehydes bearing electron-withdrawing or electron-donating substituents on the phenyl ring at ortho-, meta- or para-position all provided excellent enantioselectivities (85-94\% ee) as well as aliphatic aldehydes (80-95\% ee). The lowest enantioselectivity (70\% ee) was observed in the reaction of an heteroaromatic aldehyde $\left(\mathrm{R}^{1}=2\right.$-furyl $)$.

\subsection{Alkynylation of ketones}

The trifluoromethylated tertiary chiral alcohol moiety represents an important motif in medicinal chemistry [40]. In this context, Wolf and Cook disclosed in 2016 the first asymmetric catalytic addition of terminal ynamides $\mathbf{5 6}$ to trifluoromethyl ketones 57, affording the corresponding chiral $\mathrm{CF}_{3}$-substituted tertiary propargylic alcohols $\mathbf{5 8}$ [41]. The reaction was promoted at $-20{ }^{\circ} \mathrm{C}$ in DCE as solvent by chiral dinuclear zinc catalyst $\mathrm{EtZn}_{2}((S, S)$-ProPhenol in situ generated from only $10 \mathrm{~mol} \%$ of $\mathrm{Zn}$ $(\mathrm{OTf})_{2}$ and $(S, S)$-ProPhenol [42] as ligand (Scheme 16). The products exhibiting various substituents on the phenyl ring of the trifluoromethyl ketone were remarkably obtained in both excellent yields (91-99\%) and enantioselectivities (85-96\% ee).

In 2016, Johnson and Zavesky described the enantioselective addition of terminal alkynes $\mathbf{4 8}$ to racemic $\beta$-stereogenic $\alpha$ ketoesters 59 performed under neat conditions (Scheme 17) [43]. The use of a catalyst system, composed of $20 \mathrm{~mol} \%$ of $\mathrm{Zn}(\mathrm{OTf})_{2}$ 


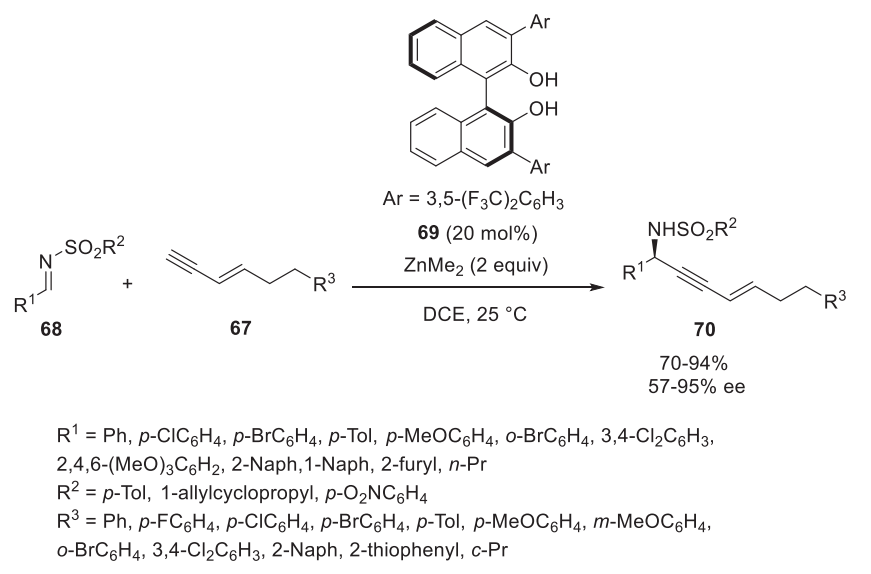

Scheme 20. Alkynylation of $\mathrm{N}$-sulfonyl aldimines with terminal 3-en-1-ynes in the presence of a BINOL-derived ligand [47].

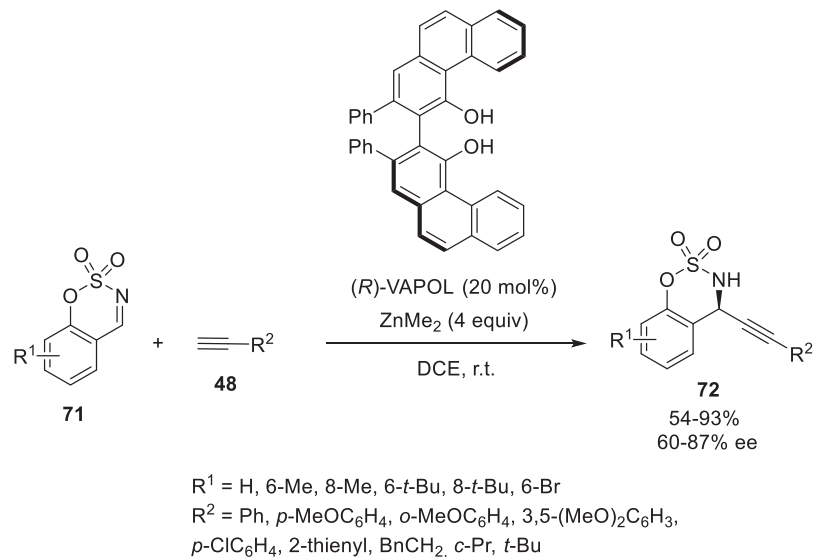

Scheme 21. Alkynylation of benzoxathiazine 2,2-dioxides in the presence of $(R)$ VAPOL [48].

and $22 \mathrm{~mol} \%$ of (-)- $\mathrm{N}$-methylephedrine-derived 1,2-amino alcohol chiral ligand 60, allowed a range of chiral tertiary propargylic alcohols $\mathbf{6 1}$ containing two stereocenters to be easily synthesized in good yields (59-78\%) and diastereoselectivities (70-88\% de) combined with uniformly high enantioselectivities (86-98\% ee). An excellent functional group tolerance was found since many aryl- and alkyl-substituted alkynes including heteroatoms

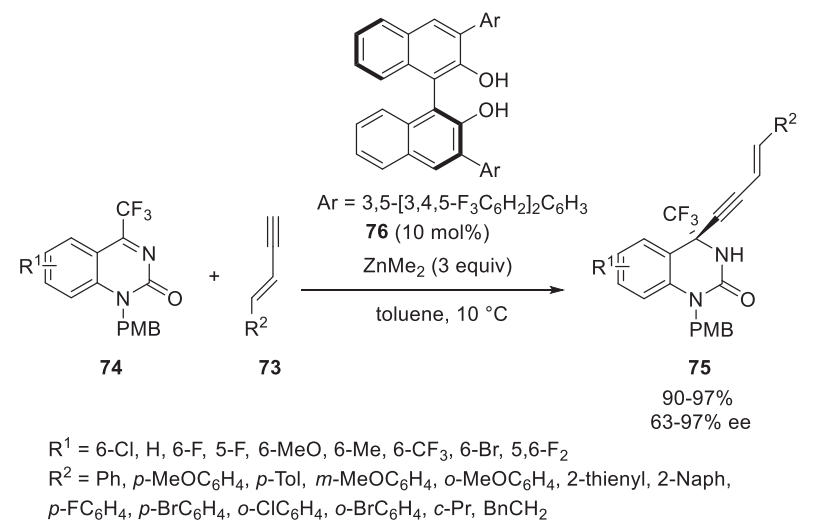

Scheme 22. Alkynylation of cyclic $N$-benzoyl trifluoromethyl ketimines in the presence of a BINOL-derived ligand [49]. provided good results. Even the presence of a free alcohol $\left(\mathrm{R}^{2}=(\mathrm{Me})_{2} \mathrm{C}(\mathrm{OH})\right)$ was tolerated (71\% yield, $74 \%$ de, $92 \%$ ee).

In 2018, Chen et al. introduced novel chloramphenicol-based chiral hydroxyl oxazoline ligands, such as $\mathbf{6 2}$, to be investigated in the first $\mathrm{Zn}(\mathrm{OTf})_{2}$-catalyzed enantioselective alkynylation of isatins 63 [44]. As depicted in Scheme 18, variously substituted isatins 63 were alkynylated with (hetero)aromatic as well as aliphatic terminal alkynes $\mathbf{4 8}$ to yield the corresponding chiral tertiary propargylic alcohols 64 in good to excellent yields (61-96\%) and high enantioselectivities (83-98\% ee). The process required $22 \mathrm{~mol} \%$ of ligand 62 combined with $50 \mathrm{~mol} \%$ of $\mathrm{Zn}(\mathrm{OTf})_{2}$ in THF at $25^{\circ} \mathrm{C}$. A broad substrate scope was found with excellent enantioselectivities achieved in the reaction of various $\mathrm{N}$-alkylated and phenylsubstituted isatins, regardless of the electronic character and position of the substituent on the phenyl ring. The authors proposed the mechanism depicted in Scheme 18 in which $\mathrm{Zn}(\mathrm{OTf})_{2}$ first interacted with chiral ligand $\mathbf{6 2}$ and terminal alkyne $\mathbf{4 8}$ to give complex A. The latter subsequently interacted with the isatin $\mathrm{N}$ substituents, leading to the formation of complex $\mathbf{B}$. The terminal alkyne then migrated to the electron-deficient carbonyl carbon from the least-sterically hindered $R e$ face to give complex $\mathbf{D}$ via transition structure $\mathbf{C}$. Finally, protonation of $\mathbf{D}$ by the alkyne led to the formation of the alkynylated product $\mathbf{6 4}$ along with the regenerated complex $\mathbf{A}$.

In 2020, Fang and Ding developed highly regio- and enantioselective alkynylation of alkynyl 1,2-diketones $\mathbf{6 5}$ under asymmetric zinc catalysis [45]. The chiral zinc catalyst was in situ generated from $20 \mathrm{~mol} \%$ of $\mathrm{Zn}(\mathrm{OTf})_{2}$ and $20 \mathrm{~mol} \%$ of chiral amino alcohol ligand $\mathbf{6 0}$ at room temperature (Scheme 19). When the reaction between variously substituted alkynyl 1,2-diketones 65 and alkynes 48 was performed in the presence of DIPEA as base, it regioselectively led to the corresponding chiral functionalized $\alpha$-hydroxy ketones 66 in moderate yields (33-47\%) and moderate to excellent ee values (69-99\% ee). Notably, diketones bearing aliphatic substituents also reacted smoothly with moderate enantioselectivities (69-71\% ee). Interestingly, the authors found that by simply changing DIPEA into TEA as base, the reaction evolved differently to selectively give chiral $3(2 \mathrm{H})$-furanones with excellent enantioselectivities (see section 15).

\subsection{Alkynylation of imines}

Chiral propargylic amines are key building blocks for the synthesis of many natural and bioactive products. They are commonly synthesized through enantioselective metal-catalyzed alkynylation of imines $[32 c, 46]$. However, most of these reactions employed single terminal alkynes. In 2015, the first catalytic

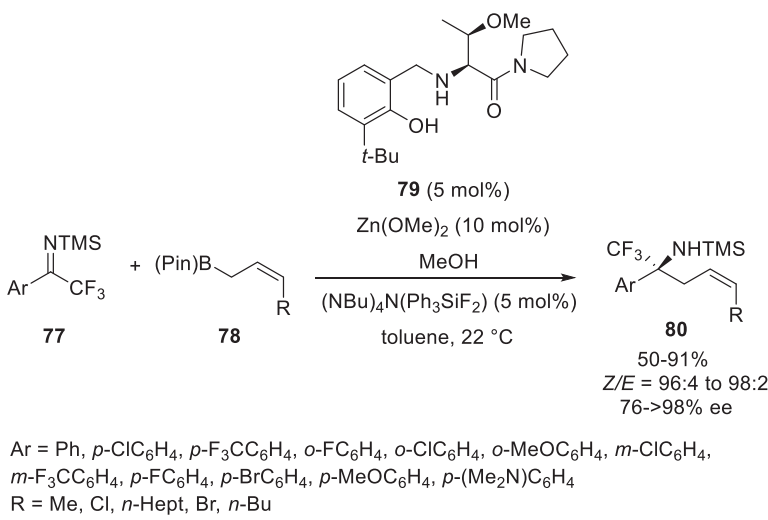

Scheme 23. Allylation of $\mathrm{CF}_{3}$-substituted $\mathrm{N}$-trimethylsilyl aryl ketimines with $Z$-allyl boronates in the presence of a threonine-derived aminophenol ligand [50]. 


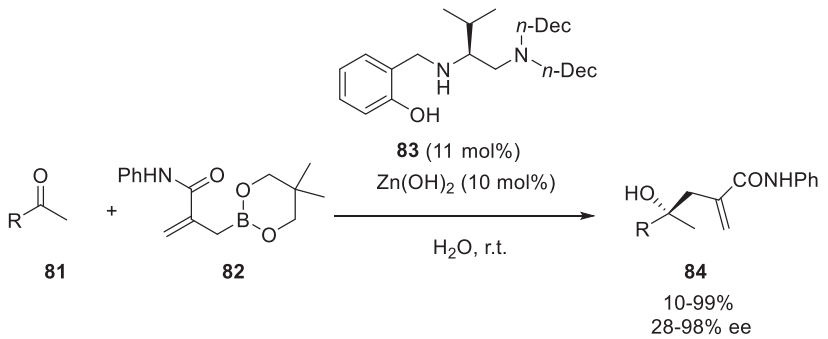

$\mathrm{R}=\mathrm{Ph}, n$-Oct, $t-\mathrm{Bu}, 2-\mathrm{Naph}$, 1-Naph, $p$ - $\mathrm{MeOC}_{6} \mathrm{H}_{4}, p-\mathrm{TBSOC}_{6} \mathrm{H}_{4}, p-\mathrm{ClC}_{6} \mathrm{H}_{4}, p-\mathrm{F}_{3} \mathrm{CC}_{6} \mathrm{H}_{4}$ $m-\mathrm{MeOC}_{6} \mathrm{H}_{4}, m-\mathrm{ClC}_{6} \mathrm{H}_{4}, m-\mathrm{F}_{3} \mathrm{CC}_{6} \mathrm{H}_{4}, m-\mathrm{O}_{2} \mathrm{NC}_{6} \mathrm{H}_{4}, o-\mathrm{Tol}, o-\mathrm{EtOC}_{6} \mathrm{H}_{4}, o-i-\mathrm{PrC}_{6} \mathrm{H}_{4}$, o- $\mathrm{PhC}_{6} \mathrm{H}_{4}, 0-\mathrm{MeOC}_{6} \mathrm{H}_{4}$, o-TBSOC $6 \mathrm{H}_{4}, 0-\mathrm{Me}_{2} \mathrm{NC}_{6} \mathrm{H}_{4}, 0-\mathrm{ClC}_{6} \mathrm{H}_{4}, o-\mathrm{FC}_{6} \mathrm{H}_{4}, o-\mathrm{BrC}_{6} \mathrm{H}_{4}$, $\mathrm{O}-\mathrm{IC}_{6} \mathrm{H}_{4}, \mathrm{O}-\mathrm{O}_{2} \mathrm{NC}_{6} \mathrm{H}_{4}$

Scheme 24. Allylation of ketones with an amido-functionalized allylboronate in water and in the presence of a tertiary amine ligand [51].

asymmetric addition of terminal 3-en-1-ynes 67 to $N$-sulfonyl aldimines 68 was reported by Ma et al., using a chiral zinc catalyst [47]. The catalyst system involved $20 \mathrm{~mol} \%$ of chiral ligand 69 derived from $(S, S)$-BINOL and two equivalents of $\mathrm{ZnMe}_{2}$ in DCE as solvent. Performed at $25^{\circ} \mathrm{C}$, the alkynylation of a wide range of aromatic $N$-sulfonyl aldimines $\mathbf{6 8}$ led to chiral enyne carbinamines 70 in both high yields (78-94\%) and enantioselectivities (8895\% ee), as illustrated in Scheme 20. When an aliphatic imine $\left(\mathrm{R}^{1}=n\right.$-Pr) was investigated as substrate, it provided the corresponding product with both the lowest yield (70\%) and enantioselectivity (57\% ee).

The same year, $(R)$-VAPOL was applied as ligand by Pedro et al. to develop the first asymmetric addition of terminal alkynes to benzoxathiazine 2,2-dioxides (Scheme 21) [48]. These cyclic rigid imines constitute versatile building blocks for the synthesis of important benzo-fused cyclic sulfamidate heterocycles. Using $20 \mathrm{~mol} \%$ of optimal ligand $(R)$-VAPOL in the presence of four equivalents of $\mathrm{ZnMe}_{2}$ in DCE as solvent, the alkynylation of a range of benzoxathiazine 2,2-dioxides $\mathbf{7 1}$ with aromatic as well as aliphatic terminal alkynes $\mathbf{4 8}$ led at room temperature to the corresponding chiral propargylic sulfamidates $\mathbf{7 2}$ in both moderate to high yields (54-93\%) and enantioselectivities (60-87\% ee). This work represented a rare example of asymmetric alkynylation of cyclic imines.

In 2018, the first enantioselective catalytic addition of terminal 3-en-1-ynes $\mathbf{7 3}$ to cyclic $N$-benzoyl trifluoromethyl ketimines $\mathbf{7 4}$ was developed by Ma and Zhang, delivering the corresponding chiral enynylated tertiary carbinamines 75 (Scheme 22) [49]. It employed a chiral zinc catalyst derived from three equivalents of $\mathrm{ZnMe}_{2}$ and $10 \mathrm{~mol} \%$ of chiral BINOL-derived ligand 76. When performed at $10{ }^{\circ} \mathrm{C}$ in toluene, these densely functionalized products bearing a tertiary trifluoromethylated carbinamine center were achieved in excellent yields (90-97\%) and good to high enantioselectivities (63-97\% ee).

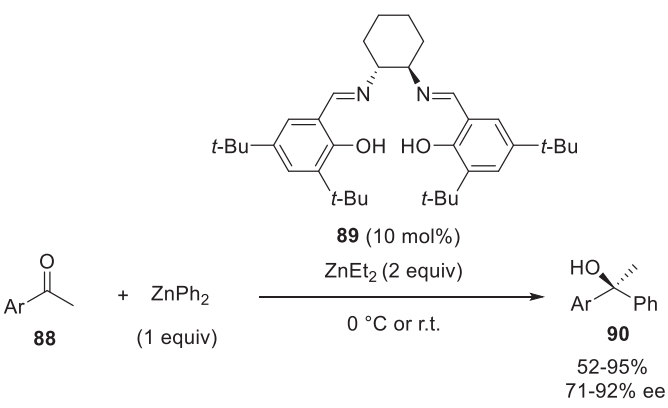

$\mathrm{Ar}=p-\mathrm{Tol}, p-\mathrm{MeOC}_{6} \mathrm{H}_{4}, p-\mathrm{BrC}_{6} \mathrm{H}_{4}, 2-\mathrm{Naph}, 2$-thienyl, 2-furyl

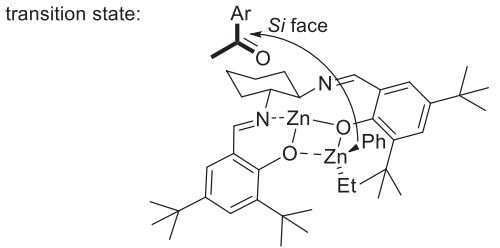

Scheme 26. Addition of $\mathrm{ZnPh}_{2}$ to aryl ketones in the presence of a salen ligand [55].

\subsection{Allylations}

In 2020, Hoveyda et al. reported the regio- and enantioselective allylation of $\mathrm{CF}_{3}$-substituted $\mathrm{N}$-trimethylsilyl aryl ketimines $\mathbf{7 7}$ with Z-allyl boronate $\mathbf{7 8}$ performed in the presence of $5 \mathrm{~mol} \%$ of L-threonine-derived aminophenol ligand $\mathbf{7 9}$ combined to only $10 \mathrm{~mol} \%$ of $\mathrm{Zn}(\mathrm{OMe})_{2}$ [50]. As illustrated in Scheme 23, the process afforded the corresponding chiral trifluoromethyl-substituted homoallylic $\alpha$-tertiary amines $\mathbf{8 0}$ as almost single $Z$ diastereomers $(Z / E=96: 4$ to $>98: 2)$ in moderate to high yields (50-91\%) and high enantioselectivities (76->98\% ee). The catalyst system was compatible to aryl imines bearing various substituents on their phenyl ring. Moreover, the allyl boronates could exhibit an alkyl-, a chloro-, or a bromo-substituted Z-alkene.

Most of asymmetric allylations of carbonyl compounds and derivatives are performed in organic solvents. In 2020, Yoda et al. reported a rare example of enantioselective allylation of ketones $\mathbf{8 1}$ carried out in water at room temperature [51]. It employed as allylating agent water-stable amido-functionalized allylboronate 82. The reaction was catalyzed with a combination of $10 \mathrm{~mol} \%$ of $\mathrm{Zn}(\mathrm{OH})_{2}$ and $11 \mathrm{~mol} \%$ of chiral tertiary amine ligand 83, resulting in the formation of the corresponding chiral homoallylic alcohols 84 in low to quantitative yields (10-99\%) and enantioselectivities (28-98\% ee), as presented in Scheme 24. Generally, good results were achieved in the reaction of acetophenones (56-98\% ee) with higher ee values for ortho-substituted substrates (70-98\% ee) than

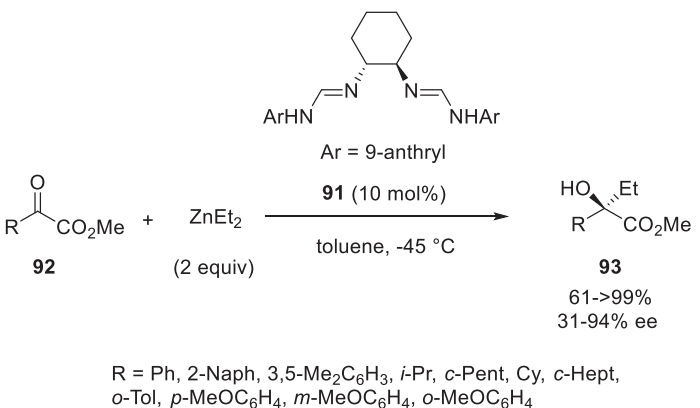

Scheme 27. Addition of $\mathrm{ZnEt}_{2}$ to $\alpha$-ketoesters in the presence of a bisamidine ligand [56].
Scheme 25. Addition of $\mathrm{ZnEt}_{2}$ to fluorinated alkyl ketones in the presence of a bisoxazoline ligand [54].

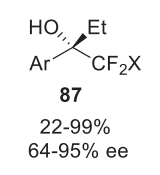

o-Tol, $p-\mathrm{MeOC}_{6} \mathrm{H}_{4}, m-\mathrm{MeOC}_{6} \mathrm{H}_{4}, o-\mathrm{MeOC}_{6} \mathrm{H}_{4}$ 


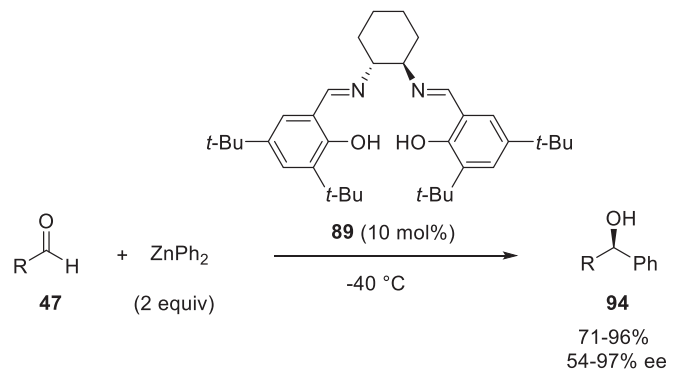

$\mathrm{R}=o-\mathrm{Tol}, o-\mathrm{MeOC}_{6} \mathrm{H}_{4}, o-\mathrm{BrC}_{6} \mathrm{H}_{4}, p-\mathrm{PhC}_{6} \mathrm{H}_{4}, p-\mathrm{Tol}, p-\mathrm{MeOC}_{6} \mathrm{H}_{4}$, $p$ - $\mathrm{BrC}_{6} \mathrm{H}_{4}, 2$-thienyl, 2-furyl, Cy, $i$ - $\mathrm{Pr}, n$-Hex

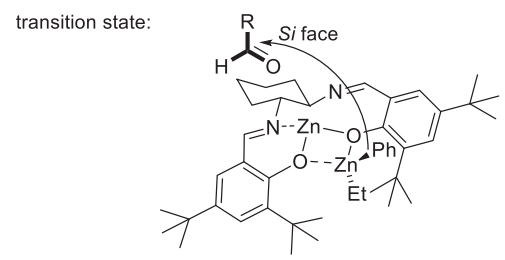

Scheme 28. Addition of $\mathrm{ZnPh}_{2}$ to aldehydes in the presence of a salen ligand [55].

meta- (56-72\% ee) or para-substituted ones (58-66\% ee). In the case of ortho-substituted acetophenones, a correlation between the enantioselectivity of the reaction and the size of the orthosubstituent was shown. Along with aromatic ketones, alkyl methyl ketones also reacted but with generally lower yield ( $10 \%$ with $\mathrm{R}=\mathrm{t}-$ $\mathrm{Bu}$ ) and enantioselectivity ( $28 \%$ with $\mathrm{R}=n$-Oct $)$.

\section{Additions of diorganozincs to carbonyl compounds and derivatives}

\subsection{Addition to ketones}

Since the first enantioselective addition of organozincs to aldehydes described in 1984 by Oguni and Omi [52], dialkylzinc reagents have been widely used for the alkylation of carbonyl compounds in direct addition as well as transmetalation reaction. In most cases, the alkylation group is transferred from zinc to a chiral Lewis acid derived from metals, such as titanium, among others. Since zinc is not directly responsible of the stereoselectivity in this type of transformations, they will not be included in the present review. So far, the direct addition of dialkylzinc reagents to carbonyl compounds and derivatives has been extensively studied using various types of chiral ligands $[7,10,53]$. In a recent example, chiral bisoxazoline $\mathbf{8 5}$ was employed by Sasaki et al. in the asymmetric nucleophilic addition of $\mathrm{ZnEt}_{2}$ to fluorinated alkyl ketones 57, 86 [54]. Performed in the presence of $10 \mathrm{~mol} \%$ of ligand $\mathbf{8 5}$, the reaction afforded chiral fluorine-containing tertiary alcohols

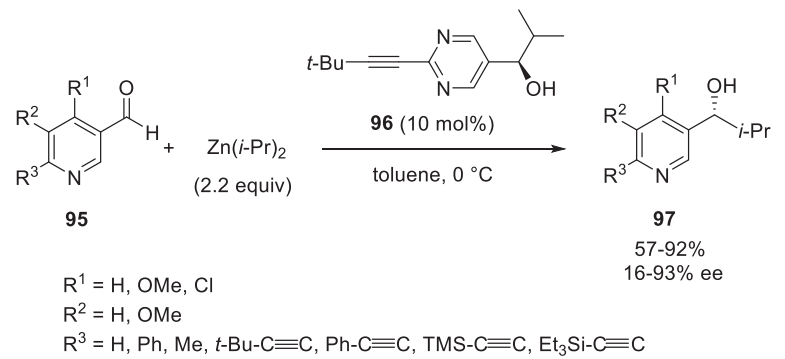

Scheme 29. Addition of $\mathrm{Zn}(i-\operatorname{Pr})_{2}$ to azaaryl aldehydes in the presence of a (5-pyrimidyl)alkanol ligand [57].
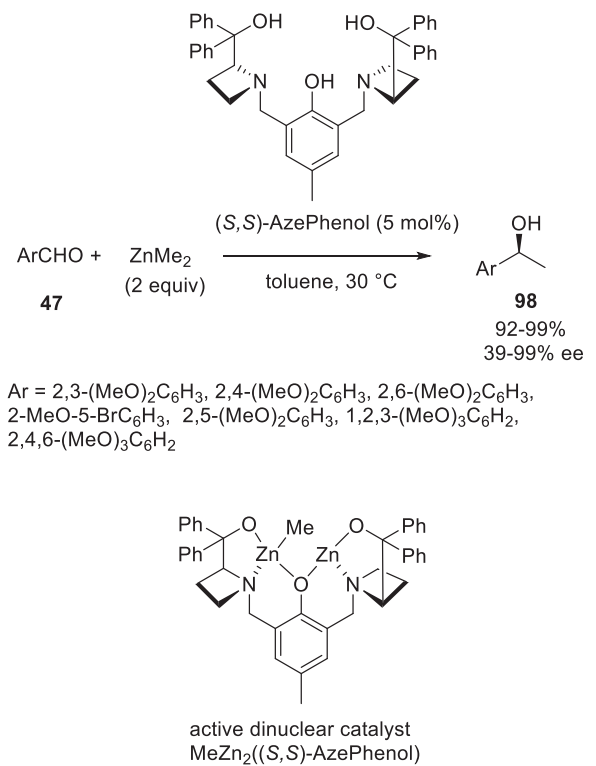

Scheme 30. Addition of $\mathrm{ZnMe}_{2}$ to aromatic aldehydes in the presence of $(S, S)$ AzePhenol [38].

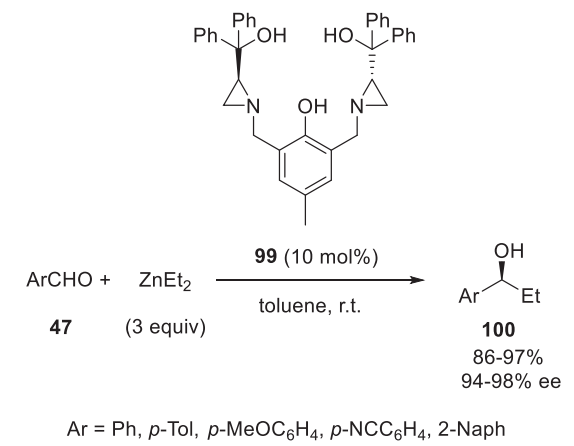

Scheme 31. Addition of $\mathrm{ZnEt}_{2}$ to aromatic aldehydes in the presence of an aziridine alcohol ligand [58].

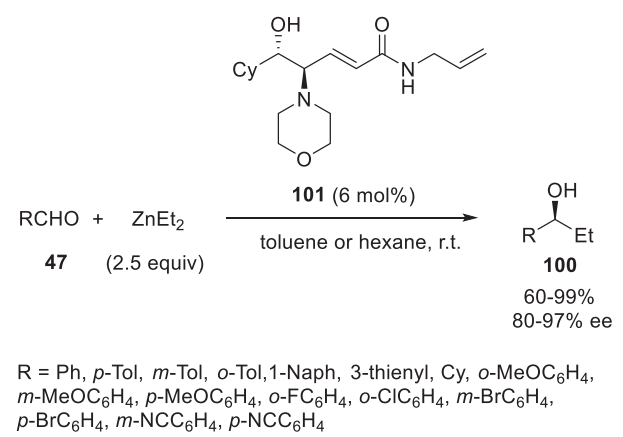

Scheme 32. Addition of $\mathrm{ZnEt}_{2}$ to aldehydes in the presence of a 1,2-amino alcohol ligand [59].

87 with variable yields (22-99\%) and enantioselectivities (6495\% ee), as depicted in Scheme 25.

The first enantioselective phenyl transfer of an organozinc reagent $\left(\mathrm{ZnPh}_{2}\right)$ to ketones $\mathbf{8 8}$ was disclosed in 2015 by Ito et al., using chiral salen ligand $\mathbf{8 9}$ (Scheme 26) [55]. In the presence of $10 \mathrm{~mol} \%$ of this ligand, the addition led at $0{ }^{\circ} \mathrm{C}$ or room temperature to the corresponding chiral tertiary alcohols $\mathbf{9 0}$ in moderate to 


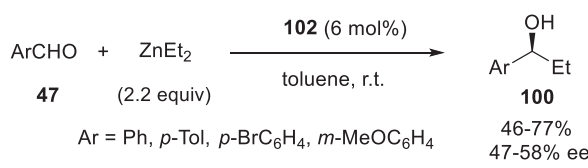

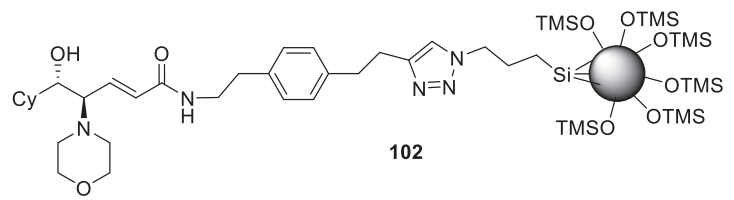

Scheme 33. Addition of $\mathrm{ZnEt}_{2}$ to aromatic aldehydes in the presence of a supported ligand [60].

excellent yields (52-95\%) and enantioselectivities (71-92\% ee). The best results were achieved in the reaction of aromatic ketones while aliphatic ones provided opposite enantioselectivity and much lower ee values ( $\leq 44 \%$ ee). The observed stereochemistry can be explained by the transition state model depicted in Scheme 26, in which the Si face of the ketone is preferentially attacked by the zinc reagent.

In 2017, Yamanaka et al. developed a newly designed zinc catalyst derived from chiral bisamidine ligand $\mathbf{9 1}$ and $\mathrm{ZnEt}_{2}$ for the enantioselective addition of $\mathrm{ZnEt}_{2}$ to methyl $\alpha$-ketoesters 92 [56]. The corresponding chiral tertiary alcohols $\mathbf{9 3}$ were generated by using $10 \mathrm{~mol} \%$ of this highly coordinative ligand combined with two equivalents of $\mathrm{ZnEt}_{2}$ in toluene at $-45^{\circ} \mathrm{C}$ (Scheme 27). Good to quantitative yields (61->99\%) associated with moderate to excellent ee values (31-94\% ee) were obtained with a series of aromatic as well as aliphatic ketones.

\subsection{Addition to aldehydes}

In 2015 , Ito et al. employed $10 \mathrm{~mol} \%$ of chiral salen ligand $\mathbf{8 9}$ in an asymmetric zinc-catalyzed addition of $\mathrm{ZnPh}_{2}$ to aldehydes $\mathbf{4 7}$ [55]. As illustrated in Scheme 28, the corresponding chiral secondary alcohols 94 were formed in good to high yields (71-96\%)

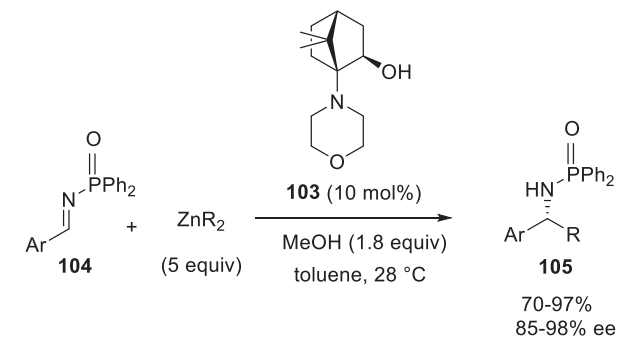

$\mathrm{Ar}=\mathrm{Ph}, p-\mathrm{Tol}, m-\mathrm{Tol}, \mathrm{o}-\mathrm{Tol}, p-\mathrm{MeOC}_{6} \mathrm{H}_{4}, p-\mathrm{MeO}_{2} \mathrm{CC}_{6} \mathrm{H}_{4}, o-\mathrm{MeOC}_{6} \mathrm{H}_{4}$, $m-\mathrm{MeOC}_{6} \mathrm{H}_{4}, o-\mathrm{ClC}_{6} \mathrm{H}_{4}, m-\mathrm{ClC}_{6} \mathrm{H}_{4}, p-\mathrm{ClC}_{6} \mathrm{H}_{4}$

$\mathrm{R}=\mathrm{Me}, \mathrm{Et}$

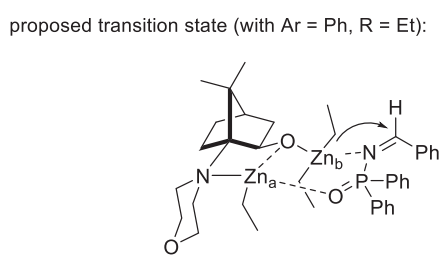

Scheme 34. Addition of $\mathrm{ZnEt}_{2} / \mathrm{ZnMe}_{2}$ to $N$-(diphenylphosphinoyl)aldimines in the presence of a camphor-derived 1,2-amino alcohol ligand [62]. and moderate to excellent enantioselectivities (54-97\% ee). Actually, aromatic aldehydes reacted with uniformly very good ee values (83-97\% ee) while much lower enantioselectivities (54$76 \%$ ee) were obtained in the reaction of aliphatic aldehydes. A possible transition state is shown in Scheme 28 in which the Si face of the aldehyde is preferentially attacked by the zinc reagent.

The same year, Amedjkouh et al. described the asymmetric zinc-catalyzed addition of $\mathrm{Zn}(i-\mathrm{Pr})_{2}$ to azaaryl aldehydes 95 [57]. The catalyst system was composed of $10 \mathrm{~mol} \%$ of chiral (5pyrimidyl)alkanol ligand 96 and 2.2 equivalents of $\mathrm{Zn}(i-\mathrm{Pr})_{2}$ in toluene. The reaction provided at $0{ }^{\circ} \mathrm{C}$ a series of chiral pyridine alcohols $\mathbf{9 7}$ in variable enantioselectivities (16-93\% ee) and good to high yields (57-92\%), as depicted in Scheme 29.

In 2017, a dinuclear zinc catalyst derived from $5 \mathrm{~mol} \%$ of $(S, S)-$ AzePhenol and two equivalents of $\mathrm{ZnMe}_{2}$ was applied by Wang et al. to promote the asymmetric addition of $\mathrm{ZnMe}_{2}$ to aromatic aldehydes 47 (Scheme 30) [38]. Performed in toluene at $30{ }^{\circ} \mathrm{C}$, the reaction provided chiral secondary alcohols $\mathbf{9 8}$ in quantitative yields (92-99\%) and moderate to excellent enantioselectivities (39-99\% ee). The enantioselectivity of the reaction was found sensitive to both the electronic nature and position of the substituents beared on the phenyl ring of aldehydes. Generally, the best enantioselectivities were achieved in the reaction of ortho-substituted aryl aldehydes.

Novel chiral aziridine alcohol ligands were designed by Rachwalski et al. in 2017 to be used in the asymmetric addition of $\mathrm{ZnEt}_{2}$ to aromatic aldehydes $\mathbf{4 7}$ (Scheme 31) [58]. For example, the use of $10 \mathrm{~mol} \%$ of optimal ligand 99 combined with three equivalents of $\mathrm{ZnEt}_{2}$ in toluene at room temperature allowed several aromatic alcohols 100 to be synthesized in remarkable enantioselectivities (94-98\% ee) and excellent yields (86-97\%).

In 2018, Righi et al. reported the design of a novel class of chiral amino alcohol ligands [59]. Among them, optimal ligand 101 was applied at $6 \mathrm{~mol} \%$ of catalyst loading to the same reactions, allowing a range of aromatic as well as aliphatic secondary alcohols $\mathbf{1 0 0}$ to be formed in good to quantitative yields (60-99\%) and high enantioselectivities (80-97\% ee), as illustrated in Scheme 32.

In 2020, the same authors described the synthesis of a chiral linear 1,2-amino alcohol catalyst $\mathbf{1 0 2}$ anchored on functionalized magnetite nanoparticles which was further investigated in the same reactions [60]. As illustrated in Scheme 33, $\mathrm{ZnEt}_{2}$ was added to aromatic aldehydes $\mathbf{4 7}$ in toluene at room temperature by using $6 \mathrm{~mol} \%$ of this heterogeneous catalyst, thus providing the corresponding chiral alcohols 100 in moderate yields (46-77\%) and enantioselectivities (47-58\% ee). The catalyst could be reused up to three times.

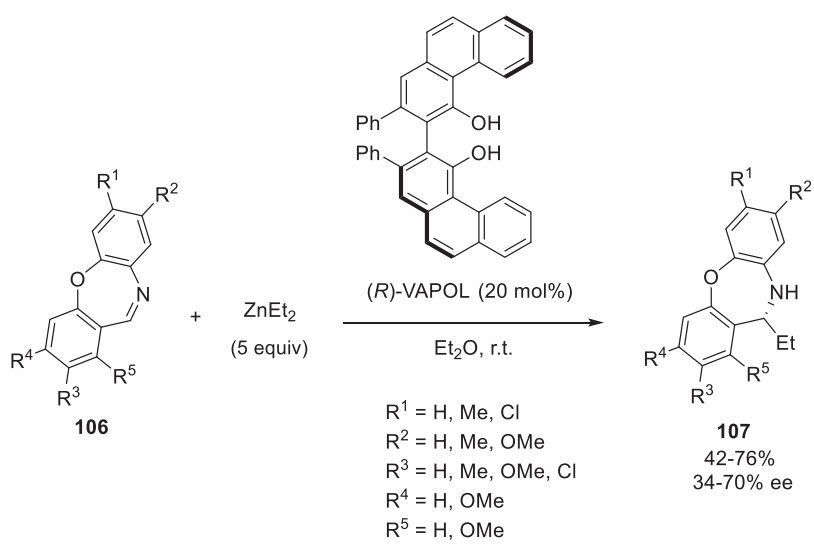

Scheme 35. Addition of $\mathrm{ZnEt}_{2}$ to seven-membered aldimines in the presence of $(R)$ VAPOL [63]. 


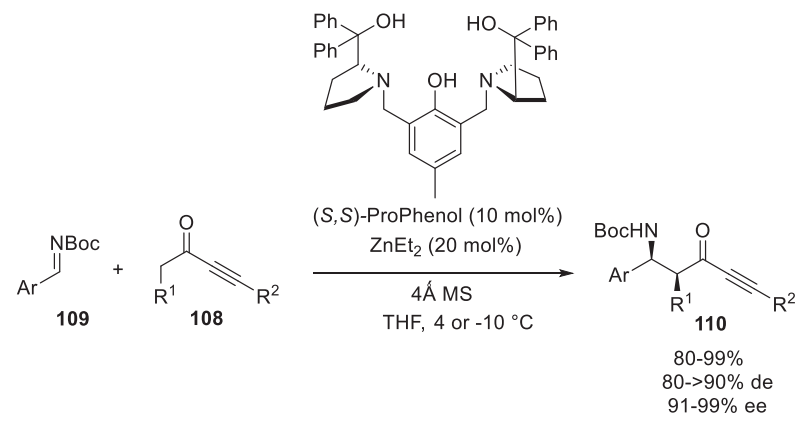

$\mathrm{Ar}=p$ - $\mathrm{FC}_{6} \mathrm{H}_{4}, 2$-furyl, $m-\mathrm{O}_{2} \mathrm{NC}_{6} \mathrm{H}_{4}, 3,4-(\mathrm{MeO})_{2} \mathrm{C}_{6} \mathrm{H}_{3}, \mathrm{Ph}, p-\mathrm{MeOC}_{6} \mathrm{H}_{4}$, 2-thienyl, o- $\mathrm{BrC}_{6} \mathrm{H}_{4}$ $\mathrm{R}^{1}=\mathrm{Bn}, i-\mathrm{Pr}$, allyl, Me, $t-\mathrm{BuO}_{2} \mathrm{CCH}_{2}, \mathrm{MeO}_{2} \mathrm{CCH}_{2}, \mathrm{TBSO}\left(\mathrm{CH}_{2}\right)_{2}, \mathrm{H}, \mathrm{HC} \equiv \mathrm{CCH}_{2}, \mathrm{Et}_{3} \mathrm{SiC} \equiv \mathrm{C}$ $\mathrm{R}^{2}=\mathrm{SiMe}_{2} \mathrm{Bn}, \mathrm{SiEt}_{3}, \mathrm{TBSO}\left(\mathrm{CH}_{2}\right)_{3}, n-\mathrm{Bu}, \mathrm{Cl}\left(\mathrm{CH}_{2}\right)_{4}$

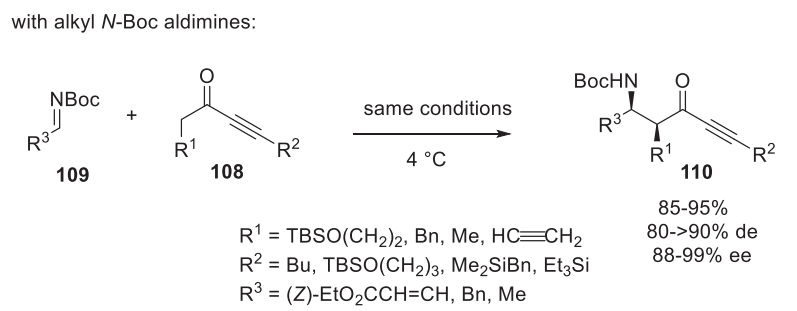

Scheme 36. Mannich reactions of ynones with $N$-Boc aldimines [64].

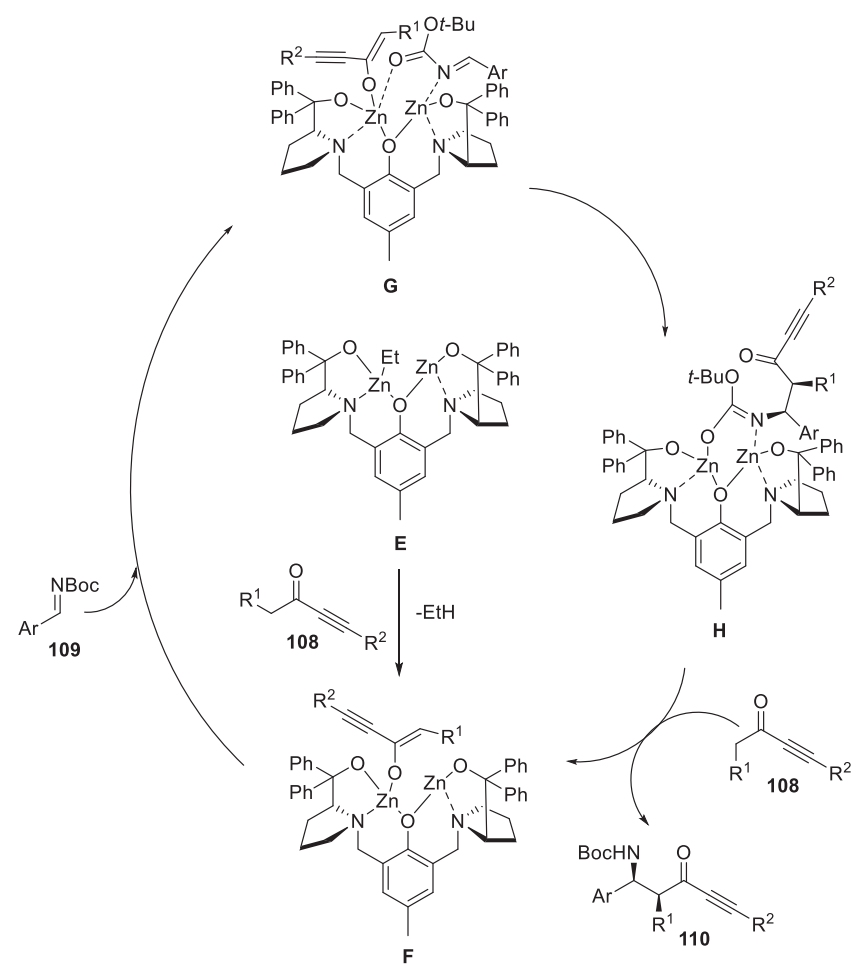

Scheme 37. Mechanism for Mannich reaction of ynones with N-Boc aldimines [64].

\subsection{Addition to imines}

Chiral amines are widely used as key building blocks in the synthesis of many natural and bioactive products. One of the most direct route to these compounds is based on the enantioselective addition of organozinc reagents to imines performed in the presence of a chiral ligand [61]. A drawback of this methodology is
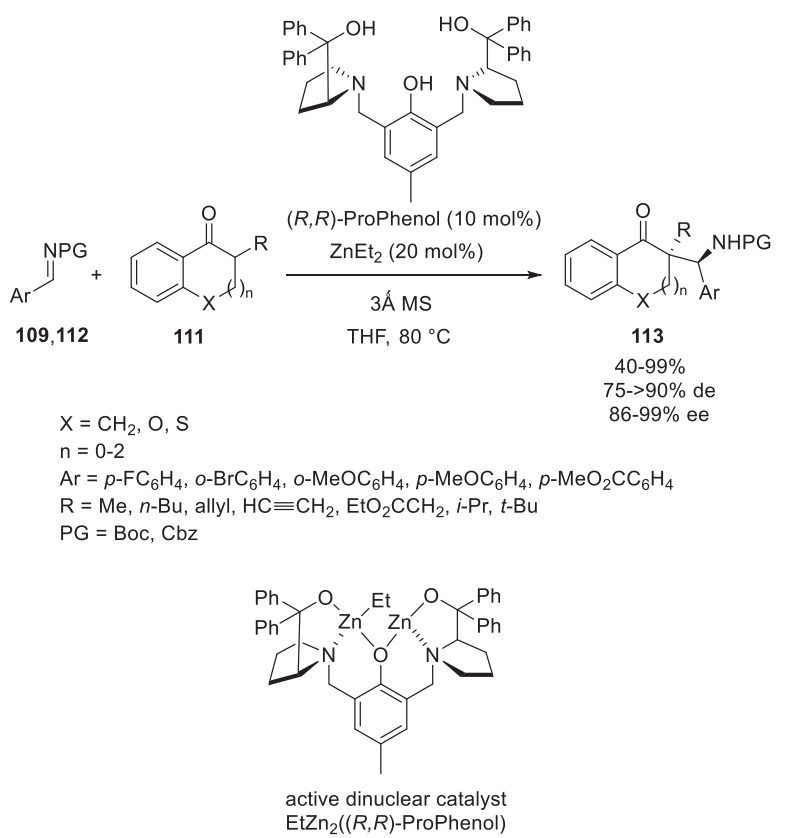

Scheme 38. Mannich reaction of $\alpha$-branched aromatic ketones with $N$-protected aryl aldimines [65].

the common requirement of stoichiometric amount of chiral ligands to ensure high conversion and enantioselectivity related to the poor electrophilic character of imines. However, Uang and Huang demonstrated in 2015 that only $10 \mathrm{~mol} \%$ of camphorderived chiral 1,2-amino alcohol ligands, such as optimal ligand 103, was sufficient to promote the enantioselective addition of dialkylzincs to $N$-(diphenylphosphinoyl)aldimines 104 [62]. As depicted in Scheme 34, the addition of $\mathrm{ZnMe}_{2} / \mathrm{ZnEt}_{2}$ to these aldimines performed in toluene at $28{ }^{\circ} \mathrm{C}$ afforded the corresponding chiral secondary amines $\mathbf{1 0 5}$ in good to quantitative yields (70-97\%) and uniformly high enantioselectivities (85-98\% ee). The obtention of these good results required the use of 1.8 equivalent of methanol as superstoichiometric additive. A transition state is proposed in Scheme 34, showing the coordination of the imine and chiral aminoalcohol ligand to two zinc atoms $\left(\mathrm{Zn}_{\mathrm{a}}\right.$ and $\left.Z n_{b}\right)$. Then, the transfer of one of the ethyl groups $(R=E t)$ on $\mathrm{Zn}_{\mathrm{b}}$ to the imine led to the addition product exhibiting a $R$-configuration.

The asymmetric addition of dialkylzincs to cyclic imines is particularly unexplored. To fill this gap, Pedro et al. investigated the enantioselective addition of $\mathrm{ZnEt}_{2}$ to seven-membered aldimines 106 in the presence of only $20 \mathrm{~mol} \%$ of $(R)$-VAPOL in $\mathrm{Et}_{2} \mathrm{O}$ as solvent [63]. The reaction led at room temperature to the corresponding chiral 11-ethyl-10,11-dihydrobenzo[b,f][1,4] oxazepines $\mathbf{1 0 7}$ which represented attractive compounds for medicinal chemistry. As shown in Scheme 35, these products were obtained in moderate to good yields (42-76\%) combined with low to moderate enantioselectivities (34-70\% ee).

\section{Mannich reactions}

\subsection{With ProPhenol ligand}

In 2015, Trost and Hung reported the first direct catalytic Mannich-type reaction between various ynones 108 and $\mathrm{N}$-Boc aldimines 109 [64]. It involved $10 \mathrm{~mol} \%$ of (S,S)-ProPhenol as ligand in combination with $20 \mathrm{~mol} \%$ of $\mathrm{ZnEt}_{2}$ in THF as solvent, resulting in the formation of the corresponding chiral $\alpha$-substituted $\beta$-amino 


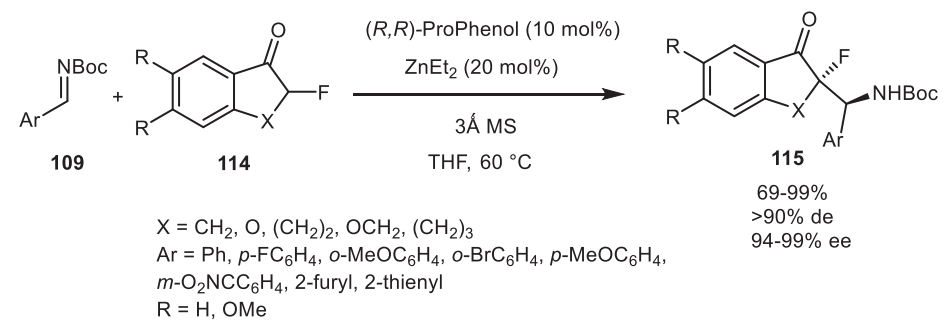

Scheme 39. Mannich reaction of fluorinated aromatic ketones with $N$-Boc aryl aldimines [66].

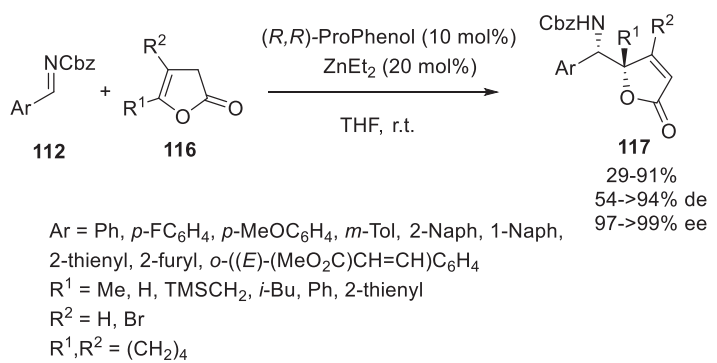

Scheme 40. Mannich reaction of butenolides with $N$-Cbz aryl aldimines [67].

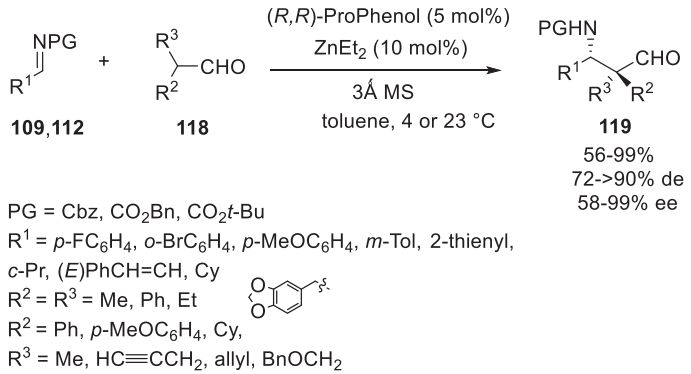

Scheme 41. Mannich reaction of $\alpha$-branched aldehydes with $N$-protected aldimines [68].

ynones 110 with excellent chemo-, diastereo-, and enantioselectivities (Scheme 36). Indeed, performed at 4 or $-10{ }^{\circ} \mathrm{C}$, the Mannich reaction of aromatic $N$-Boc aldimines 109 with various alkynones 108 afforded the corresponding products 110 in high yields (80$99 \%)$, excellent diastereoselectivities ( $80->90 \%$ de) and remarkable ee values (91-99\% ee). The scope of the methodology could be extended to aliphatic $N$-Boc imines $109\left(\mathrm{R}^{3}=\right.$ alkyl $)$ which also provided the corresponding Mannich products $\mathbf{1 1 0}$ in comparable excellent results ( $85-95 \%$ yield, $80->90 \%$ de, $88-99 \%$ ee). This powerful methodology tolerated a variety of functional groups on both the two substrates, allowing a direct access to many chiral and densely functionalized $\alpha$-substituted $\beta$-amino ynones.

The authors proposed a catalytic cycle depicted in Scheme 37 [64]. After the in situ generation of dinuclear active catalyst $\mathbf{E}$, deprotonated ynone $\mathbf{1 0 8}$ chelated to $\mathbf{E}$ to give intermediate $\mathbf{F}$. Then, $\mathrm{N}$-Boc imine $\mathbf{1 0 9}$ coordinated to both zinc atoms to afford novel complex G. The enolate further attacked the electrophile to give intermediate $\mathbf{H}$. Finally, deprotonation of ynone $\mathbf{1 0 8}$ liberated the Mannich product 110 and turnovered the catalytic cycle.

In 2016, Trost et al. disclosed the first direct asymmetric Mannich reaction of $\alpha$-branched ketones [65]. Using $20 \mathrm{~mol} \%$ of $\mathrm{ZnEt}_{2}$ and $10 \mathrm{~mol} \%$ of $(R, R)$-ProPhenol as catalyst system, the reaction of cyclic ketones 111 with $N$-Boc/Cbz aryl aldimines 109, 112 gave direct access to a range of chiral functionalized $\beta$-amino ketones 113 exhibiting an all-carbon quaternary stereocenter. These bicyc-
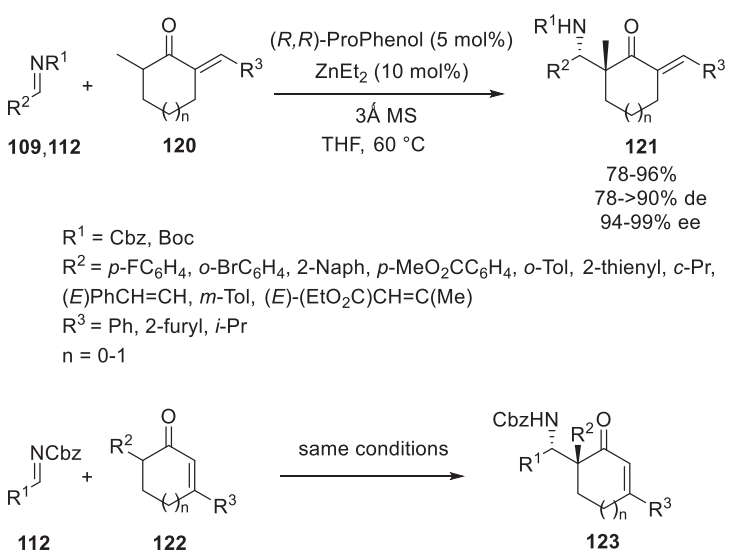

123

$73-93 \%$ $80->90 \%$ de
$98-99 \%$ ee

$\mathrm{R}^{1}=\mathrm{Ph}, p-\mathrm{FC}_{6} \mathrm{H}_{4}$ $98-99 \%$ ee

$\mathrm{R}^{2}=\mathrm{Me}, \mathrm{TBSO}\left(\mathrm{CH}_{2}\right)_{2} \mathrm{C} \equiv \mathrm{CCH}_{2}, \mathrm{HC} \equiv \mathrm{CCH}_{2}$, allyl, $\mathrm{CH}_{2}=\mathrm{C}(\mathrm{Me}) \mathrm{CH}_{2}$ $\mathrm{R}^{3}=\mathrm{Ph}, \mathrm{H}, \mathrm{PhS}, \mathrm{Et}_{3} \mathrm{SiC} \equiv \mathrm{C}$

$n=1-3$

Scheme 42. Mannich reactions of $\alpha$-branched cyclic enones with $N$-protected aldimines [69].

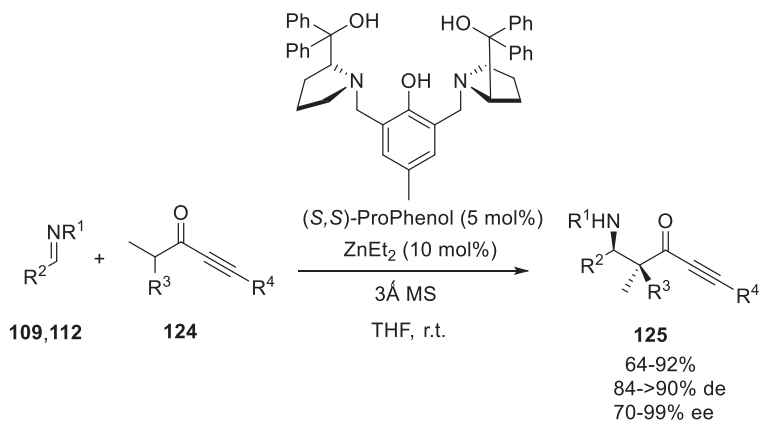

$\mathrm{R}^{1}=\mathrm{Boc}, \mathrm{Cbz}$

$\mathrm{R}^{2}=p-\mathrm{FC}_{6} \mathrm{H}_{4}, \mathrm{Ph}, o-\mathrm{BrC}_{6} \mathrm{H}_{4}, p-\mathrm{MeOC}_{6} \mathrm{H}_{4}, 2$-furyl, $(E)-\mathrm{PhCH}=\mathrm{CH}$, $m$ - $\mathrm{Tol},(E)-\mathrm{MeO}_{2} \mathrm{CCH}=\mathrm{CH}$

$\mathrm{R}^{3}=\mathrm{Me}, \mathrm{Bn}, i-\mathrm{Bu}, \mathrm{Ph}, \mathrm{CH}_{2}=\mathrm{C}(\mathrm{Me}) \mathrm{CH}_{2}, \mathrm{HC} \equiv \mathrm{CCH}_{2}$

$\mathrm{R}^{4}=\mathrm{Ph}, 1$-cyclohexenyl, $\mathrm{BnCH}_{2}, \mathrm{Et}_{3} \mathrm{Si}, p-\mathrm{Tol}, \mathrm{PhC} \equiv \mathrm{C}$

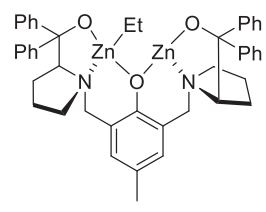

active dinuclear catalys

$\mathrm{EtZn}_{2}((S, S)$-ProPhenol)

Scheme 43. Mannich reaction of $\alpha$-branched ynones with $N$-protected aldimines [69]. 
lic products were enantio- and diastereoselectively generated with moderate to quantitative yields (40-99\%), 75->90\% de and 86$99 \%$ ee (Scheme 38). The substrate scope of the methodology included different types of aromatic cyclic ketones, such as indanones, tetralones and 4-(thio)chromanones, producing the corresponding Mannich products with comparable levels of efficiency.

The same year, these authors employed their catalyst system to develop the first highly diastereo- and enantioselective direct Mannich reaction using fluorinated aromatic ketones as nucleophilic partners [66]. Indeed, the reaction of a range of cyclic fluorinated aromatic ketones 114 with $N$-Boc aryl aldimines 109 performed at $60{ }^{\circ} \mathrm{C}$ in THF in the presence of $10 \mathrm{~mol} \%$ of $(R, R)$-ProPhenol as ligand and $20 \mathrm{~mol} \%$ of $\mathrm{ZnEt}_{2}$ as precatalyst afforded chiral $\beta$ fluoroamines 115 bearing a fluorinated tetrasubstituted carbon. These Mannich products were obtained in high yields (69-99\%) as single diastereomers (>90\% de) almost enantiopure (9499\% ee), as presented in Scheme 39.

In 2017, this catalyst system was also applied by the same group to perform the first enantio- and diastereoselective direct vinylogous Mannich reaction between butenolides 116 and $\mathrm{N}$ Cbz aryl aldimines 112 (Scheme 40) [67]. A series of butenolides bearing alkyl, aryl and halogen substituents were tolerated as well as variously substituted (hetero)aryl aldimines, leading to the corresponding chiral densely functionalized Mannich products 117 in moderate to excellent yields (29-91\%), moderate to excellent diastereoselectivities (54->94\% de) and remarkable enantioselectivities (97->99\% ee). In most cases of substrates, the products were obtained as single stereomers (>94\% de and $>99 \%$ ee).

This catalyst system also promoted an unprecedented Mannich reaction of a variety of branched aldehydes 118 substituted with aryl and linear alkyl groups with $\mathrm{N}$-protected (hetero)aromatic and aliphatic aldimines 109, 112 (Scheme 41) [68]. The reaction was carried out in toluene at 4 or $23^{\circ} \mathrm{C}$, yielding the corresponding chiral $\beta$-amino aldehydes 119 in good to excellent yields (56-99\%) and enantioselectivities (58-99\% ee). Challenging aldehydes substituted with two different groups $\left(R^{2} \neq R^{3}\right)$ also reacted smoothly. In the case of an aldehyde substituted with a branched alkyl group (cyclohexyl) and a linear alkyl group (methyl), the corresponding Mannich adduct was obtained with a high diastereoselectivity ( $>90 \%$ de) whereas an aldehyde substituted with two sterically similar linear alkyl groups (benzyl and methyl groups) led to the corresponding product with a much lower de value ( $72 \% \mathrm{de})$.

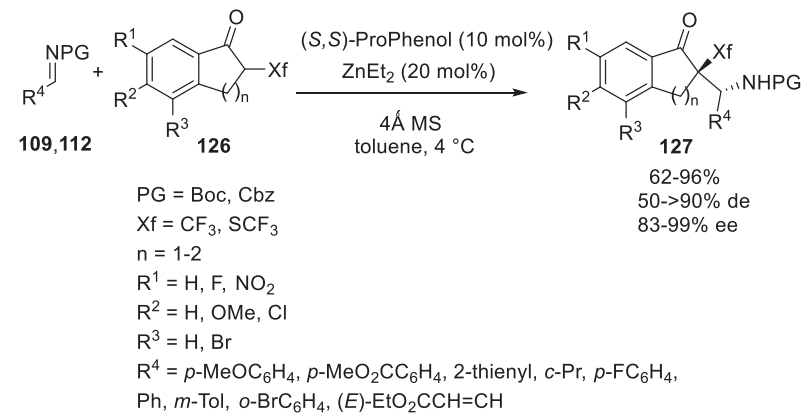

$$
\begin{array}{ll}
128 \\
109
\end{array}
$$

Scheme 44. Mannich reactions of $\alpha$-trifluoromethyl- and $\alpha$-trifluoromethylthiosubstituted ketones with $N$-protected aldimines [70].
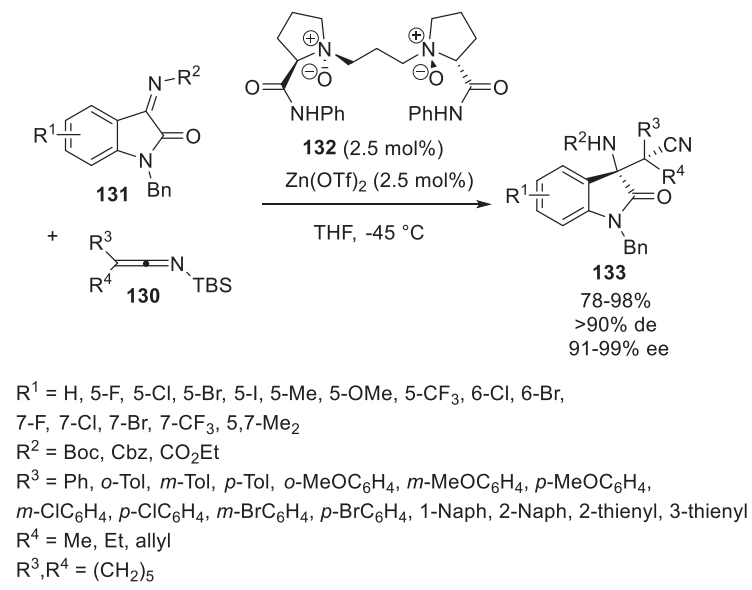

Scheme 45. Mannich reaction of silyl ketene imines with $\mathrm{N}$-protected isatinderived ketimines in the presence of a $N, N^{\prime}$-dioxide ligand [71].

Investigating the scope of the Mannich reaction of $\alpha$-branched ketones with $\mathrm{N}$-carbamoyl imines in the presence of the same catalyst system, Trost found in 2019 that the introduction of an unsaturation adjacent to the carbonyl function of $\alpha$-branched cyclic ketones dramatically improved the reactivity of the reaction [69]. When the same catalyst system was applied at $60^{\circ} \mathrm{C}$ in THF as solvent to the asymmetric Mannich reaction of a range of exocyclic enones 120 with $N$-protected aldimines 109, 112, the corresponding chiral functionalized $\beta$-aminoketones 121 were formed in uniformly high yields (78-96\%), diastereo- (78->90\% de) and enantioselectivities (94-99\% ee), as shown in Scheme 42. These conditions were also compatible with various endocyclic enones 122 which reacted with $N$-Cbz aldimines 112 to afford the corresponding $\beta$-aminoketones $\mathbf{1 2 3}$ with comparable excellent results (73-93\% yield, 80->90\% de, 98-99\% ee). These powerful novel reactions will be undoubtedly useful to prepare important alkaloids or nitrogen-containing drugs bearing a quaternary stereocenter contiguous to an amine.

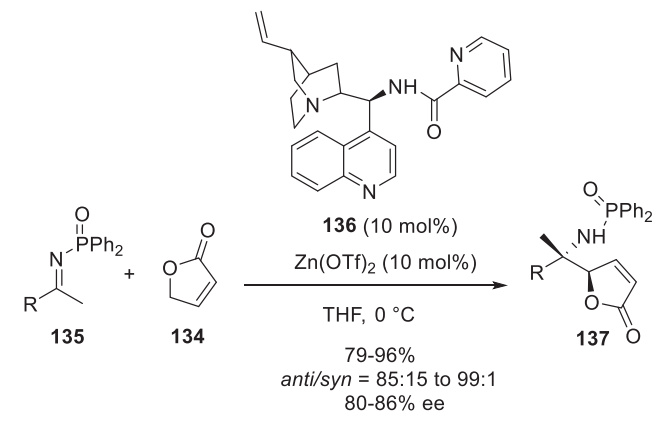

$\mathrm{R}=p-\mathrm{BrC}_{6} \mathrm{H}_{4}, \mathrm{Ph}, p-\mathrm{Tol}, p-\mathrm{MeOC}_{6} \mathrm{H}_{4}, p-\mathrm{FC}_{6} \mathrm{H}_{4}, p-\mathrm{ClC}_{6} \mathrm{H}_{4}, m-\mathrm{BrC}_{6} \mathrm{H}_{4}$ 2-Naph, 2-thienyl, $\mathrm{BnCH}_{2}$, Et, $\mathrm{EtO}_{2} \mathrm{C}\left(\mathrm{CH}_{2}\right)_{2}$

proposed transition state with $\mathrm{R}=\mathrm{Ph}$

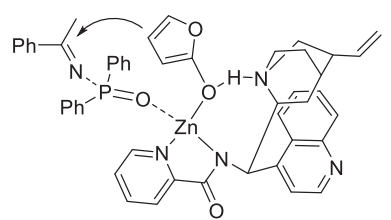

Scheme 46. Vinylogous Mannich reaction of $\gamma$-butenolide with $N$-protected ketimines in the presence of a cinchona alkaloid ligand [72]. 
$\boldsymbol{\alpha}$-Branched ynones $\mathbf{1 2 4}$ were also investigated in comparable Mannich reactions with a variety of $\mathrm{N}$-Boc and $\mathrm{N}-\mathrm{Cbz}$ aldimines 109, 112 [69]. In this case, enantiomeric $(S, S)$-ProPhenol was employed as ligand and the reaction was performed at room temperature. As illustrated in Scheme 43, a number of highly functionalized chiral $\beta$-amino ynones 125 were synthesized through this methodology with good to excellent yields (64-92\%), high diastereoselectivities ( $84->90 \% \mathrm{de}$ ) and generally very high enantioselectivities (70-99\% ee).

In 2020, the same group investigated enantioselective Mannich reaction of cyclic and acyclic $\alpha$-trifluoromethyl- and $\alpha$-trifluorome thylthio-substituted ketones with $N$-protected imines [70]. These transformations were promoted by the same catalyst system employed at $10 \mathrm{~mol} \%$ of catalyst loading in toluene at $4{ }^{\circ} \mathrm{C}$. A range of cyclic $\alpha$-trifluoromethyl- and $\alpha$-trifluoromethylthio-substituted ketones 126 smoothly reacted with both $N$-Cbz/Boc aryl and alkyl aldimines 109, 112 to yield the corresponding chiral $\beta$-amino ketones 127 bearing a tetrasubstituted $\alpha-\mathrm{CF}_{3}$ or $\alpha-\mathrm{SCF}_{3}$ stereogenic center in uniformly excellent enantioselectivities (83-99\% ee) and in most cases excellent diastereoselectivities (50->90\% de) combined with good to quantitative yields (62-96\%), as depicted in Scheme 44. The scope of the methodology could be extended to challenging acyclic $\alpha$-trifluoromethylthio-substituted ketones 128, which underwent the reaction with $N$-Boc aldimines 109 to give chiral amines 129 in excellent yields (88-90\%), diastereoselectivities ( $82-84 \%$ de) and ee values (91-99\% ee). It must be noted that this method allowed access to rare and challenging compounds with tetrasubstituted $\alpha$-trifluoromethylthio $\beta$-amines.

\subsection{With other ligands}

In 2015, Feng et al. employed a chiral $N, N^{\prime}$-dioxide ligand to develop the first enantioselective Mannich reaction between silyl ketene imines 130 and $N$-protected isatin-derived ketimines 131 [71]. Only 2.5 mol\% of optimal ligand 132 was combined with the same quantity of $\mathrm{Zn}(\mathrm{OTf})_{2}$ to generate the corresponding chiral catalyst which allowed a range of chiral $\beta$-amino nitriles 133 bearing congested vicinal tetrasubstituted stereocenters to be synthesized at $-45{ }^{\circ} \mathrm{C}$ in THF as solvent (Scheme 45). These functionalized 3-amino oxindoles were obtained as almost single diastereomers ( $>90 \%$ de) in both high yields (78-98\%) and enantioselectivities (91-99\% ee). This novel process offered a particularly broad substrate scope and functional-group tolerance.

The same year, Nakamura et al. developed the first enantioselective direct vinylogous Mannich reaction of $\gamma$-butenolide 134 with various $N$-protected ketimines 135 performed in the presence of $10 \mathrm{~mol} \%$ of a zinc chiral catalyst derived from cinchona alkaloid 136 and $\mathrm{Zn}(\mathrm{OTf})_{2}$ [72]. Carried out at $0{ }^{\circ} \mathrm{C}$ in THF as solvent, the process led to the corresponding $\delta$-amino- $\delta, \delta$-disubstituted- $\alpha, \beta$-u nsaturated carbonyl compounds $\mathbf{1 3 7}$ as major anti-diastereomers (anti/syn = 85:15 to 99:1) in high yields (79-96\%) and enantioselectivities (80-86\% ee), as illustrated in Scheme 46. A possible transition state for the reaction is depicted in this Scheme, showing

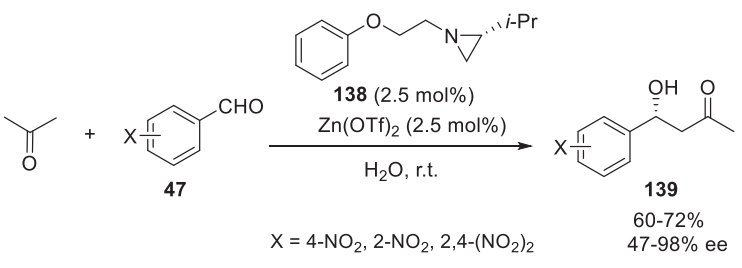

Scheme 47. Aldol reaction of acetone with nitrobenzaldehydes in water and in the presence of an aziridine-ether ligand [73].

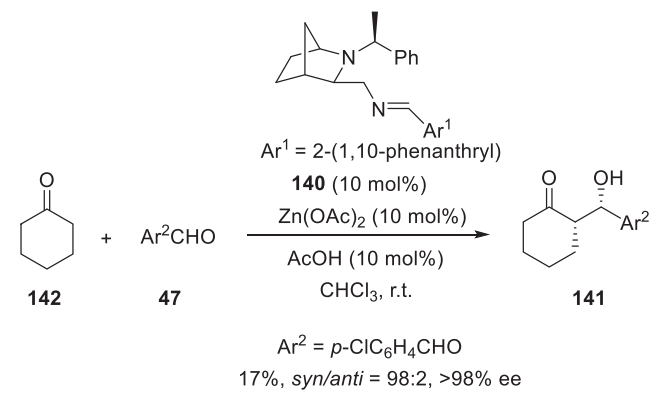

transition state:

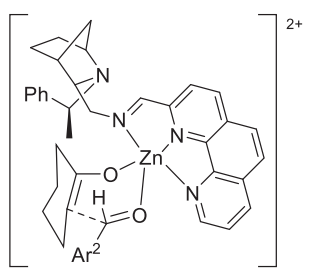

Scheme 48. Aldol reaction of cyclohexanone with p-chloro-benzaldehyde in the presence of a Schiff base ligand [74].

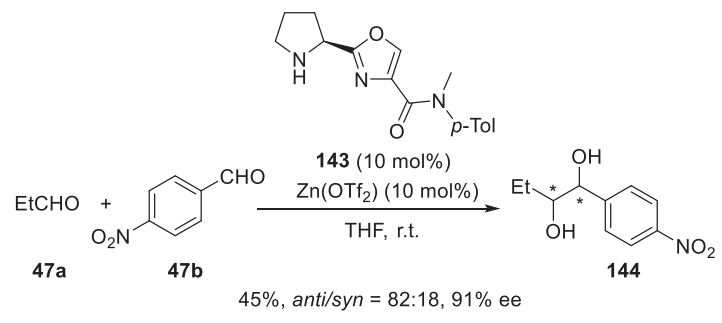

Scheme 49. Aldol reaction of propionaldehyde with p-nitrobenzaldehyde in the presence of an azole-carboxamide ligand [75].

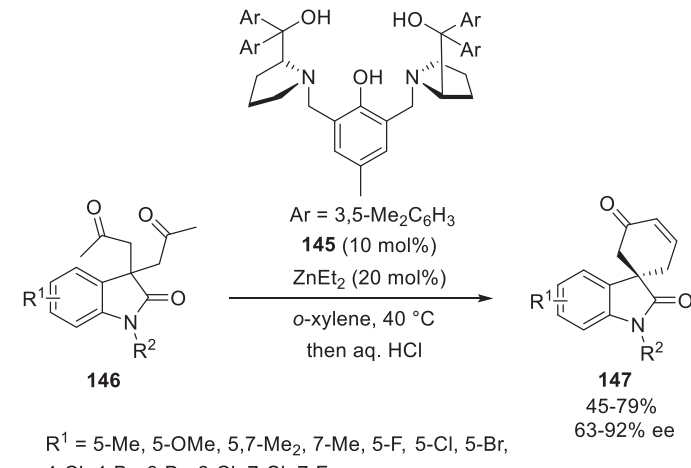
4-Cl, 4-Br, 6- $\mathrm{Br}, 6-\mathrm{Cl}, 7-\mathrm{Cl}, 7-\mathrm{F}$

$\mathrm{R}^{2}=\mathrm{Me}, \mathrm{Ph}, \mathrm{Bn}$

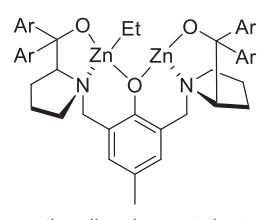

Scheme 50. Intramolecular aldol reaction of oxindole-derived diketones in the presence of a ProPhenol derivative ligand [76].

that two nitrogen atoms from the picolinoyl group, two oxygen atoms from the dienolate, and a phosphoryl group coordinate to the $\operatorname{zinc}(\mathrm{II})$ cation. Furthermore, the ammonium proton on 


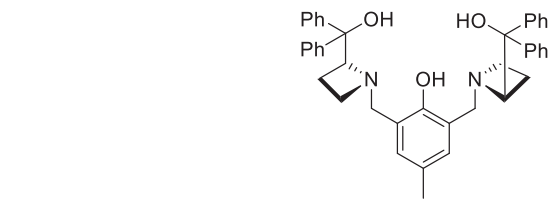

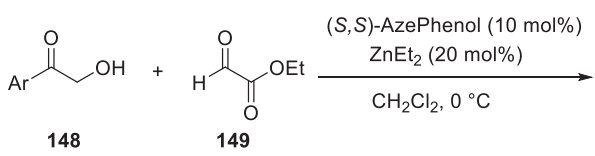

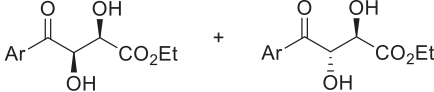

$$
\begin{aligned}
& \begin{array}{rr}
\text { syn }-150 & \text { anti-150 } \\
31-55 \% & 40-58 \%
\end{array} \\
& 76-98 \% \text { ee } \quad 72-99 \% \text { ee }
\end{aligned}
$$

$\mathrm{Ar}=\mathrm{Ph}, p-\mathrm{Tol}, p-\mathrm{MeOC}_{6} \mathrm{H}_{4}, o-\mathrm{Tol}, o-\mathrm{MeOC}_{6} \mathrm{H}_{4}, 2,5-\mathrm{MeO}_{2} \mathrm{C}_{6} \mathrm{H}_{3}$ $m-\mathrm{MeOC}_{6} \mathrm{H}_{4}, m-\mathrm{BrC}_{6} \mathrm{H}_{4}, m-\mathrm{ClC}_{6} \mathrm{H}_{4}, p-\mathrm{BrC}_{6} \mathrm{H}_{4}, p-\mathrm{ClC}_{6} \mathrm{H}_{4}, p-\mathrm{FC}_{6} \mathrm{H}_{4}$ $p$ - $\mathrm{O}_{2} \mathrm{NC}_{6} \mathrm{H}_{4}, 2$-furyl, 2-thienyl

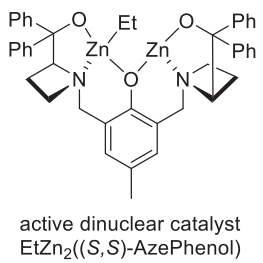

Scheme 51. Aldol reaction of 2-hydroxyacetophenones with ethyl glyoxylate in the presence of $(S, S)$-AzePhenol [77].

quinuclidine coordinates to the oxygen atom of the dienolate. In this structure, the $R e$ face of the dienolate approaches the Re face of the ketimine to avoid steric repulsion of the diphenylphosphinyl group to give the final product.

\section{6. (Nitro)aldol reactions}

\subsection{Aldol reactions}

In 2000, Trost et al. developed the first enantioselective aldol reaction using a dinuclear zinc catalyst derived from chiral ProPhenol ligand [42]. Ever since, many types of chiral ligands have been employed in these reactions which are generally performed under mild reaction conditions [3b,5c,6]. In addition to use a non-toxic and cheap metal, these green reactions present the advantage to be sometimes performed in water. As an example, asymmetric aldol reaction of acetone with nitrobenzaldehydes 47 were developed in 2015 by Rachwalski et al. by using chiral aziridineether ligands in water [73]. A low catalyst loading of $2.5 \mathrm{~mol} \%$ of optimal ligand $\mathbf{1 3 8}$ combined with the same quantity of $\mathrm{Zn}(\mathrm{OTf})_{2}$ allowed the corresponding aldol products $\mathbf{1 3 9}$ to be synthesized in good yields (60-72\%) and moderate to excellent enantioselectivities (47-98\% ee), as shown in Scheme 47.

In 2016, Wojaczynska et al. designed novel chiral rigid and bicyclic ligand $\mathbf{1 4 0}$ bearing a tertiary amine and a 1,10phenanthroline moiety appended by an imine linkage [74]. When this ligand (10 mol\%) was combined to $\mathrm{Zn}(\mathrm{OAc})_{2}(10 \mathrm{~mol} \%)$ in chloroform as solvent and $\mathrm{AcOH}$ as an additive, it promoted the stereoselective formation of enantio- (>98\% ee) and diastereopure (96\% de) syn-aldol product 141 in low yield (17\%) starting from the corresponding aromatic aldehyde $\mathbf{4 7}$ and cyclohexanone 142 (Scheme 48). A transition state is proposed in Scheme 48, in which the preferred formation of the syn-diastereomer is explained by

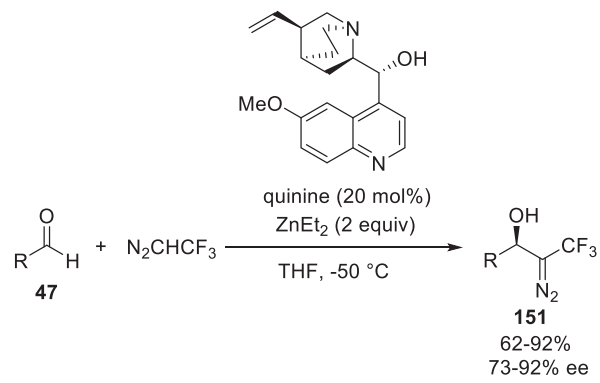

$\mathrm{R}=2-\mathrm{Naph}, \mathrm{Ph}, p-\mathrm{Tol}, m-\mathrm{Tol}, o-\mathrm{Tol}, p-\mathrm{MeOC}_{6} \mathrm{H}_{4}, m-\mathrm{MeOC}_{6} \mathrm{H}_{4}$, $p-\mathrm{PhOC}_{6} \mathrm{H}_{4}, p-\mathrm{FC}_{6} \mathrm{H}_{4}, p-\mathrm{ClC}_{6} \mathrm{H}_{4}, m-\mathrm{ClC}_{6} \mathrm{H}_{4}, o-\mathrm{ClC}_{6} \mathrm{H}_{4}, p-\mathrm{BrC}_{6} \mathrm{H}_{4}$, $o-\mathrm{BrC}_{6} \mathrm{H}_{4}, p-\mathrm{IC}_{6} \mathrm{H}_{4}, p-\mathrm{F}_{3} \mathrm{CC}_{6} \mathrm{H}_{4}, p-\mathrm{O}_{2} \mathrm{NC}_{6} \mathrm{H}_{4}, o-\mathrm{O}_{2} \mathrm{NC}_{6} \mathrm{H}_{4}, 3,4-\mathrm{Cl}_{2} \mathrm{C}_{6} \mathrm{H}_{3}$, 2,4,6- $\mathrm{Me}_{3} \mathrm{C}_{6} \mathrm{H}_{2}$, 1-Naph, 2-furyl, 2-thienyl, 2-pyridyl, 4-MeO-3-pyridyl, 4-Cl-3-pyridyl, 2-Cl-3-pyridyl, 4-Br-3-pyridyl, $(E)-\mathrm{PhCH}=\mathrm{CH}, \mathrm{Bn}^{-\mathrm{BnCH}_{2}}$

with aliphatic aldehydes:

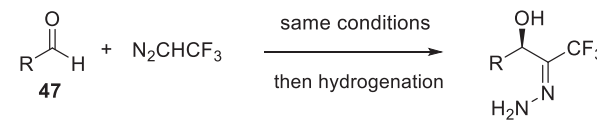

$$
\begin{aligned}
& \mathrm{R}=\mathrm{Cy}, t-\mathrm{Bu}, c-\mathrm{Pr}, n \text {-Oct, } n \text {-Hex } 152 \\
& \begin{array}{c}
152 \\
62-68 \%
\end{array} \\
& 79-90 \% \text { ee }
\end{aligned}
$$

Scheme 52. Aldol reactions of aldehydes with $\mathrm{N}_{2} \mathrm{CHCF}_{3}$ in the presence of quinine [78].

the favored formation of the $Z$-enolate of cyclohexanone and position of the aromatic group of the aldehyde $\left(\mathrm{Ar}^{2}\right)$ in the least sterically hindered place.

The same year, other novel multifunctional heterocyclic ligands were synthesized by Dockendorff et al. [75]. Among them, azolecarboxamide ligand 143 was found optimal when combined with
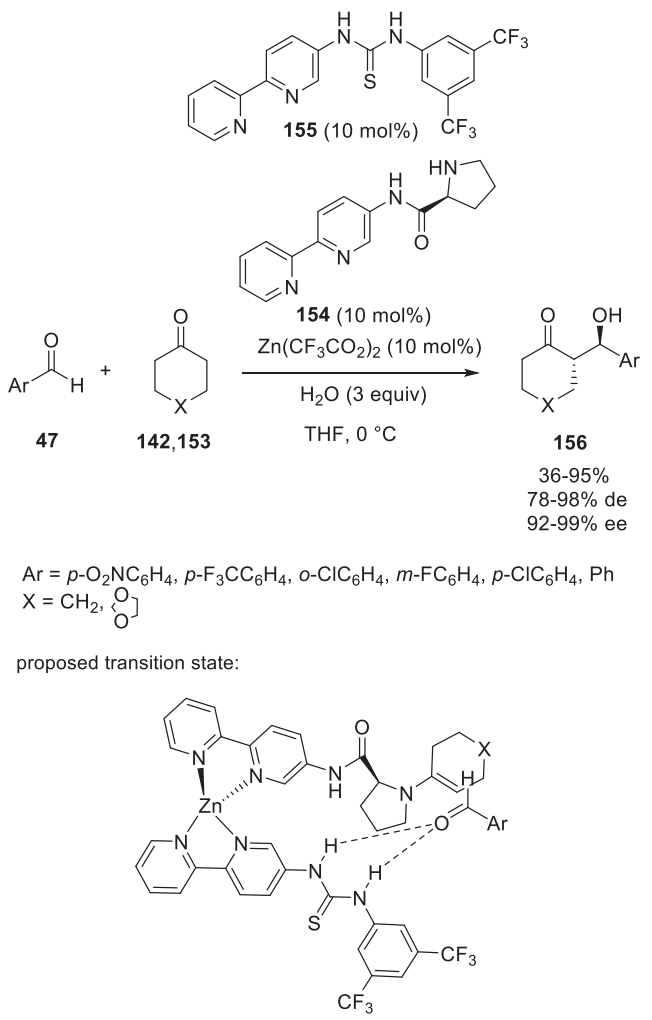

Scheme 53. Aldol reaction of cyclohexanones with benzaldehydes in the presence of bipyridine-based ligands [79]. 
$\mathrm{Zn}(\mathrm{OTf})_{2}$ to promote enantioselective aldol condensation of propionaldehyde $47 \mathbf{a}$ to $p$-nitrobenzaldehyde $4 \mathbf{7 b}$, delivering the corresponding chiral anti-diol 144 as major diastereomer (anti/ syn $=82: 18$ ) in $91 \%$ ee and $45 \%$ yield (Scheme 49 ). However, a drawback of this novel methodology was related to the limitation of its substrate scope.

In the presence of a dinuclear zinc complex derived from $\mathrm{ZnEt}_{2}$ (20 mol\%) and $10 \mathrm{~mol} \%$ of chiral ProPhenol derivative 145 as ligand, an enantioselective intramolecular aldol reaction of variously substituted oxindole-derived diketones 146 occurred at $40{ }^{\circ} \mathrm{C}$ in $\mathrm{o}$-xylene (Scheme 50) [76]. The corresponding cyclized products were subsequently submitted to dehydration by treatment with aqueous $\mathrm{HCl}$ to afford chiral spiro[cyclohexanoneoxindole] derivatives 147 in good yields (45-79\%) and good to high enantioselectivities (63-92\% ee).

Chiral $\alpha, \beta$-dihydroxy esters constitute key building blocks in the synthesis of many drugs and natural products. In 2018, Wang et al. employed $(S, S)$-AzePhenol as ligand at $10 \mathrm{~mol} \%$ of catalyst loading in combination with $20 \mathrm{~mol} \%$ of $\mathrm{ZnEt}_{2}$ in dichloromethane at $0{ }^{\circ} \mathrm{C}$ in a novel direct access to this type of products [77]. The process involved an asymmetric aldol reaction between 2hydroxyacetophenones 148 and ethyl glyoxylate 149, leading to mixtures of both syn- and anti- $\alpha, \beta$-dihydroxy $\gamma$-ketoesters 150 . The presence of a range of substituents on the phenyl ring of the 2-hydroxyacetophenones was tolerated (Scheme 51). The syn-diastereomers were obtained in low to moderate yields (31-55\%) and good to high enantioselectivities (76-98\% ee) while the antiproducts were synthesized with slightly better yields (40-58\%) and comparable enantioselectivities (72-99\% ee). These functionalized products can be considered as potential synthetic intermediates for the synthesis of various compounds.

In 2019, Ma and Zhang reported the first catalytic enantioselective reaction based on the use of trifluorodiazoethane as an effective nucleophile to be condensed on aldehydes [78]. Indeed, an asymmetric aldol reaction of $\mathrm{CF}_{3} \mathrm{CHN}_{2}$ with a wide range of aldehydes $\mathbf{4 7}$ occurred in the presence of $20 \mathrm{~mol} \%$ of quinine as ligand and two equivalents of $\mathrm{ZnEt}_{2}$. Performed at $-50{ }^{\circ} \mathrm{C}$ in THF as solvent, the reaction resulted in the formation of the corresponding chiral $\mathrm{CF}_{3}$-containing alcohols $\mathbf{1 5 1}$ in good to high yields (62-92\%) and enantioselectivities (73-92\% ee), as illustrated in Scheme 52. The catalyst system was remarkably compatible with many aromatic aldehydes with electronically varied substituents at different positions of the phenyl ring and also with naphthyl and heteroaryl aldehydes. Pyridine-derived aldehydes were also tolerated with

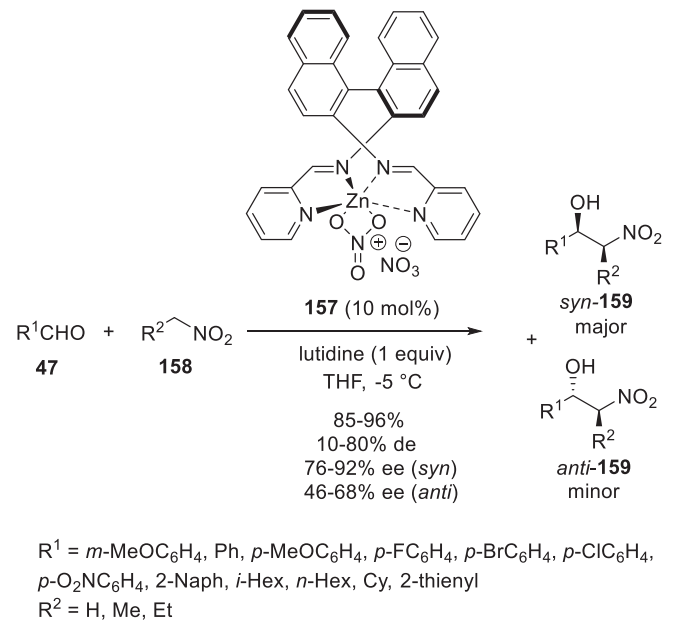

Scheme 54. Henry reaction of aldehydes with nitroalkanes in the presence of a BINIM-based Schiff base-derived catalyst [82].

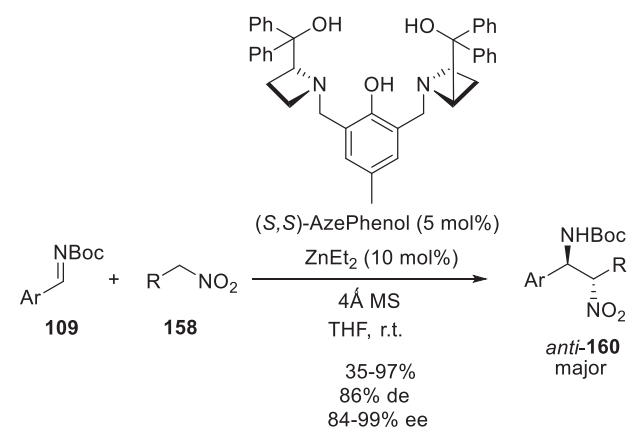

$\mathrm{Ar}=\mathrm{Ph}, o-\mathrm{Tol}, m-\mathrm{Tol}, p-\mathrm{Tol}, p-\mathrm{MeOC}_{6} \mathrm{H}_{4}, o-\mathrm{ClC}_{6} \mathrm{H}_{4}, m-\mathrm{ClC}_{6} \mathrm{H}_{4}, p-\mathrm{ClC}_{6} \mathrm{H}_{4}$ p- $\mathrm{FC}_{6} \mathrm{H}_{4}, 3,4-\mathrm{Me}_{2} \mathrm{C}_{6} \mathrm{H}_{3}, 2,3-(\mathrm{MeO})_{2} \mathrm{C}_{6} \mathrm{H}_{3}, 3,4-\left(\mathrm{OCH}_{2} \mathrm{O}\right) \mathrm{C}_{6} \mathrm{H}_{3}$, 2-furyl, 2-thienyl $\mathrm{R}=\mathrm{H}, \mathrm{Me}, \mathrm{Et}$

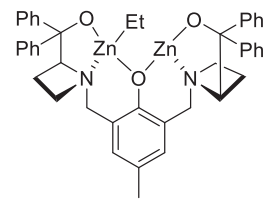

active dinuclear catalys

$\mathrm{EtZn}_{2}((S, S)$-AzePhenol)

Scheme 55. Aza-Henry reaction of $N$-Boc aryl aldimines with nitroalkanes in the presence of $(S, S)$-AzePhenol [83].

comparable enantioselectivities. Along with aromatic aldehydes, cinnamaldehyde, phenylethyl aldehyde and phenylpropyl aldehyde also reacted smoothly with comparable results. In addition, a series of simple aliphatic aldehydes $\mathbf{4 7}$ also underwent the reaction, leading in this case, to the corresponding $\mathrm{CF}_{3}$-hydrazones 152 arisen from a further hydrogenation. The latter products were obtained in good yields (62-68\%) and high enantioselectivities (79-90\% ee).

Novel bipyridine-based ligands were synthesized by Jimeno and Sola to be combined with $\mathrm{Zn}\left(\mathrm{CF}_{3} \mathrm{CO}_{2}\right)_{2}$ and further investigated in enantioselective aldol reaction of cyclohexanones 142,153 with benzaldehydes 47 [79]. Interestingly, the active catalyst was a bifunctional, cooperative self-assembled complex with a tetrahedral zinc complex forming the enamine of cyclohexanone 142 , 153 through the prolinamide moiety of chiral ligand 154, whereas the thiourea group from the perpendicular achiral ligand $\mathbf{1 5 5}$ approached the aldehyde substrate through hydrogen bonding in a way that steric repulsion from the inner complex was minimized (Scheme 53). In the presence of $10 \mathrm{~mol} \%$ of this original catalyst system and three equivalents of water in THF as solvent, a series of diversely substituted aromatic benzaldehydes 47 reacted at $0{ }^{\circ} \mathrm{C}$ with cyclohexanones 142,153 to give the corresponding chiral aldol products 156 with moderate to excellent yields (36-95\%),

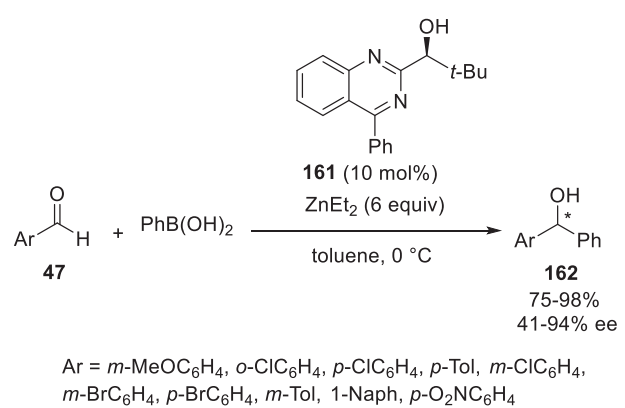

Scheme 56. Addition of $\mathrm{PhB}(\mathrm{OH})_{2}$ to aromatic aldehydes in the presence of a 4phenylquinazolinol ligand [84] 
and uniformly high diastereo- (78-98\% de) and enantioselectivities (92-99\% ee). It was found that the presence of water as an additive was crucial to ensure the activity of the catalytic system.

\subsection{Nitroaldol reactions}

The nitroaldol reaction (Henry reaction) is an important $\mathrm{C}-\mathrm{C}$ bond forming reaction to achieve key synthetic building blocks, such as $\beta$-nitroalcohols, from aldehydes and nitroalkanes [80]. This transformation has been the object of many investigations and a range of asymmetric versions have been developed by using both chiral metal complexes and organocatalysts. Among the works involving chiral zinc catalysts [9], is the first enantioselective zinc-catalyzed Henry reaction reported by Trost and Ye in 2002, allowing enantioselectivities of up to $93 \%$ ee to be reached by using a dinuclear zinc complex [81]. Later in 2016, Subramanian et al. investigated the use of preformed mononuclear chiral zinc catalyst $\mathbf{1 5 7}$ derived from a BINIM-based Schiff base ligand in asymmetric nitroaldol reaction of aldehydes 47 with nitroalkanes 158 (Scheme 54) [82]. Using $10 \mathrm{~mol} \%$ of this catalyst in THF at $-5{ }^{\circ} \mathrm{C}$ in the presence of lutidine as stoichiometric additive, the reaction of nitromethane $\left(R^{2}=H\right)$ with both aromatic and aliphatic aldehydes afforded the corresponding chiral $\beta$-nitro alcohols 159 in high yields (85-96\%) and enantioselectivities (74-92\% ee). The scope of the process was extended to other nitroalkanes, such as nitroethane and nitropropane, which afforded the corresponding

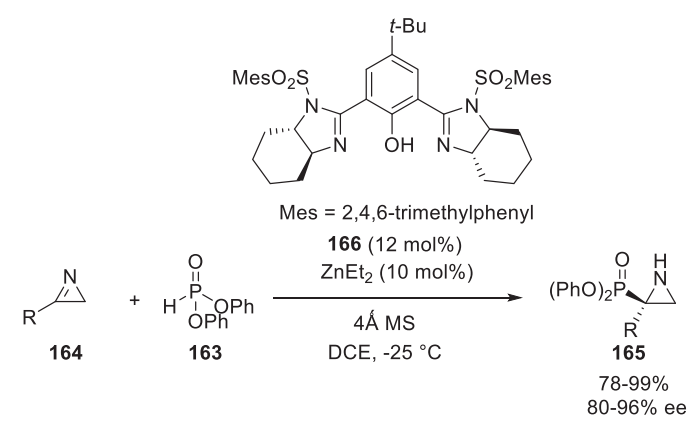

$\mathrm{R}=\mathrm{Ph}, p-\mathrm{Tol}, m-\mathrm{Tol}, 3,5-\mathrm{Me}_{2} \mathrm{C}_{6} \mathrm{H}_{3}, m-\mathrm{PhC}_{6} \mathrm{H}_{4}, m-\mathrm{MeOC}_{6} \mathrm{H}_{4}, p-\mathrm{FC}_{6} \mathrm{H}_{4}$, $m-\mathrm{FC}_{6} \mathrm{H}_{4}, \mathrm{o}-\mathrm{FC}_{6} \mathrm{H}_{4}, 2-\mathrm{Naph}, 2$-thienyl, 3-thienyl,1-Naph, $\mathrm{PhCH}=\mathrm{CH}$

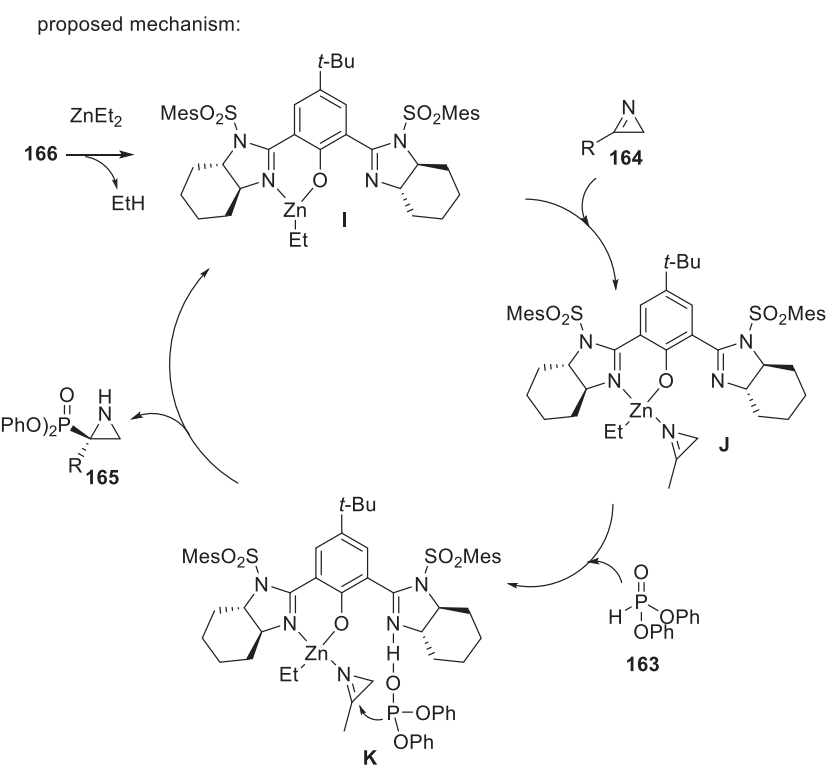

Scheme 57. Addition of diphenylphosphite to 3 -substituted $2 \mathrm{H}$-azirines in the presence of a bis(imidazoline) ligand [85].

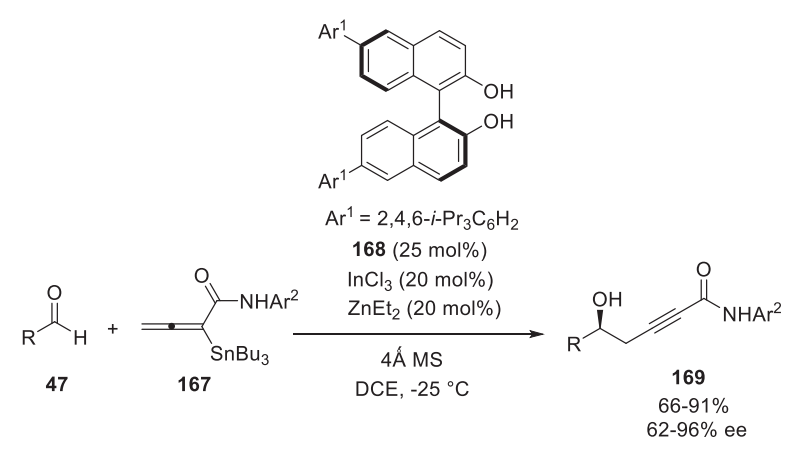

$\mathrm{R}=n-\mathrm{C}_{9} \mathrm{H}_{19}, t-\mathrm{Bu}, m-($ TBDPSO $) \mathrm{C}_{6} \mathrm{H}_{4}, p-\mathrm{Tol}, p-\mathrm{MeOC}_{6} \mathrm{H}_{4}, p-\mathrm{ClC}_{6} \mathrm{H}_{4}, p-($ TBDPSO $) \mathrm{C}_{6} \mathrm{H}_{4}$ o-Tol, o- $\mathrm{MeOC}_{6} \mathrm{H}_{4}$, o- $-\mathrm{ClC}_{6} \mathrm{H}_{4}$, o-(TBSO) $\mathrm{C}_{6} \mathrm{H}_{4}$, o-(TIPSO) $\mathrm{C}_{6} \mathrm{H}_{4}$, o-(TBDPSO) $\mathrm{C}_{6} \mathrm{H}_{4}$ $\mathrm{Ar}^{2}=\mathrm{Ph}, p-\mathrm{ClC}_{6} \mathrm{H}_{4}, p-\mathrm{MeOC}_{6} \mathrm{H}_{4}, p-\mathrm{Tol}$

Scheme 58. Propargylation of aldehydes with stannyl allenyl amides in the presence of a dual $\mathrm{Zn} / \mathrm{In}$ catalysis and a BINOL-derived ligand [86].

products as syn/anti mixtures of diastereomers with low to high diastereoselectivities in favor of the syn-diastereomers $(10-80 \%$ de). The yields were high (83-96\%) and the enantioselectivities of the syn- and anti- $\beta$-nitro alcohols of $76-92 \%$ ee and $46-68 \%$ ee, respectively. Importantly, it was found that the catalyst could be recycled and reused for up to six times without loss of efficiency.

Furthermore, the asymmetric aza-Henry reaction between imines and nitroalkanes constitutes one of the most employed methodologies to prepare chiral $\beta$-nitroamines. In 2019, Wang et al. disclosed a novel protocol for the enantioselective azaHenry reaction of $\mathrm{N}$-Boc aldimines and nitroalkanes performed at room temperature, which was based on the use of $(S, S)$ AzePhenol as zinc ligand [83]. As depicted in Scheme 55, a dinuclear catalyst in situ generated from $5 \mathrm{~mol} \%$ of this ligand and $10 \mathrm{~mol} \%$ of $\mathrm{ZnEt}_{2}$ promoted in THF as solvent the aza-Henry reaction of a range of aromatic $N$-Boc-aldimines 109 with nitroalkanes 158 to yield the corresponding chiral $\beta$-nitroamines 160 in moderate to quantitative yields (35-97\%) and uniformly excellent enantioselectivities (84-99\% ee). In addition to nitromethane, nitroethane and nitropropane were also tolerated with comparable excellent results, leading to the anti-diastereomers with $86 \%$ de.

\section{Other 1,2-nucleophilic additions to carbonyl compounds and derivatives}

In 2016, Ulukanli et al. reported the synthesis of novel chiral 4phenylquinazolinol ligands which were further used in several zinc-catalyzed asymmetric transformations, including enantioselective phenylboronic acid addition to aldehydes [84]. As presented in Scheme 56, the use of $10 \mathrm{~mol} \%$ of ligand $\mathbf{1 6 1}$ in toluene at $0{ }^{\circ} \mathrm{C}$ along with six equivalents of $\mathrm{ZnEt}_{2}$ allowed the addition of $\mathrm{PhB}$ $(\mathrm{OH})_{2}$ to a series of substituted aromatic aldehydes 47 to be achieved, producing the corresponding chiral diaryl alcohols $\mathbf{1 6 2}$ with high yields (75-98\%) and moderate to high enantioselectivities (41-94\% ee).

In 2017, Nakamura and Hayama reported the first example of a highly enantioselective reaction of azirines with nucleophiles [85]. It involved the asymmetric nucleophilic addition of diphenylphosphite 163 to 3 -substituted $2 \mathrm{H}$-azirines 164, resulting in the formation of the corresponding chiral aziridines $\mathbf{1 6 5}$. To promote these reactions, the authors designed novel chiral bis(imidazoline) ligands, such as 166, which was employed at $12 \mathrm{~mol} \%$ of catalyst loading in combination with $10 \mathrm{~mol} \%$ of $\mathrm{ZnEt}_{2}$ in DCE as solvent at $-25^{\circ} \mathrm{C}$. The corresponding chiral aziridines 165 were obtained in both uniformly high ee values (80-96\% ee) and yields (78$99 \%$ ), as illustrated in Scheme 57 . A catalytic cycle is proposed in 


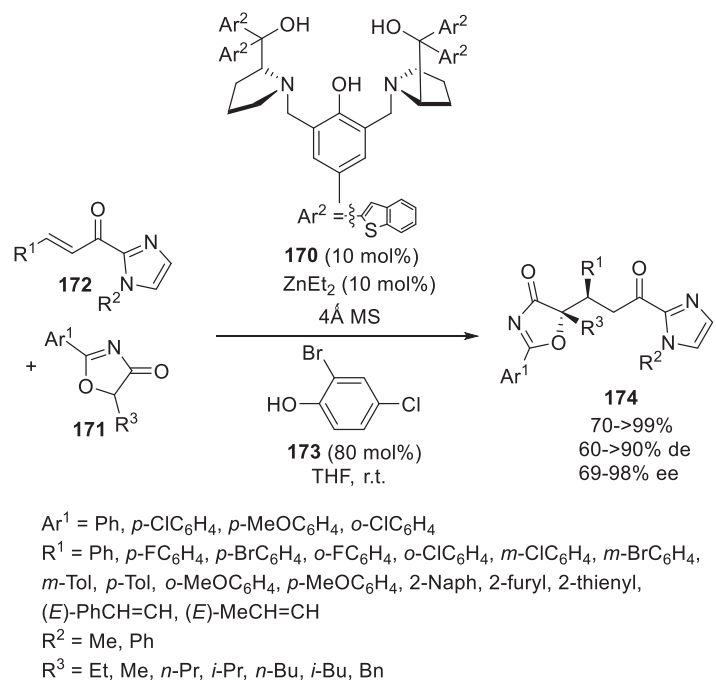

proposed mechanism with $\mathrm{Ar}^{1}=\mathrm{R}^{1}=\mathrm{Ph}, \mathrm{R}^{2}=\mathrm{Me}, \mathrm{R}^{3}=\mathrm{Et}$ :

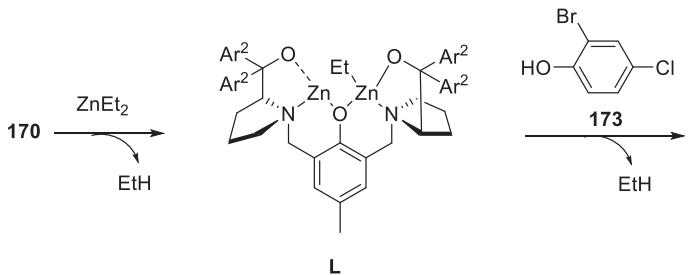

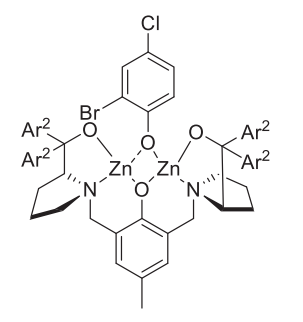

M

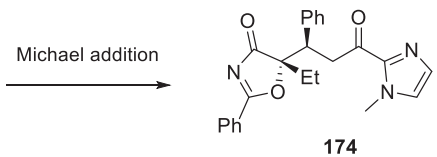

Scheme 59. Michael addition of 5H-oxazol-4-ones to $\alpha, \beta$-unsaturated acyl imidazoles in the presence of a ProPhenol derivative ligand [89].

this Scheme in which $\mathrm{ZnEt}_{2}$ reacted with the hydroxy group of the chiral ligand to form complex I. Then, the azirine coordinated to the zinc atom of $\mathbf{I}$ to give intermediate $\mathbf{J}$, which further chelated and activated diphenylphosphite in complex $\mathbf{K}$. Activated diphenylphosphite then condensed to the imine carbon atom of the azirine. Subsequently, protonation and decomplexation underwent to give the final product and regenerate $\mathbf{I}$.

In 2019, Yoda et al. developed the first catalytic enantioselective propargylation of aldehydes with newly prepared stannyl allenyl amides to give chiral propargyl amides (Scheme 58) [86]. Indeed, a variety of aldehydes 47 were efficiently coupled with these propargylating reagents $\mathbf{1 6 7}$ under multicatalysis with $20 \mathrm{~mol} \%$ of $\mathrm{ZnCl}_{2}, 20 \mathrm{~mol} \%$ of $\mathrm{InCl}_{3}$, and $25 \mathrm{~mol} \%$ of chiral BINOL-derived ligand 168 to afford the corresponding amide-functionalized homopropargyl alcohols 169 in both good to high yields (66$91 \%$ ) and enantioselectivities (62-96\% ee). The mechanistic details of the process with the exact role of each metal were not precised by the authors.
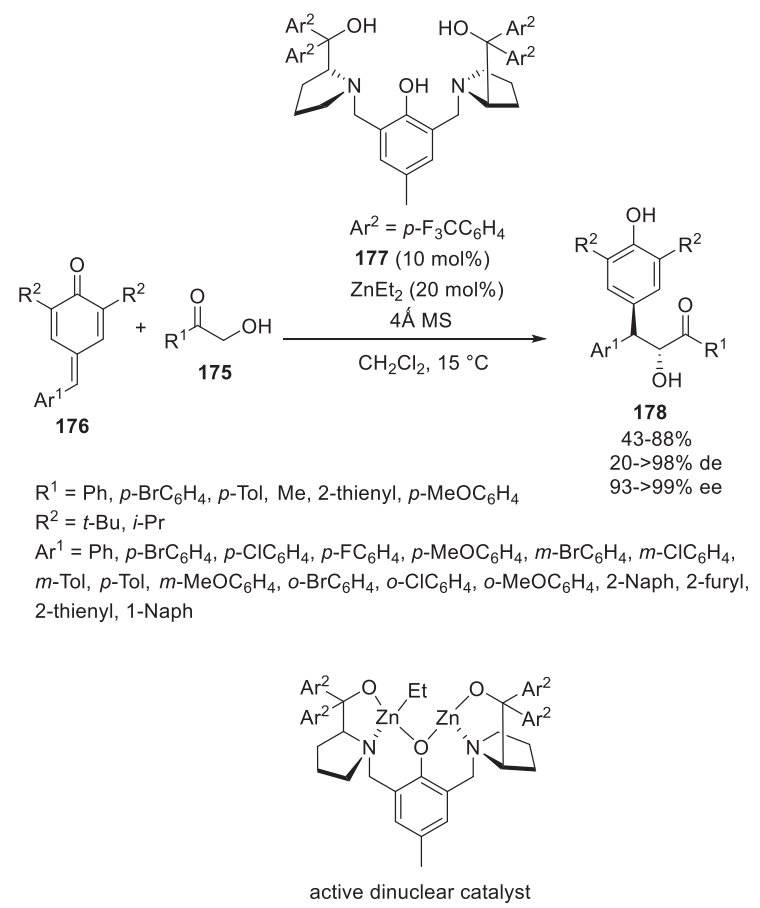

Scheme 60. 1,6-Michael addition of $\alpha$-hydroxy ketones to 1,4-quinone methides in the presence of a ProPhenol derivative ligand [90].

\section{Michael additions}

(Hetero)-Michael additions play a major role in the formation of carbon-carbon and carbon-heteroatom bonds. Many catalytic systems have been used in these reactions, including chiral organocatalysts and metal complexes. In particular, zinc catalysis in the Michael addition has achieved great importance due to the broad substrate scope, mild reaction conditions, and excellent reactivity and selectivity, along with the availability of a variety of useful chiral ligands [11]. In 2001, Shibasaki et al. reported the first highly enantioselective zinc-catalyzed Michael addition of 2-hydroxy-2'methoxyacetophenone to $\alpha, \beta$-unsaturated ketones [87]. Catalyzed by a BINOL-derived zinc complex, the reaction afforded the corresponding Michael products with up to $99 \%$ ee. Ever since, many types of ligands have been combined to zinc to promote such reactions [ $5 c, 88]$. In an example reported in 2015 by Wang et al., novel chiral ProPhenol derivative ligand $\mathbf{1 7 0}$ was synthesized and used in the asymmetric Michael reaction of $5 \mathrm{H}$-oxazol-4-ones 171 to $\alpha, \beta-$ unsaturated acyl imidazoles 172 [89]. The conjugate addition was performed in THF at room temperature in the presence of phenol 173 as an additive, leading to a wide range of chiral imidazolemodified $\alpha, \beta$-unsaturated ketones 174 with high yields ( $70->99 \%$ ), moderate to generally excellent diastereoselectivities (60->90\% de) and good to high enantioselectivities (69-98\% ee), as shown in Scheme 59. The authors proposed the mechanism depicted in this Scheme in which active dinuclear zinc complex $\mathbf{L}$ was generated from the chiral ligand and $\mathrm{ZnEt}_{2}$.Then, the phenol additive coordinated to the zinc center to provide chiral intermediate $\mathbf{M}$. Then, independent coordination of the two substrates to the two zinc atoms of complex $\mathbf{M}$ provided complex $\mathbf{N}$ which stereoselectively led to the chiral product through Michael addition.

In 2018, Wang et al. described the first asymmetric 1,6-Michael addition of $\alpha$-hydroxy ketones 175 to 1,4-quinone methides 176 (Scheme 60) [90]. It employed $10 \mathrm{~mol} \%$ of (S,S)-ProPhenol derivative 177 as ligand and $20 \mathrm{~mol} \%$ of $\mathrm{ZnEt}_{2}$ in dichloromethane as solvent. Carried out at $15^{\circ} \mathrm{C}$, it resulted in the formation of chiral 


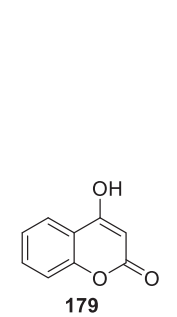

$+179$<smiles>[R]OC(=O)C=C[Al][Te]</smiles>

181

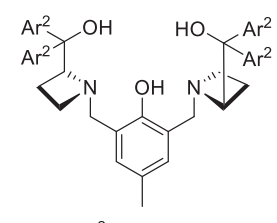

$\mathrm{Ar}^{2}=p-\mathrm{F}_{3} \mathrm{CC}_{6} \mathrm{H}_{4}$

$177(10 \mathrm{~mol} \%)$ $\mathrm{ZnEt}_{2}(10 \mathrm{~mol} \%)$ toluene, r.t.

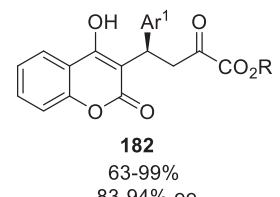

$\mathrm{Ar}^{1}=\mathrm{Ph}, p-\mathrm{FC}_{6} \mathrm{H}_{4}, p-\mathrm{ClC}_{6} \mathrm{H}_{4}, p-\mathrm{BrC}_{6} \mathrm{H}_{4}, p-\mathrm{Tol}, m-\mathrm{ClC}_{6} \mathrm{H}_{4}, m-\mathrm{BrC}_{6} \mathrm{H}_{4}, m-\mathrm{Tol}$, $m-\mathrm{MeOC}_{6} \mathrm{H}_{4}, \mathrm{o}-\mathrm{ClC}_{6} \mathrm{H}_{4}, \mathrm{o}-\mathrm{BrC}_{6} \mathrm{H}_{4}, 2-\mathrm{Naph}$, 2-thienyl

$\mathrm{R}=\mathrm{Me}, \mathrm{Et}, i-\mathrm{Pr}, t-\mathrm{Bu}$

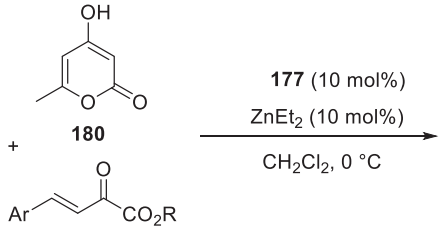

181

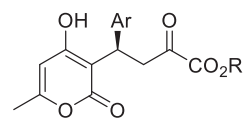

183

$68-96 \%$ $72-90 \%$ ee

$\mathrm{Ar}=\mathrm{Ph}, p-\mathrm{FC}_{6} \mathrm{H}_{4}, p-\mathrm{ClC}_{6} \mathrm{H}_{4}, p-\mathrm{BrC}_{6} \mathrm{H}_{4}, p-\mathrm{Tol}, m-\mathrm{ClC}_{6} \mathrm{H}_{4}, m-\mathrm{BrC}_{6} \mathrm{H}_{4}, m-\mathrm{Tol}$

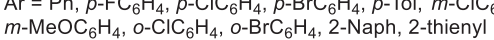
$m-\mathrm{MeOC}_{6} \mathrm{H}_{4}, \mathrm{O}-\mathrm{ClC}_{6} \mathrm{H}_{4}$,
$\mathrm{R}=\mathrm{Me}, \mathrm{Et}, i-\mathrm{Pr}, t-\mathrm{Bu}$

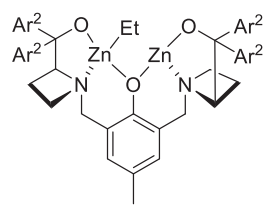

active dinuclear catalyst

Scheme 61. Michael additions of 4-hydroxyl pyrones and 4-hydroxycoumarins to aryl-substituted $\alpha, \beta$-unsaturated $\alpha$-ketoesters in the presence of an AzePhenol derivative ligand [91].
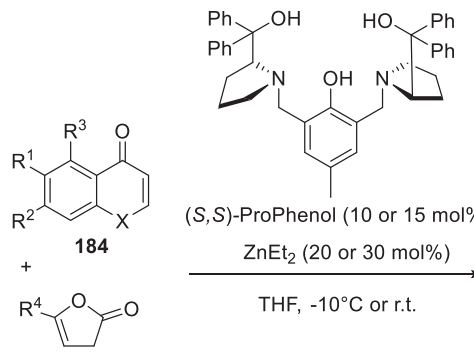

(S,S)-ProPhenol (10 or $15 \mathrm{~mol} \%$ )

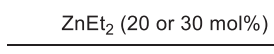

185

$\mathrm{R}^{1}=\mathrm{H}, \mathrm{NO}_{2}, \mathrm{~F}, \mathrm{Cl}, \mathrm{Br}, \mathrm{Me}, \mathrm{OMe}$

$\mathrm{R}^{2}=\mathrm{H}, \mathrm{Me}, \mathrm{OMe}$

$\mathrm{R}^{3}=\mathrm{H}, \mathrm{OMe}$

$\mathrm{R}^{4}=\mathrm{Me}$, allyl, $\mathrm{HC} \equiv \mathrm{CCH}_{2}, \mathrm{Bn}, \mathrm{NPhth}\left(\mathrm{CH}_{2}\right)_{4}$

$\mathrm{X}=\mathrm{O}, \mathrm{S}, \mathrm{NCbz}$

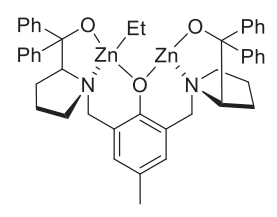

active dinuclear catalyst

Scheme 62. Michael addition of butenolides to chromones and derivatives in the presence of $(S, S)$-ProPhenol [92].

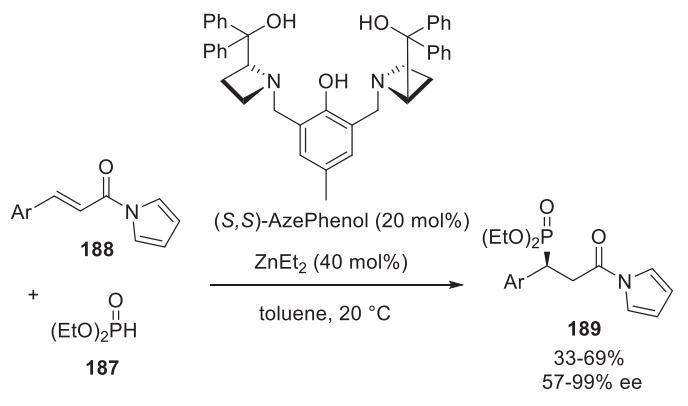

$\mathrm{Ar}=\mathrm{Ph}, \mathrm{o}-\mathrm{BrC}_{6} \mathrm{H}_{4}, \mathrm{o}-\mathrm{MeOC}_{6} \mathrm{H}_{4}, m-\mathrm{MeOC}_{6} \mathrm{H}_{4}, 2$-furyl, 2-Naph, 1-Naph, 2-thienyl, $p$ - $\mathrm{FC}_{6} \mathrm{H}_{4}, p$ - $\mathrm{Tol}, p-\mathrm{ClC}_{6} \mathrm{H}_{4}, p-\mathrm{FC}_{6} \mathrm{H}_{4}, p-\mathrm{BrC}_{6} \mathrm{H}_{4}$ $p-\mathrm{MeOC}_{6} \mathrm{H}_{4}, p-\mathrm{O}_{2} \mathrm{NC}_{6} \mathrm{H}_{4}$

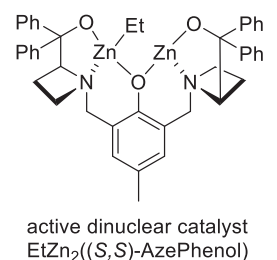

Scheme 63. Phospha-Michael addition of diethyl phosphite to aryl-substituted $N$ acylpyrroles in the presence of $(S, S)$-AzePhenol [93].

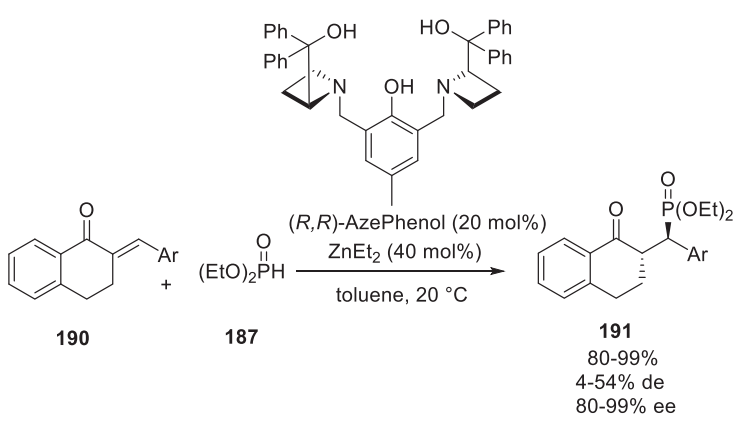

$\mathrm{Ar}=\mathrm{Ph}, p-\mathrm{FC}_{6} \mathrm{H}_{4}, p-\mathrm{ClC}_{6} \mathrm{H}_{4}, p-\mathrm{BrC}_{6} \mathrm{H}_{4}, p-\mathrm{F}_{3} \mathrm{CC}_{6} \mathrm{H}_{4}, p-\mathrm{O}_{2} \mathrm{NC}_{6} \mathrm{H}_{4}, p-\mathrm{Tol}, 2$-furyl, 2-Naph, 1-Naph, 2-thienyl, $p$ - $\mathrm{MeOC}_{6} \mathrm{H}_{4}, p$ - $\left(\mathrm{NMe}_{2}\right) \mathrm{C}_{6} \mathrm{H}_{4}, m-\mathrm{FC}_{6} \mathrm{H}_{4}, m-\mathrm{ClC}_{6} \mathrm{H}_{4}$, $m-\mathrm{O}_{2} \mathrm{NC}_{6} \mathrm{H}_{4}, m$-Tol, $m$ - $\mathrm{MeOC}_{6} \mathrm{H}_{4}, o-\mathrm{BrC}_{6} \mathrm{H}_{4}$, o-Tol, 4-Br-2- $\mathrm{FC}_{6} \mathrm{H}_{3}, 3,4-\mathrm{Cl}_{2} \mathrm{C}_{6} \mathrm{H}_{3}$, $3,4-\mathrm{Me}_{2} \mathrm{C}_{6} \mathrm{H}_{3}$

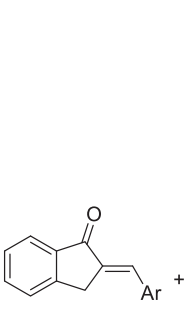

192

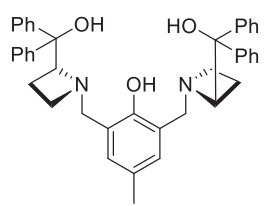

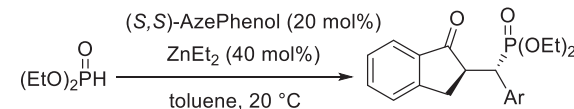

187
$85-99 \%$ $4-74 \%$ de
$99 \%$ ee

$\mathrm{Ar}=\mathrm{Ph}, p-\mathrm{FC}_{6} \mathrm{H}_{4}, p-\mathrm{ClC}_{6} \mathrm{H}_{4}, p-\mathrm{BrC}_{6} \mathrm{H}_{4}, p$-Tol, 2-furyl, 2-Naph, 1-Naph, 2-thienyl, $p-\mathrm{MeOC}_{6} \mathrm{H}_{4}, m-\mathrm{ClC}_{6} \mathrm{H}_{4}, o-\mathrm{MeOC}_{6} \mathrm{H}_{4}, 2,6-\mathrm{Me}_{2} \mathrm{C}_{6} \mathrm{H}_{3}, m$-Tol, $m$ - $\mathrm{MeOC}_{6} \mathrm{H}_{4}, o-\mathrm{Tol}$, $3,4-\mathrm{Cl}_{2} \mathrm{C}_{6} \mathrm{H}_{3}, 3,4-\mathrm{Me}_{2} \mathrm{C}_{6} \mathrm{H}_{3}$, piperonyl

Scheme 64. Phospha-Michael additions of diethyl phosphonate to exocyclic $\alpha, \beta-$ unsaturated benzocyclic ketones arising from 1-tetralones and 1-indanones in the presence of $(R, R)$ - and $(S, S)$-AzePhenols [94]. 


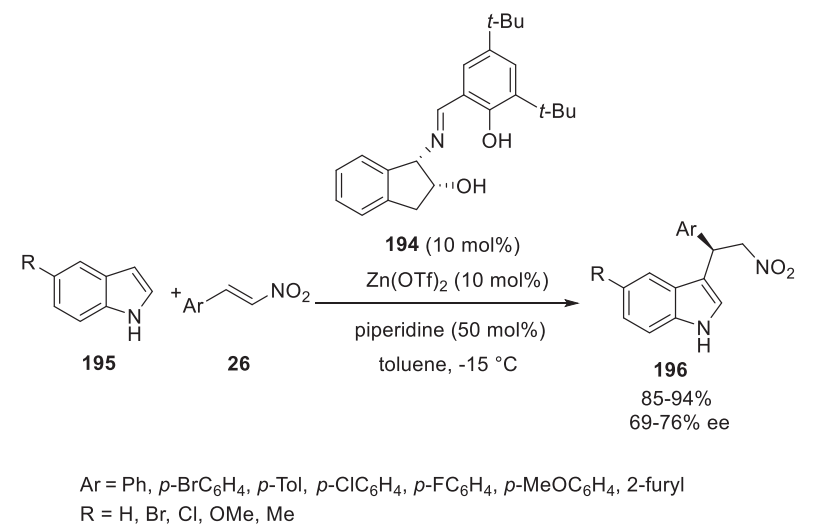

Scheme 65. Friedel-Crafts C3-alkylation of indoles with aromatic nitroalkenes in the presence of a Schiff base ligand [96].

$\beta$, $\beta$-diaryl- $\alpha$-hydroxy ketones 178 in moderate to high yields (43$88 \%$ ), variable diastereoselectivities (20->98\% de) and uniformly excellent enantioselectivities ( $93->99 \%$ ee).

In 2019, the same authors also applied this catalyst system in asymmetric Michael additions of 4-hydroxyl pyrones $\mathbf{1 7 9}$ and 4hydroxycoumarins 180 to aromatic $\beta, \gamma$-unsaturated $\alpha$-ketoesters 181 [91]. In this case, the dinuclear active zinc catalyst was generated from AzePhenol derivative 177 and $\mathrm{ZnEt}_{2}$. The reaction of 4hydroxyl pyrones 179 with $\beta, \gamma$-unsaturated $\alpha$-ketoesters 181 was performed at room temperature in toluene while that of 4hydroxycoumarins 180 occurred in dichloromethane at $0{ }^{\circ} \mathrm{C}$ (Scheme 61). The corresponding chiral products 182 and $\mathbf{1 8 3}$ were respectively formed in good to quantitative yields (63-99\% and 68-96\%, respectively) and good to high enantioselectivities (8394\% ee and 72-90\% ee, respectively). This novel simple methodology offered a direct access to various bioactive products.

The first enantioselective conjugate addition of butenolides to chromones $(\mathrm{X}=\mathrm{O})$ and derivatives was disclosed in 2019 by Trost et al. (Scheme 62) [92]. The process was catalyzed by 10 or $15 \mathrm{~mol} \%$ of dinuclear zinc complex derived from (S,S)-ProPhenol and $\mathrm{ZnEt}_{2}$ in THF at $-10^{\circ} \mathrm{C}$ or room temperature. Variously substituted chromones but also a thiochromone $(X=S)$ and a protected quinolone $(X=N C b z) 184$ reacted smoothly with differently substituted butenolides 185 to give the corresponding chiral lactones 186 in moderate to excellent yields (31-98\%), diastereoselectivities (50->94\% de) combined with uniformly high enantioselectivities (84-98\% ee).

Earlier in 2017, an asymmetric phospha-Michael addition of diethyl phosphite 187 to $\alpha, \beta$-unsaturated carbonyl compounds, such as aryl-substituted $\alpha, \beta$-unsaturated $N$-acylpyrroles $\mathbf{1 8 8}$, cat-

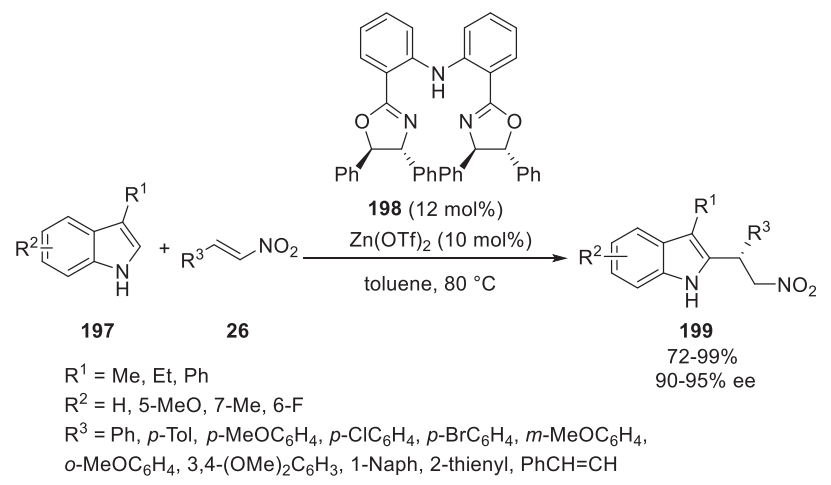

Scheme 66. Friedel-Crafts C2-alkylation of 3-substituted indoles with nitroalkenes in the presence of a bisoxazoline ligand [97].

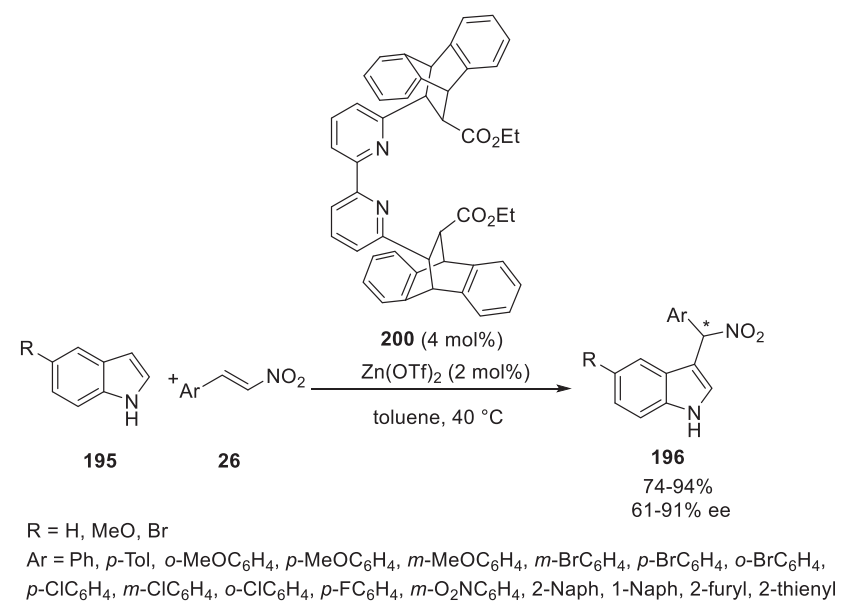

Scheme 67. Friedel-Crafts C3-alkylation of indoles with aromatic nitroalkenes in the presence of a bipyridine ligand [98].

alyzed by a dinuclear zinc catalyst in situ generated from $20 \mathrm{~mol}$ $\%$ of $(S, S)$-Azephenol and $40 \mathrm{~mol} \%$ of $\mathrm{ZnEt}_{2}$ was developed by Wang et al. (Scheme 63) [93]. The reaction performed in toluene at $20^{\circ} \mathrm{C}$ provided a wide range chiral phosphonate-containing products 189 in moderate to good yields (33-69\%) and generally excellent enantioselectivities (91-99\% ee). In only one case of substrate bearing a methoxy group at the ortho-position of the phenyl ring, the reaction provided a much lower enantioselectivity (57\% ee).

The first asymmetric phospha-Michael addition of diethyl phosphonate to exocyclic $\alpha, \beta$-unsaturated benzocyclic ketones arising from 1-tetralones and 1-indanones was reported by Wang and Hua, in 2018 (Scheme 64) [94]. Indeed, the reaction of 1tetralone derivatives 190 with diethyl phosphonate 187, catalyzed by a combination of $40 \mathrm{~mol} \%$ of $\mathrm{ZnEt}_{2}$ with $20 \mathrm{~mol} \%$ of $(R, R)-$ AzePhenol, afforded the corresponding chiral organophosphate products 191 exhibiting an 1-indanone skeleton as mixtures of diastereomers $\left(4-54 \%\right.$ de) with high $\left(\mathrm{R}^{1}=\mathrm{Ph}\right)$ yields $(80-99 \%)$ and enantioselectivities (80-99\% ee). On the other hand, the Michael addition of diethyl phosphonate 187 to 1-indanone

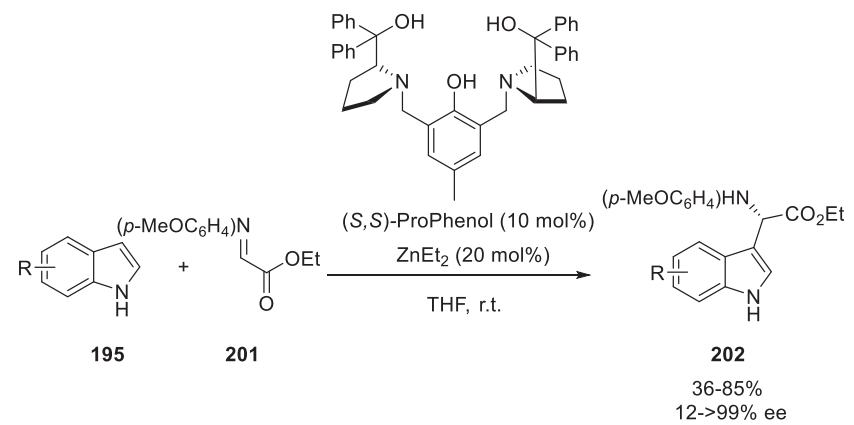

$\mathrm{R}=\mathrm{H}, 4-\mathrm{F}, 4-\mathrm{Cl}, 4-\mathrm{Br}$, 4-MeO, 4-OBoc, 4-OAc, 4-Ph, 5- $\mathrm{NO}_{2}$, 5- $\mathrm{F}, 5-\mathrm{Cl}$ 5-Br, 5-Me, 5-OMe, 6- F, 6-Cl, 6-Br, 6-Me, 6- $\mathrm{CO}_{2} \mathrm{Me}, 6-\mathrm{Me}, 7-\mathrm{Me}, 7-\mathrm{Cl}$

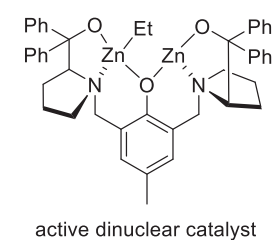

$\mathrm{EtZn}_{2}((S, S)$-ProPhenol)

Scheme 68. Friedel-Crafts C3-alkylation of indoles with a protected ethyl glyoxylate imine in the presence of $(S, S)$-ProPhenol [99]. 

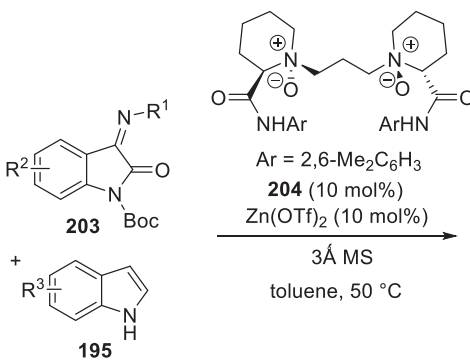

$\mathrm{Ar}=2,6-\mathrm{Me}_{2} \mathrm{C}_{6} \mathrm{H}_{3}$
$204(10 \mathrm{~mol} \%)$ $\mathrm{Zn}(\mathrm{OTf})_{2}(10 \mathrm{~mol} \%)$

$3 \hat{A} \mathrm{MS}$

toluene, $50^{\circ} \mathrm{C}$

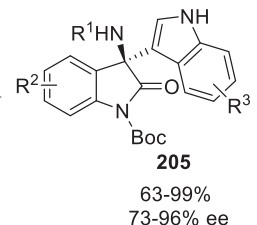

$\mathrm{R}^{1}=\mathrm{Boc}, \mathrm{CO}_{2} \mathrm{Et}$

$\mathrm{R}^{2}=\mathrm{H}, 5-\mathrm{F}, 5-\mathrm{Cl}, 6-\mathrm{Cl}, 5-\mathrm{Br}, 6-\mathrm{Br}, 5-\mathrm{I}, 5,6-\mathrm{F}_{2}, 5-\mathrm{Me}, 5-\mathrm{CF}_{3} \mathrm{O}, 5-\mathrm{MeO}, 7-\mathrm{Me}$

$\mathrm{R}^{3}=5-\mathrm{F}, 5-\mathrm{Cl}, 6-\mathrm{Cl}, 5-\mathrm{Br}, 6-\mathrm{Br}, 5-\mathrm{Me}, 6-\mathrm{Me}, 5-\mathrm{OMe}, 6-\mathrm{OMe}, 7-\mathrm{Me}, 2-\mathrm{Me}$

Scheme 69. Friedel-Crafts $\mathrm{C} 3$-alkylation of indoles with isatin-derived ketimines in the presence of a $N, N^{\prime}$-dioxide ligand [100].

derivatives 192 were performed in the presence of enantiomeric ligand $(S, S)$-AzePhenol, leading to the corresponding enantiopure phosphates 193 (99\% ee) in excellent yields (85-99\%) albeit as diastereomeric mixtures (4-74\% de).

\section{Friedel-Crafts reactions}

The first enantioselective zinc-catalyzed Friedel-Crafts reaction was described by Zhou et al., in 2006 [95]. It involved indoles and nitrostyrene as substrates, being the two most studied partners in the asymmetric Friedel-Crafts reaction. The reaction occurred at the C3-position of indoles in the presence of a chiral bisoxazoline ligand with enantioselectivities of up to $90 \%$ ee. Ever since, other types of ligands have been successfully applied to this type of transformations. For example, chiral multidentate Schiff base ligand 194 was applied in 2015 by Bhanage et al. at $10 \mathrm{~mol} \%$ of catalyst loading in combination of $10 \mathrm{~mol} \%$ of $\mathrm{Zn}(\mathrm{OTf})_{2}$ in toluene at $-15{ }^{\circ} \mathrm{C}$ to promote the same Friedel-Crafts reaction (Scheme 65) [96]. Indeed, unprotected indoles $\mathbf{1 9 5}$ reacted with aromatic nitroalkenes $\mathbf{2 6}$ in the presence of piperidine as an additive to give the corresponding chiral indoles 196 in high yields (85-94\%) and good enantioselectivities (69-76\% ee).

Generally, Friedel-Crafts alkylations of indoles occur on the more nucleophilic C3 position of indoles. On the other hand, Frie-

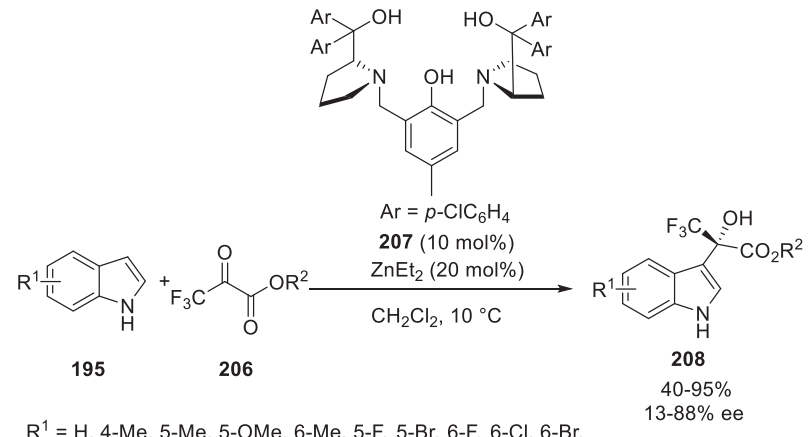

年, $13-88 \%$ $5-\mathrm{NO}_{2}, 6-\mathrm{CO}_{2} \mathrm{Me}, 2-\mathrm{Me}, 2-\mathrm{Ph}$ $\mathrm{R}^{2}=\mathrm{Me}, \mathrm{Et}$

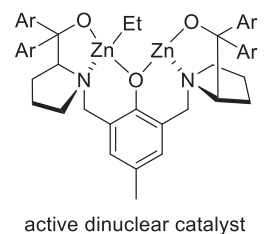

Scheme 70. Friedel-Crafts C3-alkylation of indoles with trifluoromethyl pyruvates in the presence of a ProPhenol derivative ligand [101].
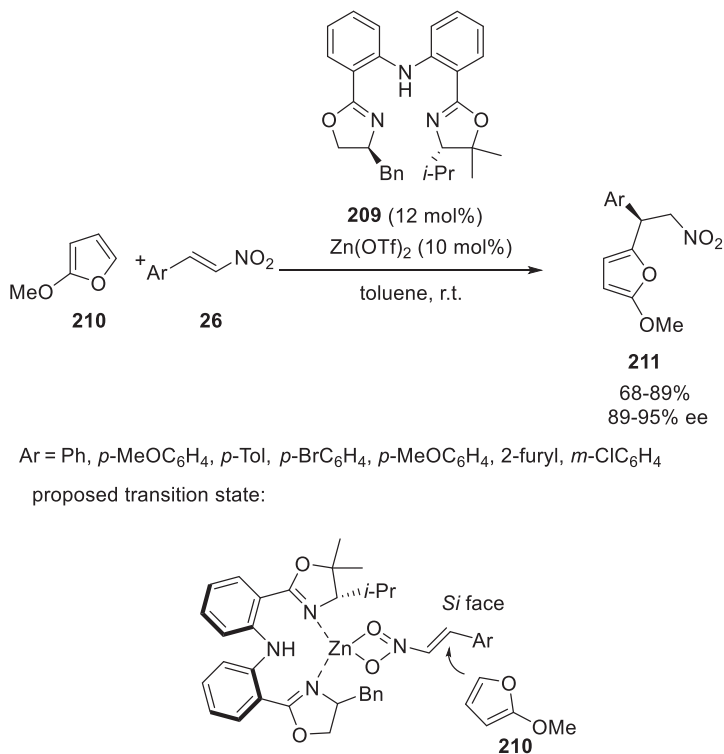

Scheme 71. Friedel-Crafts reaction of 2-methoxyfuran with aromatic nitrostyrenes in the presence of a bisoxazoline ligand [102].

del-Crafts reaction occurring at the less reactive $\mathrm{C} 2$ position of indoles to deliver biologically potential chiral indoles bearing C2benzylic stereocenters remain rare. To fill this gap, Jia et al. reported in 2016 an enantioselective Friedel-Crafts C2-alkylation reaction of 3-substituted indoles 197 with nitroalkenes 26 catalyzed by a chiral zinc complex derived from bisoxazoline ligand 198 [97]. As illustrated in Scheme 66, the process furnished chiral indole derivatives 199 bearing C2-benzylic stereogenic centers in

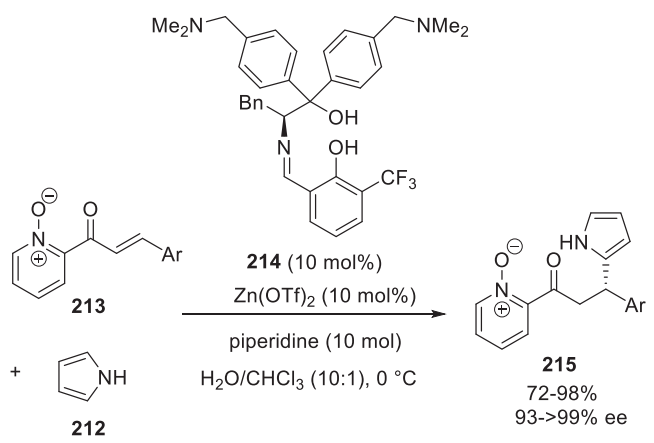

$\mathrm{Ar}=\mathrm{Ph}, p$-Tol, $p-\mathrm{MeOC}_{6} \mathrm{H}_{4}, p-\mathrm{FC}_{6} \mathrm{H}_{4}, p-\mathrm{ClC}_{6} \mathrm{H}_{4}, p-\mathrm{BrC}_{6} \mathrm{H}_{4}, p-\mathrm{F}_{3} \mathrm{CC}_{6} \mathrm{H}_{4}$ $p-\mathrm{O}_{2} \mathrm{NC}_{6} \mathrm{H}_{4}, m$-Tol, $m-\mathrm{ClC}_{6} \mathrm{H}_{4}, m-\mathrm{O}_{2} \mathrm{NC}_{6} \mathrm{H}_{4}, 3,4-(\mathrm{MeO})_{2} \mathrm{C}_{6} \mathrm{H}_{3}, 2-\mathrm{Naph}$, 2-furyl, 2-thienyl

proposed transition state:

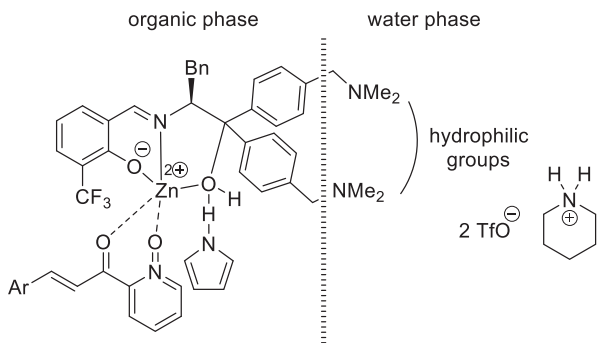

Scheme 72. Friedel-Crafts reaction of pyrrole with 2-enoyl-pyridine $\mathrm{N}$-oxides in the presence of a Schiff base ligand in aqueous media [103]. 
high yields (72-99\%) and excellent enantioselectivities (9095\% ee).

Later in 2019, Ramanathan et al. reported the first use of a chiral bipyridine ligand in asymmetric Friedel-Crafts C3-alkylation of unprotected indoles 195 with aromatic nitroalkenes 26 [98]. Indeed, the use of only $4 \mathrm{~mol} \%$ of chiral bipyridine ligand $200 \mathrm{com}-$ bined with $2 \mathrm{~mol} \%$ of $\mathrm{Zn}(\mathrm{OTf})_{2}$ allowed in toluene at $40{ }^{\circ} \mathrm{C}$ a range of chiral alkylated indole derivatives 196 to be synthesized in good to high yields (74-94\%) and moderate to high ee values (61$91 \%$ ee), as shown in Scheme 67.

Earlier in 2016, asymmetric Friedel-Crafts reaction of unprotected indoles 195 were developed by Wang and Hua by using protected ethyl glyoxylate imine $\mathbf{2 0 1}$ as electrophile in the presence of Trost's dinuclear zinc complex derived from (S,S)-ProPhenol [99]. A series of 3-indolylglycine derivatives $\mathbf{2 0 2}$ were formed in low to excellent enantioselectivities ( $12->99 \%$ ee) using $10 \mathrm{~mol} \%$ of catalyst loading in THF at room temperature. As shown in Scheme 68, a wide range of substituents on the phenyl ring of indoles were compatible, providing the corresponding products $\mathbf{2 0 2}$ in moderate to high yields (36-85\%).

An enantioselective Friedel-Crafts reaction of unprotected indoles 195 with $\mathrm{N}$-protected isatin-derived ketimines 203 was reported by Feng et al. in 2016 on the basis of an asymmetric catalysis with a chiral zinc complex in situ generated from $10 \mathrm{~mol} \%$ of $\mathrm{Zn}(\mathrm{OTf})_{2}$ and the same quantity of chiral $N, N^{\prime}$-dioxide ligand 204 (Scheme 69) [100]. A series of chiral 3-indolyl-3-aminooxindoles 205 containing a tetrasubstituted stereocenter were obtained in good to high yields (63-99\%) and enantioselectivities (73$96 \%$ ee). It must be noted that generally the enantioselectivities were found excellent (90-96\% ee) excepted in the reactions of 7methyl-substituted ketimine and 2-methyl indole which afforded the corresponding products with 74 and $73 \%$ ee, respectively.

In 2018, Wang and Yang disclosed the asymmetric FriedelCrafts reaction of unprotected indoles 195 with trifluoromethyl pyruvates 206 (Scheme 70) [101]. Chiral ProPhenol derivative 207 was employed at $10 \mathrm{~mol} \%$ of catalyst loading in combination with $20 \mathrm{~mol} \%$ of $\mathrm{ZnEt}_{2}$ in dichloromethane as solvent at $10^{\circ} \mathrm{C}$. The corresponding in situ generated chiral dinuclear complex promoted the alkylation, yielding chiral trifluoromethyl alcohol and indole-containing biological compounds $\mathbf{2 0 8}$ in moderate to excellent yields (40-95\%) and variable enantioselectivities (13-88\% ee).

Earlier in 2015, these reactions were also investigated by Guiry et al. by using novel $(S)$-valine-derived bisoxazoline ligands, providing the alkylated products in moderate enantioselectivities ( $\leq 74 \%$ ee) [102]. However, when one of these ligands, namely 209, was applied in the asymmetric Friedel-Crafts reaction of aromatic nitroalkenes 26 with 2-methoxyfuran 210, the corresponding products $\mathbf{2 1 1}$ were formed in much better enantioselectivities

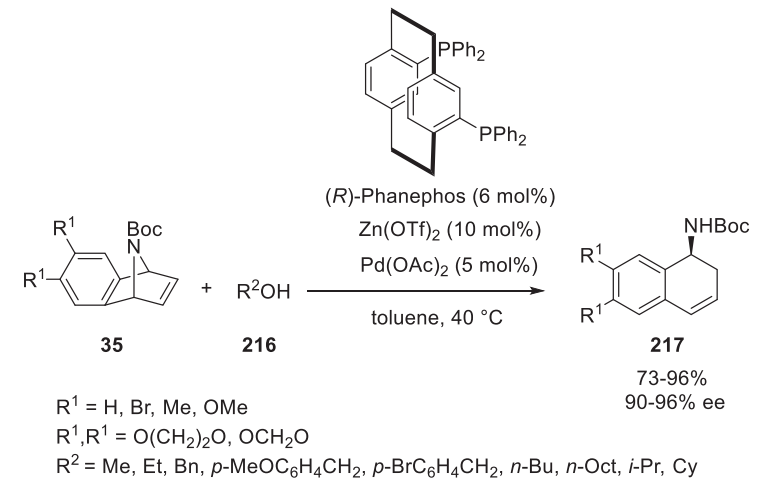

Scheme 73. Transfer hydrogenation of azabenzonorbornadienes with alcohols in the presence of a dual $\mathrm{Zn} / \mathrm{Pd}$ catalyst system [104].

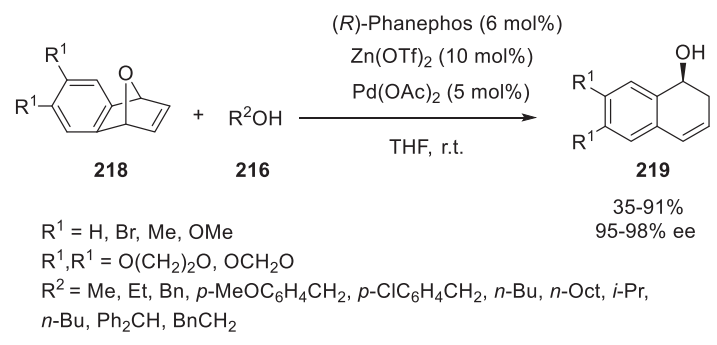

Scheme 74. Transfer hydrogenation of oxabenzonorbornadienes with alcohols in the presence of a dual $\mathrm{Zn} / \mathrm{Pd}$ catalyst system [105].

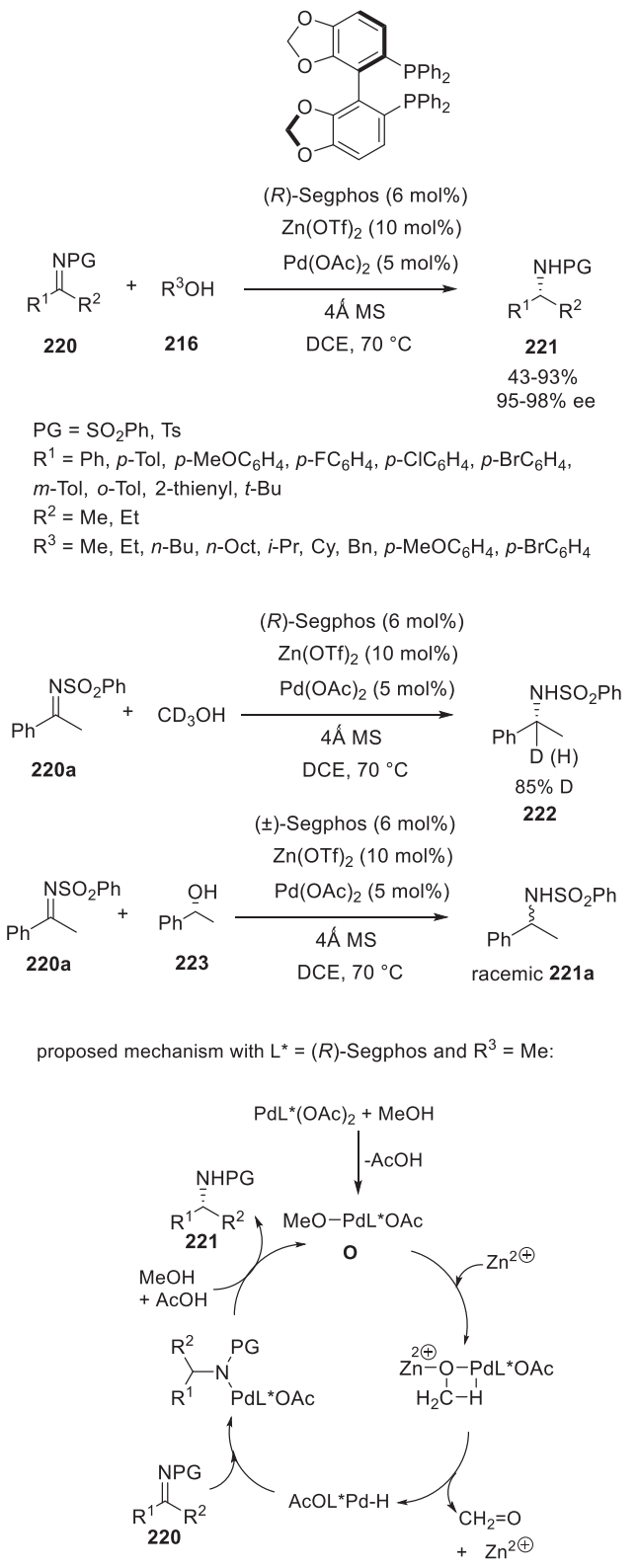

Scheme 75. Transfer hydrogenations of $\mathrm{N}$-sulfonylimines with alcohols in the presence of a dual Zn/Pd catalyst system and (R)-Segphos [106].

(89-95\% ee) combined with high yields (68-89\%), as shown in Scheme 71 . The stereoselectivity of the reaction can be explained by the transition state depicted in this Scheme in which the two oxazolinyl nitrogen atoms are coordinated to the zinc center and 
the nitro group of the nitroalkene coordinates through the two oxygen atoms to the Lewis acid center. This activates the nitroalkene to undergo a nucleophilic attack by the electron-rich arene. The attack occurs preferentially from the Si face due to the influence of the substituents on each of the oxazoline rings, providing chiral product 211.

Examples of asymmetric Friedel-Crafts alkylations performed in aqueous media remain rare. In 2020, a highly enantioselective Friedel-Crafts reaction of pyrroles $\mathbf{2 1 2}$ with 2-enoyl-pyridine $\mathrm{N}$ oxides 213 was achieved in a 10:1 mixture of water/chloroform as solvent by Wang and Yang (Scheme 72) [103]. The process was promoted by a chiral catalyst in situ generated from $10 \mathrm{~mol}$ $\%$ of $\mathrm{Zn}(\mathrm{OTf})_{2}$ and $10 \mathrm{~mol} \%$ of chiral multidentate Schiff base ligand 214 at $0{ }^{\circ} \mathrm{C}$, allowing a range of chiral multifunctionalized FriedelCrafts products $\mathbf{2 1 5}$ to be synthesized in uniformly excellent enantioselectivities (93->99\% ee) and high yields (72-98\%). The authors proposed a transition state (Scheme 72) in which the two hydrophilic dimethylamino groups of the chiral ligand were dissolved in the water phase, while the 2-enoylpyridine $\mathrm{N}$-oxide was activated through coordination to zinc in the catalyst complex, and the $\mathrm{NH}$ group of pyrrole served as a hydrogen bond-donating group to direct the alkylation at the $\mathrm{Si}$ face of the 2-enoylpyridine $N$-oxide, leading to chiral product 215.

\section{Reduction reactions}

\section{1. (Transfer) hydrogenation reactions}

In 2016, a dual catalysis based on Zn/Pd was employed by Fan et al. in an enantioselective transfer hydrogenation of azaben-

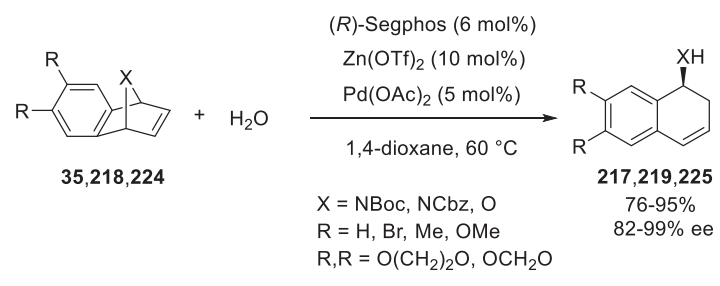

proposed mechanism (with $\mathrm{X}=\mathrm{NBoc}, \mathrm{R}=\mathrm{H}, \mathrm{L}^{*}=(R)$-Segphos):

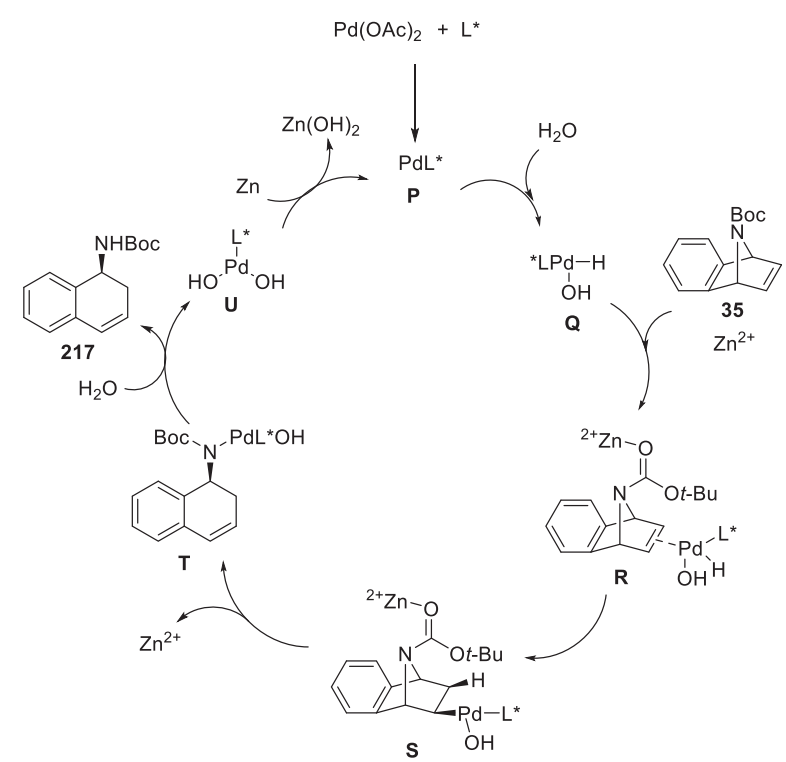

Scheme 76. Transfer hydrogenation of oxa- and azabenzonorbornadienes with water in the presence of $(R)$-Segphos [107]. zonorbornadienes $\mathbf{3 5}$ with alcohols 216 as reductants [104]. Good chemo-, regio-, and enantioselectivities were obtained when this reaction was catalyzed by a combination of $10 \mathrm{~mol} \%$ of $\mathrm{Zn}(\mathrm{OTf})_{2}$, $6 \mathrm{~mol} \%$ of $(R)$-Phanephos as ligand, and $5 \mathrm{~mol} \%$ of $\mathrm{Pd}(\mathrm{OAc})_{2}$ in toluene at $40{ }^{\circ} \mathrm{C}$ (Scheme 73). A range of aliphatic alcohols were compatible, leading to chiral ring-opened amines 217 in uniformly excellent ee values (90-96\% ee) and good to high yields (73-96\%). The authors demonstrated that the alcohol partner was the hydrogen source. It must be noted that this work could also appear in Section 12 dealing with ring-opening reactions.

Later in 2017, the same dual $\mathrm{Zn} / \mathrm{Pd}$ catalysis was applied to develop related asymmetric transfer hydrogenation of oxabenzonorbornadienes 218 with alcohols 216 (Scheme 74) [105]. Indeed, in the presence of the same quantities of $\mathrm{Zn}(\mathrm{OTf})_{2}$, $(R)$-Phanephos and $\mathrm{Pd}(\mathrm{OAc})_{2}$, a range of primary and secondary alcohols 216 reacted with variously substituted oxabenzonorbornadienes 218 to afford at room temperature in THF as solvent the corresponding almost enantiopure 1,2-dihydronaphth-1-ol products 219 (95-98\% ee) in moderate to high yields (35-91\%). This work could also appear in Section 12 highlighting ringopening reactions.

A related $\mathrm{Zn} / \mathrm{Pd}$ co-catalytic system was successfully employed by the same group in the asymmetric transfer hydrogenation reactions of $\mathrm{N}$-sulfonylimines $\mathbf{2 2 0}$ with alcohols $\mathbf{2 1 6}$ (Scheme 75) [106]. Along with $10 \mathrm{~mol} \%$ of $\mathrm{Zn}(\mathrm{OTf})_{2}$ and $5 \mathrm{~mol} \%$ of $\mathrm{Pd}(\mathrm{OAc})_{2}$, was used $6 \mathrm{~mol} \%$ of $(R)$-Segphos as optimal ligand. Various aliphatic and aromatic alcohols $\mathbf{2 1 6}$ reacted with a range of alkylsulfonylimines 220 in DCE at $70{ }^{\circ} \mathrm{C}$ to give the corresponding almost enantiopure amines 221 (95-98\% ee) in moderate to high yields (43-93\%). To get insight into the mechanism of the reaction, the authors investigated deuterium-labeling experiments. Indeed, the reaction of phenyl $N$-sulfonylimine 220a $\left(R 1=P h, R^{2}=M e\right.$, $\left.\mathrm{PG}=\mathrm{SO}_{2} \mathrm{Ph}\right)$ with $\mathrm{CD}_{3} \mathrm{OH}\left(\mathrm{R}^{3}=\mathrm{CD}_{3}\right)$, resulted in the formation of the corresponding product $\mathbf{2 2 2}$ incorporating $85 \%$ deuterium at the benzylic position (Scheme 75). Furthermore, performing the reaction of the same phenyl $N$-sulfonylimine 220a with enantiopure (R)-1-phenyl ethanol 223 in the presence of racemic Segphos as ligand, resulted in the formation of the corresponding racemic product 221a. On the basis of these results, the authors assumed that the process was initiated from the $[\mathrm{Pd}-\mathrm{H}]$ hydride intermediate $\mathbf{O}$ generated through dehydrogenation of the alcohol reagent rather than through metal alkoxide mechanism.

Involving the same dual catalyst system in 1,4-dioxane as solvent, these authors also accomplished asymmetric transfer hydrogenation of azabenzonorbornadienes 35, 224 and oxabenzonorbornadienes $\mathbf{2 1 8}$ by using water as the sole hydrogen source

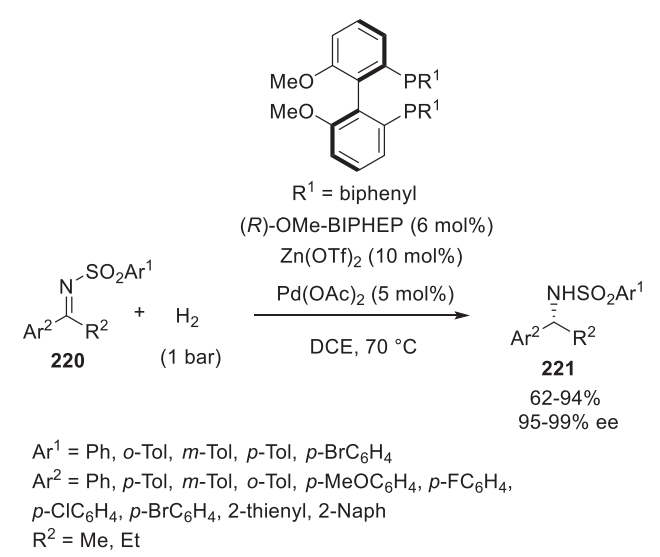

Scheme 77. Hydrogenation of $N$-sulfonylimines in the presence of $(R)$-OMe-BIPHEP [108]. 


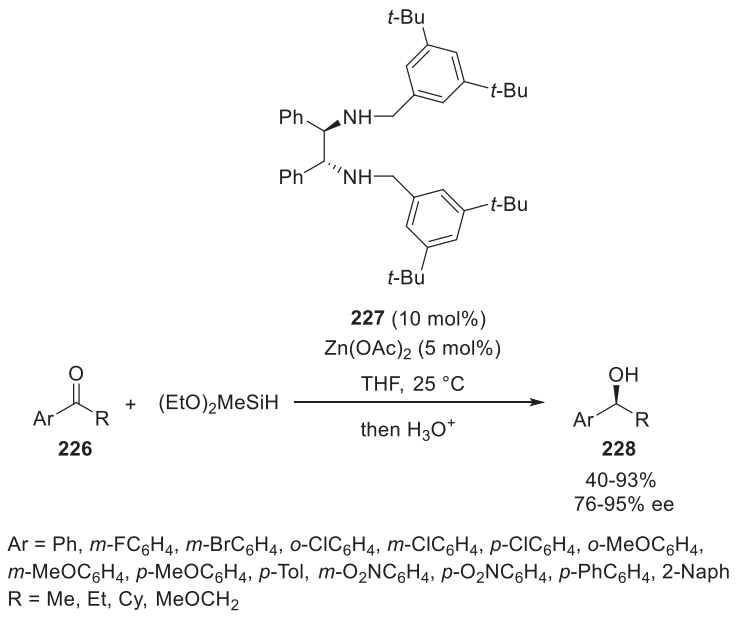

Scheme 78. Hydrosilylation of aromatic ketones in the presence of a 1,2-diamine ligand [110].

[107]. As depicted in Scheme 76, a range of chiral 1,2dihydronaphthalenes 217, 219, 225 were synthesized in both high yields (76-95\%) and ee values (82-99\% ee). Based on deuteriumlabeling experiments, the mechanism depicted in Scheme 76 was proposed. It began with the coordination of $(R)$-Segphos to Pd $(\mathrm{OAc})_{2}$ to generate chiral palladium catalyst $\mathbf{P}$. Then, the oxidative addition of water to complex $\mathbf{P}$ gave intermediate $\mathbf{Q}$ which further coordinated the azabenzonorbornadiene substrate and zinc ion to provide intermediate $\mathbf{R}$. The subsequent insertion of the alkene to the $\mathrm{Pd}-\mathrm{H}$ bond led to intermediate $\mathbf{S}$. Next, the $\beta$-elimination of nitrogen afforded ring-opened intermediate $\mathbf{T}$, the hydration of which provided the final product. Finally, the reduction of $\mathbf{U}$ by zinc metal regenerated chiral palladium catalyst $\mathbf{P}$. This work could also appear in Section 12 dealing with ring-opening reactions.

In 2018, Fan and Laishram described an efficient synthesis of chiral sultams 221 employing $\mathrm{Zn}(\mathrm{OTf})_{2}$ and $\mathrm{Pd}(\mathrm{OAc})_{2}$ as cocatalysts, evolving through asymmetric hydrogenation of a range of $\mathbf{N}$-sulfonylimines $\mathbf{2 2 0}$ under ambient pressure of hydrogen [108]. As illustrated in Scheme 77, the reaction employed $(R)$ OMe-BIPHEP as optimal ligand, which allowed a wide range of almost enantiopure amines 221 (95-99\% ee) to be prepared in good to high yields (62-94\%).

\subsection{Hydrosilylations of carbonyl compounds and derivatives}

The asymmetric hydrosilylation of ketones followed by hydrolysis constitutes a direct route to chiral alcohols [109]. So far, most of chiral zinc catalysts employed in these transformations have been prepared from $\mathrm{ZnEt}_{2}$. In contrast, hydrosilylation catalyzed by inorganic $\mathrm{Zn}$ salts, such as cheap $\mathrm{Zn}(\mathrm{OAc})_{2}$, is still undeveloped. To fill this gap, Mlynarski et al. disclosed in 2015 the first example of highly enantioselective hydrosilylation of aromatic ketones $\mathbf{2 2 6}$ promoted by a chiral complex in situ generated from $5 \mathrm{~mol} \%$ of $\mathrm{Zn}$ $(\mathrm{OAc})_{2}$ and $10 \mathrm{~mol} \%$ of chiral 1,2-diamine ligand 227 (Scheme 78) [110]. The reaction carried out in THF at $25^{\circ} \mathrm{C}$ led to the formation, after subsequent hydrolysis of the formed intermediate silyl ethers, to chiral alcohols 228 in good to high yields (40-93\%) and high enantioselectivities (76-95\% ee). The catalyst system was compatible with a broad range of aryl ketones, providing better enantioselectivities than those obtained by using previously investigated diethylzinc complexes.

With the aim of finding even greener reaction conditions for these hydrosilylations, the same authors developed in 2016 a more

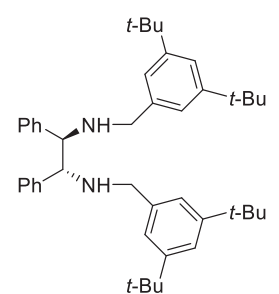

$227(0.1 \mathrm{~mol} \%)$

$\mathrm{Zn}(\mathrm{OAc})_{2}(0.05 \mathrm{~mol} \%)$

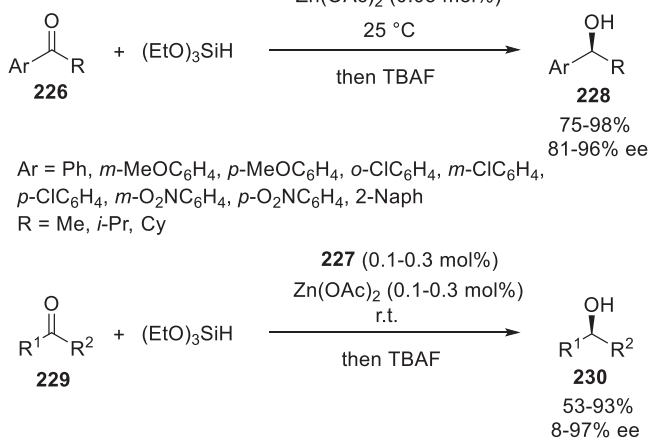

$\mathrm{R}^{1}=(E)-\mathrm{PhCH}=\mathrm{CH},(E)-\mathrm{PhCH}=\mathrm{CMe},(E)-\mathrm{PhCH}=\mathrm{CPh},(E)-\mathrm{PhCH}=\mathrm{CBn}$ $(E)-\mathrm{BnCH}=\mathrm{CMe}, \mathrm{o}-\mathrm{Tol}, \mathrm{o}-\mathrm{ClC}_{6} \mathrm{H}_{4}, \mathrm{PhC}=\mathrm{C},(E)-\mathrm{PhCH}=\mathrm{CH}-\mathrm{CH}=\mathrm{CH}$, (E) $-\mathrm{PhCH}=\mathrm{CH}-\mathrm{CH}=\mathrm{CMe}$

$\mathrm{R}^{2}=\mathrm{Me}, \mathrm{Et}, \mathrm{Ph}$

$$
\begin{aligned}
& \mathrm{Ph}_{Y} \mathrm{NHBn}
\end{aligned}
$$

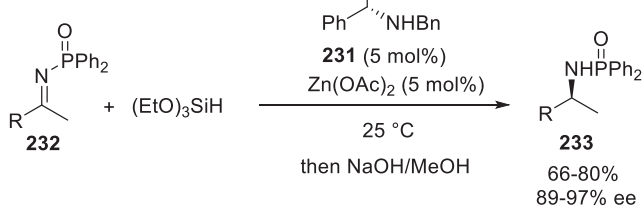

$\mathrm{R}=\mathrm{Ph}, p-\mathrm{Tol}, p-\mathrm{BrC}_{6} \mathrm{H}_{4}, 2-\mathrm{Naph}, 2$-furyl, $(E)-\mathrm{PhCH}=\mathrm{CH},(E)-\mathrm{PhCH}=\mathrm{CMe}$

proposed transition state in the reaction of aryl ketones:

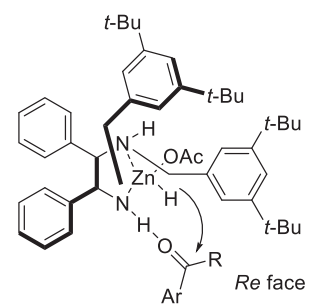

Scheme 79. Hydrosilylations of conjugated ketones and $\mathrm{N}$-diphenylphosphinoylimines in the presence of 1,2-diamine ligands under solvent-free conditions [111].

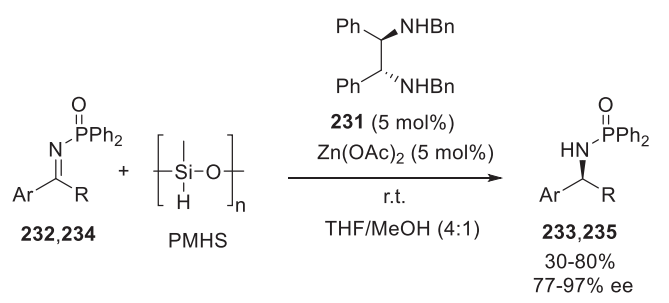

$\mathrm{Ar}=\mathrm{Ph}, p-\mathrm{Tol}, p-\mathrm{MeOC}_{6} \mathrm{H}_{4}, p-\mathrm{BrC}_{6} \mathrm{H}_{4}, p-\mathrm{ClC}_{6} \mathrm{H}_{4}, p-\mathrm{IC}_{6} \mathrm{H}_{4}, m-\mathrm{MeOC}_{6} \mathrm{H}_{4}$ $m$ - $\mathrm{BrC}_{6} \mathrm{H}_{4}, \mathrm{o}-\mathrm{MeOC}_{6} \mathrm{H}_{4}, \mathrm{O}-\mathrm{ClC}_{6} \mathrm{H}_{4}, 2$ - Naph, 1-Naph, 2-furyl $\mathrm{R}=\mathrm{Me}, \mathrm{Et}$

Scheme 80. Hydrosilylation of $N$-diphenylphosphinoylimines with PMHS in the presence of a 1,2-diamine ligand [112].

convenient protocol based on the use of unprecedented very low catalyst loadings and under solvent-free conditions [111]. Indeed, the enantioselective hydrosilylation of aromatic ketones $\mathbf{2 2 6}$ could 


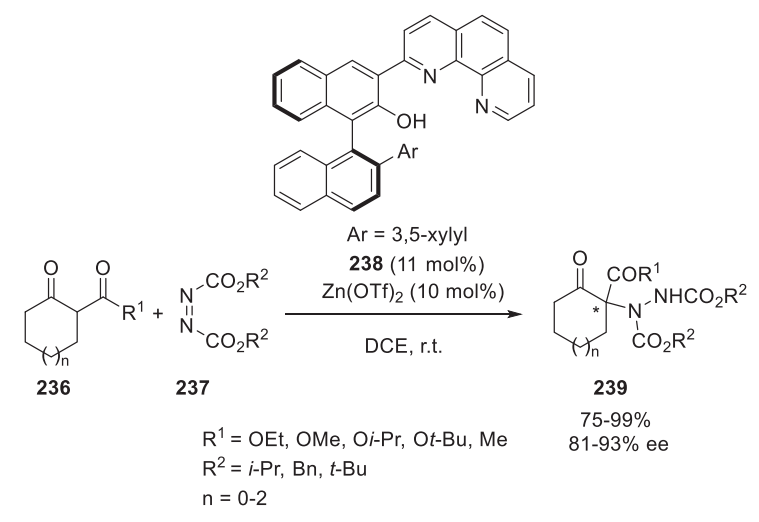

Scheme 81. $\alpha$-Amination of $\beta$-ketocarbonyl compounds with dialkyl azodicarboxylates in the presence of a phenanthroline ligand [116].

be realized in the presence of as low as $0.05 \mathrm{~mol} \%$ of $\mathrm{Zn}(\mathrm{OAc})_{2}$ and $0.1 \mathrm{~mol} \%$ of the same chiral 1,2-diamine ligand 227 at $25{ }^{\circ} \mathrm{C}$ under neat conditions (Scheme 79). This green and remarkable process employed (EtO) $)_{3} \mathrm{SiH}$ as silane and provided, after subsequent silyl deprotection by treatment with TBAF, a range of aromatic chiral alcohols 228 in both uniformly high yields (75-98\%) and ee values (81-96\% ee). The catalyst system could also be applied to the asymmetric hydrosilylation of more challenging unsaturated ketones 229, which afforded in the presence of $0.1-0.3 \mathrm{~mol} \%$ of the same chiral zinc catalyst the corresponding alcohols 230 in good to high yields (53-93\%) and variable enantioselectivities (8$97 \%$ ee). Moreover, in the presence of a combination of $5 \mathrm{~mol} \%$ of related chiral 1,2-diamine ligand $\mathbf{2 3 1}$ with the same quantity of $\mathrm{Zn}(\mathrm{OAc})_{2}$ under solvent-free conditions, various conjugated $\mathrm{N}$ -
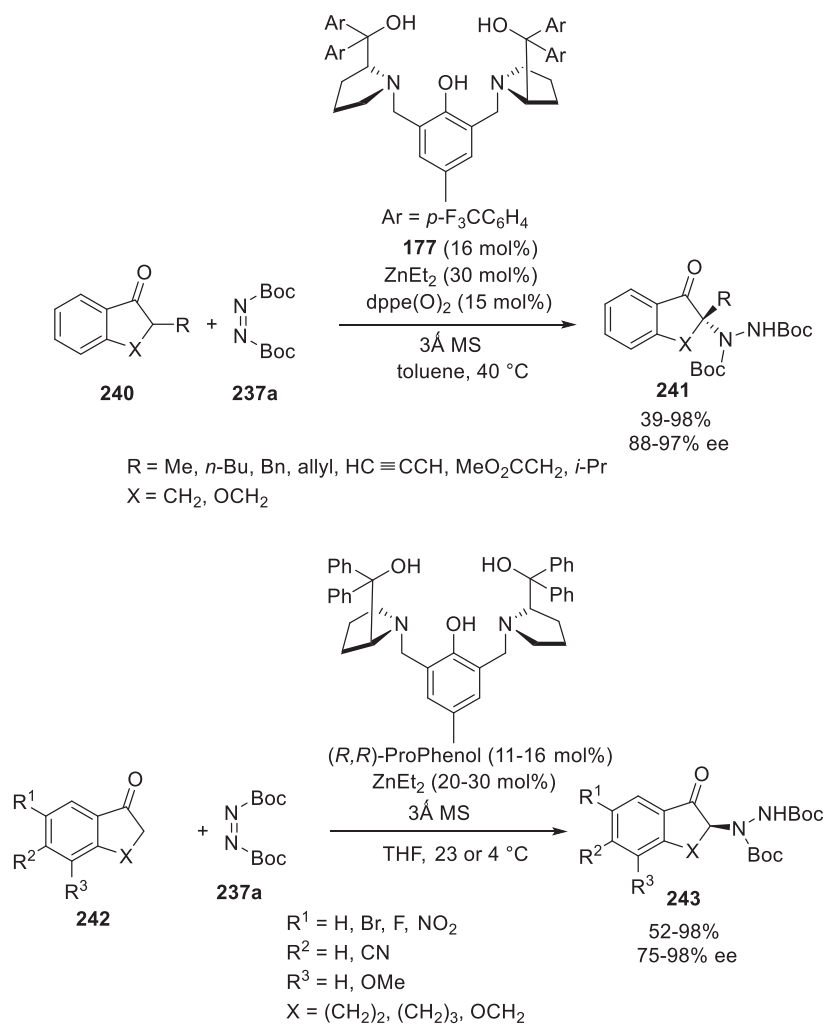

Scheme 82. $\alpha$-Aminations of branched and unbranched aromatic ketones with ditert-butyl azodicarboxylate in the presence of $(R, R)$-ProPhenol (derivative) ligands [117]. diphenylphosphinoylimines 232 could be reduced into the corresponding chiral amines 233 with good yields (66-80\%) and uniformly high enantioselectivities (89-97\% ee). A possible transition state for the hydrosilylation of aryl ketones $\mathbf{2 2 6}$ in the presence of ligand $\mathbf{2 2 7}$ is depicted in Scheme 79. It involves the formation of a hydrogen bond between the amino group of the active $\mathrm{Zn}-\mathrm{H}$ catalyst and the carbonyl group of the ketone. The relative orientation of the substrate is determined by steric repulsion between the bulky 3,5-di-tert-butylbenzene moiety of the ligand and the larger substituent adjacent to the carbonyl group of the ketone substrate. In this favored approach, zinc hydride attacks the ketone from the Re face, which results in the formation of chiral product 228.

The asymmetric hydrosilylation of a range of $\mathrm{N}$ diphenylphosphinoylimines 232, 234 catalyzed by $5 \mathrm{~mol} \%$ of the same catalyst system (ligand 231) was also performed by using inexpensive polymethylhydrosilane (PMHS) as hydrosilane in a 4:1 mixture of THF and methanol as solvent [112]. At room temperature, a series of chiral (hetero)aromatic $N$ diphenylphosphinoylamines 233, 235 were synthesized in low to

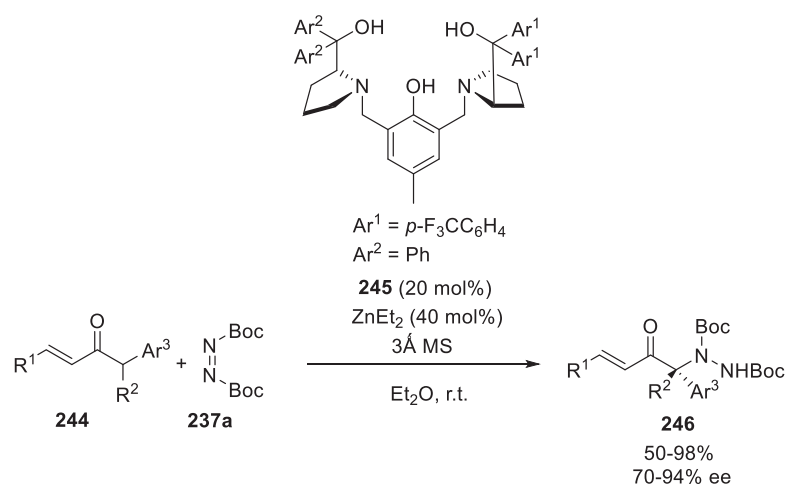

$\mathrm{R}^{1}=\mathrm{Ph}, p-\mathrm{FC}_{6} \mathrm{H}_{4}, p-\mathrm{ClC}_{6} \mathrm{H}_{4}, o-\mathrm{ClC}_{6} \mathrm{H}_{4}, m-\mathrm{MeOC}_{6} \mathrm{H}_{4}, \mathrm{o}-\mathrm{Tol}, 2-\mathrm{Naph}_{2} \mathrm{BnCH}_{2}$, 10 $\mathrm{R}^{2}=\mathrm{Me}$, allyl, $p-\mathrm{F}_{3} \mathrm{CC}_{6} \mathrm{H}_{4}, \mathrm{HC} \equiv \mathrm{CCH}_{2}$

$\mathrm{Ar}^{3}=\mathrm{Ph}, m-\mathrm{ClC}_{6} \mathrm{H}_{4}, p-\mathrm{ClC}_{6} \mathrm{H}_{4}, p-\mathrm{FC}_{6} \mathrm{H}_{4}, o-\mathrm{ClC}_{6} \mathrm{H}_{4}, p$-Tol, $p$ - $(n-\mathrm{Bu}) \mathrm{C}_{6} \mathrm{H}_{4}, 3$-thienyl, 7-MeO-2-Naph

proposed mechanism $\left(\mathrm{R}^{1}=\mathrm{Ar}^{3}=\mathrm{Ph}, \mathrm{R}^{2}=\mathrm{Me}\right)$ :

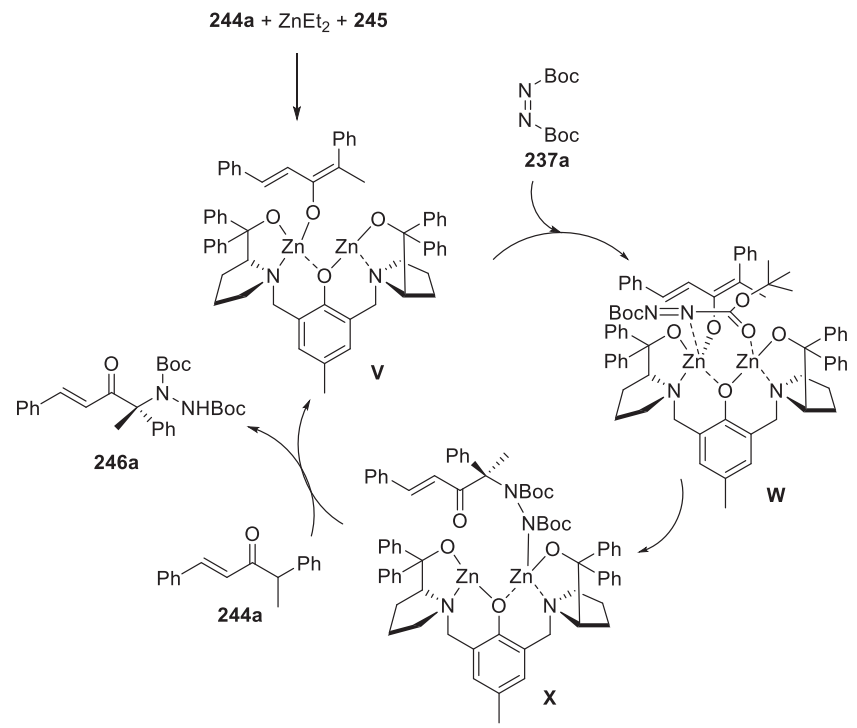

Scheme 83. $\alpha$-Amination of acyclic $\alpha$-branched ketones with di-tert-butyl azodicarboxylate in the presence of a non- $C_{2}$-symmetric ProPhenol derivative ligand [118]. 
good yields (30-80\%) and high ee values (77-97\% ee), as shown in Scheme 80 . In addition, novel chiral $C_{2}$-symmetric bisoxazoline ligands immobilized on mesoporous silica SBA-15 were synthesized by Le Roux et al. in 2015 and further used in the asymmetric hydrosilylation of acetophenone in the presence of $\mathrm{ZnEt}_{2}$ as precatalyst [113]. However, only moderate enantioselectivities ( $\leq 50 \%$ ee) were achieved in these reactions.

\section{1. $\alpha$-Functionalizations of carbonyl compounds}

\section{1. $\alpha$-Aminations}

Chiral $\alpha$-amino acid derivatives are widely present in nature [114]. Among synthetic strategies to reach these important molecules, asymmetric electrophilic $\alpha$-amination of $\beta$-ketocarbonyl compounds is one of the most direct routes [115]. Only very rare versions of these reactions using chiral zinc catalysts have been developed so far. In order to fill this gap, Naganawa and Nishiyama reported in 2015 asymmetric $\alpha$-amination of $\beta$-ketocarbonyl compounds 236 using dialkyl azodicarboxylates 237 as electrophilic nitrogen sources catalyzed by a combination of $10 \mathrm{~mol} \%$ of $\mathrm{Zn}$ $(\mathrm{OTf})_{2}$ and $11 \mathrm{~mol} \%$ of axially chiral phenanthroline ligand 238 (Scheme 81) [116]. The reaction afforded at room temperature by using DCE as solvent the corresponding chiral $\alpha$-amino- $\beta$-ketocar bonyl compounds 239 in both high yields (75-99\%) and enantioselectivities (81-93\% ee). With the aim of extending the scope of the reaction, the authors investigated acyclic $\beta$-ketoesters as substrates albeit without success.

In 2018, Trost et al. reported an asymmetric amination reaction of unactivated aromatic ketones using di-tert-butyl azodicarboxylate 237a as electrophilic nitrogen source [117]. As depicted in Scheme 82, a range of 2-substituted indanones $240\left(\mathrm{X}=\mathrm{CH}_{2}\right)$ reacted with di-tert-butyl azodicarboxylate $\mathbf{2 3 7 a}$ in the presence of $16 \mathrm{~mol} \%$ of a $(S, S)$-ProPhenol derivative $\mathbf{1 7 7}$ as ligand, $30 \mathrm{~mol} \%$ of $\mathrm{ZnEt}_{2}$, and $15 \mathrm{~mol} \%$ of 1,2-bis(diphenylphosphino)ethane (dppe $\left.(\mathrm{O})_{2}\right)$ as additive in toluene at $40{ }^{\circ} \mathrm{C}$ to afford the correspond-

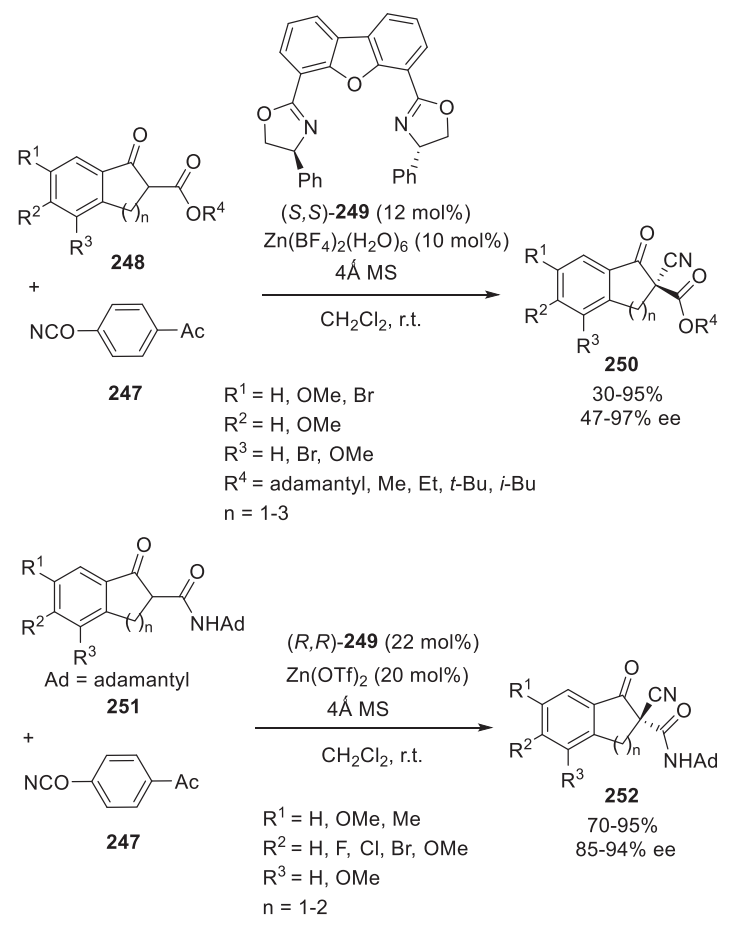

Scheme 84. $\alpha$-Cyanations of $\beta$-ketoesters and $\beta$-ketoamides with $p$-acetylphenylcyanate in the presence of a bisoxazoline ligand [119]. ing chiral hydrazines $\mathbf{2 4 1}$ in moderate to quantitative yields (39$98 \%$ ) and uniformly excellent enantioselectivities (88-97\% ee). Especially, indanones bearing a linear alkyl chain at the 2position provided the best results (77-98\% yield, 90-97\% ee) while the presence of an $i$-propyl group in this position resulted in both lower yield (39\%) and ee value ( $88 \%$ ee). The presence of various functional groups, such as esters, alkenes and terminal alkynes, were tolerated on the alkyl chain (R). Furthermore, a sixmembered aromatic ketone $\left(\mathrm{X}=\mathrm{OCH}_{2}\right)$ was compatible, also providing good results (61\% yield and $92 \%$ ee). Then, the authors employed $(R, R)$-ProPhenol as ligand in a related reaction between di-tert-butyl azodicarboxylate 237a and unbranched 1-tetralones $242\left(\mathrm{X}=\left(\mathrm{CH}_{2}\right)_{2}\right)$, eventually substituted at the 5-, 6- and 7-positions, as nucleophile partners. It yielded the corresponding chiral hydrazines $\mathbf{2 4 3}$ in both high yields (81-98\%) and enantioselectivities (90-96\% ee). The scope of the process was extended to 1-chromanone $\left(\mathrm{X}=\mathrm{OCH}_{2}\right)$ and 1-benzosuberone $\left(\mathrm{X}=\left(\mathrm{CH}_{2}\right)_{3}\right)$ which led to the corresponding products with moderate to high yields (52-98\%) and good to high ee values (75-98\% ee).

Later in 2019, the same authors disclosed the first use of challenging acyclic $\alpha$-branched ketones $\mathbf{2 4 4}$ as nucleophiles in comparable electrophilic hydrazination (Scheme 83) [118]. In this case, the optimal ligand was a non- $C_{2}$-symmetric ProPhenol derivative 245 (20 mol\%) associated to $\mathrm{ZnEt}_{2}$ (40 mol\%) in diethyl ether as solvent. The amination of a range of acyclic $\alpha$-branched ketones $\mathbf{2 4 4}$ with di-tert-butyl azodicarboxylate 237a resulted in the formation of chiral hydrazines $\mathbf{2 4 6}$ in good to quantitative yields (50-98\%) and high enantioselectivities (70-94\% ee). The catalyst system tolerated the presence of electron-donating and electronwithdrawing substituents on the aromatic and heteroaromatic rings of $\mathrm{R}^{1}$. Moreover, an alkyl-substituted substrate $\left(\mathrm{R}^{1}=\mathrm{BnCH}_{2}\right)$ was also compatible, providing the corresponding product in moderate yield (50\%) and good ee value ( $80 \%$ ee). Variously substituted aromatic groups at $\mathrm{Ar}^{3}$ were also tolerated but the lowest enantioselectivity (70\% ee) was obtained in the reaction of an heteroaromatic group $\left(\mathrm{Ar}^{3}=3\right.$-thienyl). Furthermore, substitution at $\mathrm{R}^{2}$ was not limited to methyl group since longer alkyl chains eventually including functional groups, such as alkenes and terminal alkynes, reacted smoothly, however, with lower yields (58-64\%) than those observed with methyl substitution. The resulting hydrazines could be chemoselectively cleaved to the corresponding amines, constituting potential building blocks for medicinal synthesis. To explain the stereochemical outcome of the reaction, the authors proposed the catalytic cycle depicted in Scheme 83. After formation of the initial dinuclear zinc catalyst,

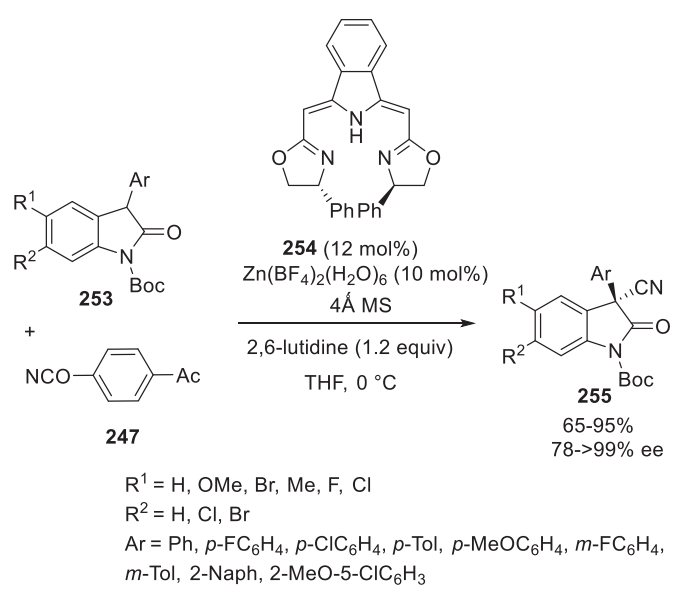

Scheme 85. $\alpha$-Cyanation of 3 -aryl-substituted oxindoles with $p$-acetylphenylcyanate in the presence of a bisoxazoline ligand [120]. 


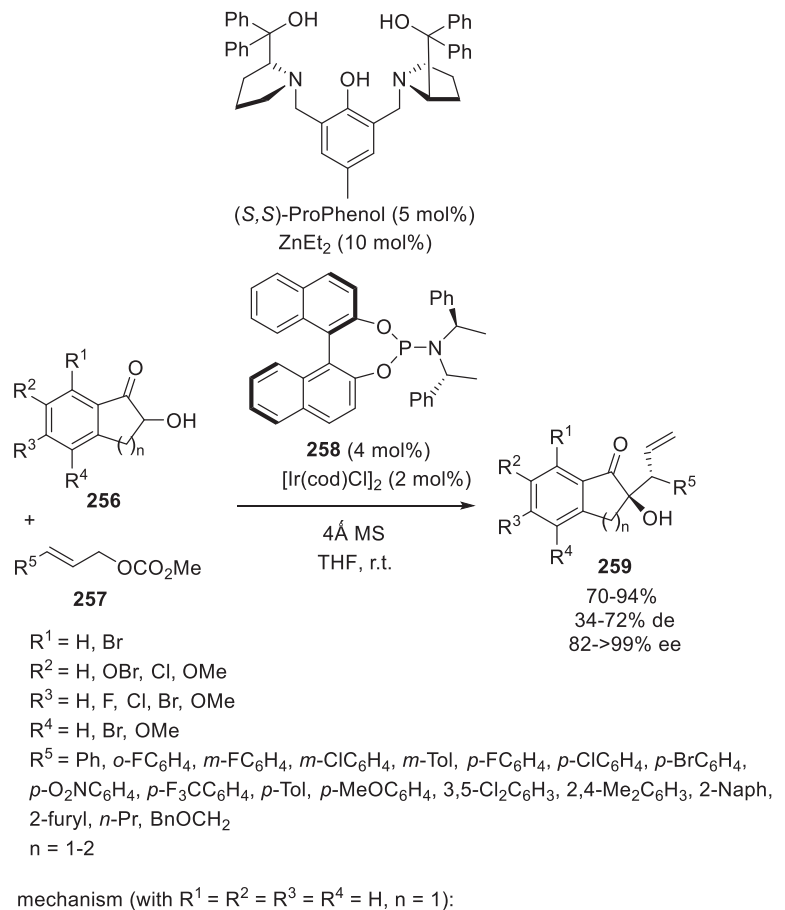

mechanism (with $R^{1}=R^{2}=R^{3}=R^{4}=H, n=1$ ):

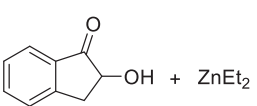

256

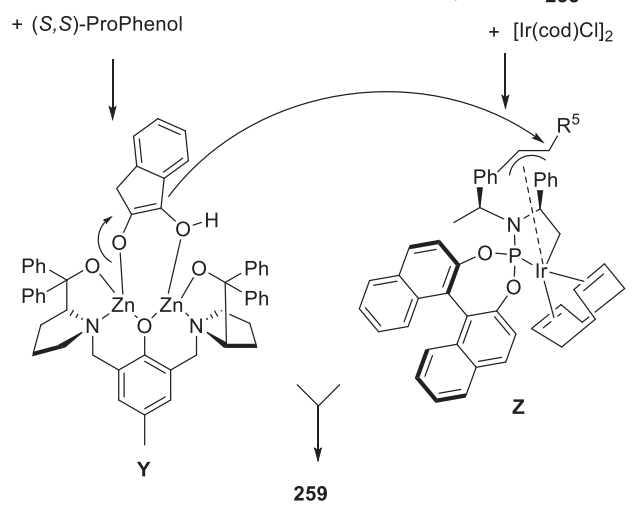

Scheme 86. $\alpha$-Allylation of unprotected $\alpha$-hydroxy indanones with allyl methyl carbonates in the presence of a dual $\mathrm{Zn} / \mathrm{Ir}$ catalyst system [121].

deprotonation of the ketone resulted in the formation of intermediate $\mathbf{V}$. Then, coordination of the electrophile via two-point binding across the two zinc centers generated complex $\mathbf{W}$ in which the E-enolate occurred to minimize 1,3-diaxial strain between the enolate and the bulky Boc group of the di-tert-butyl azodicarboxylate. The resulting hydrazine complex $\mathbf{X}$ served as a base to deprotonate a new molecule of ketone, releasing the final product and closing the catalytic cycle.

\subsection{Other $\alpha$-functionalizations}

Along with $\alpha$-aminations, asymmetric $\alpha$-cyanations of $\beta$ ketocarbonyl compounds have been developed in the presence of chiral zinc catalysts. For example, Chen et al. reported a novel methodology for enantioselective $\alpha$-cyanation of $\beta$-ketoesters which was based for the first time on the use of $p$-acetylphenyl cyanate $\mathbf{2 4 7}$ as cationic cyano source [119]. As illustrated in Scheme 84 , the reaction of the latter with a series of $\beta$-ketoesters
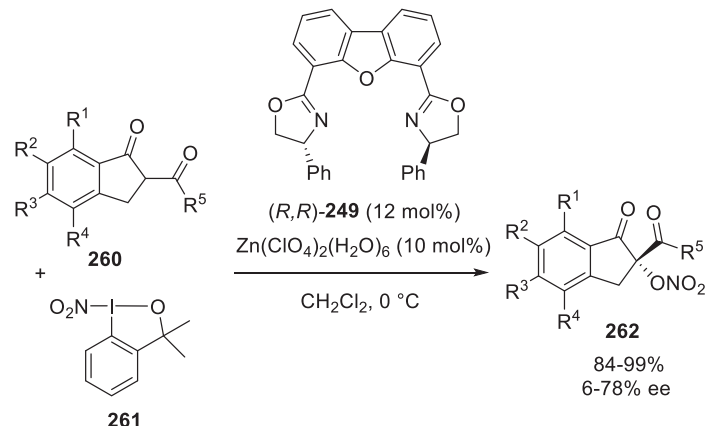

$\mathrm{R}^{1}=\mathrm{H}, \mathrm{OMe}$

$\mathrm{R}^{2}=\mathrm{H}, \mathrm{OMe}, \mathrm{Me}$

$\mathrm{R}^{3}=\mathrm{H}, \mathrm{F}, \mathrm{Cl}, \mathrm{Br}, \mathrm{OMe}, \mathrm{Me}, \mathrm{Ph}$

$\mathrm{R}^{4}=\mathrm{H}, \mathrm{OMe}$

$\mathrm{R}^{5}=\mathrm{O} t-\mathrm{Bu}, \mathrm{OMe}, \mathrm{OEt}, \mathrm{O} i-\mathrm{Pr}, \mathrm{OAd}, \mathrm{NHAd}, \mathrm{NHBn}, \mathrm{NBn}_{2}$

Scheme 87. $\alpha$-Nitrooxylation of indanone-derived $\beta$-keto esters/amides with a nitrooxylating reagent in the presence of a bisoxazoline ligand [122].

248 performed at room temperature in dichloromethane as solvent in the presence of a chiral zinc catalyst in situ generated from $10 \mathrm{~mol} \%$ of $\mathrm{Zn}\left(\mathrm{BF}_{4}\right)_{2}\left(\mathrm{H}_{2} \mathrm{O}\right)_{6}$ and $12 \mathrm{~mol} \%$ of bisoxazoline ligand $(\mathrm{S}$, S)-249 yielded the corresponding chiral $\alpha$-nitriles 250 in both moderate to high yields (30-95\%) and enantioselectivities (47$97 \%$ ee). Actually, five- and six-membered $\beta$-ketoesters $(n=1-2)$ provided the highest ee values while the reaction of a sevenmembered substrate $(n=3)$ occurred with only $47 \%$ ee and $30 \%$ yield. As an extension, the authors could apply enantiomeric ligand $(R, R)-\mathbf{2 4 9}$ to the related asymmetric $\alpha$-cyanation of both five- and six-membered $\beta$-ketoamides $\mathbf{2 5 1}$, which were converted into the corresponding $\alpha$-nitriles $\mathbf{2 5 2}$ with uniformly high enantioselectivities (85-94\% ee) combined with good to excellent yields (70-95\%).

In the same context, the first example of catalytic asymmetric cyanation of 3-aryl-substituted oxindoles $\mathbf{2 5 3}$ was disclosed by these authors using the same cyano source 247 (Scheme 85) [120]. Employing chiral pincer bisoxazoline 254 (12 mol\%) in combination with $\mathrm{Zn}\left(\mathrm{BF}_{4}\right)_{2}\left(\mathrm{H}_{2} \mathrm{O}\right)_{6}$ as precatalyst $(10 \mathrm{~mol} \%)$ in the presence of 2,6-lutidine as a base in THF as solvent, a range of chiral 3aryl-3-cyano oxindoles $\mathbf{2 5 5}$ were synthesized with both good to high yields (65-95\%) and enantioselectivities (78->99\% ee). The poorest result (65\% yield, $78 \%$ ee) was obtained in the reaction of a disubstituted aromatic group $\left(\mathrm{Ar}=2-\mathrm{MeO}-5-\mathrm{ClC}_{6} \mathrm{H}_{3}\right)$.

In 2017, Zhang et al. described enantioselective $\alpha$ allylation of unprotected $\alpha$ kydroxy indanones $256(n=1)$ with allyl methyl carbonates $\mathbf{2 5 7}$ on the basis of a dual $\mathrm{Zn} / \mathrm{Ir}$ catalysis (Scheme 86) [121]. Indeed, the catalyst system was composed of a chiral zinc complex derived from $10 \mathrm{~mol} \%$ of $\mathrm{ZnEt}_{2}$ and $5 \mathrm{~mol} \%$ of $(S, S)-$ ProPhenol as ligand and a chiral iridium catalyst in situ generated

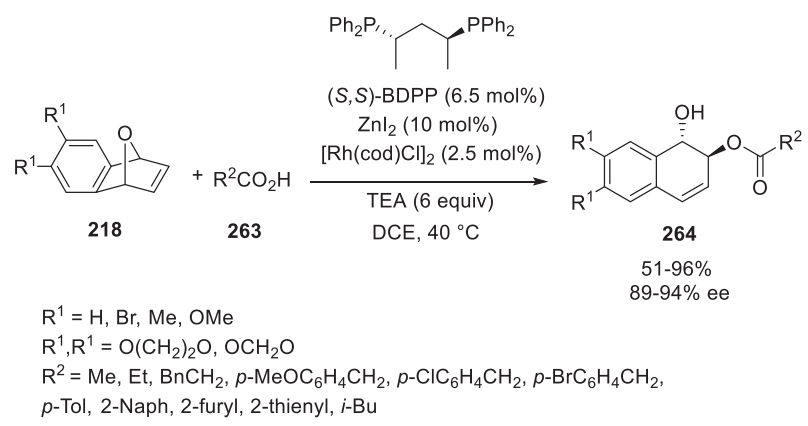

Scheme 88. Ring-opening reaction of oxabenzonorbornadienes with carboxylic acids in the presence of a dual $\mathrm{Zn} / \mathrm{Rh}$ catalyst system [123]. 

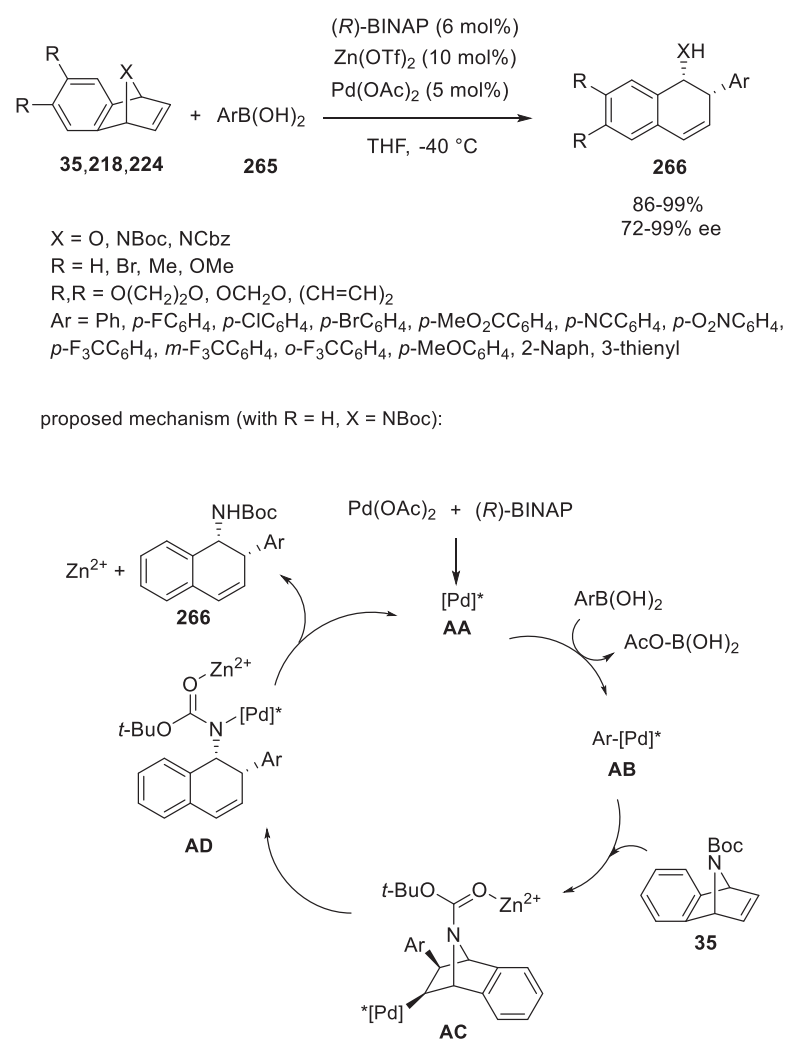

Scheme 89. Ring-opening reaction of oxa- and azabenzonorbornadienes with aryl boronic acids in the presence of a dual $\mathrm{Zn} / \mathrm{Pd}$ catalyst system [124].

from $2 \mathrm{~mol} \%$ of $\left[\operatorname{Ir}(\operatorname{cod}) \mathrm{Cl}_{2}\right.$ and $4 \mathrm{~mol} \%$ of chiral phosphoramidite ligand 258. When the latter was used at room temperature in THF as solvent, a range of variously substituted chiral $\alpha$ kydroxy indanones $\mathbf{2 5 9}$ containing a vicinal stereocenter were synthesized with good to high yields (70-94\%), low to good diastereoselectivities (34-72\% de) and high enantioselectivities ( $82->99 \%$ ee). Moreover, an $\alpha$ kydroxy tetralone ( $\mathrm{n}=2$ ) was tolerated, yielding the corresponding $\alpha$-allylated product in $92 \%$ yield, $34 \%$ de and $96 \%$ ee. The role of the multicatalysis is illustrated in Scheme 86. The $\alpha$-hydroxy indanone coordinated to the chiral dinuclear zinc catalyst with the two $\mathrm{O}$ atoms of the carbonyl and the hydroxyl group, separately chelated to the two distinct zinc atoms, facilitating enolization. In the same time, the chiral iridium catalyst derived from $[\operatorname{Ir}(\operatorname{cod}) \mathrm{Cl}]_{2}$ and chiral phosphoramidite ligand $\mathbf{2 5 8}$ interacted with the allylic methyl carbonate to give allyl iridium

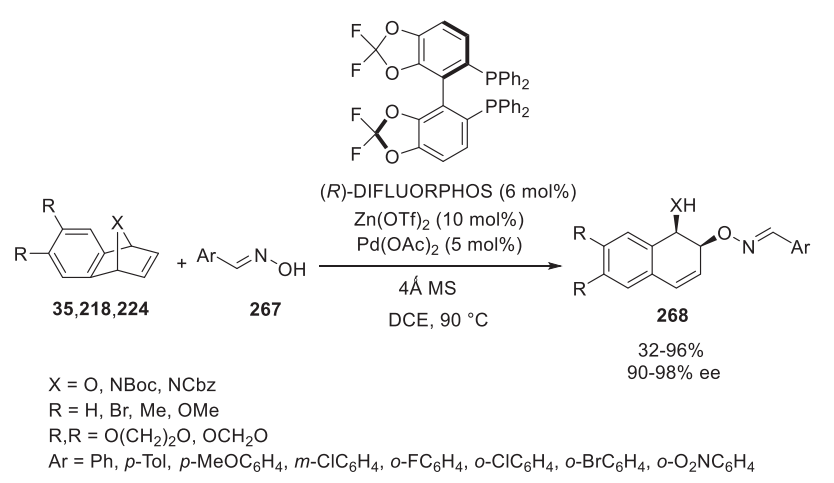

Scheme 90. Ring-opening reaction of oxa- and azabenzonorbornadienes with aromatic oximes in the presence of a dual $\mathrm{Zn} / \mathrm{Pd}$ catalyst system [125]. intermediate $\mathbf{Z}$ which was attacked by enolate $\mathbf{Y}$ to afford the final product.

In 2020, Deng et al. described the first example of asymmetric nitrooxylation of 1,3-dicarbonyl compounds, allowing the synthesis of chiral organic nitrates [122]. As depicted in Scheme 87, the reaction of a range of indanone-derived $\beta$-keto esters 260 $(\mathrm{R} 5=\mathrm{O} t-\mathrm{Bu}, \mathrm{OMe}, \mathrm{OEt}, \mathrm{O} i-\mathrm{Pr}, \mathrm{OAd})$ with nitrooxylating reagent 261 performed at $0{ }^{\circ} \mathrm{C}$ in dichloromethane as solvent and in the presence of a chiral zinc catalyst derived from $12 \mathrm{~mol} \%$ of bisoxazoline $(R, R)-249$ and $10 \mathrm{~mol} \%$ of cheap $\mathrm{Zn}\left(\mathrm{ClO}_{4}\right)_{2} \cdot 6 \mathrm{H}_{2} \mathrm{O}$ gave access to the corresponding $\alpha$-nitrooxy $\beta$-keto esters $\mathbf{2 6 2}$ in homogeneous high yields (84-99\%) and low to good enantioselectivities (6-78\% ee). The best ee values (40-78\% ee) were achieved in the reaction of indanone-derived tert-butyl $\beta$-keto esters bearing different substituents ( $\mathrm{Me}, \mathrm{OMe}, \mathrm{F}, \mathrm{Cl}, \mathrm{Br}, \mathrm{Ph}$ ) on the phenyl ring. The stereocontrol of the reaction was found highly dependent to the presence of a tert-butyl on the ester group. Indeed, methyl, ethyl, isopropyl but also adamantyl esters provided much lower enantioselectivities (6-24\% ee) than tert-butyl esters. Furthermore, the scope of the process could be extended to indanone-derived $\beta$-keto amides $\left(R^{5}=\mathrm{NHBn}, \mathrm{NHAd}, \mathrm{NBn}_{2}\right)$ which afforded to the corresponding products 262 in high yields (84-91\%) albeit with uniformly low enantioselectivities (6-20\% ee).

\section{Ring-opening reactions}

In 2017, Fan and Chen applied a Zn/Rh dual catalyst system to enantioselective ring-opening reaction of oxabenzonorbornadienes $\mathbf{2 1 8}$ with aromatic as well as aliphatic carboxylic acids 263 [123]. Carried out in DCE at $40{ }^{\circ} \mathrm{C}$ in the presence of $10 \mathrm{~mol} \%$ of $\mathrm{ZnI}_{2}$, $2.5 \mathrm{~mol} \%$ of $[\mathrm{Rh}(\operatorname{cod}) \mathrm{Cl}]_{2}$ and $6.5 \mathrm{~mol} \%$ of chiral biphosphine $(S$, $S$ )-BDPP, the reaction resulted in the formation of chiral hydronaphthalenes 264 in uniformly excellent ee values (89-94\% ee) and moderate to excellent yields (51-96\%), as depicted in Scheme 88.

The same group also described asymmetric ring opening reactions of aza- and oxabenzonorbornadienes 35, 218, 224 with aryl boronic acids $\mathbf{2 6 5}$ by using a $\mathrm{Zn} / \mathrm{Pd}$ dual catalyst system [124]. As shown in Scheme 89, a combination of $10 \mathrm{~mol} \%$ of $\mathrm{Zn}(\mathrm{OTf})_{2}$, $6 \mathrm{~mol} \%$ of $(R)$-BINAP and $5 \mathrm{~mol} \%$ of $\mathrm{Pd}(\mathrm{OAc})_{2}$ was applied to promote these reactions which delivered a wide variety of chiral
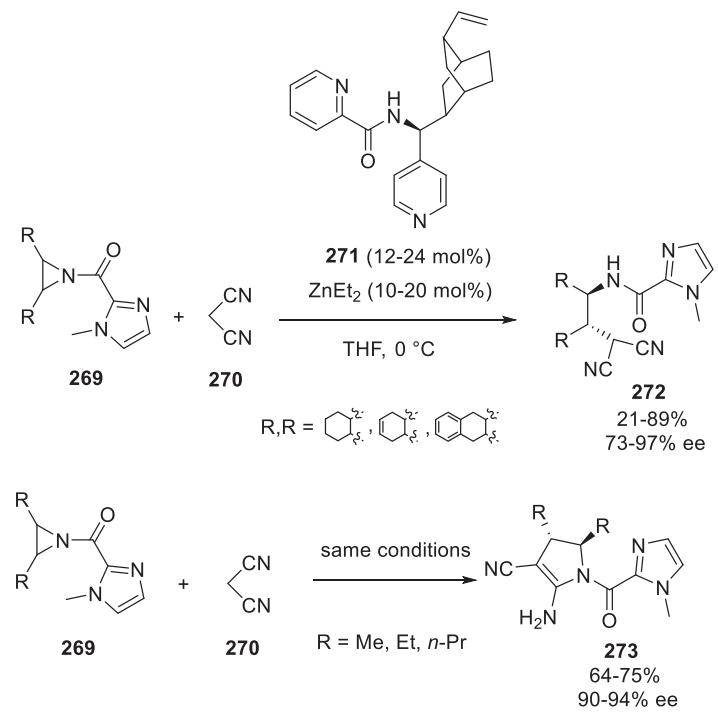

Scheme 91. Ring-opening reactions of aziridines with malononitrile in the presence of a cinchona alkaloid ligand [126]. 


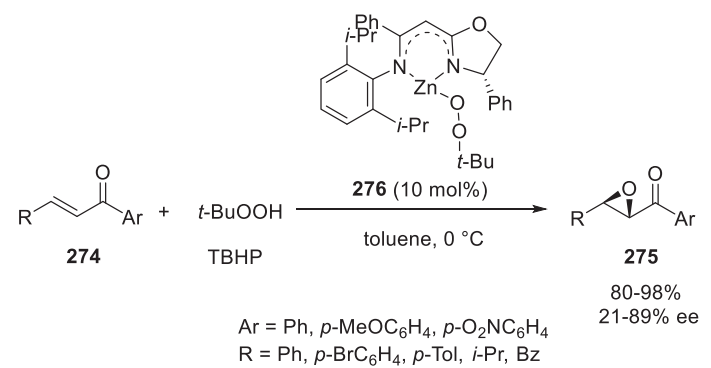

proposed mechanism (with $\mathrm{Ar}=\mathrm{Ph}$ ):

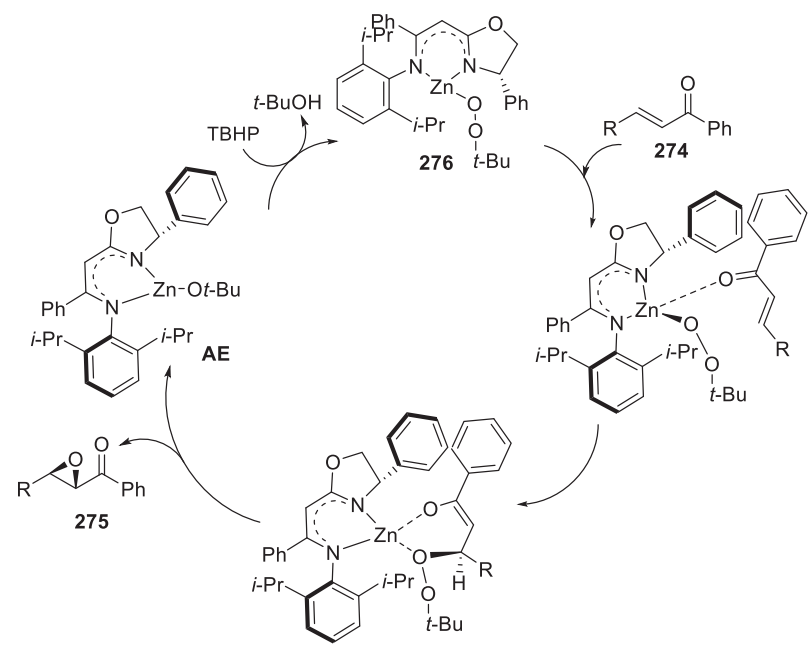

Scheme 92. Epoxidation of $\alpha, \beta$-unsaturated ketones in the presence of a $C_{1}$ symmetric enaminooxazolinate zinc tert-butyl peroxide-based catalyst [129].

hydronaphthalene products $\mathbf{2 6 6}$ in homogeneous high yields (86$99 \%$ ) and good to excellent enantioselectivities (72-99\% ee). The mechanism depicted in Scheme 89 is initiated by the coordination of $\mathrm{Pd}(\mathrm{OAC})_{2}$ with $(R)$-BINAP to give the corresponding chiral palladium catalyst AA. Then, transmetalation of arylboronic acid generates arylpalladium intermediate $\mathbf{A B}$. A subsequent insertion of azabenzonorbornadiene $\mathbf{3 5}$ into the carbon-palladium bond results in the formation of intermediate $\mathbf{A C}$. Then, $\beta$-elimination of nitrogen opens the pyrrolidine ring and yields the ring-opened species AD. Finally, hydrolysis of the latter gives the final product.

In 2019, asymmetric ring-opening reactions of oxa- and azabenzonorbornadienes 35, 218, 224 were also achieved by using aromatic oximes $\mathbf{2 6 7}$ as nucleophiles (Scheme 90) [125]. In this case, the employed dual $\mathrm{Zn} / \mathrm{Pd}$ catalyst system contained $10 \mathrm{~mol}$ $\%$ of $\mathrm{Zn}(\mathrm{OTf})_{2}, 6 \mathrm{~mol} \%$ of $(R)$-DIFLUORPHOS as ligand, and $5 \mathrm{~mol} \%$ of $\mathrm{Pd}(\mathrm{OAC})_{2}$. Performed in DCE as solvent, the process stereoselec-

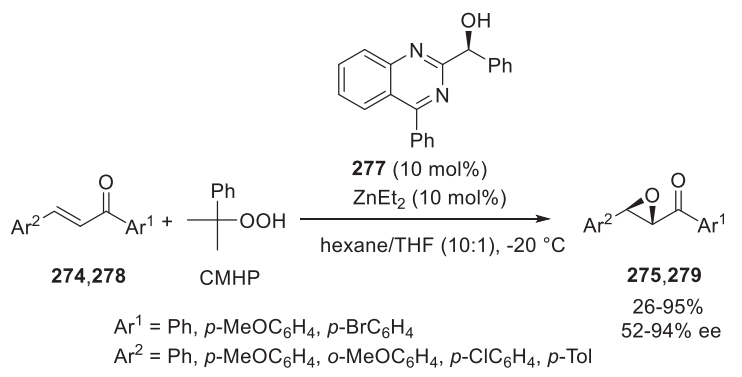

Scheme 93. Epoxidation of chalcones in the presence of a 4-phenylquinazolinol ligand [84].

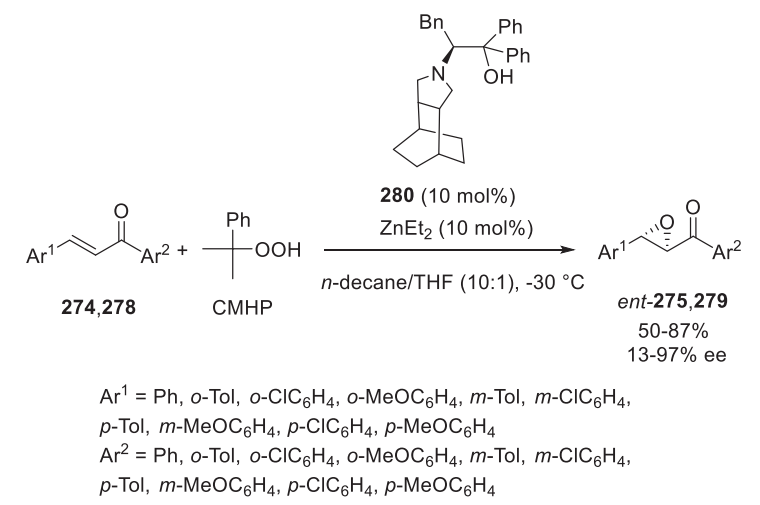

Scheme 94. Epoxidation of chalcones in the presence of a pyrrolidine alcohol ligand [130].

tively afforded at $90{ }^{\circ} \mathrm{C}$ the corresponding cis-products 268 in moderate to quantitative yields (32-96\%) and uniformly excellent ee values (90-98\% ee).

Earlier in 2017, Nakamura et al. developed the first catalytic desymmetrization of protected aziridines $\mathbf{2 6 9}$ with malononitrile 270 using 12-24 mol\% of a cinchona alkaloid zinc catalyst derived from ligand 271 and $\mathrm{ZnEt}_{2}$ [126]. As illustrated in Scheme 91, the reaction of aziridines $\mathbf{2 6 9}$ having six-membered ring structures afforded by reaction with malononitrile $\mathbf{2 7 0}$ the corresponding chiral products 272 with high enantioselectivities (73-97\% ee) and low to high yields (21-89\%). Acyclic aziridines were also compatible substrates, leading in this case to chiral 2,3-dihydro-1H-pyrrole products $\mathbf{2 7 3}$ formed by subsequent intramolecular nucleophilic addition of amide nitrogen to the cyano group. These cyclic products were all obtained with excellent ee values (90-94\% ee) combined with good yields (64-75\%). These latter results could also be situated in Section 15 dealing with domino and tandem reactions since they involve a domino ring-opening/cyclization reaction.

\section{Epoxidations}

The asymmetric epoxidation of olefins is a powerful tool to synthesize chiral epoxides, which constitute the structure of many biologically active compounds and synthetic intermediates [127]. Especially, the enantioselective epoxidation of $\alpha, \beta$-unsaturated ketones is challenging because it offers an efficient route to many useful chiral products through further functionalization [128]. In 2016, Jurczak and Lewinski reported enantioselective epoxidation of various $\alpha, \beta$-unsaturated ketones $\mathbf{2 7 4}$ into the corresponding chiral epoxides 275 promoted by novel zinc alkyl peroxides supported by $C_{1}$-symmetric $N, N$-bidentate ligands [129]. Among them, chiral

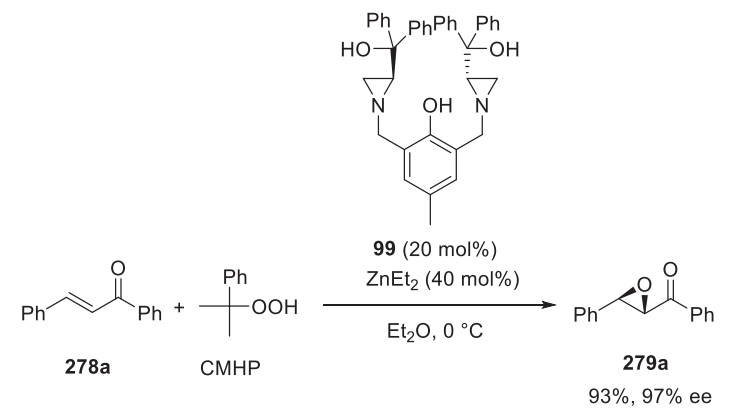

Scheme 95. Epoxidation of chalcone in the presence of an aziridine alcohol ligand [58]. 


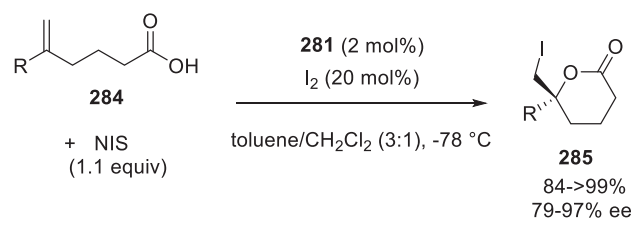

$\mathrm{R}=\mathrm{Ph}, p-\mathrm{Tol}, p-\mathrm{FC}_{6} \mathrm{H}_{4}, m-\mathrm{Tol}, p-\mathrm{ClC}_{6} \mathrm{H}_{4}, p-\mathrm{BrC}_{6} \mathrm{H}_{4}, \mathrm{Me}, \mathrm{Cy}$

Synthesis of catalyst 281:

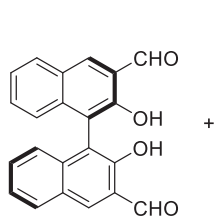

282
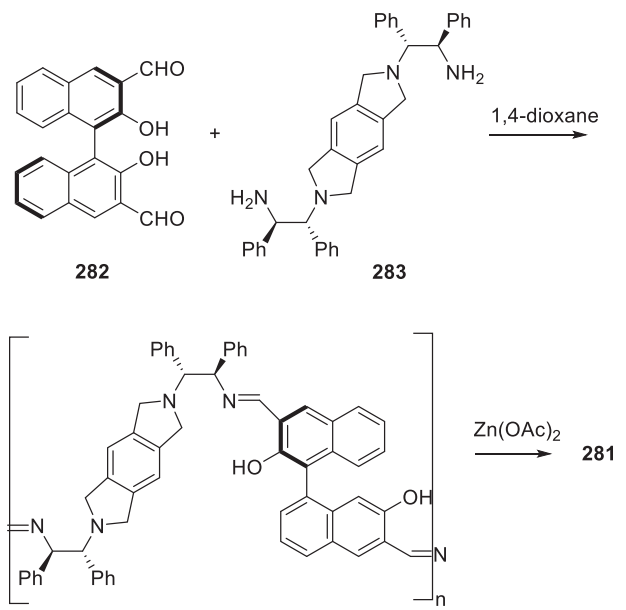
a poly- $\mathrm{Zn}_{3}(\mathrm{OAc})_{4}-3,3^{\prime}$-bis(aminoimino)binaphthoxide catalyst [131].

enaminooxazolinate zinc tert-peroxide 276, in situ prepared in toluene from $\mathrm{Zn}(t-\mathrm{Bu})_{2}$, tert-butyl hydroperoxide (TBHP), and the corresponding chiral $\mathrm{N}, \mathrm{N}$-bidentate ligand, was found to efficiently promote the epoxidation of both aliphatic and aromatic $\alpha, \beta-$ unsaturated ketones in high yields (80-98\%) and generally good enantioselectivities (56-89\% ee). In only one case of aliphatic substrate $(\mathrm{R}=i$-Pr), a low ee value was observed $(21 \%$ ee). In the catalytic cycle highlighted in Scheme 92, the first step consisted in the coordination of the carbonyl oxygen of the enone to zinc atom, followed by a nucleophilic attack of oxygen from the $S i$ face of the activated enone, leading to the final epoxide. The cycle was completed by exchanging the $\mathrm{O}-\mathrm{t}$ - $\mathrm{Bu}$ group in intermediate $\mathbf{A E}$ by a $\mathrm{O}-\mathrm{O}-\mathrm{t}$-Bu group arisen from TBHP.

The same year, Ulukanli et al. reported the synthesis of novel 4phenylquinazolinol ligands to be investigated in such reactions [84]. Among them, ligand $\mathbf{2 7 7}$ was found optimal to catalyze at $10 \mathrm{~mol} \%$ of catalyst loading in a 10:1 mixture of hexane and THF cumene hydroperoxide (CMHP) as oxidant (Scheme 93). The corresponding chiral epoxides $\mathbf{2 7 5}, \mathbf{2 7 9}$ were produced in low to excellent yields (26-95\%) and variable enantioselectivities (52-94\% ee).

In 2017, these reactions were also studied by Kilic et al. by using chiral pyrrolidine alcohol ligand 280 (Scheme 94) [130]. In the presence of $10 \mathrm{~mol} \%$ of this ligand combined with the same quantity of $\mathrm{ZnEt}_{2}$ in a 10:1 mixture of $n$-decane and THF as solvent, a

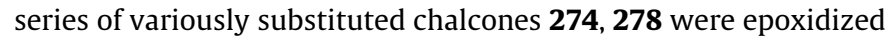
with CMHP as oxidant at $-30{ }^{\circ} \mathrm{C}$ into the corresponding chiral epoxides ent-275, 279 with good yields (50-87\%) and low to excellent enantioselectivities (13-97\% ee). chiral aziridine alcohol ligands which were investigated in different zinc-catalyzed asymmetric transformations, including enantioselective epoxidation of chalcone 278a into chiral epoxides 279a (Scheme 95) [58]. The authors selected ligand 99 as optimal to be used at $20 \mathrm{~mol} \%$ of catalyst loading in combination with
Scheme 96. Iodolactonization of 5-substituted hex-5-enoic acids in the presence of

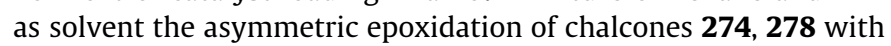

The same year, Rachwalski et al. reported the synthesis of novel
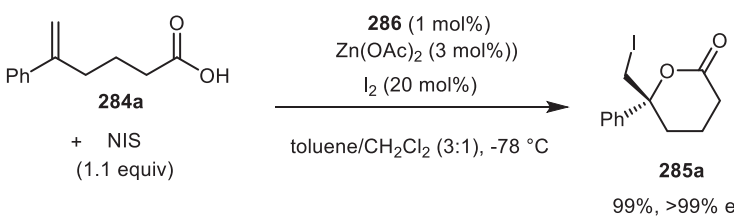

285a
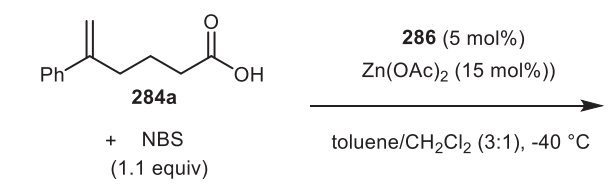

$99 \%,>99 \%$ ee
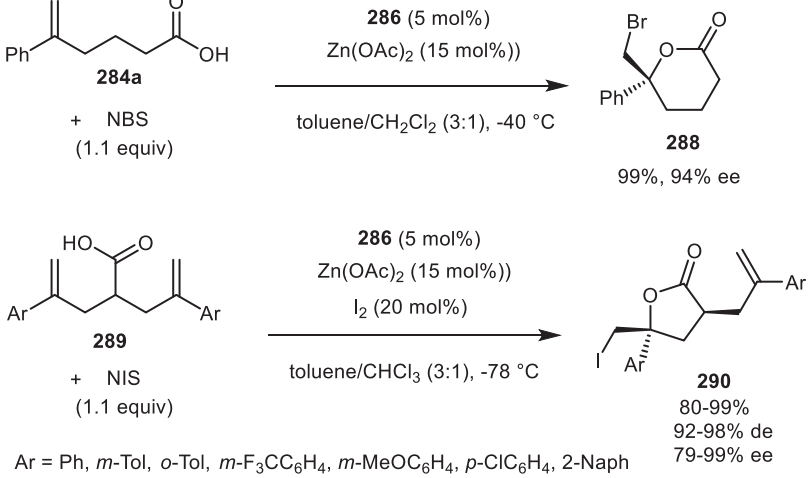

$\mathrm{Ar}=\mathrm{Ph}, m-\mathrm{Tol}, o-\mathrm{Tol}, m-\mathrm{F}_{3} \mathrm{CC}_{6} \mathrm{H}_{4}, m-\mathrm{MeOC}_{6} \mathrm{H}_{4}, p-\mathrm{ClC}_{6} \mathrm{H}_{4}, 2-\mathrm{Naph}$

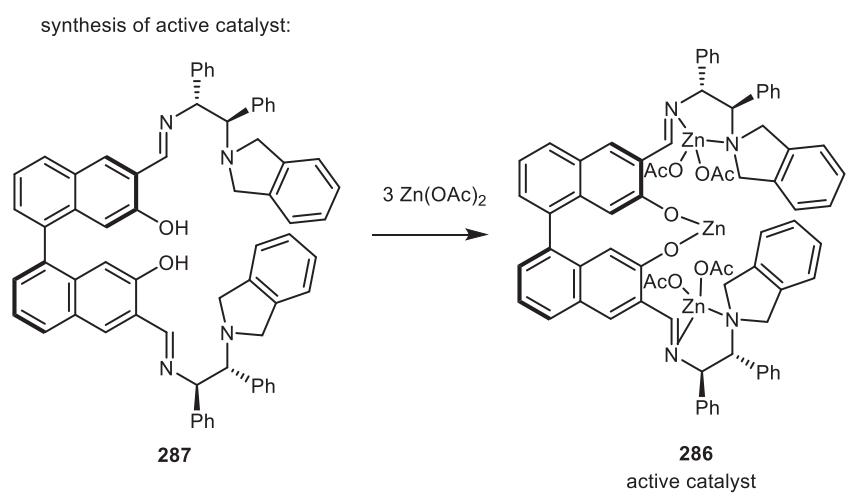

Scheme 97. Halolactonizations of 5-phenyl hex-5-enoic acid and diallyl carboxylic acids in the presence of a $\mathrm{Zn}_{3}(\mathrm{OAc})_{4}-3,3^{\prime}$-bis(aminoimino)binaphthoxide catalyst [132].

$40 \mathrm{~mol} \%$ of $\mathrm{ZnEt}_{2}$ in the epoxidation of chalcone 278a with CMHP as oxidant in diethyl ether as solvent. Carried out at $0{ }^{\circ} \mathrm{C}$, the oxidation provided both excellent yield (93\%) and ee value (97\% ee).

\section{Halolactonizations}

In 2015, Arai et al. described the synthesis of novel polymeric $\mathrm{Zn}_{3}(\mathrm{OAc})_{4}-3,3^{\prime}$-bis(aminoimino)binaphthoxide catalyst $\mathbf{2 8 1}$ through self-assembly of chiral 3,3'-diformylbinaphthol ligand 282, chiral tetramine ligand $\mathbf{2 8 3}$, and $\mathrm{Zn}(\mathrm{OAc})_{2}$ (Scheme 96) [131]. This complex was found stable and efficient at only $2 \mathrm{~mol}$ $\%$ of catalyst loading to promote at $-78{ }^{\circ} \mathrm{C}$ the asymmetric iodolactonization of a range of 5-substituted hex-5-enoic acids 284 into the corresponding chiral iodolactones 285. 5-Arylhex-5-enoic acids bearing various electron-withdrawing or electron-donating substituents on the phenyl ring led to the corresponding iodolactones with both uniformly excellent enantioselectivities (91-97\% ee) and yields (92->99\%). 5-Alkyl-substituted hex-5-enoic acids 284 $(\mathrm{R}=$ alkyl $)$ also reacted smoothly with high yields (84->99\%) and ee values (79-95\% ee). Importantly, this novel catalyst was recyclable and could be reused for up to five cycles.

In 2019, the same group investigated asymmetric iodo- and bromolactonizations of carboxylic acid substrates performed in the presence of $\mathrm{Zn}_{3}(\mathrm{OAc})_{4}-3,3^{\prime}$-bis(aminoimino)binaphthoxide chiral active complex $\mathbf{2 8 6}$ in situ generated from the corresponding chiral ligand $\mathbf{2 8 7}$ and $\mathrm{Zn}(\mathrm{OAc})_{2}$ (Scheme 97) [132]. The 


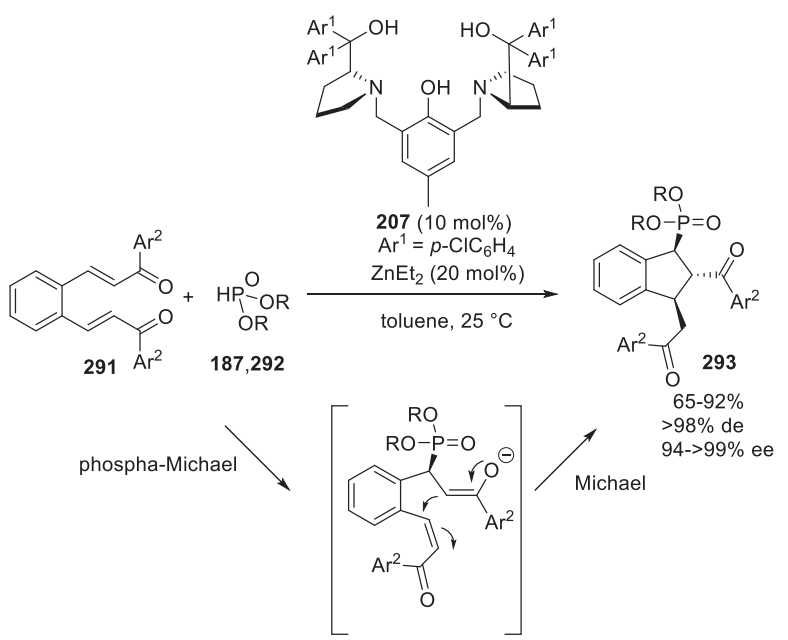

$\mathrm{Ar}^{2}=\mathrm{Ph}, m-\mathrm{FC}_{6} \mathrm{H}_{4}, m-\mathrm{ClC}_{6} \mathrm{H}_{4}, m-\mathrm{BrC}_{6} \mathrm{H}_{4}, m-\mathrm{MeOC}_{6} \mathrm{H}_{4}, p-\mathrm{FC}_{6} \mathrm{H}_{4}, p-\mathrm{ClC}_{6} \mathrm{H}_{4}$ $p$ - $\mathrm{BrC}_{6} \mathrm{H}_{4}, p$-Tol, $p$ - $\mathrm{MeOC}_{6} \mathrm{H}_{4}, p-\mathrm{PhC}_{6} \mathrm{H}_{4}, 2$-thienyl

$\mathrm{R}=\mathrm{Et}, \mathrm{Me}, i-\mathrm{Pr}, i-\mathrm{Bu}$

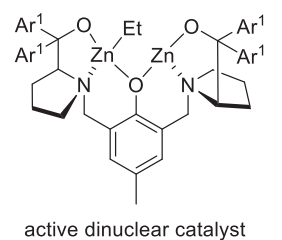

Scheme 98. Domino phospha-Michael/Michael reaction of o-dienones with dialkyl phosphates in the presence of a ProPhenol derivative ligand [135].

iodolactonization of 5-phenyl hex-5-enoic acid 284a was achieved in the presence of only $1 \mathrm{~mol} \%$ of ligand $\mathbf{2 8 7}$ in combination with $3 \mathrm{~mol} \%$ of $\mathrm{Zn}(\mathrm{OAc})_{2}$ at $-78{ }^{\circ} \mathrm{C}$ with NIS and $\mathrm{I}_{2}$ as iodine sources,
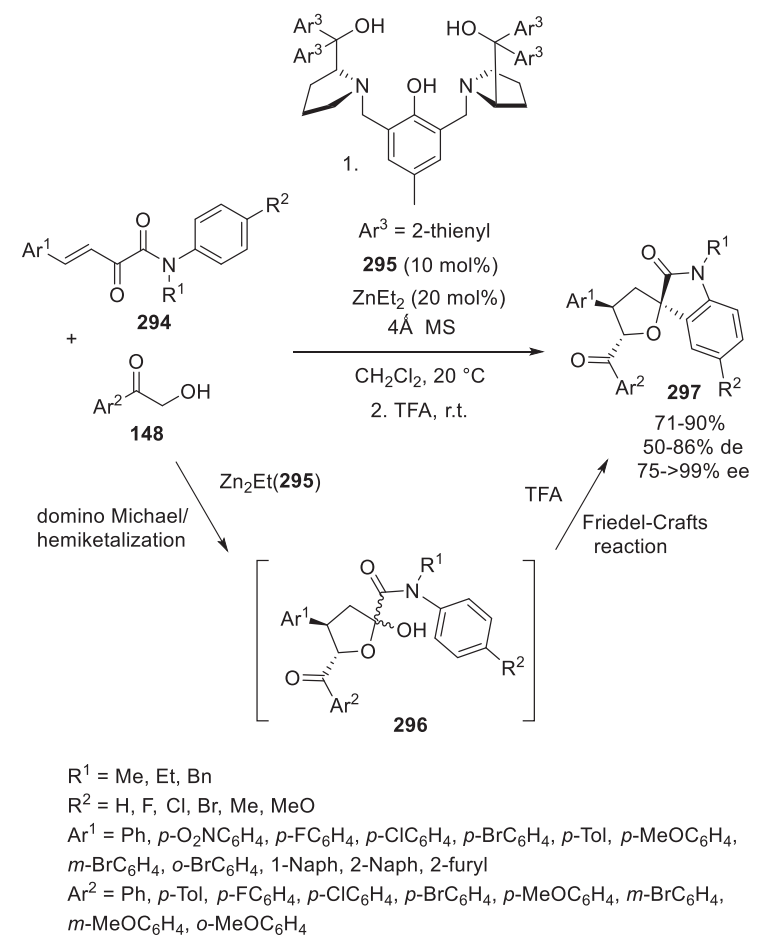

Scheme 99. Domino Michael/hemiketalization reaction of $\alpha$-hydroxy aryl ketones with $\beta, \gamma$-unsaturated $\alpha$-ketoamides followed by Friedel-Crafts reaction in the presence of a ProPhenol derivative ligand [137]. leading to enantiopure six-membered iodolactone 285a (>99\% ee) in quantitative yield (99\%). The same substrate was also submitted to related bromolactonization by using NBS as bromide source, providing in the presence of $5 \mathrm{~mol} \%$ of ligand 287 and $15 \mathrm{~mol} \%$ of $\mathrm{Zn}(\mathrm{OAc})_{2}$ at $-40{ }^{\circ} \mathrm{C}$ the corresponding almost enantiopure bromolactone $\mathbf{2 8 8}$ (94\% ee) in 99\% yield. Furthermore, the same catalyst system was employed in the asymmetric iodolactonization of diallyl carboxylic acids 289. The process required $5 \mathrm{~mol} \%$ of ligand $\mathbf{2 8 7}$ and $15 \mathrm{~mol} \%$ of $\mathrm{Zn}(\mathrm{OAc})_{2}$ to produce the corresponding chiral five-membered iodolactones 290 in high yields (80-99\%), diastereoselectivities (92-98\% de) and enantioselectivities (79-99\% ee).

\section{Domino/tandem reactions}

The challenging goal for rapid construction of molecular complexity has become possible through the spectacular development of asymmetric one-pot reactions, such as tandem and domino reactions, that avoid the use of costly protection/deprotection processes and purification of intermediates [133]. In most cases, these economic reactions are remarkably enantioselective, and consequently they have been intensely applied in the total synthesis of complex chiral molecules, such as bioactive and natural products [134]. This is only in the last decade that the first examples of asymmetric domino reactions catalyzed with chiral zinc complexes have been disclosed.

\subsection{Michael-initiated domino reactions}

In 2019, Hua and Wang reported an enantioselective domino phospha-Michael/Michael reaction of 0 -dienones 291 with dialkyl phosphates 187, 292 based on the use of chiral ProPhenol

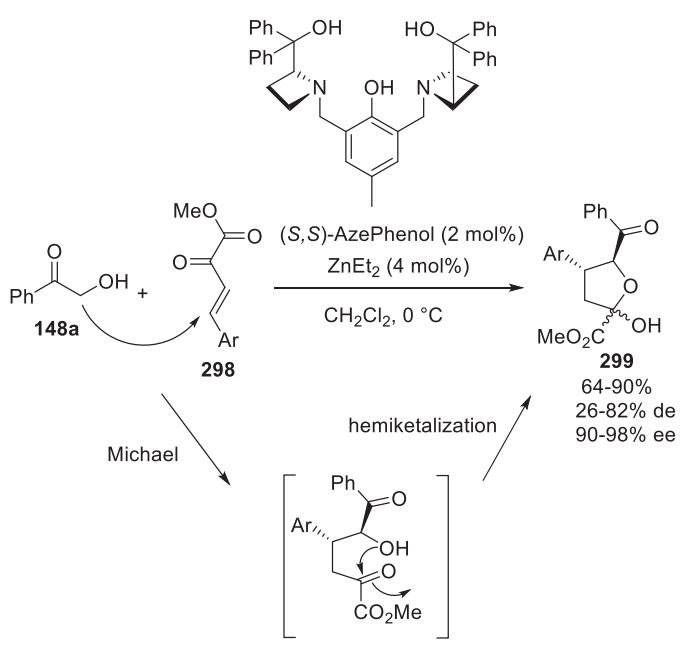

$\mathrm{Ar}=\mathrm{Ph}, p-\mathrm{FC}_{6} \mathrm{H}_{4}, p-\mathrm{ClC}_{6} \mathrm{H}_{4}, p-\mathrm{BrC}_{6} \mathrm{H}_{4}, p-\mathrm{O}_{2} \mathrm{NC}_{6} \mathrm{H}_{4}, p-\mathrm{Tol}, p-\mathrm{MeOC}_{6} \mathrm{H}_{4}$ $m-\mathrm{ClC}_{6} \mathrm{H}_{4}, m-\mathrm{BrC}_{6} \mathrm{H}_{4}, m-\mathrm{MeOC}_{6} \mathrm{H}_{4}, m$-Tol, 3-Br-4-ClC $6 \mathrm{H}_{3}$

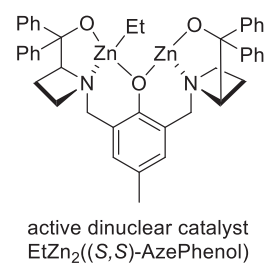

Scheme 100. Domino Michael/hemiketalization reaction of aryl-substituted $\beta, \gamma-$ unsaturated $\alpha$-ketoesters with $\alpha$-hydroxyacetophenone in the presence of $(S, S)$ AzePhenol [138]. 


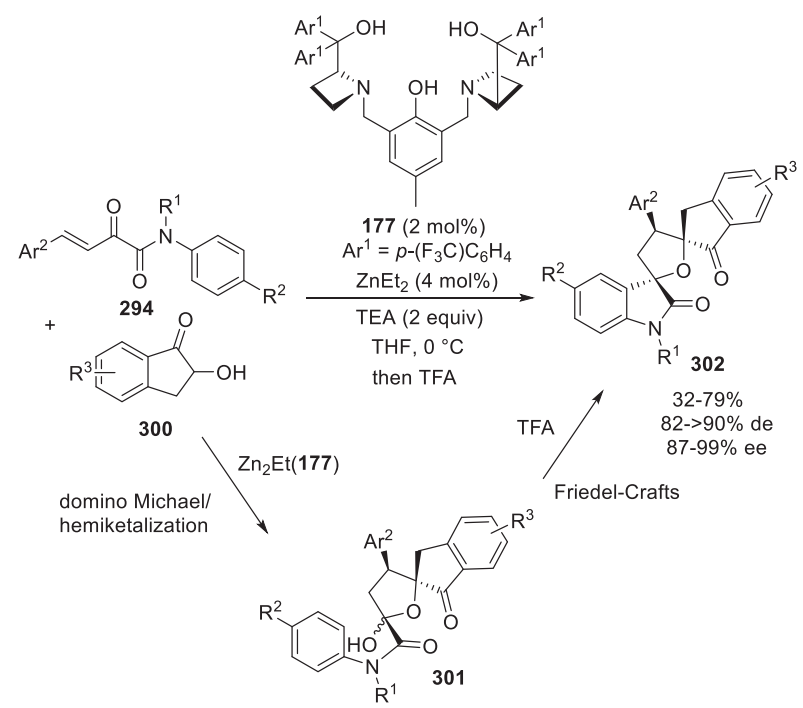

$\mathrm{R}^{1}=\mathrm{Me}, \mathrm{Et}, \mathrm{Bn}, \mathrm{p}-\mathrm{BrC}_{6} \mathrm{H}_{4} \mathrm{CH}_{2}$

$\mathrm{R}^{2}=\mathrm{H}, \mathrm{F}, \mathrm{Cl}, \mathrm{Br}, \mathrm{Me}, \mathrm{OMe}$

$\mathrm{R}^{3}=\mathrm{H}, 5-\mathrm{F}, 5-\mathrm{Cl}, 5-\mathrm{Br}, 5-\mathrm{OMe}, 4-\mathrm{Br}, 6-\mathrm{Br}$

$\mathrm{Ar}^{2}=\mathrm{Ph}, p-\mathrm{FC}_{6} \mathrm{H}_{4}, p-\mathrm{ClC}_{6} \mathrm{H}_{4}, p-\mathrm{BrC}_{6} \mathrm{H}_{4}, p-\mathrm{O}_{2} \mathrm{NC}_{6} \mathrm{H}_{4}, p-\mathrm{Tol}, p-\mathrm{MeOC}_{6} \mathrm{H}_{4}$,

$m$ - $\mathrm{BrC}_{6} \mathrm{H}_{4}, m$-Tol, o- $\mathrm{BrC}_{6} \mathrm{H}_{4}$, 2-Naph, 2-thienyl, 2-furyl

Scheme 101. Domino Michael/hemiketalization reaction of aryl-substituted $\beta, \gamma-$ unsaturated $\alpha$-ketoamides with 2-hydroxy-1-indanones followed by Friedel-Crafts reaction in the presence of an AzePhenol derivative ligand [139].

derivative 207 as ligand (10 mol\%) in combination with $\mathrm{ZnEt}_{2}$ (20 mol\%) in toluene at $25^{\circ} \mathrm{C}$ [135]. The sequence led to the corresponding chiral 1,2,3-trisubstituted indane derivatives 293, bearing phosphoryl groups and three contiguous stereocenters, as almost single stereomers (>98\% de, $94->99 \%$ ee) in good to high yields (65-92\%), as illustrated in Scheme 98. Various dialkyl phosphates were compatible with the catalytic system, providing homogeneously excellent results (96-99\% ee). Furthermore, comparable excellent yields and enantioselectivities were achieved in the reaction of a series of aryl substituted 0 -dienones, regardless

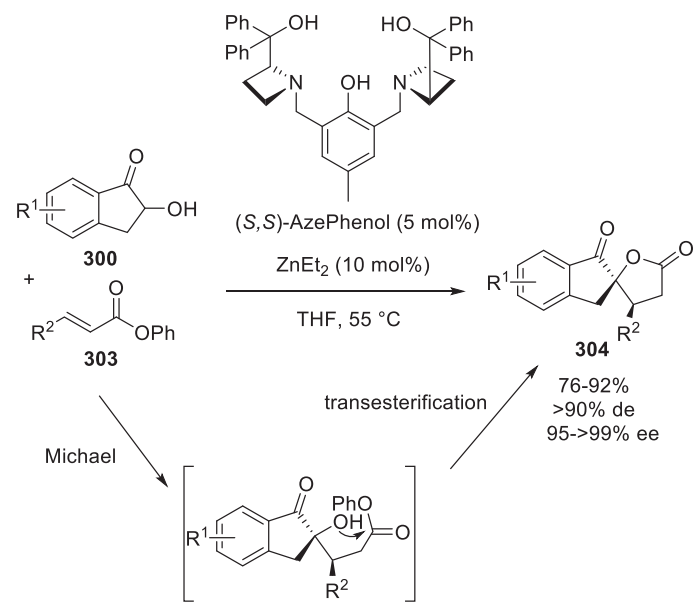

$\mathrm{R}^{1}=\mathrm{H}, 5-\mathrm{F}, 5-\mathrm{Cl}, 5-\mathrm{Br}, 5-\mathrm{OMe}, 4-\mathrm{Br}, 6-\mathrm{Br}$

$\mathrm{R}^{2}=\mathrm{Ph}, p-\mathrm{FC}_{6} \mathrm{H}_{4}, p-\mathrm{ClC}_{6} \mathrm{H}_{4}, p-\mathrm{Tol}, p-\mathrm{MeOC}_{6} \mathrm{H}_{4}, m-\mathrm{ClC}_{6} \mathrm{H}_{4}, m-\mathrm{BrC}_{6} \mathrm{H}_{4}$ $m$-Tol, $m$ - $\mathrm{MeOC}_{6} \mathrm{H}_{4}, o-\mathrm{BrC}_{6} \mathrm{H}_{4}, o-\mathrm{MeOC}_{6} \mathrm{H}_{4}, 3-\mathrm{Br}_{-}-\mathrm{ClC}_{6} \mathrm{H}_{3}, 2-\mathrm{F}-4-\mathrm{BrC}_{6} \mathrm{H}_{3}$, 2,4- $\mathrm{Cl}_{2} \mathrm{C}_{6} \mathrm{H}_{3}, 3,4-\mathrm{OCH}_{2} \mathrm{O}-\mathrm{C}_{6} \mathrm{H}_{3}$, 1-Naph, 2-Naph, 2-thienyl, $\mathrm{H}, \mathrm{Me}$

Scheme 102. Domino Michael/transesterification reaction of $\alpha$-hydroxy-1-indanones with phenyl $\alpha, \beta$-unsaturated esters in the presence of $(S, S)$-AzePhenol [140].

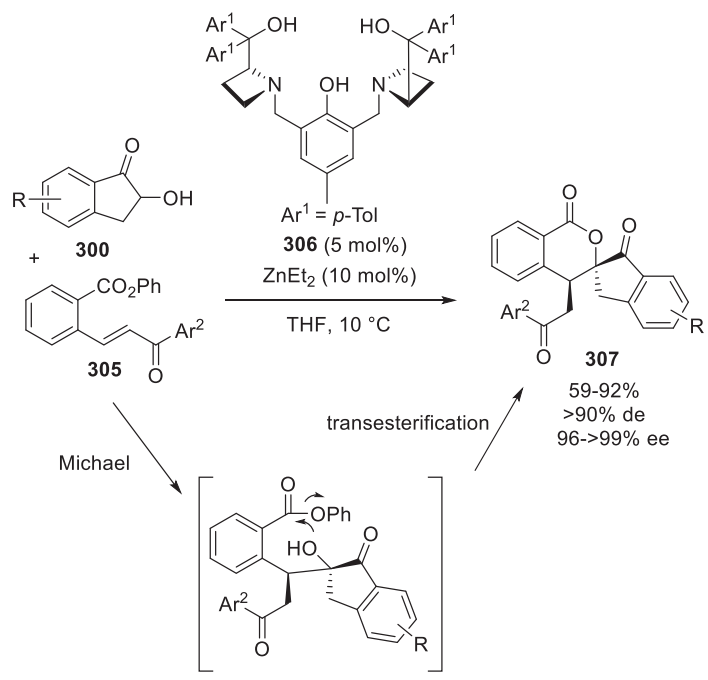

$\mathrm{R}=\mathrm{H}, 5-\mathrm{F}, 5-\mathrm{Cl}, 5-\mathrm{Br}, 5-\mathrm{OMe}, 4-\mathrm{Br}, 6-\mathrm{Br}$

$\mathrm{Ar}^{2}=\mathrm{Ph}, p-\mathrm{BrC}_{6} \mathrm{H}_{4}, p-\mathrm{Tol}, p-\mathrm{FC}_{6} \mathrm{H}_{4}, p-\mathrm{ClC}_{6} \mathrm{H}_{4}, p-\mathrm{MeOC}_{6} \mathrm{H}_{4}, m-\mathrm{FC}_{6} \mathrm{H}_{4}$, $m-\mathrm{ClC}_{6} \mathrm{H}_{4}, m-\mathrm{BrC}_{6} \mathrm{H}_{4}, m-\mathrm{MeOC}_{6} \mathrm{H}_{4}, o-\mathrm{ClC}_{6} \mathrm{H}_{4}, o-\mathrm{BrC}_{6} \mathrm{H}_{4}, o-\mathrm{MeOC}_{6} \mathrm{H}_{4}$, 2,4- $\mathrm{Cl}_{2} \mathrm{C}_{6} \mathrm{H}_{3}, 3,4-\mathrm{Cl}_{2} \mathrm{C}_{6} \mathrm{H}_{3}, 2,4-\mathrm{Cl}_{2}-5-\mathrm{FC}_{6} \mathrm{H}_{2}$, 2-thienyl, 2-Naph

Scheme 103. Domino Michael/transesterification reaction of $\alpha$-hydroxy-1-indanones with ortho-ester chalcones in the presence of an AzePhenol derivative ligand [141].

of the electronic nature of the substituents beared on the aryl group $\left(\mathrm{Ar}^{2}\right)$.

The synthesis of chiral tetrahydrofuran spirooxindoles is challenging related to the potent biological activities of these products [136]. In this context, the same authors developed in 2020 an enantioselective zinc-catalyzed domino Michael/hemiketalization reaction of $\alpha$-hydroxy aryl ketones 148 with $\beta, \gamma$-unsaturated $\alpha$-ketoamides 294 [137]. The reaction, performed at $20{ }^{\circ} \mathrm{C}$ in dichloromethane as solvent, was promoted by a chiral dinuclear zinc catalyst in situ generated from $20 \mathrm{~mol} \%$ of $\mathrm{ZnEt}_{2}$ and $10 \mathrm{~mol}$ $\%$ of chiral ProPhenol derivative ligand 295. The domino products 296 were not isolated but directly submitted to Friedel-Crafts reaction performed at room temperature by adding TFA to give chiral tetrahydrofuran spirooxindoles $\mathbf{2 9 7}$ in high yields (71-90\%), moderate to high diastereoselectivities (50-86\% de) and good to high enantioselectivities (75->99\% ee), as shown in Scheme 99. Actually, the enantioselectivities were uniformly excellent $(90->99 \%$ ee) for differently substituted substrates excepted for ortho-methoxy-substituted $\alpha$-hydroxy aryl ketone $\left(\mathrm{Ar}^{2}=0-\mathrm{MeOC}_{6} \mathrm{H}_{4}\right)$, which yielded the corresponding product with a lower ee value (75\% ee).

The chiral dinuclear zinc catalyst $\mathrm{Zn}_{2} \mathrm{Et}((S, S)$-AzePhenol), in situ generated from $2 \mathrm{~mol} \%$ of $(S, S)$-AzePhenol and $4 \mathrm{~mol} \%$ of $\mathrm{ZnEt}_{2}$, was employed in 2015 by Chang and Wang to promote an enantioselective domino Michael/hemiketalization reaction (Scheme 100) [138]. It involved aryl-substituted $\beta, \gamma$-unsaturated $\alpha$-ketoesters 298 and $\alpha$-hydroxyacetophenone 148a as substrates in dichloromethane as solvent, leading at $0{ }^{\circ} \mathrm{C}$ to the corresponding chiral 2,2,4,5-tetrasubstituted tetrahydrofurans 299 in good yields (64$90 \%$ ), uniformly excellent enantioselectivities (90-98\% ee) and low to good diastereoselectivities $(26-82 \%$ de). The lowest diastereoselectivities (26-40\% de) were obtained in the reaction of $\beta, \gamma$-unsaturated $\alpha$-ketoesters bearing substituents at the metaposition of the phenyl ring.

In 2019, the same authors developed a novel route to chiral bispirotetrahydrofuran oxindoles based on an enantioselective cascade Michael/hemiketalization/Friedel-Crafts reaction of $\beta, \gamma$ unsaturated $\alpha$-ketoamides 294 with 2 -hydroxy-1-indanones $\mathbf{3 0 0}$ 


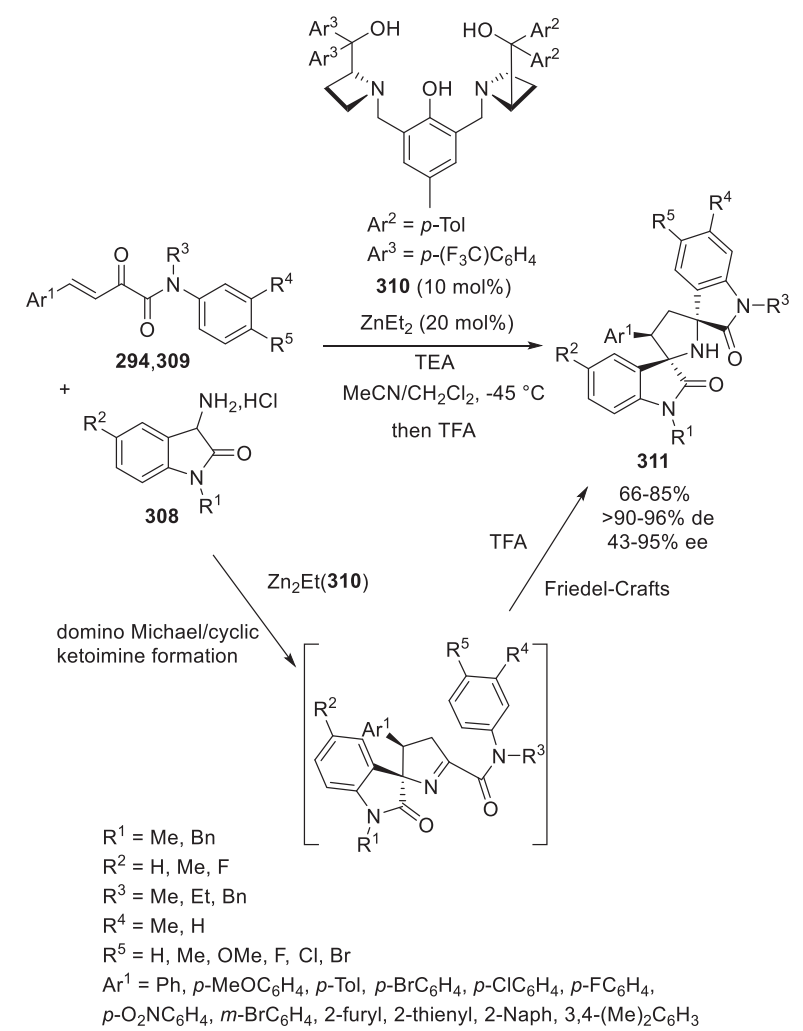

Scheme 104. Domino Michael/cyclic ketoimine formation reaction of 3-amino oxindole hydrochlorides with $\beta, \gamma$-unsaturated $\alpha$-keto amides followed by FriedelCrafts reaction in the presence of a $C_{1}$-symmetric AzePhenol derivative ligand [142].

(Scheme 101) [139]. The sequence was initiated by an asymmetric domino Michael/hemiketalization catalyzed by a chiral dinuclear zinc complex in situ generated from $4 \mathrm{~mol} \%$ of $\mathrm{ZnEt}_{2}$ and $2 \mathrm{~mol} \%$ of chiral AzePhenol derivative ligand 177. The reaction, performed in THF at $0{ }^{\circ} \mathrm{C}$, provided unstable hemiketal domino products 301 which were not isolated but directly submitted to a Friedel-Crafts reaction by treatment with TFA. This led to chiral bispiro[3,2'tetrahydrofuran $-5^{\prime}, 2^{\prime \prime}$ indanone] oxindoles $\mathbf{3 0 2}$ exhibiting three contiguous stereocenters in variable yields (32-79\%), and high diastereo- (82->90\% de) and enantioselectivities (87-99\% ee).

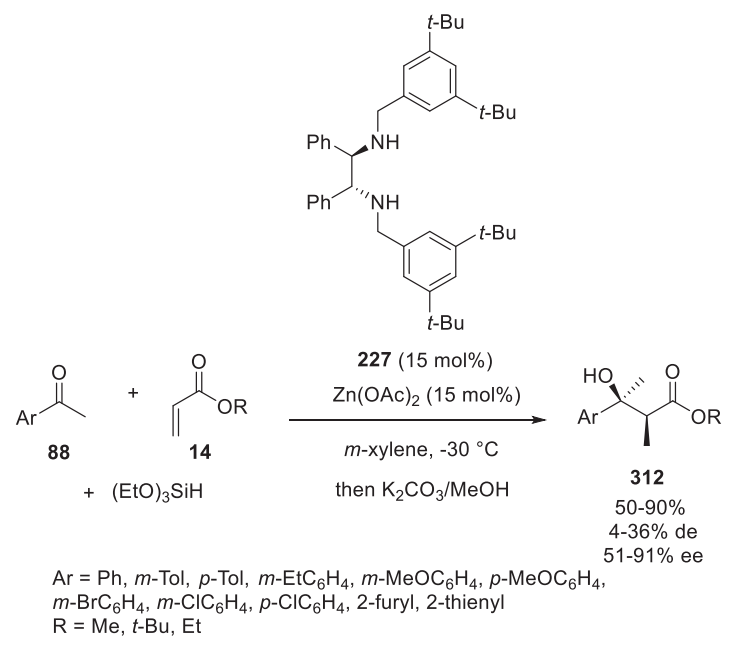

Scheme 105. Three-component domino reductive Michael/aldol reaction of acrylates, aromatic ketones and $(\mathrm{EtO})_{3} \mathrm{SiH}$ in the presence of a diamine ligand [143].
The scope of the process was wide since a range of electrondonating and electron-withdrawing substituents were tolerated on the phenyl ring of each substrates.

In the same year, these authors also employed dinuclear zinc complex in situ generated from $5 \mathrm{~mol} \%$ of $(S, S)$-AzePhenol as ligand and $10 \mathrm{~mol} \%$ of $\mathrm{ZnEt}_{2}$ to catalyze an enantioselective domino Michael/transesterification reaction between $\alpha$-hydroxy-1indanones $\mathbf{3 0 0}$ and phenyl $\alpha, \beta$-unsaturated esters $\mathbf{3 0 3}$ (Scheme 102) [140]. Indeed, variously substituted chiral spiro[1-i ndanone-5,2'- $\gamma$-butyrolactones] 304 were synthesized at $55{ }^{\circ} \mathrm{C}$ in THF as solvent as almost single stereomers (>90\% de, $95->99 \%$ ee) in high yields (76-92\%).

In 2020, a related enantioselective zinc-catalyzed domino Michael/transesterification reaction of $\alpha$-hydroxy indanones $\mathbf{3 0 0}$ with ortho-ester chalcones $\mathbf{3 0 5}$ was disclosed by the same group (Scheme 103) [141]. In this case, chiral AzePhenol derivative 306 was used at $5 \mathrm{~mol} \%$ of catalyst loading as optimal ligand in combination with $10 \mathrm{~mol} \%$ of $\mathrm{ZnEt}_{2}$ to generate the active dinuclear catalyst. The latter allowed at $10{ }^{\circ} \mathrm{C}$ in THF as solvent a range of chiral spiro[indanone-2,3'-isochromane-1-one] derivatives $\mathbf{3 0 7}$ to be obtained as almost single stereomers (>90\% de, $96->99 \%$ ee) in good yields (59-92\%). It was found that the electronic nature and position of substituents on the phenyl ring of either $\alpha$-hydroxy indanones or ortho-ester chalcones had little impact on the stereoselectivity of the reaction.

Earlier in 2019, the same group also developed a new asymmetric domino Michael/cyclic ketoimine formation reaction of

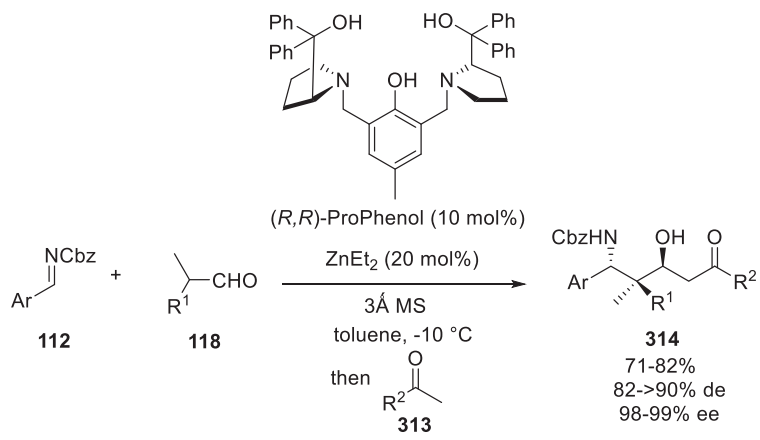

$\mathrm{Ar}=p-\mathrm{FC}_{6} \mathrm{H}_{4}, m-\mathrm{Tol}, \mathrm{o}-\mathrm{BrC}_{6} \mathrm{H}_{4}, \mathrm{o}-\mathrm{Tol}$

$\mathrm{R}^{1}=\mathrm{Me}, \mathrm{Ph}$

$\mathrm{R}^{2}=\mathrm{TMS}-\mathrm{C} \equiv \mathrm{C}, \mathrm{Ph}-\mathrm{C} \equiv \mathrm{C}, \mathrm{Ph}, \mathrm{TBS}\left(\mathrm{CH}_{2}\right)_{3} \mathrm{C} \equiv \mathrm{C},(1$-cyclohexenyl) $\mathrm{C} \equiv \mathrm{C}$

mechanism:
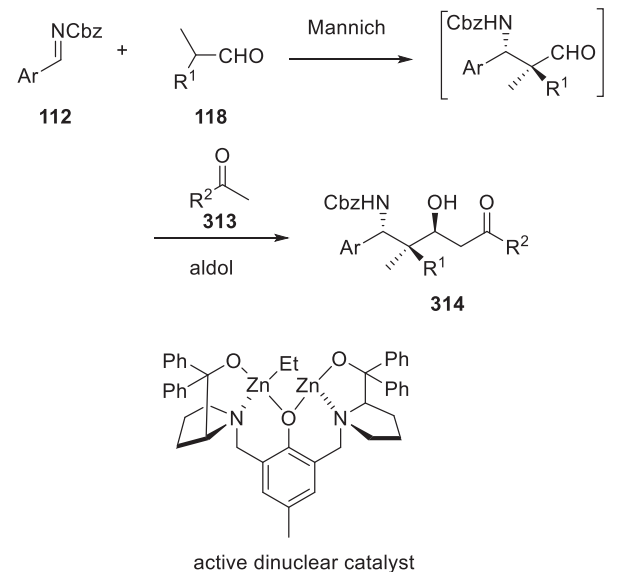

$\mathrm{EtZn}_{2}((R, R)$-ProPhenol)

Scheme 106. Tandem Mannich/aldol reaction of branched aldehydes, aromatic aldimines and ketones in the presence of $(R, R)$-ProPhenol [68]. 


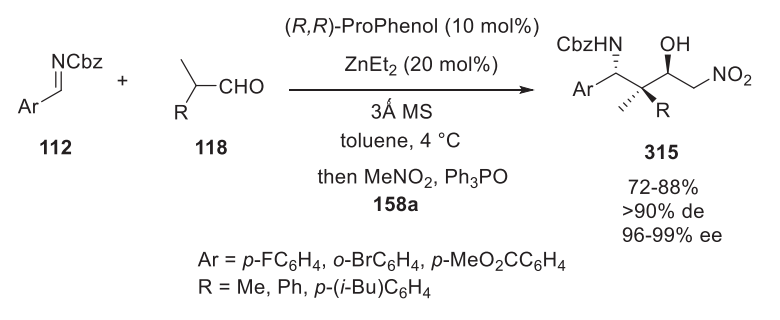

Scheme 107. Tandem Mannich/Henry reaction of branched aldehydes, aromatic aldimines and nitromethane in the presence of $(R, R)$-ProPhenol [68].

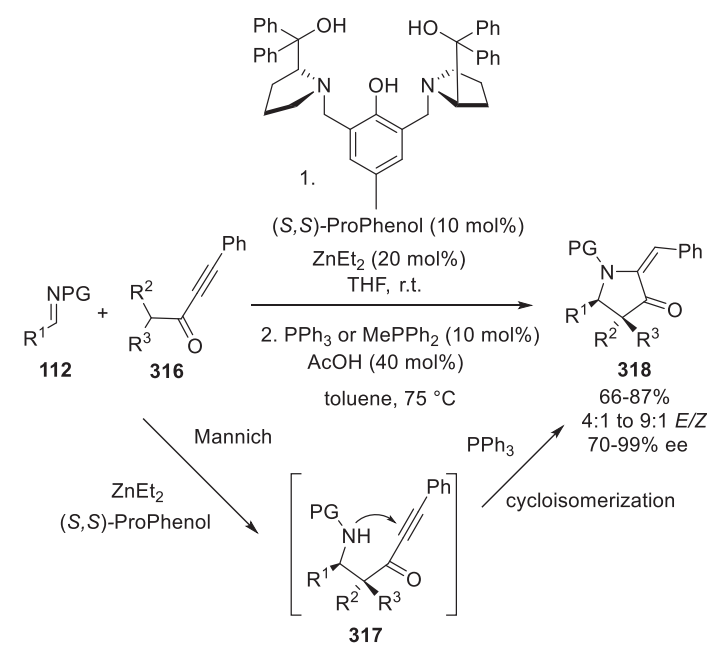

$\mathrm{R}^{1}=p-\mathrm{FC}_{6} \mathrm{H}_{4}, \mathrm{Ph}, p-\mathrm{MeOC}_{6} \mathrm{H}_{4}, o-\mathrm{BrC}_{6} \mathrm{H}_{4}, 1$-furyl, o-Tol, $o-\left(\mathrm{MeO}_{2} \mathrm{CH}=\mathrm{CH}\right) \mathrm{C}_{6} \mathrm{H}_{4}, c-\mathrm{Pr},(E)-\mathrm{PhCH}=\mathrm{CH}$ $\mathrm{R}^{2}=\mathrm{Me}, \mathrm{HC} \equiv \mathrm{C}-\mathrm{CH}_{2}$

$\mathrm{R}^{3}=\mathrm{Me}, \mathrm{Bn}, i-\mathrm{Bu}, \mathrm{Ph}, \mathrm{CH}_{2}=\mathrm{C}(\mathrm{Me})-\mathrm{CH}_{2}$ $\mathrm{R}^{2}, \mathrm{R}^{3}=\left(\mathrm{CH}_{2}\right)_{5},\left(\mathrm{CH}_{2}\right)_{3},\left(\mathrm{CH}_{2}\right)_{2} \mathrm{O}\left(\mathrm{CH}_{2}\right)_{2},\left(\mathrm{CH}_{2}\right)_{2} \mathrm{NBoc}\left(\mathrm{CH}_{2}\right)_{2}$ $P G=B o c, C b z$

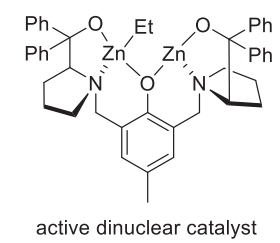

active dinuclear catalyst
$\operatorname{EtZn}_{2}((S, S)-$ ProPhenol)

Scheme 108. Tandem Mannich/cycloisomerization reaction of aldimines with alkynones in the presence of (S,S)-ProPhenol [144].

3-amino oxindole hydrochlorides $\mathbf{3 0 8}$ with aryl-substituted $\beta, \gamma$ unsaturated $\alpha$-ketoamides 294, 309 followed by a Friedel-Crafts reaction performed in a single vessel [142]. This cascade process occurred at $-45{ }^{\circ} \mathrm{C}$ in a mixture of acetonitrile and dichloromethane as solvent, leading to chiral pyrrolidinyl dispirooxindoles 311. Among chiral ligands investigated in this process, $C_{2}$ symmetric $(S, S)$-ProPhenol and AzePhenol derivatives all provided low enantioselectivities ( $\leq 33 \%$ ee). In this context, the authors developed nonsymmetrical ligands, such as $C_{1}$-symmetric ligand 310, with electronically and sterically divergent units (Scheme 104). The use of a combination of $10 \mathrm{~mol} \%$ of this ligand with $20 \mathrm{~mol} \%$ of $\mathrm{ZnEt}_{2}$ allowed pyrrolidinyl dispirooxindoles $\mathbf{3 1 1}$ exhibiting two quaternary stereocenters to be obtained as single diastereomers (>90-96\% de) in high yields (66-85\%) and moderate to high enantioselectivities (43-95\% ee). The presence of various substituents at the phenyl ring of aryl-substituted $\beta, \gamma$ unsaturated $\alpha$-ketoamides 294, 309 was tolerated. Generally, substrates with electron-donating groups at the para position of the

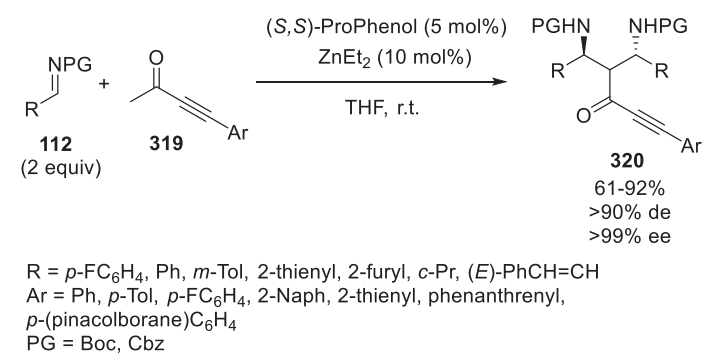

Scheme 109. Pseudo-three-membered domino double Mannich reaction of ynones with aldimines in the presence of $(S, S)$-ProPhenol [145].

phenyl ring $\left(\operatorname{Ar}^{1}\right)$ provided higher enantioselectivities than those with electron-withdrawing groups. The catalytic system was also compatible with heteroaromatic-substituted $\beta, \gamma$-unsaturated $\alpha$ ketoamides and $\gamma$-naphthyl-substituted substrates.

In 2020, Mlynarski et al. described the first enantioselective three-component domino reductive Michael/aldol reaction of acrylates 14, (hetero)aromatic ketones 88 and (EtO) $)_{3} \mathrm{SiH}$ using $\mathrm{Zn}$ $(\mathrm{OAc})_{2}$ as cheap precatalyst [143]. Optimal diamine ligand $\mathbf{2 2 7}$ was employed at $15 \mathrm{~mol} \%$ of catalyst loading in $m$-xylene as solvent to promote the reaction at $-30^{\circ} \mathrm{C}$. As shown in Scheme 105, a series of chiral $\beta$-hydroxy esters $\mathbf{3 1 2}$ were synthesized in moderate to high yields (50-90\%) and enantioselectivities (51-91\% ee) in combination with generally low diastereoselectivities (4-36\% de).

\subsection{Mannich-initiated domino/tandem reactions}

In 2018, Trost et al. described an enantioselective tandem Mannich/aldol reaction between branched aldehydes 118 , aromatic aldimines 112 and ketones 313 catalyzed by a combination of $10 \mathrm{~mol} \%$ of $(R, R)$-ProPhenol and $20 \mathrm{~mol} \%$ of $\mathrm{ZnEt}_{2}$ in toluene at $-10{ }^{\circ} \mathrm{C}$ (Scheme 106) [68]. This one-pot three-component process required the separated addition of ketone $\mathbf{3 1 3}$ into the reaction vessel upon completion of the asymmetric Mannich process. It delivered the corresponding enantiopure 1,3-amino alcohols $\mathbf{3 1 4}$ (98-99\% ee) exhibiting three contiguous stereocenters in high yields (71-82\%) and diastereoselectivities ( $82->90 \%$ de).

In addition, the same catalyst system was applied to develop related enantioselective tandem three-component Mannich/Henry reaction between aromatic aldimines 112, branched aldehydes 118 and nitromethane 158a as added nucleophilic third partner, affording the corresponding chiral 1,3-amino alcohols $\mathbf{3 1 5}$ as almost single stereomers (>90\% de, $96-99 \%$ ee) in high yields (72-88\%), as presented in Scheme 107 [68].

Later in 2019, an enantioselective zinc-catalyzed tandem Mannich/cycloisomerization reaction of aldimines 112 with alkynones $\mathbf{3 1 6}$ was described by the same group [144]. A combination of $20 \mathrm{~mol} \%$ of $\mathrm{ZnEt}_{2}$ and $10 \mathrm{~mol} \%$ of $(S, S)$-ProPhenol was used as catalyst system in THF at room temperature. The Mannich reaction led to intermediate $\beta$-amino ynone $\mathbf{3 1 7}$, which was subsequently cycloisomerized at $75{ }^{\circ} \mathrm{C}$ in the presence of $10 \mathrm{~mol}^{2}$ of $\mathrm{PPh}_{3}$ and $40 \mathrm{~mol} \%$ of $\mathrm{AcOH}$ in toluene as solvent, to afford pyrrolidones 318 in good yields (66-87\%) and enantioselectivities (70-99\% ee) combined with a good $E / Z$ stereoselectivity (up to 9:1) as shown in Scheme 108. Aromatic aldimines with neutral or electron-rich substituents on the phenyl ring gave uniformly excellent enantioselectivities (83-99\% ee) while the lowest enantioselectivity (70\% ee) was obtained in the reaction of an heteroaromatic aldimine $\left(\mathrm{R}^{1}=1\right.$-furyl). Moreover, a vinyl aldimine $\left(\mathrm{R}^{1}=(E)-\mathrm{PhCH}=\mathrm{CH}\right)$ was cyclized in $68 \%$ yield and $87 \%$ ee whereas the reaction of $c$-propyl aldimine $\left(\mathrm{R}^{1}=c\right.$-Pr) required the use of a more nucleophilic additive, such as $\mathrm{MePPh}_{2}$ instead of $\mathrm{PPh}_{3}$, to 


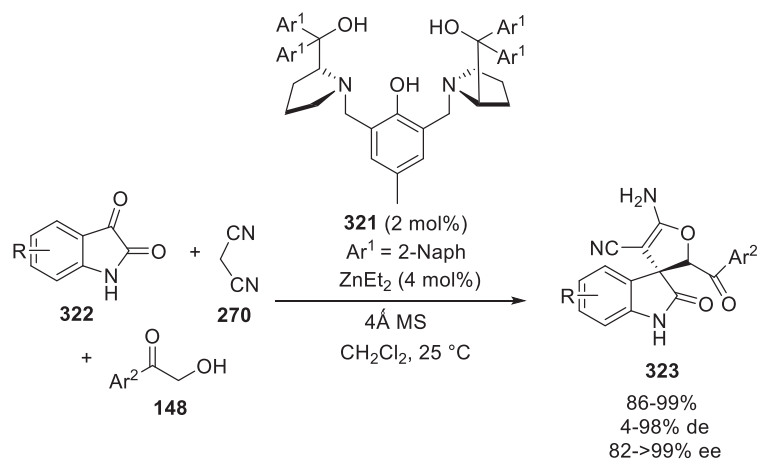

$\mathrm{Ar}^{2}=\mathrm{Ph}, p-\mathrm{FC}_{6} \mathrm{H}_{4}, p-\mathrm{ClC}_{6} \mathrm{H}_{4}, p-\mathrm{BrC}_{6} \mathrm{H}_{4}, p-\mathrm{MeOC}_{6} \mathrm{H}_{4}, p-\mathrm{Tol}, m-\mathrm{ClC}_{6} \mathrm{H}_{4}$ $m$ - $\mathrm{BrC}_{6} \mathrm{H}_{4}, o-\mathrm{MeOC}_{6} \mathrm{H}_{4}, m$-Tol, 2-Naph, 2-thienyl, 2,5-(MeO $)_{2} \mathrm{C}_{6} \mathrm{H}_{3}$ $\mathrm{R}=\mathrm{H}, 5-\mathrm{Me}, 5-\mathrm{MeO}, 5-\mathrm{F}, 5-\mathrm{Cl}, 5-\mathrm{Br}, 6-\mathrm{Br}$

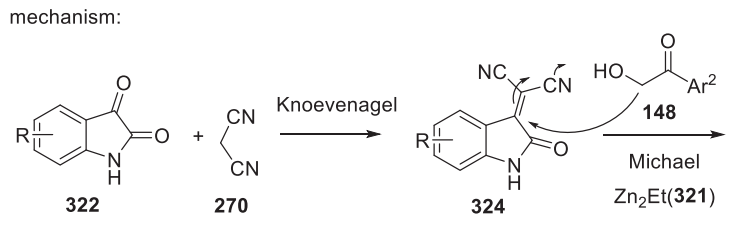

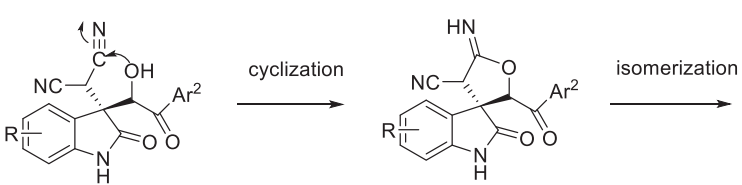
325

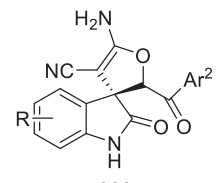

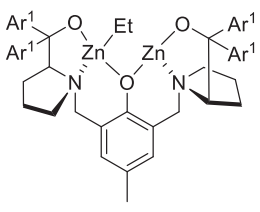

active dinuclear catalyst

Scheme 110. Three-component domino Knoevenagel/Michael/cyclization/isomerization reaction of isatins, malononitrile and $\alpha$-hydroxy acetophenones in the presence of a ProPhenol derivative ligand [146].

perform the cycloisomerization, leading to the corresponding pyrrolidone in $79 \%$ yield and $92 \%$ ee. Interestingly, heterocyclic chiral spirocycles, such as a tetrahydropyran $\left(\mathrm{R}^{2}, \mathrm{R}^{3}=\left(\mathrm{CH}_{2}\right)_{2} \mathrm{O}\right.$ $\left.\left(\mathrm{CH}_{2}\right)_{2}\right)$ and a $\mathrm{N}$-Boc piperidine $\left(\mathrm{R}^{2}, \mathrm{R}^{3}=\left(\mathrm{CH}_{2}\right)_{2} \mathrm{NBoc}\left(\mathrm{CH}_{2}\right)_{2}\right)$, could be synthesized with good yields ( 86 and $66 \%$, respectively) and high enantioselectivities (92 and $82 \%$ ee, respectively).

In 2020, a combination of $5 \mathrm{~mol} \%$ of (S,S)-ProPhenol with $10 \mathrm{~mol}$ $\%$ of $\mathrm{ZnEt}_{2}$ was used by Trost and Gnanamani at room temperature in THF as solvent to promote an asymmetric pseudo-threecomponent reaction between ynones $\mathbf{3 1 9}$ and two equivalents of aldimines 112 (Scheme 109) [145]. This domino double Mannich reaction produced enantio- and almost diastereopure 1,3diamines 320 (>90\% de, >99\% ee) in good to high yields (6192\%). Along with (hetero)aromatic aldimines, cyclopropyl imine $(\mathrm{R}=c$ - $\mathrm{Pr}$ ) also underwent the reaction with comparable excellent results (78\% yield, $>90 \%$ de and $>99 \%$ ee). Furthermore, a variety of (hetero)aromatic ynones were tolerated.
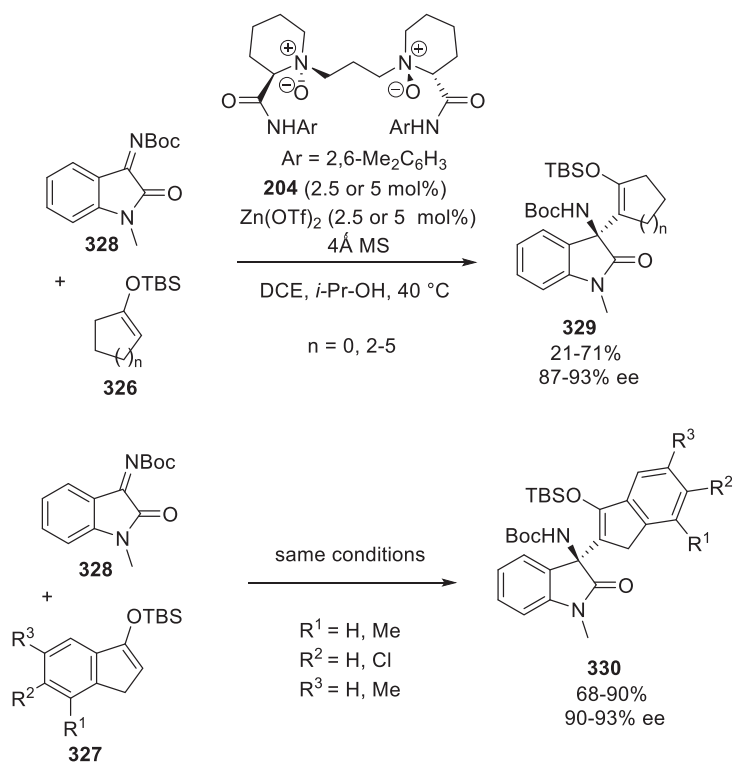

Scheme 111. Domino $\alpha$-alkenyl addition/proton shift reactions of silyl enol ethers with isatin-derived ketimines in the presence of a $N, N^{\prime}$-dioxide ligand [147].

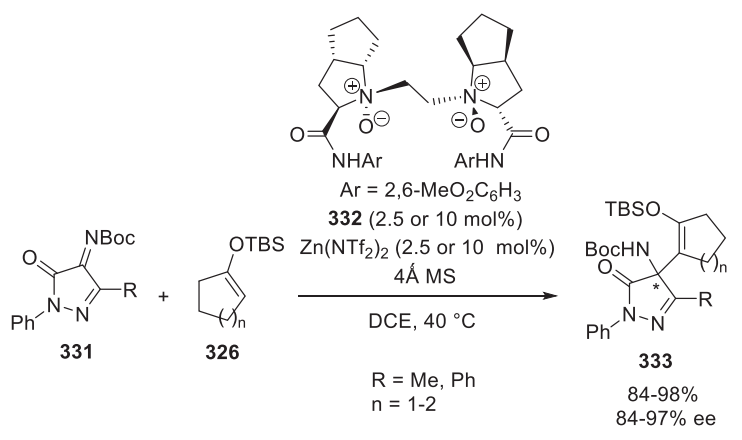

Scheme 112. Domino $\alpha$-alkenyl addition/proton shift reaction of silyl enol ethers with pyrazolinone-derived ketimines in the presence of a $N, N^{\prime}$-dioxide ligand [147].

\subsection{Other domino reactions}

A three-component reaction was disclosed in 2019 by Wang et al. based on the use of ProPhenol derivative ligand $\mathbf{3 2 1}$ (Scheme 110) [146]. Only $2 \mathrm{~mol} \%$ of this semi-aza-crown ligand was combined with $4 \mathrm{~mol} \%$ of $\mathrm{ZnEt}_{2}$ in this domino Knoevenagel/ Michael/cyclization/isomerization reaction between isatins $\mathbf{3 2 2}$, malononitrile 270 and $\alpha$-hydroxy acetophenones 148. Carried out at $25{ }^{\circ} \mathrm{C}$ in dichloromethane as solvent, the process resulted in the formation of chiral 3,3'-dihydrofuran spirooxindoles 323 in high yields (86-99\%) and enantioselectivities (82->99\% ee) with variable diastereoselectivities (4-98\% de). Generally, the reaction of isatins bearing electron-rich substituents provided slightly higher enantioselectivities than those exhibiting electrondeficient groups. As depicted in Scheme 110, the Knoevenagel reaction of isatin $\mathbf{3 2 2}$ with malononitrile $\mathbf{2 7 0}$ afforded intermediate 324, which was further submitted to asymmetric zinc-catalyzed Michael addition of $\alpha$-hydroxy acetophenone 148 to give intermediate 325. The latter was then submitted to cyclization followed by isomerization to afford the final product.

In 2019, chiral $N, N^{\prime}$-dioxide ligands were applied by Feng et al. to develop the first enantioselective domino $\alpha$-alkenyl addition/ proton shift reaction of silyl enol ethers with cyclic ketimines [147]. As depicted in Scheme 111, silyl enol ethers 326 and 327 


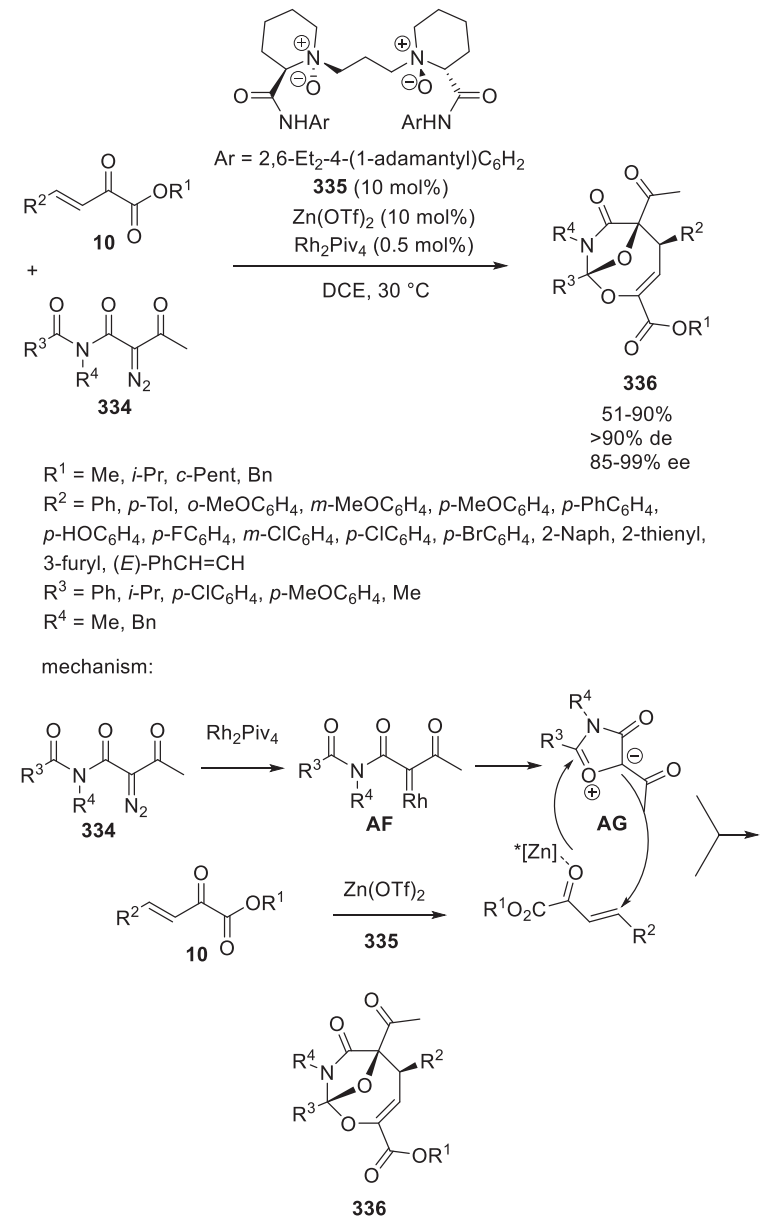

Scheme 113. Domino carbonylimide formation/[4+3] cycloaddition reaction of $\beta$, $\gamma$-unsaturated $\alpha$-ketoesters with diazoimides in the presence of a $N, N^{\prime}$-dioxide ligand [148].

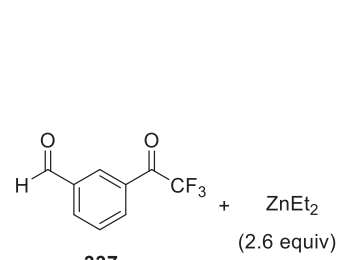

337
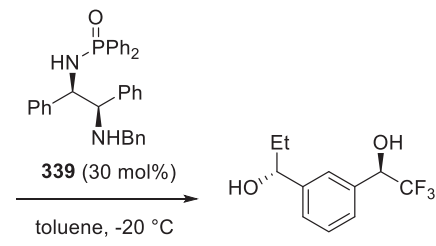

340

$86 \%$ $40 \%$ de
$92 \%$ ee<smiles>CCO[C@H](C)C(=O)c1ccc(C=O)cc1</smiles><smiles>CCC(O)c1ccc(C(O)C(F)(F)F)cc1</smiles>

Scheme 114. Domino transfer reduction/ethylation reactions of aryl $\alpha$-trifluoromethylketones with $\mathrm{ZnEt}_{2}$ in the presence of a 1,2-amino phosphoramide ligand [149].

reacted with isatin-derived ketimine $\mathbf{3 2 8}$ in the presence of 2.5$5 \mathrm{~mol} \%$ of a chiral zinc catalyst in situ generated from $\mathrm{Zn}(\mathrm{OTf})_{2}$ and chiral $N, N^{\prime}$-dioxide ligand 204 at $40{ }^{\circ} \mathrm{C}$ to give the correspond-

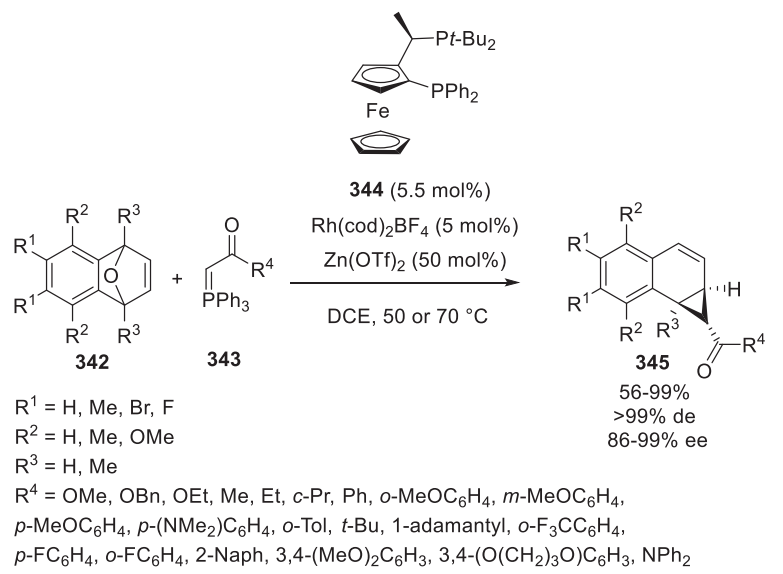

mechanism with $\mathrm{R}^{1}=\mathrm{R}^{2}=\mathrm{R}^{3}=\mathrm{H}, \mathrm{R}^{4}=\mathrm{OEt}$ :

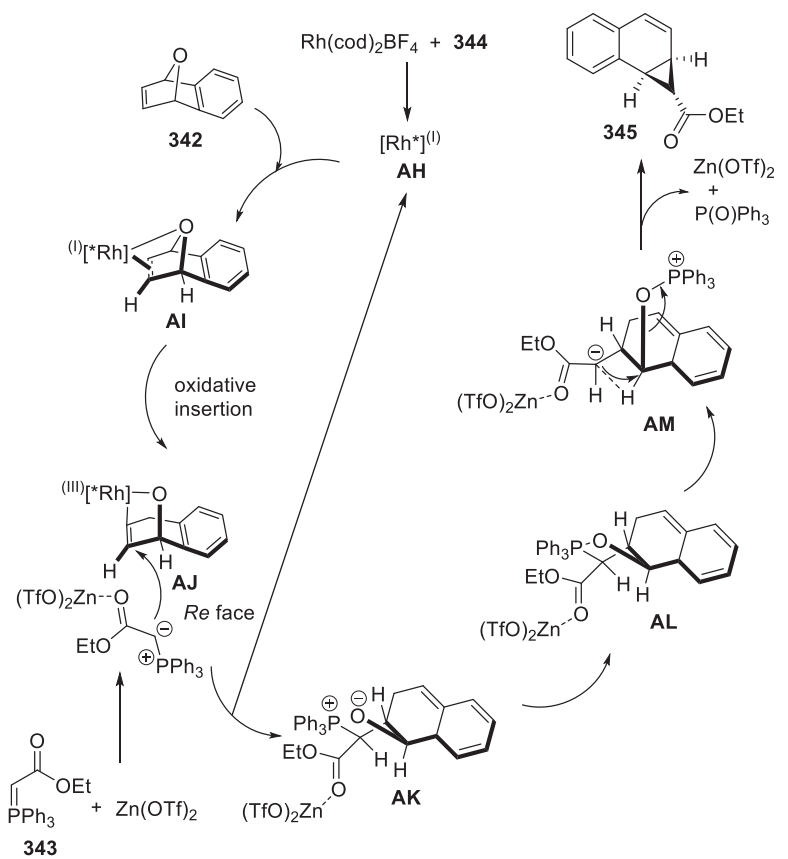

Scheme 115. Domino ring-opening/cyclopropanation reaction of oxabenzonorbornadienes with phosphorus ylides in the presence of a biphosphine ligand [150].

ing $\beta$-amino silyl enol ethers $\mathbf{3 2 9}$ and 330, respectively, in high enantioselectivities (87-93\% ee) and variable yields (21-90\%).

These authors extended the scope of this novel process to pyrazolinone-derived ketimines $\mathbf{3 3 1}$ which reacted with silyl enol ethers 326 (Scheme 112) [147]. In this case, the catalyst system was composed of a related $N, N^{\prime}$-dioxide ligand 332 and $\mathrm{Zn}$ $\left(\mathrm{NTf}_{2}\right)_{2}$, allowing the formation of chiral $\beta$-amino silyl enol ethers 333 with both high yields (84-98\%) and enantioselectivities (84$97 \%$ ee)

In 2019, a dual bimetallic relay catalysis was employed by Feng and Lin in an enantioselective domino reaction of $\beta, \gamma$-unsaturated $\boldsymbol{\alpha}$-ketoesters 10 with diazoimides 334 (Scheme 113) [148]. The catalyst system included an achiral rhodium complex, such as $\mathrm{Rh}_{2}-$ $\mathrm{Piv}_{4}$, and a chiral zinc catalyst in situ generated from $\mathrm{Zn}(\mathrm{OTf})_{2}$ and chiral $N, N^{\prime}$-dioxide ligand 335 . The rhodium catalyst allowed the generation of a carbonyl ylide intermediate from the diazoimide substrate which subsequently reacted through asymmetric $[4+3]$ cycloaddition with the $\beta, \gamma$-unsaturated $\alpha$-ketoester 


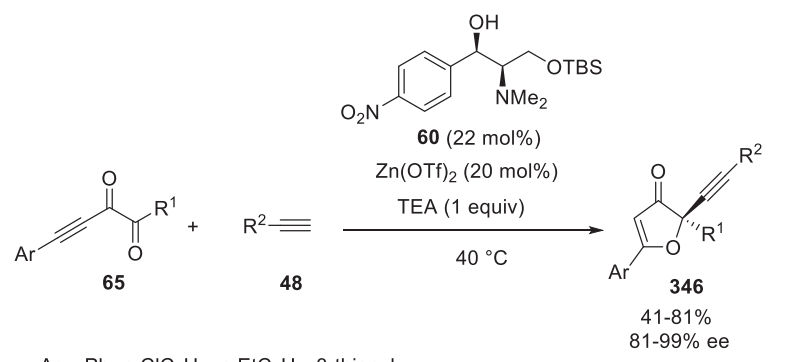

$\mathrm{Ar}=\mathrm{Ph}, p-\mathrm{ClC}_{6} \mathrm{H}_{4}, p-\mathrm{EtC}_{6} \mathrm{H}_{4}, 3$-thieny

$\mathrm{R}^{1}=\mathrm{Ph}, p-\mathrm{ClC}_{6} \mathrm{H}_{4}, 1-\mathrm{Naph}$, 2-thienyl, $(E)-\mathrm{PhCH}=\mathrm{CH}, p-\mathrm{MeOC}_{6} \mathrm{H}_{4}, p$-Tol

$\mathrm{R}^{2}=p$-Tol, $\mathrm{Ph}, p-\mathrm{FC}_{6} \mathrm{H}_{4},(E)-\mathrm{PhCH}=\mathrm{CH}, p$ - $\mathrm{EtOC}_{6} \mathrm{H}_{4}, 3$-thienyl, $p$ - $\mathrm{MeOC}_{6} \mathrm{H}_{4}$ $p-\mathrm{EtC}_{6} \mathrm{H}_{4}, m-\mathrm{ClC}_{6} \mathrm{H}_{4}, o-\mathrm{FC}_{6} \mathrm{H}_{4}$

$$
\text { mechanism: }
$$

$$
\stackrel{-\mathrm{TEA}}{\longrightarrow}
$$

Scheme 116. Domino alkynylation/cyclization reaction of alkynyl 1,2-diketones with alkynes in the presence of a 1,2-amino alcohol ligand [45].

catalyzed by the chiral zinc complex. This domino carbonyl imide formation/[4 + 3] cycloaddition reaction provided chiral oxabridged oxazocines $\mathbf{3 3 6}$ as almost single exo-diastereomers ( $>90 \%$ de) in good to high yields (51-90\%) and high enantioselectivities (85-99\% ee). Various (hetero)aryl-substituted $\beta, \gamma$-unsaturated $\alpha$ ketoesters 10, bearing either electron-withdrawing or electrondonating substituents at different positions of the phenyl group, were tolerated. Heteroaromatic-substituted substrates were also compatible as well as various alkyl ester groups $\left(\mathrm{R}^{1}\right)$. Furthermore, variously $(N)$-substituted diazoimides reacted smoothly. The process evolved through the formation of rhodium carbene species AF from the reaction between diazoimide 334 and $\mathrm{Rh}_{2} \mathrm{Piv}_{4}$. Then, an intramolecular carbonyl attack on the rhodium carbene occurred to generate 1,3-dipole AG. The latter reacted with the $\beta$, $\gamma$-unsaturated $\alpha$-ketoester substrate activated by the chiral zinc catalyst through a [4+3] cycloaddition to provide the final domino product.

Earlier in 2015, Song et al. described enantioselective zinccatalyzed domino transfer reduction/ethylation reaction of aryl $\alpha$-trifluoromethylketones 337, 338 with $\mathrm{ZnEt}_{2}$ performed in the presence of $30 \mathrm{~mol} \%$ of chiral 1,2-amino phosphoramide ligand 339 [149]. The process included the asymmetric $\beta-\mathrm{H}$ transfer reduction of the aryl $\alpha$-trifluoro ketones and the enantioselective addition of $\mathrm{ZnEt}_{2}$ to the aromatic aldehyde moieties (Scheme 114). It produced in toluene at $-20{ }^{\circ} \mathrm{C}$ almost enantiopure fluorinated diols 340, 341 (92-97\% ee) in high yields (86-90\%) albeit with low diastereoselectivities (40-42\% de).

In 2019, Shao et al. developed the first enantioselective domino ring-opening/cyclopropanation reaction of oxabenzonorbornadienes $\mathbf{3 4 2}$ with phosphorus ylides $\mathbf{3 4 3}$ (Scheme 115) [150]. The process involved a dual bimetallic rhodium/zinc catalysis with $5 \mathrm{~mol} \%$ of $\mathrm{Rh}(\mathrm{cod})_{2} \mathrm{BF}_{4}, 50 \mathrm{~mol} \%$ of $\mathrm{Zn}(\mathrm{OTf})_{2}$ and $5.5 \mathrm{~mol} \%$ of chiral biphosphine ligand 344. It formed chiral benzonorcaradienes 345 as sin-

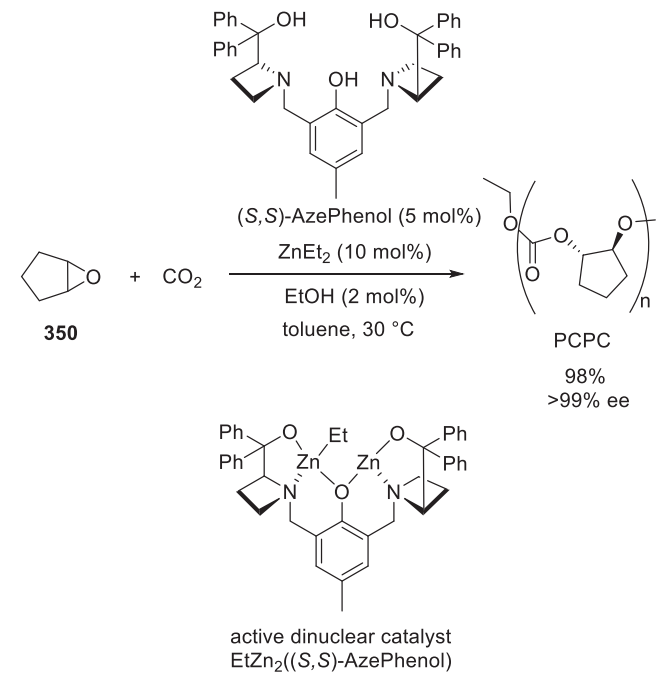

Scheme 117. Copolymerization of cyclopentene oxide with $\mathrm{CO}_{2}$ in the presence of (S,S)-AzePhenol [152].

gle diastereomers in good to high yields (56-99\%) and high enantioselectivities ( $86-99 \%$ ee). A possible mechanism is depicted

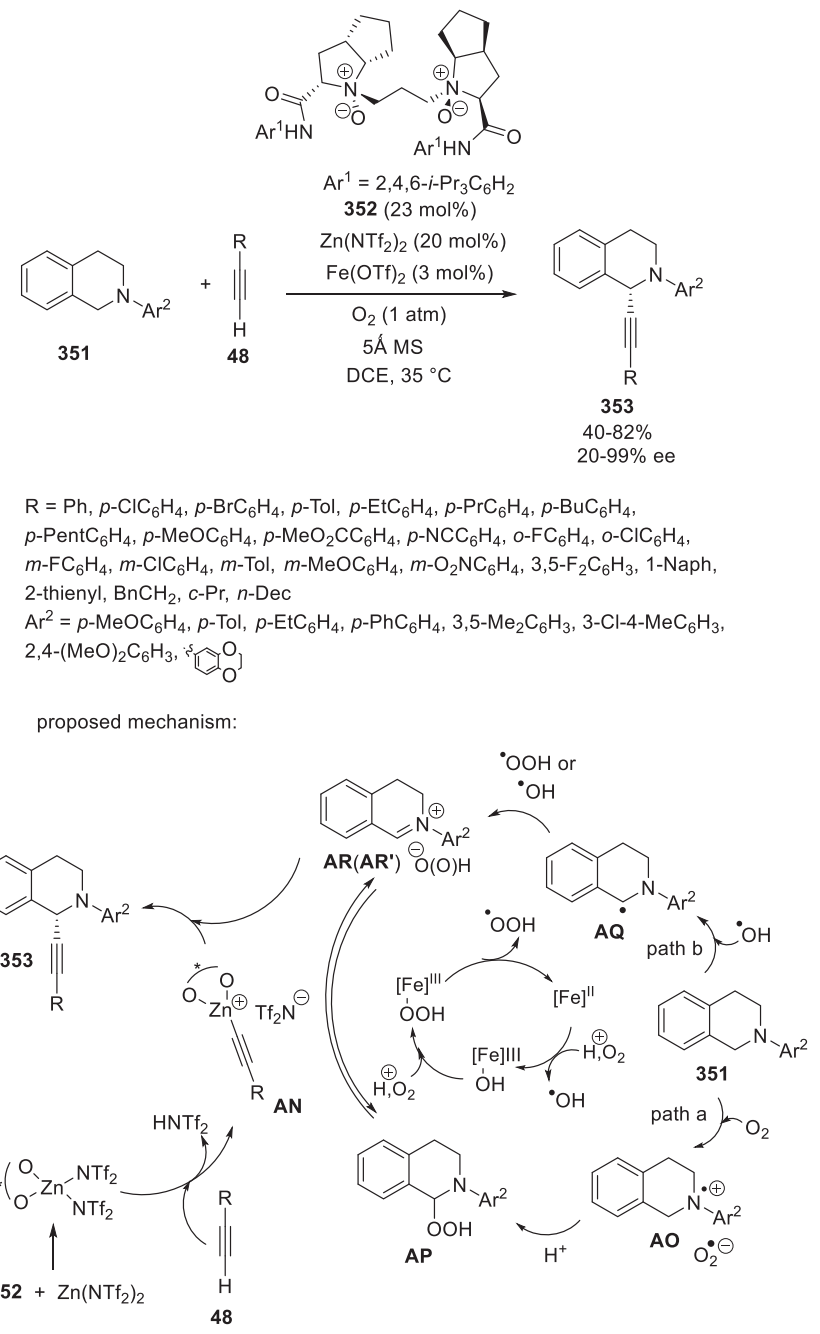

Scheme 118. Cross-dehydrogenative coupling of tetrahydroisoquinolines with terminal alkynes in the presence of a $N, N^{\prime}$-dioxide ligand [153] 
in Scheme 115, beginning with the formation of chiral rhodium catalyst $\mathbf{A H}$ which coordinated the oxabenzonorbornadiene from the exo face to give intermediate $\mathbf{A I}$. Then, oxidative insertion with retention into a bridgehead $\mathrm{C}-\mathrm{H}$ bond provided complex AJ. Subsequently, phosphorus ylide $\mathbf{3 4 3}$ activated by $\mathrm{Zn}(\mathrm{OTf})_{2}$ attacked $\mathbf{A J}$ from the $R e$ face to give intermediate $\mathbf{A K}$ and regenerated rhodium catalyst. Then, AK was submitted to ring-closing to give intermediate $\mathbf{A L}$. The latter underwent ring-opening to produce the intermediate AM through cleavage of the C-P bond. Finally, intermediate AM underwent an intramolecular $\mathrm{S}_{\mathrm{N}} 2$ reaction to deliver the product with elimination of $\mathrm{O}=\mathrm{PPh}_{3}$. In this mechanism, $\mathrm{Zn}(\mathrm{OTf})_{2}$ played the role of Lewis acid cocatalyst, by activating the phosphorus ylide and bridging oxygen, facilitating the asymmetric ringopening.

In 2020, Fang and Ding developed highly regio- and enantioselective domino alkynylation/cyclization reaction of alkynyl 1,2diketones 65 with alkynes 48 under asymmetric zinc catalysis [45]. The zinc catalyst was in situ generated from $20 \mathrm{~mol} \%$ of $\mathrm{Zn}$ $(\mathrm{OTf})_{2}$ and $20 \mathrm{~mol} \%$ of chiral amino alcohol ligand 60 at room temperature (Scheme 116). Whereas in the presence of DIPEA as base, the reaction evolved through a simple alkynylation (see Scheme 19, section 3.2), when performed with TEA as base at $40^{\circ} \mathrm{C}$, the alkynylation was followed by cyclization. As depicted in Scheme 116, alkynyl 1,2-diketones 65 reacted with alkynes 48 in the presence of TEA through a domino alkynylation/cyclization reaction to give the corresponding chiral biologically important $3(2 \mathrm{H})$-furanones 346 in moderate to good yields (41-81\%) and high enantioselectivities (81-99\% ee). A mechanism is proposed in Scheme 116, involving the nucleophilic addition of TEA to the alkyne unit of the intermediate alkynylation product $\mathbf{3 4 7}$ to give allenic intermediate 348. Then, the latter underwent a proton transfer to provide intermediate 349 which cyclized into the final 3(2H)-furanone 346.

\section{Miscellaneous reactions}

Chiral polycarbonates constitute starting materials for the synthesis of new materials because of their well-defined chemical structures and special physical properties [151]. Previous studies on the asymmetric copolymerization of cyclopentene oxide $\mathbf{3 5 0}$ with $\mathrm{CO}_{2}$ have been catalyzed by chiral zinc catalysts, providing chiral poly(cyclopentene carbonate) with moderate enantioselectivities. To improve these results, Chang and Wang reinvestigated this reaction by using a chiral dinuclear catalyst derived from $10 \mathrm{~mol} \%$ of $\mathrm{ZnEt}_{2}$ and $5 \mathrm{~mol} \%$ of $(S, S)$-AzePhenol as ligand [152]. The process employed ethanol as an additive and toluene as a sol-

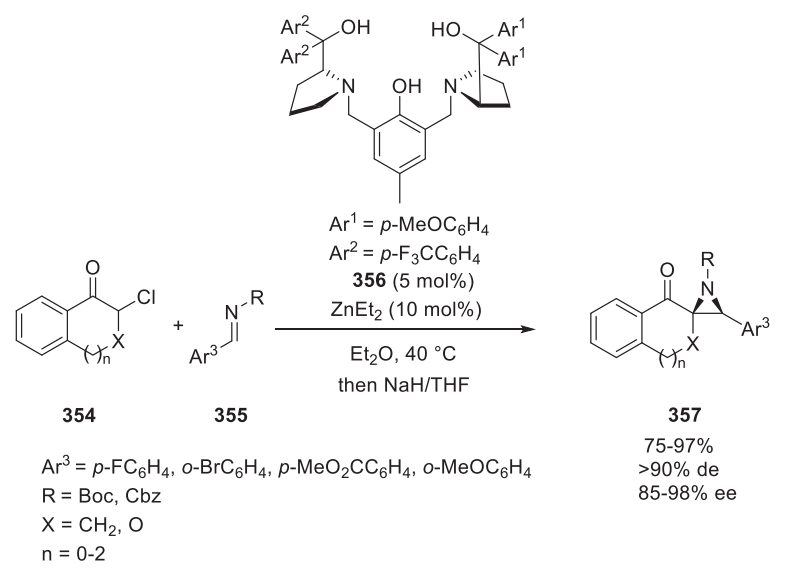

Scheme 119. Aza-Darzens reaction of chlorinated aromatic ketones with $\mathrm{N}$ protected aldimines in the presence of a $C_{1}$-symmetric ProPhenol derivative ligand [154].
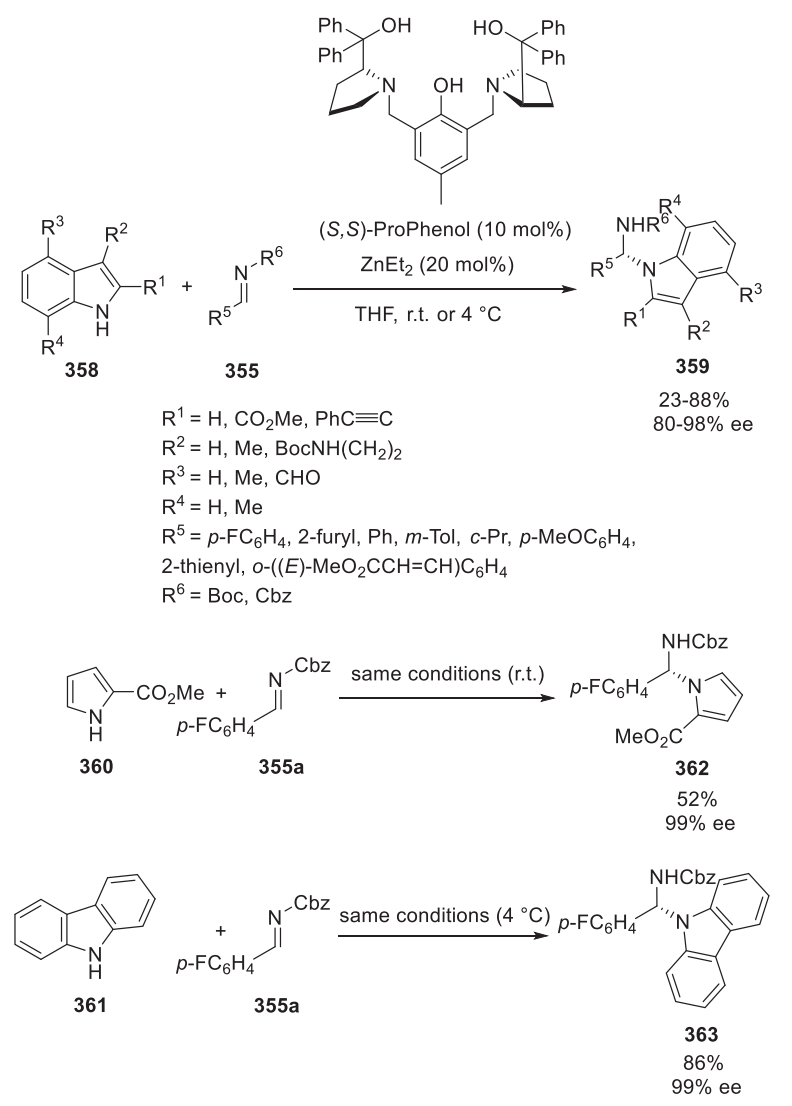

Scheme 120. $N$-Alkylations of indoles, methyl pyrrole-2-carboxylate and carbazole with $N$-protected aldimines in the presence of $(S, S)$-ProPhenol [155].

vent. Performed at $30^{\circ} \mathrm{C}$, it led to enantiopure completely alternating copolymer poly(cyclopentene carbonate) (PCPC) (>99\% ee) in quantitative yield (98\%), as illustrated in Scheme 117.

With the aim of synthesizing biologically active tetrahydroisoquinoline derivatives, Feng and Liu developed in 2017 the first enantioselective aerobic cross-dehydrogenative coupling between tetrahydroisoquinolines $\mathbf{3 5 1}$ and terminal alkynes $\mathbf{4 8}$ under mild reaction conditions (Scheme 118) [153]. The process, which employed $\mathrm{O}_{2}$ as the sole oxidant, was based on a bimetallic cooperative catalysis involving $20 \mathrm{~mol} \%$ of $\mathrm{Zn}\left(\mathrm{NTf}_{2}\right)_{2}, 3 \mathrm{~mol} \%$ of $\mathrm{Fe}$ $(\mathrm{OTf})_{2}$, and $23 \mathrm{~mol} \%$ of chiral $N, N^{\prime}$-dioxide ligand $\mathbf{3 5 2}$. The reaction occurred in DCE at $35{ }^{\circ} \mathrm{C}$ to afford a wide range of chiral $\alpha$-alkynyl substituted tetrahydroisoquinolines $\mathbf{3 5 3}$ in good yields (40-82\%) and in most cases high enantioselectivities (20-99\% ee). Many substituted ethynylbenzenes underwent the reaction with good yields (40-82\%) and uniformly high enantioselectivities (85-99\% ee) regardless of the electronic nature or position of the substituents on the phenyl group. On the other hand, the reaction of alkylsubstituted terminal alkynes gave lower enantioselectivities (20$61 \%$ ee). A mechanism is proposed in Scheme 118 in which the in situ generated chiral $N, N^{\prime}$-dioxide-Zn(II) complex reacts with terminal alkyne $\mathbf{4 8}$ to form zinc acetylide intermediate AN. Concomitantly, without additional Fe(II) catalyst (path a), autooxidation of the tetrahydroisoquinoline results in the formation of AO containing the amine radical cation of tetrahydroisoquinoline $^{+}$and superoxide radical anion $\mathrm{O}^{2-}$. A further $\mathrm{H}$-abstraction provides hydroperoxide tetrahydroisoquinoline- $\mathrm{OOH}$ AP which is in equilibrium with iminium species $\mathbf{A} \mathbf{R}^{\prime}$. In the presence of aerobic iron catalyst, $\mathrm{Fe}(\mathrm{III})$ species are generated along with HO radical. The latter abstracts a $\mathrm{H}$ atom from the tetrahydroisoquinoline to 


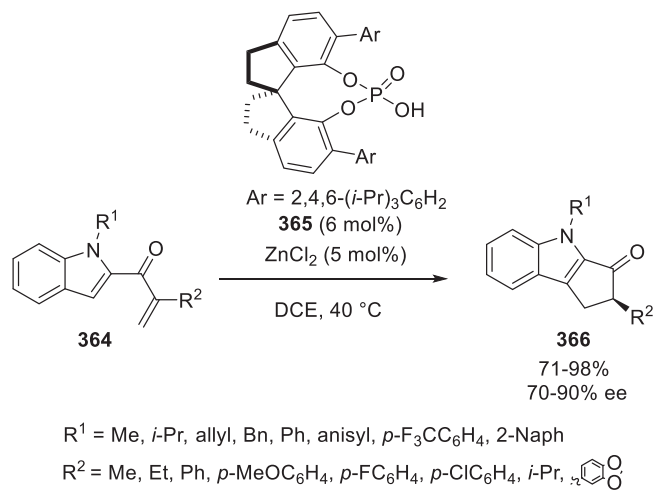

mechanism through cooperative catalysis:
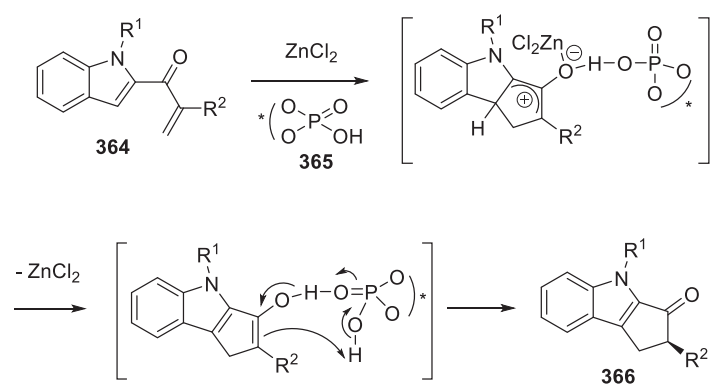

Scheme 121. Nazarov reaction of indoles in the presence of a cooperative dual $\mathrm{Zn} /$ phosphoric acid catalysis [157].

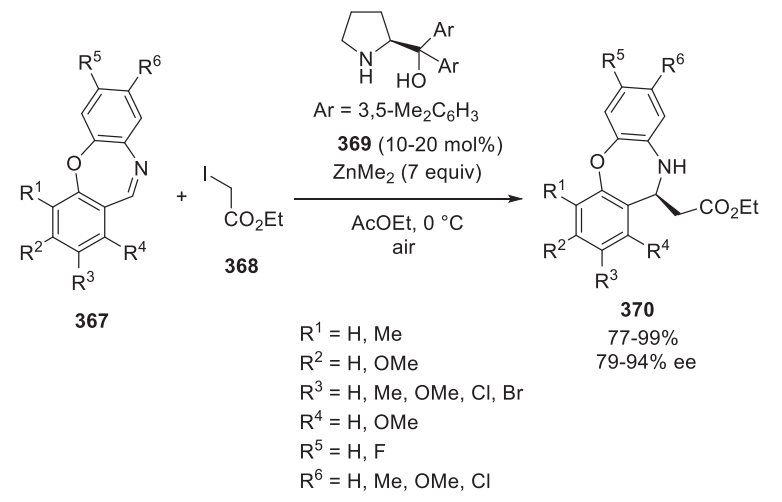

Scheme 122. Aza-Reformatsky reaction of seven-membered cyclic imines with ethyl iodoacetate in the presence of a diaryl prolinol ligand [158].

give radical $\mathbf{A Q}$ (path b). On the other hand, Fe(III) species convert into $\mathrm{Fe}(\mathrm{III}) \mathrm{OOH}$ species, which undergoes homolysis of $\mathrm{Fe}-\mathrm{O}$ bond to generate HOO radical, which benefits to the formation of iminium species AR. Enantioselective alkynylation controlled by the chiral $N, N^{\prime}$-dioxide-Zn(II) complex finally yields the crosscoupling product and the regenerated catalyst.

To date, the only reported catalytic enantioselective azaDarzens reaction is restricted to chloroacetylacetone, which affords aziridines possessing a single stereogenic center. With the aim of developing a new access to chiral complex trisubstituted aziridines, Trost et al. disclosed in 2017 enantioselective aza-Darzens reactions of chlorinated aromatic ketones 354 with aromatic aldimines 355 [154]. The reaction was catalyzed at $40^{\circ} \mathrm{C}$ by a combination of $10 \mathrm{~mol} \%$ of $\mathrm{ZnEt}_{2}$ and $5 \mathrm{~mol} \%$ of ProPhenol derivative ligand 356 in diethyl ether as solvent, leading after subsequent treatment with $\mathrm{NaH}$ in THF to the corresponding chiral aziridines 357 as almost single diastereomers $(>90 \%$ de) in high yields

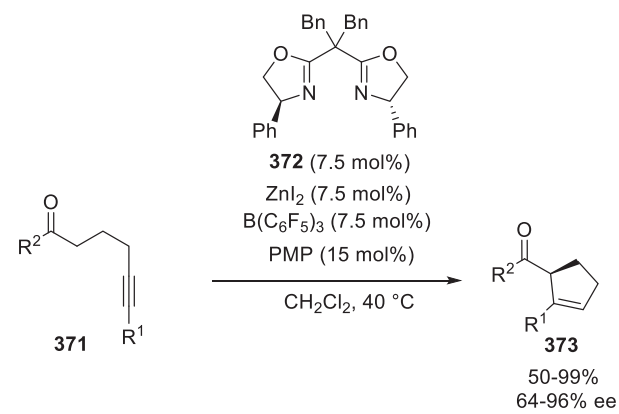

$\mathrm{R}^{1}=n-\mathrm{Pr}, \mathrm{Me}, \mathrm{Et}, n-\mathrm{Bu}, i-\mathrm{Bu}, \mathrm{Bn}, \mathrm{Ph}, \mathrm{MeO}_{2} \mathrm{C}\left(\mathrm{CH}_{2}\right)_{2}$, allyl $\mathrm{R}^{2}=\mathrm{Ph}, p-\mathrm{MeOC}_{6} \mathrm{H}_{4}, p-\mathrm{BrC}_{6} \mathrm{H}_{4}, 2$-furyl, 2-thienyl, Et, $n$-Bu

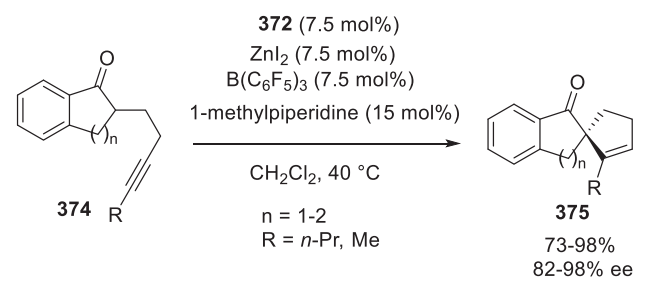

Scheme 123. Conia-ene-type cyclizations of alkynyl ketones in the presence of a multicatalyst system [159].

(75-97\%) and enantioselectivities (85-98\% ee), as presented in Scheme 119.

The same authors also developed the first asymmetric $\mathrm{N}$ alkylation of indoles 358 with $N$-protected aldimines 355 promoted by a dinuclear zinc catalyst derived from (S,S)-ProPhenol (10 $\mathrm{mol} \%)$ and $\mathrm{ZnEt}_{2}$ (20 mol\%) [155]. This reaction was performed at room temperature or $4{ }^{\circ} \mathrm{C}$ in THF as solvent, leading to the corresponding chiral $\mathrm{N}$-alkylated indoles $\mathbf{3 5 9}$ in low to high yields (23-88\%) and high enantioselectivities (80-98\% ee), as illustrated in Scheme 120. In addition to be compatible to a wide range of indoles, the catalyst system was applicable to other nitrogencontaining heterocycles, such as pyrrole derivative $\mathbf{3 6 0}$ and carbazole 361. Indeed, the reaction of methyl pyrrole-2-carboxylate 360 with imine 355a led to the corresponding enantiopure (99\% ee) $N$-alkylated pyrrole $\mathbf{3 6 2}$ in 52\% yield and that of carbazole

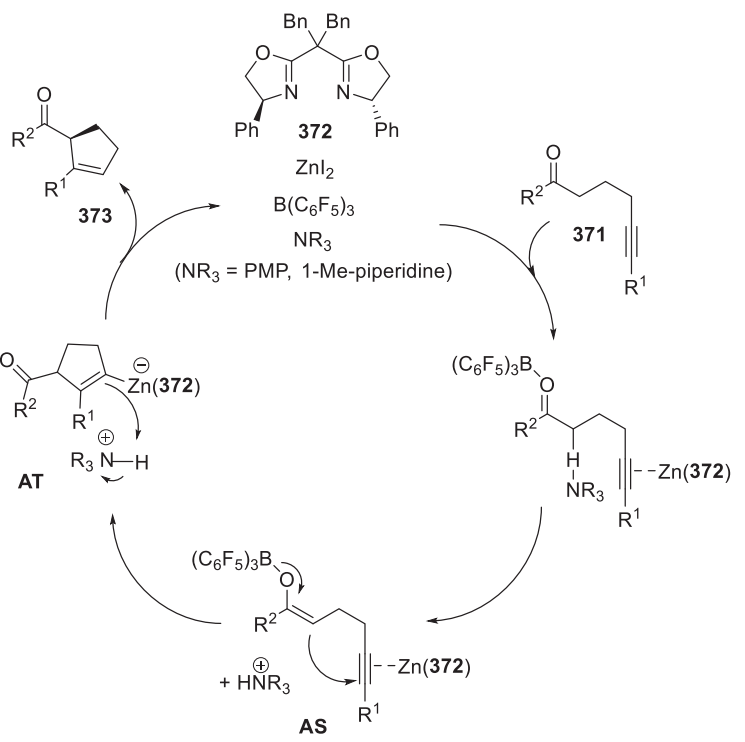

Scheme 124. Mechanism for Conia-ene-type cyclization of alkynyl ketones in the presence of a multicatalyst system [159]. 
$\mathbf{3 6 1}$ with the same imine provided enantiopure amine 363 in 86\% yield.

The combination of metal catalysis with asymmetric organocatalysis attracts increasing attention in the synthetic community [156]. In 2017, this powerful methodology was applied by Zhou and Zhu to promote asymmetric Nazarov cyclizations of indole enones 364 [157]. Indeed, a combination of $5 \mathrm{~mol} \%$ of $\mathrm{ZnCl}_{2}$ with $6 \mathrm{~mol} \%$ of chiral phosphoric acid $\mathbf{3 6 5}$ was found to cooperatively catalyze these reactions in DCE at $40{ }^{\circ} \mathrm{C}$ to give the corresponding chiral cyclopenta[b]indoles 366 in high yields (71-98\%) and good to high enantioselectivities (70-90\% ee), as presented in Scheme 121. The cooperative catalysis with $\mathrm{ZnCl}_{2}$ as Lewis acid and chiral phosphoric acid $\mathbf{3 6 5}$ as Brønsted acid is illustrated in this Scheme. This work represents a very rare example of cooperative catalysis involving a chiral organocatalyst and zinc.

Many biologically interesting products are constructed on a dibenzo[b,f][1,4]oxazepine skeleton and, consequently, the synthesis of such complex structures attracts great attention from chemists. In 2017, Pedro and Vila described a novel asymmetric access to this type of products based on an enantioselective zinccatalyzed aza-Reformatsky reaction of seven-membered cyclic imines dibenzo[b,f][1,4]oxazepines $\mathbf{3 6 7}$ with ethyl iodoacetate $\mathbf{3 6 8}$ [158]. The process was carried out at $0{ }^{\circ} \mathrm{C}$ under air atmosphere in ethyl acetate as solvent, using seven equivalents of $\mathrm{ZnMe}_{2}$ as precatalyst and $10-20 \mathrm{~mol} \%$ of chiral diaryl prolinol 369 as ligand. It allowed the formation of the corresponding chiral $\beta$-amino esters 370 with both high yields (77-99\%) and enantioselectivities (79$94 \%$ ee), as illustrated in Scheme 122. It must be highlighted that this work represented the first enantioselective aza-Reformatsky reaction of seven-membered cyclic imines.
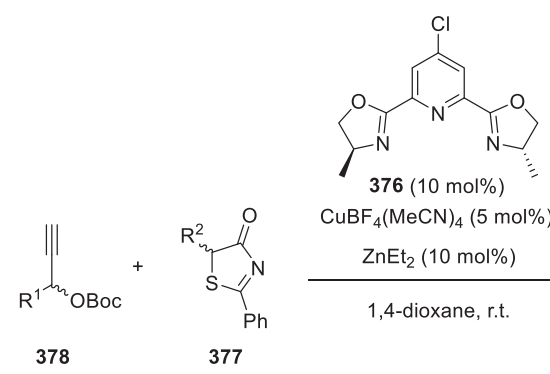

$$
\begin{gathered}
\mathrm{CuBF}_{4}(\mathrm{MeCN})_{4}(5 \mathrm{~mol} \%) \\
\mathrm{ZnEt}_{2}(10 \mathrm{~mol} \%) \\
\text { 1,4-dioxane, r.t. }
\end{gathered}
$$

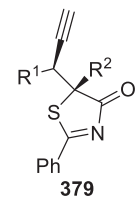

$59-99 \%$

$66-88 \%$ de

$85-95 \%$ ee

$\mathrm{R}^{1}=\mathrm{Ph}, p-\mathrm{MeOC}_{6} \mathrm{H}_{4}, p-\mathrm{F}_{3} \mathrm{CC}_{6} \mathrm{H}_{4}, p-\mathrm{BrC}_{6} \mathrm{H}_{4}, o-\mathrm{Tol}$, 2-Naph,

1-Naph, 3-pyridyl, 2-furyl, 2-thienyl, Cy

$\mathrm{R}^{2}=\mathrm{Me}, \mathrm{Et}, i-\mathrm{Bu}, i-\mathrm{Pr}, \mathrm{Cy}, \mathrm{Bn}, p-\mathrm{FC}_{6} \mathrm{H}_{4}, p-\mathrm{ClC}_{6} \mathrm{H}_{4}, \mathrm{MeO}_{2} \mathrm{C}\left(\mathrm{CH}_{2}\right)_{2}$

possible mechanism:

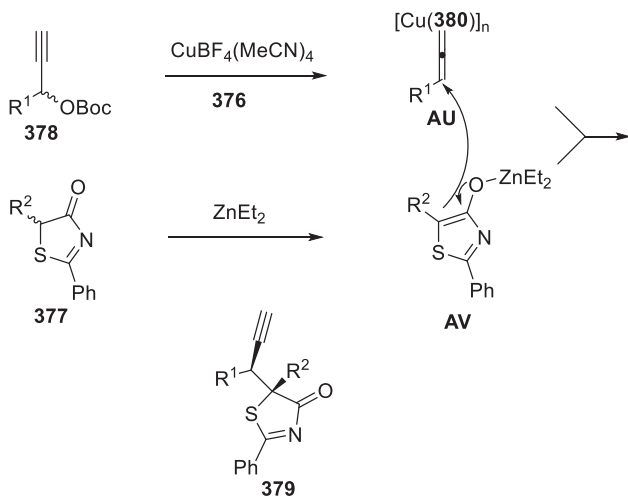

Scheme 125. Propargylic substitution of 5H-thiazol-4-ones with propargyl carbonates in the presence of a dual $\mathrm{Zn} / \mathrm{Cu}$ catalyst system [160].

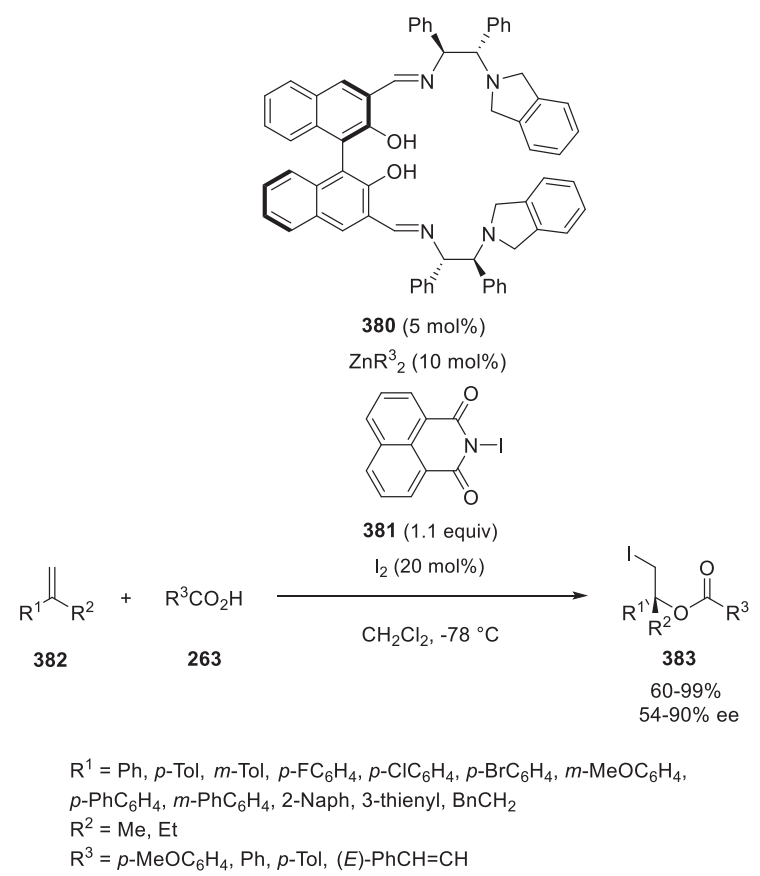

Scheme 126. Iodoesterification of alkenes in the presence of a BINOL-derived ligand [161].

In 2019, Wasa et al. developed enantioselective Conia-ene-type cyclizations of alkynyl ketones $\mathbf{3 7 1}$ on the basis of a threecomponent catalyst system composed of a zinc catalyst derived from chiral bisoxazoline $372, \mathrm{~B}\left(\mathrm{C}_{6} \mathrm{~F}_{5}\right)_{3}$, and an $N$ alkylamine, such as 1,2,2,6,6-pentamethylpiperidine (PMP), as shown in Scheme 123 [159]. Indeed, through the cooperative action of $\mathrm{B}\left(\mathrm{C}_{6} \mathrm{~F}_{5}\right)_{3}$ and amine, ketones $\mathbf{3 7 1}$ with poorly acidic $\alpha-\mathrm{C}-\mathrm{H}$ bonds could be converted in situ into the corresponding enolates. Subsequent asymmetric zinc-catalyzed cyclization led to the formation of chiral cyclopentenes 373 with good to quantitative yields (50-99\%) and moderate to excellent ee values (64-96\% ee). In most cases of substrates, the enantioselectivity of the reaction was $\geq 90 \%$ ee. The catalyst system was compatible with both aromatic and aliphatic ketones, providing comparable results. In addition, indanone and tetralone derivatives $\mathbf{3 7 4}$ also underwent the reaction but required a less hindered Brønsted base, such as 1-methylpiperidine instead of PMP. The corresponding chiral spiro cyclopentenes $\mathbf{3 7 5}$ were obtained with good to high yields (73-98\%) and ee values (82$98 \%$ ee).

A mechanism shown in Scheme 124 explains the role of this multicatalyst system, composed of strong Lewis acid $B\left(C_{6} F_{5}\right)_{3}$, Brønsted base $\mathrm{NR}_{3}$, and chiral zinc Lewis acid derived from $\mathrm{ZnI}_{2}$ and bisoxazoline 372, in the stereoselectivity of these reactions [159]. First, base $\mathrm{NR}_{3}$ could deprotonate $\mathrm{B}\left(\mathrm{C}_{6} \mathrm{~F}_{5}\right)_{3}$-activated ketone 371, generating enolate in AS along with ammonium ion ${ }^{+} \mathrm{H}^{-} \mathrm{NR}_{3}$. Simultaneously, the chiral zinc catalyst activated the alkyne unit in AS. Then, a stereoselective 5-endo-dig cyclization of the enolate with the alkyne group occurred, leading to cyclic intermediate AT. Subsequent protonation with the ammonium ion resulted in the formation of final chiral cyclopentenyl product 373.

In 2018, Zhang and Niu investigated a dual metal catalytic system based on zinc and copper in the asymmetric propargylic substitution reaction of 5H-thiazol-4-ones [160]. Indeed, the combined used of $5 \mathrm{~mol} \%$ of $\mathrm{CuBF}_{4}(\mathrm{MeCN})_{4}, 10 \mathrm{~mol} \%$ of $\mathrm{ZnEt}_{2}$ and $10 \mathrm{~mol} \%$ of chiral Pybox ligand 376 promoted the asymmetric propargylic substitution of aryl- and alkyl-substituted 5H-thiazol4-ones 377 with various propargyl carbonates 378 in 1,4-dioxane 
as solvent, leading at room temperature to the corresponding chiral highly functionalized terminal-alkyne-containing products $\mathbf{3 7 9}$ in good to high yields (59-99\%) and diastereoselectivities (66-88\% de) associated to uniformly high enantioselectivities (85-95\% ee), as presented in Scheme 125. In this process, the chiral copper catalyst was supposed to form chiral allenic intermediate AU with propargyl carbonate $\mathbf{3 7 8}$ while $\mathrm{ZnEt}_{2}$ activated the $5 \mathrm{H}$-thiazol-4one nucleophile into enolate $\mathbf{A V}$.

While asymmetric intramolecular halocyclizations have been well studied (Section 14), intermolecular versions using alkenes and carboxylic acids are still limited due to the difficulty of controlling the intermolecular reaction. In 2020, Arai et al. described the first example of asymmetric iodoesterification of simple nonfunctionalized alkenes, which was catalyzed by a chiral zinc complex derived from $(R)$-BINOL-derived bis(aminoimino) ligand $\mathbf{3 8 0}$ (5 mol\%) [161]. As shown in Scheme 126, the process employed $\mathrm{N}$-iodonaphthalenimide $\mathbf{3 8 1}$ as iodide agent combined with $\mathrm{I}_{2}$. The iodoesterification of a series of simple alkenes $\mathbf{3 8 2}$ with different carboxylic acids $\mathbf{2 6 3}$ performed in dichloromethane at $-78{ }^{\circ} \mathrm{C}$ led to the corresponding chiral iodoesters $\mathbf{3 8 3}$ in good to quantitative yields (60-99\%) and moderate to high enantioselectivities (54$90 \%$ ee).

\section{Conclusions}

As an inexpensive, abundant and less toxic metal, zinc has gained a significant importance in green catalysis. While underestimated for a long time, zinc catalysts are more and more applied to promote all types of economic and ecologic transformations. Especially, a spectacular development of highly enantioselective zinc-catalyzed transformations has emerged. This review highlights the recent advances in asymmetric synthesis promoted by chiral zinc catalysts reported since the beginning of 2015, demonstrating that zinc has become capable of replacing other transition metals. The diversity of the chiral zinc complexes employed reflects that of the asymmetric reactions successfully developed, including cycloadditions, alkynylation and allylation reactions of carbonyl compounds and derivatives, additions of diorganozincs to carbonyl compounds and derivatives, Mannich reactions, (nitro)aldol reactions, other 1,2-nucleophilic additions to carbonyl compounds and derivatives, Michael additions, Friedel-Crafts reactions, reductions, $\boldsymbol{\alpha}$-functionalizations of carbonyl compounds, ring-opening reactions, epoxidations, halolactonizations, domino and tandem reactions among other reactions. In these generally highly enantioselective processes, a wide variety of chiral ligands have been chelated to zinc, such as semi-aza-crown ligands, e.g. chiral ProPhenol and AzePhenol respectively introduced by Trost and Wang, but also bisoxazolines, $N, N^{\prime}$-dioxides, biphosphines, amino alcohols, BINOL derivatives, diamines, Schiff bases, cinchona alkaloids, bisamidines, and salen ligands among others. Moreover, dual metal catalysis, combining a chiral zinc catalyst with another metal, such as nickel, indium, palladium, iridium, rhodium, palladium, iron or copper, has generated excellent results in many types of enantioselective transformations, spanning from [2+2] cycloadditions, propargylations of aldehydes, transfer hydrogenations, $\alpha$-allylations of indanones, ring-opening reactions, crossdehydrogenative couplings, propargylic substitutions, etc to more complex domino reactions. The low price of zinc makes zinc catalysis suiting the growing demand for more environmentally benign processes and offers the real opportunity to replace other toxic and expensive metals in the near future. This review demonstrates that zinc brings a novel potential for green catalysis and that this original field is growing very rapidly. Even if remarkable results have been described, challenges remain such as the use of zinc in more multicatalyzed processes especially that based on the combi- nation of zinc with organocatalysts. Moreover, more applications in the total synthesis of important biologically active and natural products are needed.

\section{Declaration of Competing Interest}

The authors declare that they have no known competing financial interests or personal relationships that could have appeared to influence the work reported in this paper.

\section{References}

[1] R.L. Rudnick, D.M. Fountain, Rev. Geophys. 33 (1995) 267.

[2] A.S. Prasad, BMJ 326 (2003) 409.

[3] (a) R. Noyori, Asymmetric Catalysts in Organic Synthesis, Wiley-VCH, NewYork, 1994;

(b) M. Beller, C. Bolm, Transition Metals for Organic Synthesis, Wiley-VCH, Weinheim, 1998:

(c) E.N. Jacobsen, A. Pfaltz, H. Yamamoto, Comprehensive Asymmetric Catalysis, Springer, Berlin, 1999;

(d) I. Ojima, Catalytic Asymmetric Synthesis, second ed., Wiley-VCH, NewYork, 2000:

(e) E. Negishi, Handbook of Organopalladium Chemistry for Organic Synthesis, John Wiley \& Sons, Hoboken NJ, 2002;

(f) A. de Meijere, P. von Zezschwitz, H. Nüske, B. Stulgies, J. Organomet. Chem. 653 (2002) 129;

(g) M. Beller, C. Bolm, Metals for Organic Synthesis, second ed., Wiley-VCH, Weinheim, 2004

(h) L.F. Tietze, I. Hiriyakkanavar, H.P. Bell, Chem. Rev. 104 (2004) 3453.

[4] D. Lowicki, S. Bas, J. Mlynarski, Tetrahedron 71 (2015) 1339.

[5] (a) S. Enthaler, X.-F. Wu, Zinc Catalysis, Wiley, Weinheim, 2015;

(b) S. Enthaler, ACS Catal. 3 (2013) 150;

(c) X.-F. Wu, H. Neumann, Adv. Synth. Catal. 354 (2012) 3141

[6] A.P. Thankachan, S. Asha, K.S. Sindhu, G. Anilkumar, RSC Adv. 5 (2015) 62179.

[7] T. Bauer, Coord. Chem. Rev. 299 (2015) 83.

[8] J.H. Kim, H.O. Ko, J. Bouffard, S.-G. Lee, Chem. Soc. Rev. 44 (2015) 2489.

[9] S. Saranya, N.A. Harry, S.M. Ujwaldev, G. Anilkumar, Asian J. Org. Chem. 6 (2017) 1349

[10] H.-L. Wu, C.-A. Chang, P.-Y. Wu, B.-J. Uang, Tetrahedron Lett. 58 (2017) 706.

[11] K.R. Rohit, S.M. Ujwaldev, K.K. Krishnan, G. Anilkumar, Asian J. Org. Chem. 7 (2018) 85

[12] S. Dagorne, 50 (2018) 3662.

[13] K.K. Krishnan, S.M. Ujwaldev, S. Saranya, G. Anilkumar, M. Beller, Adv. Synth. Catal. 361 (2019) 382.

[14] M. Neetha, K.R. Rohit, S. Sranya, G. Anilkumar, ChemistrySelect 5 (2020) 1054

[15] J.M. Takacs, E.C. Lawson, M.J. Reno, M.A. Youngman, D.A. Quincy, Tetrahedron: Asymmetry 8 (1997) 3073.

[16] S. Yao, M. Johannsen, K.A. Jørgensen, J. Chem. Soc., Perkin Trans. 1 (1997) 2345.

[17] T. Kang, Z. Wang, L. Lin, Y. Liao, Y. Zhou, X. Liu, X. Feng, Adv. Synth. Catal. 357 (2015) 2045 .

[18] J. Zheng, L. Lin, K. Fu, H. Zheng, X. Liu, X. Feng, J. Org. Chem. 80 (2015) 8836.

[19] Q. Xiong, L. Lin, X. Zhao, J. Lang, X. Liu, X. Feng, J. Org. Chem. 83 (2018) 12527.

[20] J. Ishihara, S. Nakadachi, Y. Watanabe, S. Hatakeyama, J. Org. Chem. 80 (2015) 2037.

[21] K. Morimoto, T.P. Le, S.K. Manna, I.N.C. Kiran, S. Tanaka, M. Kitamura, Chem. Asian J. 14 (2019) 3287.

[22] S. Zhao, S. Cheng, H. Liu, J. Zhang, M. Liu, W. Yuan, X. Zhang, Chem. Commun. 56 (2020) 4200.

[23] G. Masson, C. Lalli, M. Benohoud, G. Dagousset, Chem. Soc. Rev. 42 (2013) 902.

[24] J.C.K. Chu, D.M. Dalton, T. Rovis, J. Am. Chem. Soc. 137 (2015) 4445.

[25] E. Lee-Ruff, G. Mladenova, Chem. Rev. 103 (2003) 1449.

[26] T. Kang, S. Ge, L. Lin, Y. Lu, X. Liu, X. Feng, Angew. Chem., Int. Ed. 55 (2016) 5541.

[27] J. Chen, X. Xu, Z. He, H. Qin, W. Sun, B. Fana, Adv. Synth. Catal. 360 (2018) 427.

[28] A.S. Gothelf, K.V. Gothelf, R.G. Hazell, K.A. Jørgensen, Angew. Chem., Int. Ed. 41 (2002) 4236.

[29] J.-Q. Zhao, X.-J. Zhou, Y. Zhou, X.-Y. Xu, X.-M. Zhang, W.-C. Yuan, Org. Lett. 360 (2018) 427.

[30] I.N.C. Kiran, K. Fujita, S. Tanaka, M. Kitamura, ChemCatChem (2020), https:// doi.org/10.1002/cctc.202001202.

[31] L. Delion, T. Poisson, P. Jubault, X. Pannecoucke, A.B. Charrette, Can. J. Chem. 98 (2020) 516.

[32] (a) J.-C. Kizirian, Chem. Rev. 108 (2008) 140;

(b) M. Hatano, K. Ishihara, Synthesis (2008) 1647;

(c) E. Tyrrell, Curr. Org. Chem. 13 (2009) 1540;

(d) B.M. Trost, A.H. Weiss, Adv. Synth. Catal. 351 (2009) 963;

(e) , Comprehensive Chirality vol. 4 (2012) 355;

(f) L. Pu, Acc. Chem. Res. 47 (2014) 1523;

(g) H. Pellissier, Tetrahedron 71 (2015) 2487;

(h) V. Bisai, V.K. Singh, Tetrahedron Lett. 57 (2016) 4771; 
(i) F. Schmidt, R.T. Stemmler, J. Rudolph, C. Bolm, Chem. Soc. Rev, 35 (2016) 454.

[33] (a) E.M. Carreira, P. Aschwanden, Sci. Synth. 2 (2011) 517;

(b) E.M. Carreira, D.E. Frantz, Sci. Synth. 2 (2011) 497;

(c) G. Blay, A. Monleon, J.R. Pedro, Curr. Org. Chem. 13 (2009) 1498;

(d) L. Li, W. Rui, Curr. Org. Chem. 13 (2009) 1565;

(e) S. Plé, K. Banchet, A. Liard, A. Haudrechy, Chem. Rev. 106 (2006) 2355;

(f) G. Lu, Y.-M. Li, X.-S. Li, A.S.C. Chan, Coord. Chem. Rev. 249 (2005) 1736;

(g) P.G. Cozzi, R. Hilgraf, N. Zimmermann, Eur. J. Org. Chem. (2004) 4095;

(h) L. Pu, Tetrahedron 59 (2003) 9873;

(i) D.E. Frantz, R. Fässler, C.S. Tomooka, E.M. Carreira, Acc. Chem. Res. 33 (2000) 373;

(j) B.M. Trost, M.J. Krische, J. Am. Chem. Soc. 121 (1999) 6131;

(k) P.J. Stang, F. Diederich, Modern Acetylene Chemistry, VCH, Weinheim, Germany, 1995.

[34] S. Niwa, K. Soai, J. Chem. Soc., Perkin Trans. 1 (1990) 937.

[35] W.-C. Huang, W. Liu, X.-D. Wu, J. Ying, L. Pu, J. Org. Chem. 80 (2015) 11480.

[36] Y.S. Molina, J. Ruchti, E.M. Carreira, Org. Lett. 19 (2017) 743.

[37] Y.-Z. Hua, X.-W. Han, X.-C. Yang, X. Song, M.-C. Wang, J.-B. Chang, J. Org. Chem. 79 (2014) 11696

[38] S. Liu, G.-W. Li, X.-C. Yang, D.-Y. Zhang, M.-C. Wang, Org. Biomol. Chem. 15 (2017) 7147.

[39] Y. Zhou, L. Wang, S. Li, S. Ma, P.J. Walsh, Q. Bian, F. Li, M. Wang, J. Zhong, Synlett $31(2020) 60$

[40] K. Gopalaiah, H.B. Kagan, Chem. Rev. 111 (2011) 4599.

[41] A.M. Cook, C. Wolf, Angew. Chem., Int. Ed. 55 (2016) 2929.

[42] B.M. Trost, H. Ito, J. Am. Chem. Soc. 122 (2000) 12003.

[43] B.P. Zaveskyand, J.S. Johnson, Angew. Chem., Int. Ed. 56 (2017) 8805.

[44] L. Chen, G. Huang, M. Liu, Z. Huang, F.-E. Chen, Adv. Synth. Catal. 360 (2018) 3497.

[45] R. Liu, S. Yang, Z. Chen, X. Kong, H. Ding, X. Fang, Org. Lett. 17 (2020) 6948.

[46] W.-J. Yoo, L. Zhao, C.-J. Li, Aldrichim. Acta 44 (2011) 43.

[47] Z.-Y. Yang, T.-L. Liu, Y. Zheng, S. Li, J.-A. Ma, Eur. J. Org. Chem. (2015) 3905.

[48] L. De Munck, A. Monleón, C. Vila, M.C. Muñozb, J.R. Pedro, Org. Biomol. Chem. 13 (2015) 7393.

[49] Y. Zhang, J. Nie, F.-G. Zhang, J.-A. Ma, J. Fluorine Chem. 208 (2018) 1.

[50] D.C. Fager, R.J. Morrison, A.H. Hoveyda, Angew. Chem., Int. Ed. 59 (2020) 11448.

[51] T. Sengoku, R. Maegawa, H. Imamura, M. Wada, H. Yod, Adv. Synth. Catal. 362 (2020) 2397.

[52] N. Oguni, T. Omi, Tetrahedron Lett. 25 (1984) 2823.

[53] (a) K. Soai, S. Niwa, Chem. Rev. 92 (1992) 833;

(b) S. Kobayashi, H. Ishitani, Chem. Rev. 99 (1999) 1069;

(c) L. Pu, H.-B. Yu, Chem. Rev. 101 (2001) 757;

(d) C.M. Binder, B. Singaram, Org. Prep. Proced. Int. 43 (2011) 139.

[54] S. Sasaki, T. Yamauchi, M. Kanai, A. Ishii, K. Higashiyama, Bull. Chem. Soc. Jpn. 88 (2015) 200.

[55] K. Shimizu, H. Uetsu, T. Gotanda, K. Ito, Synlett 26 (2015) 1238.

[56] M. Yamanaka, M. Inaba, R. Gotoh, Y. Ueki, K. Matsui, Chem. Commun. 53 (2017) 7513.

[57] C. Romagnoli, B. Sieng, M. Amedjkouh, Eur. J. Org. Chem. (2015) 4087.

[58] S. Jarzynski, G. Utecht, S. Lesniak, M. Rachwalski, Tetrahedron: Asymmetry 28 (2017) 1774.

[59] C. Sappino, A. Mari, A. Mantineo, M. Moliterno, M. Palagri, C. Tatangelo, L. Suber, P. Bovicelli, A. Ricelli, G. Righi, Org. Biomol. Chem. 16 (2018) 1860.

[60] C. Sappino, L. Primitivo, M. De Angelis, F. Righi, F. Di Pietro, M. Iannino, L. Pilloni, S. Vecchio Ciprioti, L. Suber, A. Micelli, G. Righi, RSC Adv., 10, 2020 29688.

[61] K.-I. Yamada, K. Tomioka, Chem. Rev. 108 (2008) 2874.

[62] W.-M. Huang, B.-J. Uang, Chem. Asian J. 10 (2015) 998.

[63] L. Fe Munck, V. Sudowski, C. Vila, J.R. Pedro, Tetrahedron Lett. 58 (2017) 3358.

[64] B.M. Trost, C.-I. Hung, J. Am. Chem. Soc. 137 (2015) 15940.

[65] B.M. Trost, T. Saget, C.-I. Hung, J. Am. Chem. Soc. 138 (2016) 3659.

[66] B.M. Trost, T. Saget, A. Lerchen, C.-I. Hung, Angew. Chem., Int. Ed. 55 (2016) 781.

[67] B.M. Trost, E. Gnanamani, J.S. Tracy, C.A. Kalnmals, J. Am. Chem. Soc. 139 (2017) 18198.

[68] B.M. Trost, C.-I. Hung, T. Saget, E. Gnanamani, Nature Catalysis 1 (2018) 523.

[69] B.M. Trost, C.-I.-J. Hung, E. Gnanamani, ACS Catal. 9 (2019) 1549.

[70] B.M. Trost, C.-I.-J. Hung, G. Mata, Y. Liu, Y. Lu, E. Gnanamani, Org. Lett. 22 (2020) 2437.

[71] J. Zhao, B. Fang, W. Luo, X. Hao, X. Liu, L. Lin, X. Feng, Angew. Chem., Int. Ed. 54 (2015) 241.

[72] S. Nakamura, R. Yamaji, M. Hayashi, Chem. Eur. J. 21 (2015) 9615.

[73] A.M. Pieczonka, S. Jarzynski, Z. Wujkowska, S. Lesniak, M. Rachwalski, Tetrahedron Lett. 56 (2015) 6506

[74] E. Wojaczynska, J. Skarzewski, Ł. Sidorowicz, R. Wieczorek, J. Wojaczynski, New J. Chem. 40 (2016) 9795.

[75] D. Wiedenhoeft, A.R. Benoit, Y. Wu, J.D. Porter, E. Meyle, T.H.W. Yeung, R. Huff, S.V. Lindeman, C. Dockendorff, Tetrahedron 72 (2016) 3905.

[76] Y.F. Zhang, S.J. Yin, M. Zhao, J.Q. Zhang, H.-Y. Li, X.-W. Wang, RSC Adv. 6 (2016) 30683.

[77] Z.-F. Zhang, X.-C. Yang, H.-J. Lu, M.-C. Wang, Eur. J. Org. Chem. (2018) 785.

[78] M.-Y. Rong, L. Yang, J. Nie, F.-G. Zhang, J.-A. Ma, Org. Lett. 21 (2019) 4280.

[79] A. Serra-Pont, I. Alfonso, J. Sola, C. Jimeno, Chem. Commun. 55 (2019) 7970.

[80] M. Shibasaki, N. Yoshikawa, Chem. Rev. 102 (2002) 2187.
[81] B.M. Trost, V.S.C. Yeh, Angew. Chem., Int. Ed. 41 (2002) 861.

[82] E. Chinnaraja, R. Arunachalam, P.S. Subramanian, ChemistrySelect 1 (2016) 5331.

[83] S. Liu, W.-C. Gao, Y.-H. Miao, M.-C. Wang, J. Org. Chem. 84 (2019) 2652.

[84] I. Karakaya, S. Karabuga, M. Mart, R. Altundas, S. Ulukanli, Synthesis 48 (2016) 864.

[85] S. Nakamura, D. Hayama, Angew. Chem., Int. Ed. 56 (2017) 8785.

[86] T. Sengoku, I. Ikeda, K. Ai, M. Takahashi, H. Yoda, Org. Biomol. Chem. 17 (2019) 2614.

[87] N. Kumagai, S. Matsunaga, M. Shibasaki, Org. Lett. 3 (2001) 4251.

[88] T. Thaler, P. Knochel, Angew. Chem., Int. Ed. 48 (2009) 645.

[89] B. Zhang, F. Han, L. Wang, D. Li, D. Yang, X. Yang, J. Yang, X. Li, D. Zhao, R. Wang, Chem. Eur. J. 21 (2015) 17234.

[90] Y.-Y. Gao, Y.-Z. Hua, M.-C. Wang, Adv. Synth. Catal. 360 (2018) 80.

[91] S. Liu, Z.-H. Xu, X. Wang, H.-R. Zhu, M.-C. Wang, J. Org. Chem. 84 (2019) 13881.

[92] B.M. Trost, E. Gnanamani, C.A. Kalnmals, C.-I. Hung, J.S. Tracy, J. Am. Chem. Soc. 141 (2019) 1489.

[93] S. Liu, N. Shao, F.-Z. Li, X.-C. Yang, M.-C. Wang, Org. Biomol. Chem. 15 (2017) 9465.

[94] N. Shao, Y.-Y. Luo, H.-J. Lu, Y.-Z. Hua, M.-C. Wang, Tetrahedron 74 (2018) 2130.

[95] Y.-X. Jia, S.-F. Zhu, Y. Yiang, Q.-L. Zhou, J. Org. Chem. 71 (2006) 75.

[96] G.V. More, B.M. Bhanage, Catal, Sci. Technol. 5 (2015) 1514.

[97] J.-Q. Weng, R.-J. Fan, Q.-M. Deng, R.-R. Liu, J.-R. Gao, Y.-X. Jia, J. Org. Chem. 81 (2016) 3023.

[98] K. Venkatanna, S.Y. Kumar, M. Karthick, R. Padmanaban, C.R. Ramanathan, Org. Biomol. Chem. 17 (2019) 4077.

[99] X.-W. Wang, Y.-Z. Hua, M.-C. Wang, J. Org. Chem. 81 (2016) 9227.

[100] X. Zhang, J. Zhang, L. Lin, H. Zheng, W. Wu, X. Liu, X. Feng, Adv. Synth. Catal. 358 (2016) 3021.

[101] Y.-Z. Hua, J.-W. Chen, H. Yang, M.-C. Wang, J. Org. Chem. 83 (2018) 1160.

[102] S. O'Reilly, M. Aylward, C. Keogh-Hansen, B. Fitzpatrick, H.A. McManus, H. Muiller-Bunz, P.J. Guiry, J. Org. Chem. 80 (2015) 10177.

[103] J. Sun, Y. Gui, Y. Huang, J. Li, Z. Zha, Y. Yang, Z. Wang, ACS Omega 5 (2020) 11962.

[104] F. Yang, J. Chen, J. Xu, F. Ma, Y. Zhou, M.V. Shinde, B. Fan, Org. Lett. 18 (2016) 4832.

[105] F. Ma, J. Chen, F. Yang, M.V. Shinde, Y. Zhou, B. Fan, Org. Biomol. Chem. 15 (2017) 2359.

[106] F. Yang, J. Chen, G. Shen, X. Zhanga, B. Fan, Chem. Commun. 54 (2018) 4963.

[107] G. Shen, J. Chen, D. Xu, X. Zhang, Y. Zhou, B. Fan, Org. Lett. 21 (2019) 1364.

[108] Y. Gao, F. Yang, D. Pu, R.D. Laishram, R. Fan, G. Shen, X. Zhang, J. Chen, B. Fan, Eur. J. Org. Chem. (2018) 6274.

[109] B. Marciniec, Hydrosilylation: A Comprehensive Review on Recent Advances, Springer, Netherlands, 2009.

[110] M. Szewczyk, F. Stanek, A. Bezłada, J. Mlynarski, Adv. Synth. Catal. 357 (2015) 3727.

[111] M. Szewczyk, A. Bezłada, J. Mlynarski, ChemCatChem 8 (2016) 3575.

[112] A. Bezłada, M. Szewczyk, J. Mlynarski, J. Org. Chem. 81 (2016) 3336.

[113] E. Le Roux, A. De Mallmann, N. Merle, M. Taoufik, R. Anwander, Organometallics 34 (2015) 5146.

[114] C. Nájera, J.M. Sansano, Chem. Rev. 107 (2007) 4584.

[115] (a) J.-P. Genet, C. Greck, D. Lavergne, in: Modern Amination Methods, WileyVCH, Weinheim, 2000, pp. 65-102; (b) A. Va llribera, R.M. Sebastian, A. Shafir, Curr. Org. Chem. 15 (2011) 1539.

[116] Y. Naganawa, H. Komatsu, H. Nishiyama, Chem. Lett. 44 (2015) 1652.

[117] B.M. Trost, J.S. Tracy, T. Saget, Chem. Sci. 9 (2018) 2975.

[118] B.M. Trost, J.S. Tracy, E.Y. Lin, ACS Catal. 9 (2019) 11082.

[119] J.-S. Qiu, Y.-F. Wang, G.-R. Qi, P.G. Karmaker, H.-Q. Yin, F.-X. Chen, Chem. Eur. J. 23 (2017) 1775

[120] J. Qiu, D. Wu, P.G. Karmaker, G. Qi, P. Chen, H. Yin, F.-X. Chen, Org. Lett. 19 (2017) 4018.

[121] R. He, P. Liu, X. Huo, W. Zhang, Org. Lett. 19 (2017) 5513.

[122] B. Li, X. Cheng, Z. Guan, S. Li, T. Huo, G. Cheng, Y. Fan, F. Zhou, Q. Deng, Org. Chem. Front. (2020), https://doi.org/10.1039/D0Q001022G.

[123] X. He, J. Chen, X. Xu, F. Yang, C. Gu, Y. Zhou, B. Fan, Tetrahedron: Asymmetry 28 (2017) 62

[124] W. Zhang, J. Chen, G. Zeng, F. Yang, J. Xu, W. Sun, M.V. Shinde, B. Fan, J. Org. Chem. 82 (2017) 2641

[125] G. Shen, R. Khan, F. Yang, Y. Yang, D. Pu, Y. Gao, Y. Zhan, Y. Luo, B. Fan, Asian J. Org. Chem. 8 (2019) 97.

[126] N. Shiomi, M. Kurodaa, S. Nakamura, Chem. Commun. 53 (2017) 1817.

[127] (a) Q.-H. Xia, H.-Q. Ge, C.-P. Ye, Z.-M. Liu, K.-X. Su, Chem. Rev. 105 (2005) 1603;

(b) H. Pellissier, A. Lattanzi, R. Dalpozzo (Eds.), Asymmetric Synthesis of Three-Membered Rings, Wiley, Weinheim, 2017.

[128] R. Davis, J. Stiller, T. Naicker, H. Jiang, K.A. Jørgensen, Angew. Chem., Int. Ed. 53 (2014) 7406.

[129] A.R. Keeri, I. Justyniak, J. Jurczak, J. Lewinski, Adv. Synth. Catal. 358 (2016) 864.

[130] H.S. Karaman, H. Kilic, E. Sahin, Tetrahedron: Asymmetry 28 (2017) 1626.

[131] T. Arai, T. Kojima, O. Watanabe, T. Itoh, H. Kanoh, ChemCatChem 7 (2015) 3234.

[132] T. Arai, K. Horigane, O. Watanabe, J. Kakino, N. Sugiyama, H. Makino, Y. Kamei, S. Yabe, M. Yamanaka, iScience 12 (2019) 280. 
[133] (a) L.F. Tietze, U. Beifuss, Angew. Chem., Int. Ed. Engl. 32 (1993) 131;

(b) L.F. Tietze, Chem. Rev. 96 (1996) 115;

(c) C. Hulme, V. Gore, Curr. Med. Chem. 10 (2003) 51;

(d) H. Pellissier, Tetrahedron 62 (2006) 1619;

(e) H. Pellissier, Tetrahedron 62 (2006) 2143;

(f) L.F. Tietze, G. Brasche, K. Gericke, Domino Reactions in Organic Synthesis, Wiley-VCH, Weinheim, 2006:

(g) A. Padwa, S.K. Bur, Tetrahedron 63 (2007) 5341;

(h) G. Guillena, D.J. Ramon, M. Yus, Tetrahedron: Asymmetry 18 (2007) 693;

(i) M. Colombo, I. Peretto, Drug Discovery Today 13 (2008) 677;

(j) B.B. Touré, D.G. Hall, Chem. Rev. 109 (2009) 4439;

(k) K.C. Nicolaou, J.S. Chen, Chem. Soc. Rev. 38 (2009) 2993;

(l) C. Grondal, M. Jeanty, D. Enders, Nat. Chem. 2 (2010) 167;

(m) H. Pellissier, Adv. Synth. Catal. 354 (2012) 237;

(n) H. Clavier, H. Pellissier, Adv. Synth. Catal. 354 (2012) 3347;

(o) H. Pellissier, Chem. Rev. 113 (2013) 442;

(p) H. Pellissier, Asymmetric Domino Reactions, Royal Society of Chemistry, Cambridge, 2013;

(q) H. Pellissier, Adv. Synth. Catal. 358 (2016) 2194;

(r) H. Pellissier, Adv. Synth. Catal. 361 (2019) 1733.

[134] (a) D.J. Ramon, M. Yus, Angew. Chem., Int. Ed. 44 (2005) 1602;

(b) J. Zhu, H. Bienaymé, Multicomponent Reactions, Wiley-VCH, Weinheim, 2005;

(c) D. Enders, C. Grondal, M.R.M. Hüttl, Angew. Chem., Int. Ed. 46 (2007) 1570 ;

(d) C.J. Chapman, C.G. Frost, Synthesis (2007) 1;

(e) A.-N. Alba, X. Companyo, M. Viciano, R. Rios, Curr. Org. Chem. 13 (2009) 1432 ;

(f) J.E. Biggs-Houck, A. Younai, J.T. Shaw, Curr. Opin. Chem. Biol. 14 (2010) 371 ;

(g) M. Ruiz, P. Lopez-Alvarado, G. Giorgi, J.C. Menéndez, Chem. Soc. Rev. 40 (2011) 3445;

(h) C. De Graaff, E. Ruijter, R.V.A. Orru, Chem. Soc. Rev. 41 (2012) 3969.

[135] B.-K. Tao, H. Yang, Y.-Z. Hua, M.-C. Wang, Org. Biomol. Chem. 17 (2019) 4301.

[136] (a) P.-W. Xu, J.-S. Yu, C. Chen, Z.-Y. Cao, F. Zhou, J. Zhou, ACS Catal. 9 (2019) 1820

(b) H. Pellissier, Synthesis 51 (2019) 1311.

[137] Y.-J. Guo, X. Guo, D.-Z. Kong, H.-J. Lu, L.-T. Liu, Y.-Z. Hua, M.-C. Wang, J. Org. Chem. 85 (2020) 4195.

[138] Y.-Z. Hua, M.-M. Liu, P.-J. Huang, X. Song, M.-C. Wang, J.-B. Chang, Chem. Eur. J. 21 (2015) 11994.

[139] M.-M. Liu, X.-C. Yang, Y.-Z. Hua, J.-B. Chang, M.-C. Wang, Org. Lett. 21 (2019) 2111.

[140] M.-M. Liu, X.-C. Yang, Y.-Z. Hua, J.-B. Chang, M.-C. Wang, Org. Lett. 19 (2019) 7089.

[141] X.-C. Yang, M. Xu, J.-B. Wang, M.-M. Liu, F. Mathey, Y.-Z. Hua, M.-C. Wang, Org. Biomol. Chem. 18 (2020) 3917.
[142] X.-C. Yang, M.-M. Liu, F.H.Y. Mathey, Y.-Z. Hua, M.-C. Wang, J. Org. Chem. 84 (2019) 7762.

[143] I. Węglarz, M. Szewczyk, J. Mlynarski, Adv. Synth. Catal. 362 (2020) 1532.

[144] B.M. Trost, E. Gnanamani, C.-I. Hung, C.A. Kalnmals, Org. Lett. 21 (2019) 1890.

[145] B.M. Trost, E. Gnanamani, Org. Lett. 22 (2020) 1675.

[146] Y.-H. Miao, Y.-Z. Hua, M.-C. Wang, Org. Biomol. Chem. 17 (2019) 7172.

[147] T. Kang, W. Cao, L. Hou, Q. Tang, S. Zou, X. Liu, X. Feng, Angew. Chem., Int. Ed. 58 (2019) 2464.

[148] C. Xu, K. Wang, D. Li, L. Lin, X. Feng, Angew. Chem., Int. Ed. 58 (2019) 18348.

[149] H. Huang, H. Zong, G. Bian, L. Song, J. Org. Chem. 80 (2015) 12614.

[150] T. Chen, L. Gan, R. Wang, Y. Deng, F. Peng, M. Lautens, Z. Shao, Angew. Chem., Int. Ed. 58 (2019) 15819

[151] M.I. Childers, J.M. Longo, N.J. Van Zee, A.M. LaPointe, G.W. Coates, Chem. Rev. $114(2014) 8129$.

[152] Y.-Z. Hua, X.-C. Yang, M.-M. Liu, X. Song, M.-C. Wang, J.-B. Chang Macromolecules 48 (2015) 1651.

[153] T. Huang, X. Liu, J. Lang, J. Xu, L. Lin, X. Feng, ACS Catal. 7 (2017) 5654.

[154] B.M. Trost, T. Saget, C.-I. Hung, Angew. Chem., Int. Ed. 56 (2017) 2440.

155] B.M. Trost, E. Gnanamani, C.-I. Hung, Angew. Chem., Int. Ed. 56 (2017) 10451.

[156] (a) B.G. Jellerichs, J.-R. Kong, M.J. Krische, J. Am. Chem. Soc. 125 (2003) 7758:

(b) J.-A. Ma, D. Cahard, Angew. Chem., Int. Ed. 43 (2004) 4566;

(c) Z. Shao, H. Zhang, Chem. Soc. Rev. 38 (2009) 2745;

(d) C. Zhong, X. Shi, Eur. J. Org. Chem. (2010) 2999;

(e) J. Zhou, Chem. Asian J. 5 (2010) 422;

(f) S. Piovesana, D.M. Scarpino Schietroma, M. Bella, Angew. Chem., Int. Ed. 50 (2011) 6216;

(g) N.T. Patil, V.S. Shinde, B. Gajula, Org. Biomol. Chem. 10 (2012) 211;

(h) A.E. Allen, D.W.C. MacMillan, Chem. Sci. 3 (2012) 633;

(i) Z. Du, Z. Shao, Chem. Soc. Rev. 42 (2013) 1337;

(j) H. Pellissier, Tetrahedron 69 (2013) 7171;

(k) H. Pellissier, Enantioselective Multicatalysed Tandem Reactions, Royal Society of Chemistry, Cambridge, 2014;

(1) D. Parmar, E. Sugiono, S. Raja, M. Rueping, Chem. Rev. 114 (2014) 9047;

(m) T.L. Lohr, T.J. Marks, Nat. Chem. 7 (2015) 477;

(n) S.M. Inamdar, V.S. Shinde, N.T. Patil, Org. Biomol. Chem. 13 (2015) 8116; (o) J. Zhou, Multicatalyst System in Asymmetric Catalysis, Wiley, Weinheim, 2015;

(p) S. Afewerki, A. Cordova, Chem. Rev. 116 (2016) 13512;

(q) H. Pellissier, Adv. Synth. Catal. 362 (2020) 2289.

[157] G.-P. Wang, M.-Q. Chen, S.F. Zhu, Q.-L. Zhou, Chem. Sci. 8 (2017) 7197.

[158] L. De Munck, V. Sukowski, C. Vila, M.C. Muñoz, J.R. Pedro, Org. Chem. Front. 4 (2017) 1624.

[159] M. Cao, A. Yesilcimen, M. Wasa, J. Am. Chem. Soc. 141 (2019) 4199.

[160] Z. Fu, N. Deng, S.-N. Su, H. Li, R.-Z. Li, X. Zhang, J. Liu, D. Niu, Angew. Chem., Int. Ed. 57 (2018) 15217.

[161] T. Arai, K. Horigane, T.K. Suzuki, R. Itoh, M. Yamanaka, Angew. Chem., Int. Ed. 59 (2020) 12680. 